\title{
Brain network alterations due to cardiometabolic risk factors
}

Citation for published version (APA):

Vergoossen, L. (2021). Brain network alterations due to cardiometabolic risk factors: insights from population magnetic resonance imaging. [Doctoral Thesis, Maastricht University]. Drukkerij Econoom. https://doi.org/10.26481/dis.20210401lv

Document status and date:

Published: 01/01/2021

DOI:

$10.26481 /$ dis.20210401lv

Document Version:

Publisher's PDF, also known as Version of record

\section{Please check the document version of this publication:}

- A submitted manuscript is the version of the article upon submission and before peer-review. There can be important differences between the submitted version and the official published version of record.

People interested in the research are advised to contact the author for the final version of the publication, or visit the DOI to the publisher's website.

- The final author version and the galley proof are versions of the publication after peer review.

- The final published version features the final layout of the paper including the volume, issue and page numbers.

Link to publication

\footnotetext{
General rights rights.

- You may freely distribute the URL identifying the publication in the public portal. please follow below link for the End User Agreement:

www.umlib.nl/taverne-license

Take down policy

If you believe that this document breaches copyright please contact us at:

repository@maastrichtuniversity.nl

providing details and we will investigate your claim.
}

Copyright and moral rights for the publications made accessible in the public portal are retained by the authors and/or other copyright owners and it is a condition of accessing publications that users recognise and abide by the legal requirements associated with these

- Users may download and print one copy of any publication from the public portal for the purpose of private study or research.

- You may not further distribute the material or use it for any profit-making activity or commercial gain

If the publication is distributed under the terms of Article $25 \mathrm{fa}$ of the Dutch Copyright Act, indicated by the "Taverne" license above, 


\section{Brain Network Alterations due to Cardiometabolic Risk Factors}

Insights from Population Magnetic Resonance Imaging 
(c) 2021 Laura Wilfrieda Maria Vergoossen - All rights reserved.

No part of this publication may be reproduced, stored in a retrieval system or transmitted in any form or by any means, electronic, mechanical, photocopying, recording or otherwise, without the prior permission of the author.

Printed by Drukkerij Econoom, Beek, The Netherlands

Layout by Laura Vergoossen

Cover design by leukerDESIGN Susteren and Laura Vergoossen

ISBN: 978-94-6423-171-7

Printing of this thesis was financially supported by Maastricht University. 


\title{
Brain Network Alterations due to Cardiometabolic Risk Factors
}

\section{Insights from Population Magnetic Resonance Imaging}

\author{
PROEFSCHRIFT \\ ter verkrijging van de graad van doctor aan de Universiteit Maastricht, \\ op gezag van de Rector Magnificus, Prof dr. Rianne M. Letschert \\ volgens het besluit van het College van Decanen, \\ in het openbaar te verdedigen \\ op donderdag 1 april 2021 om 12.00 uur \\ door
}

Laura Wilfrieda Maria Vergoossen

Geboren 7 januari 1992 te Geleen 


\section{Promotor}

Prof. dr. ir. W.H. Backes

\section{Copromotores}

Dr. J.F.A. Jansen

Dr. M.T. Schram

\section{Beoordelingscommissie}

Prof. dr. P.A.M. Hofman (voorzitter)

Prof. dr. F.R.J. Verhey

Prof. dr. G.J. Biessels (University Medical Center Utrecht)

Prof. dr. S.A.R.B. Rombouts (Leiden University Medical Center) 


\section{Table of Contents}

Chapter 1: General introduction 1

Chapter 2: Cardiometabolic determinants of early and advanced brain alterations: Insights from conventional and novel MRI techniques

Chapter 3: White matter connectivity abnormalities in prediabetes and type 2 diabetes: The Maastricht Study.

Chapter 4: Association of physical activity and sedentary time with structural brain networks - The Maastricht Study

Chapter 5: Interplay of white matter hyperintensities, cerebral networks, and cognitive function in an adult population - Diffusion Tensor Imaging in The Maastricht Study. 105

Chapter 6: Exploring the neuronal and systemic physiological contribution to spontaneous cerebral fluctuations - Insights from functional MRI in The Maastricht Study.

Chapter 7: General discussion

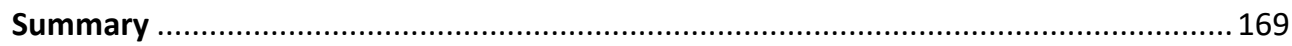

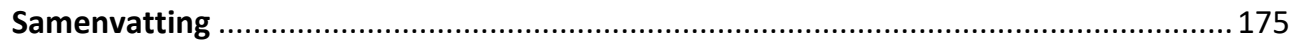

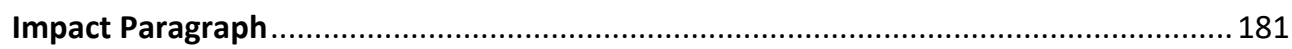

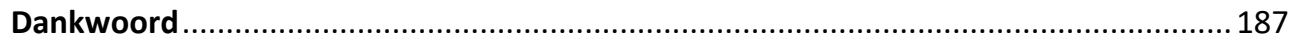

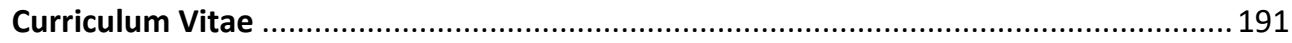

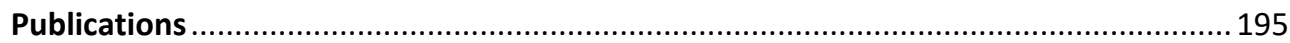


Chapter 1

General Introduction

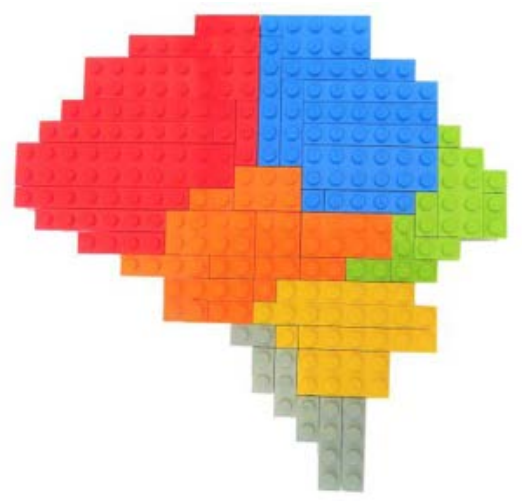




\section{Cardiometabolic risk and lifestyle}

Chronic diseases, such as diabetes, cardiovascular disease, and dementia, are one of the main challenges for the health system $(1,2)$, partly through the ageing population and increasing prevalence of obesity and paucity of physical activity. Wide scale prevention of these diseases remains elusive, because they are caused by multiple, often additive, complications arising from cardiometabolic risk factors. Cardiometabolic risk factors include hyperglycemia, physical inactivity, sedentary behavior, central obesity, hypertension, and dyslipidemia, and are factors that increase the risk of cardiovascular problems, including (pre)diabetes, and dementia.

\section{What is (pre)diabetes?}

Type 2 diabetes is a chronic disease that occurs when the body has become resistant to the hormone insulin, which leads to raised blood glucose levels called hyperglycemia. Additionally, the insulin producing cells become damaged and stop the production. Prediabetes is an intermediate hyperglycemic condition between normal glucose metabolism and type 2 diabetes. Subjects with prediabetes have an increased risk of developing type 2 diabetes $(3,4)$. Over time, hyperglycemia leads to tissue damage and macro- and microvascular complications such as cardiovascular disease, nephropathy, retinopathy, and neuropathy. The cardiovascular effects are thought to disturb the blood supply in the brain (5).

Accumulating evidence shows that cardiometabolic risk factors are associated with a higher risk of latelife (65+ years) cognitive impairment and eventually brain diseases such as dementia and depression (613). In particular, these risk factors affect the smallest brain vessels and are thought to lead to cerebral small vessel disease (CSVD) and neurodegeneration (brain atrophy) $(14,15)$, which represent early features in the pathophysiology of cognitive decline and dementia (16). More specifically, at mid-life age (40-65 years), the most important risk factor for cognitive decline is hypertension, while later in life $(65+)$, diabetes imposes the greatest risk factor $(17,18)$. Currently, it is not fully understood how these risk factors exactly contribute to cognitive decline. Therefore, this thesis aims to gain more insight into the brain alterations underlying cognitive decline and brain pathology (Figure 1.1). 


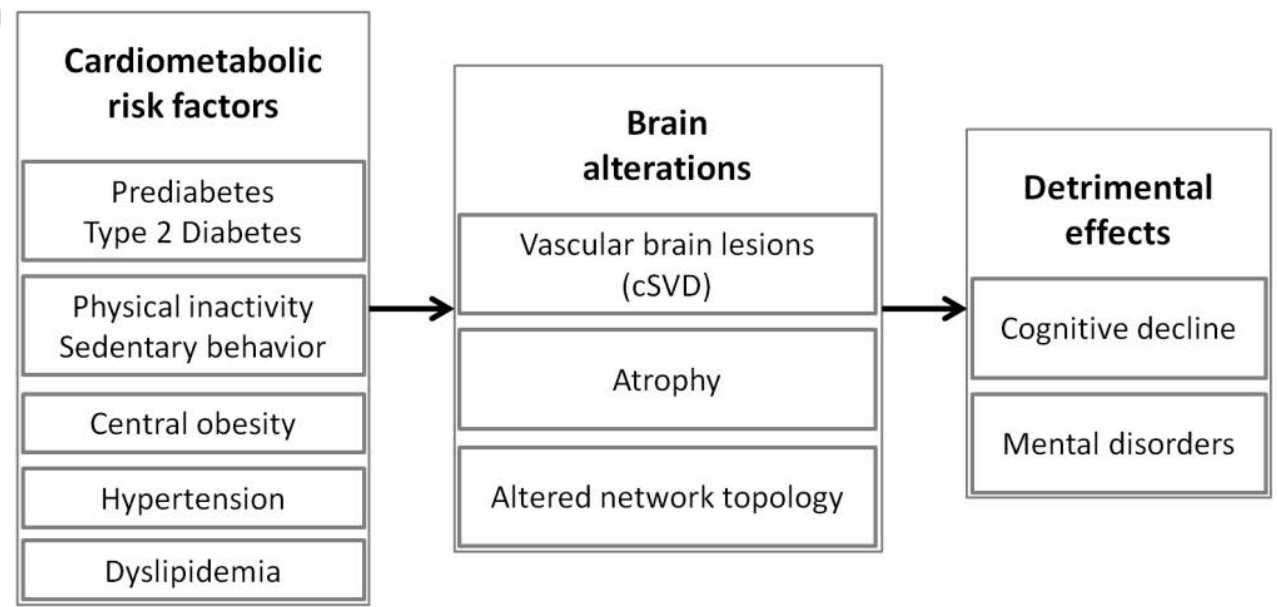

Figure 1.1: Schematic description of the underlying concept of this thesis on the association between cardiometabolic risk factors, the developing, or expressing alterations of the brain tissue and the emerging health detriments and disorders.

\section{Added value of MRI}

The brain tissue is difficult to access for scientific research, because it is protected by the skull. However, magnetic resonance imaging (MRI) enables the visualization of the anatomical structures within the skull. MRI is a noninvasive method that uses a powerful magnetic field to examine internal body structures. MRI provides information to describe shape, size, and integrity of white and gray structures in the brain. The gray matter contains most of the brain's neuronal cell bodies and small vessels. The white matter is composed of long-range nerve fibers connecting the neurons. Structural brain MRI techniques can also detect macroscopically visible morphological brain abnormalities, such as atrophy and microvascular lesions. Brain lesions interfere with the trajectories of the white matter, and may disrupt the connections between gray matter regions. These changes in white matter connectivity may contribute to general cognitive decline, and decline in various specific cognitive domains, as information processing speed, executive function and attention, and memory $(19,20)$. Additionally, advanced MR imaging methods can provide detailed insights into subtle brain changes, and thus early development of pathology, enhancing our understanding of brain disease (21). Multiple advanced MRI techniques are available to assess different characteristics of the brain. Intermezzo 1 and 2 provides more information about the advanced imaging (Intermezzo 1) and image quantification (Intermezzo 2) methods to assess the brain's network in this thesis. Intermezzo 3 explains how physiological information can be extracted from the rs-fMRI signal. 


\section{Intermezzo 1: Advanced MRI methods used in this thesis}

\section{White matter structure and diffusion-weighted MRI}

The white matter is organized as a complex network of connected fibers, which is responsible for efficient information exchange between brain regions (22). Alterations in one region may affect the function of other regions to which they are connected via white matter fiber tracts. Diffusion weighted MRI (dMRI) can probe the white matter fiber architecture, based on the diffusion characteritics of water molecules. This technique yields quantitative measures that reflect microstructural properties related to preferences in diffusion direction relative to the fiber trajectories.

The structure and efficiency of the constellation of the white matter fiber tracts, the so-called structural network, can be investigated by applying graph theory analysis (Intermezzo 2). In short, structural connectivity refers to the amount and integrity of white matter tracts between brain areas, thus in general, a lower structural connectivity is a marker of brain pathology. The use of dMRI-derived white matter tracts, in combination with graph theoretical analysis, addresses both the regional volumes, and their connections to other regions.

\section{Resting-state functional MRI}

To measure brain activity one can make use of the coupling between neuronal activity and microvascular blood supply that is expressed as spontaneous brain fluctuations (23). Functional MRI ( $\mathrm{FMRI}$ ) is sensitive to changes in blood oxygenation through the blood oxygen level dependent (BOLD) signal, which is related to brain function; more oxygenation consumption (indirectly) reflects higher brain activity. Neuronal activity can be measured during brain activation (task-based or stimulusinduced) and in rest (resting-state). Resting-state fMRI is used to determine the so-called resting-state networks, consisting of functionally connected regions with comparable spontaneous fluctuation signatures, which show a high level of correlated BOLD time-signal activity such as the default mode network (Intermezzo 2). In task-based fMRI, a cognitive or behavioral task is performed while sensory stimuli (e.g., auditory or visual) are presented during scanning to visualize the brain regions that are involved in the specific tasks.

The temporal correlations between the measured time signals of neuronal activity is used to assess collaborations between brain regions, which is termed as the so-called functional connectivity. The spatial organization of functional connectivity throughout the brain can also be expressed in terms of graph theoretical measures. 


\section{Intermezzo 2: Graph theory}

In graph theory the brain is represented as a graph, which is a network of gray matter regions (nodes) connected by white matter connections (edges). A simple representation of such a white matter network is depicted below; with in the red square an enlarged node connected with edges to five other nodes. The organization of such a graph can be quantitatively characterized by using graph measures that describe the efficiency and integrity of the white matter network.

These connections can either be represented by streamlines or temporal correlations between dMRI of fMRI measurements, respectively.

Node $=$ Gray matter region

Edge $=$ Connection between brain regions

Node degree $=\#$ edges connected to a node

Sparsity $=1-\frac{\text { number of edges }}{\text { number of possible edges }}$

Path = sequence of connections in the network which represent potential routes for communication between brain regions.

Graph $=$ network of nodes connected by edges .

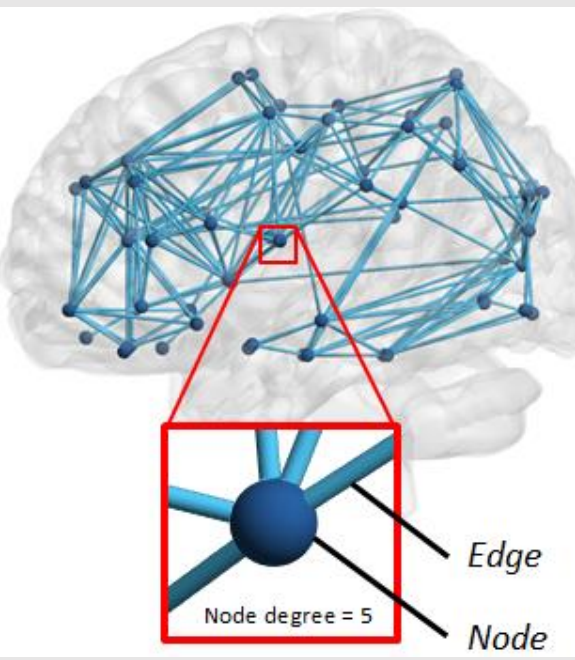

\section{Calculation of graph measures}

In structural connectivity analysis, connectivity matrices are based on tractography. As a result, not all pairs of nodes will have white matter connections, which leads to 'sparse' connectivity matrices. The measure sparsity reflects the extent of a graph's deviation from the corresponding fully connected graph. However, this differs between subjects and is also influenced by scan quality. Therefore, thresholding is applied, which ensures that each subject has the same number of nodes and edges. This is needed, because otherwise the differences in graph measures found are not due to differences in topological organization, but caused by differences in number of edges. The reference network was calculated from all individual binarized connectivity matrices, for a specific subset of subjects with the following steps (illustrated in the figure): 

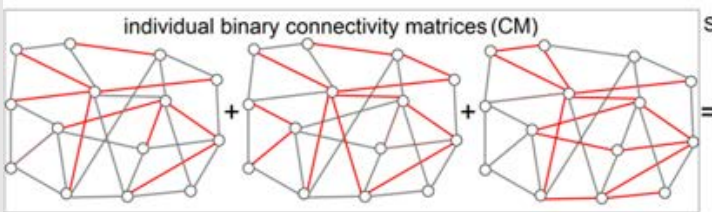

Step 1: summarize individual CMs
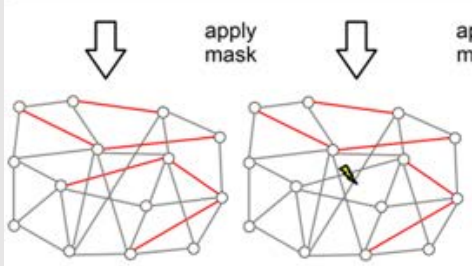

apply

mask

real sparsity $=0.8$

real sparsity $=0.83$

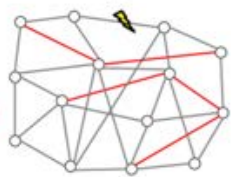

real sparsity $=0.83$

Step 4: apply mask and calculate real sparsity

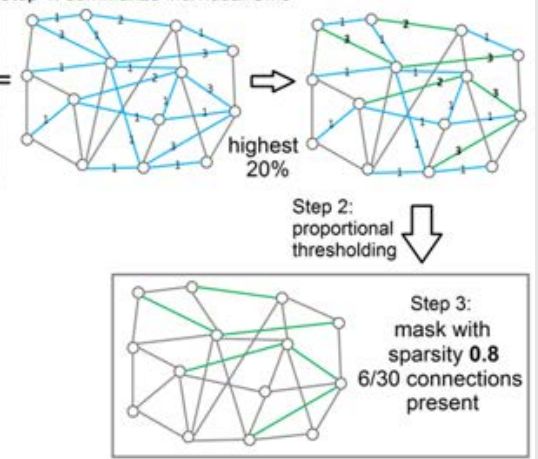

Step 1: Sum all individual binarized connectivity matrices.

Step 2: Proportional thresholding to a selected sparsity, e.g., 0.8 . This means selection of the $20 \%$ connections that are present in most of the participants, in other words, the $20 \%$ of the nodes with the highest sum score.

Step 3: Creation of a binary mask containing the $20 \%$ nodes from step 2.

Step 4: Application of the binary mask to select for each participant a weighted, undirected network with a sparsity close to the sparsity of the reference network. The actual sparsity in the individuals is a bit higher than 0.80 , because not each individual has a white matter tract at each connection in the reference network.

To describe network organization, measures indicative of network segregation, to assess the presence of local densely interconnected groups of brain regions, and indicative of integration, to assess large-scale communication between nodes, can be calculated:

- Graph measures of segregation: local connectivity properties

- $\quad$ Clustering coefficient $=$ number of connections between nearest neighbors of a node as a proportion of the maximum number of possible connections.

- $\quad$ Local efficiency = inverse shortest path length of connections to neighbors of a specific node.

- Graph measures of integration: global connectivity properties

- Characteristic path length = minimum number of connections that must be traversed on average to go from one region to another.

- $\quad$ Global efficiency = average inverse shortest path length in the network.

- $\quad$ Communicability = measure of all possible paths between regions weighted according to their length. 


\section{Intermezzo 3: Wavelet Transformation in resting-state fMRI.}

fMRI data consists of measured time signals of neuronal activity. A commonly used method to obtain insightful information from these time-series, by separating the signals related neuronal activity from nuisance, is to obtain a power spectrum by performing a Fourier transform. This power spectrum is usually dominated by nuisance signals, including the low frequency noise arising from physical sources (e.g., scanner drift, i.e., slowly varying changes in ambient temperature) and the highfrequency physiological sources, such as respiratory and cardiac signals. By applying a band pass filter these "noise signals" can be removed to some extent. Unfortunately, by taking a Fourier transform from a time signal, all time information is lost in return for frequency information. As the BOLD signal is not purely harmonic but contains frequencies that vary over time, the use of the frequency components is far from ideal (24). The technique of wavelet transformation (WT) can offer a solution here, because it has a high resolution in both the frequency and time domain, and therefore provides information about at which frequency and time the signal oscillates. Moreover, it preserves the low frequencies, which can be used as a sensitive measure of a variety of physiological signals. WT splits the time signal in frequency subbands, which can be matched with the frequencies of physiological signals. Typical physiological signals and their frequency ranges are cardiac activity $(0.6-2.0 \mathrm{~Hz})$, respiration $(0.145-0.6 \mathrm{~Hz})$, myogenic activity $(0.052-0.145 \mathrm{~Hz})$, neurogenic activity $(0.021-0.052 \mathrm{~Hz})$, and endothelial activity $(0.0095-0.021 \mathrm{~Hz})$. In the figure below, we illustrate how the frequency subbands acquired with WT relate to the physiological measures.

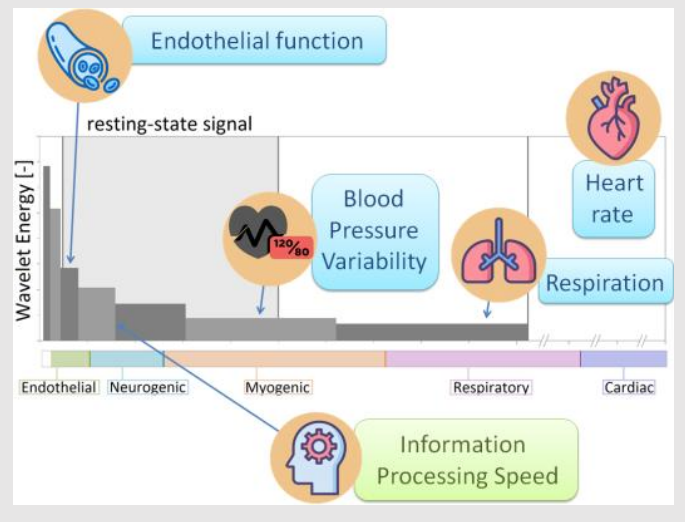

\section{Brain imaging in population-based cohort studies}

Large population-based cohort studies play a key role in revealing pathways and underlying mechanisms of chronic diseases like type 2 diabetes, cardiovascular disease, brain dysfunction, and dementia. Particularly, the combination of advanced phenotyping, obtained by functional measurements, questionnaires, and medical history, in such studies with brain imaging is a major strength of populationbased cohort studies. Table 1.1 gives an overview of ongoing European population-based cohort studies with brain MRI scans available. The main goal of these studies is to find imaging biomarkers in order to on the one hand, predict and early diagnose diseases, and on the other hand develop treatment strategies. 
Table 1.1: European population imaging studies with brain MRI scans available.

\begin{tabular}{|c|c|c|c|}
\hline Cohort and target & Population & Number* and age & MRI scans: measures \\
\hline $\begin{array}{l}\text { The Maastricht Study } \\
\text { Maastricht, Netherlands } \\
\text { Etiology, complications, and } \\
\text { comorbidities of type } 2 \text { diabetes. }\end{array}$ & $\begin{array}{l}\text { General } \\
\text { population, } \\
\text { over- } \\
\text { sampling of } \\
\text { T2DM }\end{array}$ & $\begin{array}{c}\mathrm{N}=5323, \text { age } 40-75 \\
\text { 2012-ongoing }\end{array}$ & $\begin{array}{c}\text { Structural: volumes, cSVD; } \\
\text { DWI: tractography, SC; } \\
\text { Rs-fMRI: FC }\end{array}$ \\
\hline $\begin{array}{c}\text { Rotterdam Scan Study } \\
\text { Rotterdam, Netherlands } \\
\text { Causes of neurological disease. }\end{array}$ & $\begin{array}{c}\text { General } \\
\text { population }\end{array}$ & $\begin{array}{c}\mathrm{N}=5886 \text {, age } 45+ \\
\text { 2005-ongoing }\end{array}$ & $\begin{array}{c}\text { Structural: volumes, cSVD; } \\
\text { DWI: diffusion metrics, SC; } \\
\text { Rs-fMRI: FC }\end{array}$ \\
\hline $\begin{array}{c}\text { RUN DMC Study } \\
\text { Nijmegen, Netherlands } \\
\text { Risk factors and clinical consequences of } \\
\text { brain changes during aging. }\end{array}$ & cSVD & $\begin{array}{l}\mathrm{N}=503 \text {, age } 50-85 \\
\text { 2006: baseline; } \\
\text { 2012: follow-up }\end{array}$ & $\begin{array}{l}\text { Structural: volumes, cSVD; } \\
\text { DWI: diffusion metrics }\end{array}$ \\
\hline
\end{tabular}

\begin{tabular}{|c|c|c|c|}
\hline $\begin{array}{c}\text { SMART-MR Study } \\
\text { Utrecht, Netherlands } \\
\text { Examine risk factors and consequences } \\
\text { of brain MRI abnormalities in patients } \\
\text { with manifest arterial disease. }\end{array}$ & $\begin{array}{l}\text { Arterial } \\
\text { disease }\end{array}$ & $\begin{array}{c}\mathrm{N}=1300, \text { age } 18-79 \\
2001-2005\end{array}$ & Structural: volumes, cSVD; \\
\hline $\begin{array}{l}\text { Lothian Birth Cohort } 1936 \\
\text { Scottland } \\
\text { Genetic contributions to individual } \\
\text { differences in normal cognitive ageing. }\end{array}$ & $\begin{array}{c}\text { General } \\
\text { population }\end{array}$ & $\begin{array}{c}\mathrm{N}=729, \text { age } 65-75 \\
2004-2007\end{array}$ & $\begin{array}{c}\text { Structural: volumes, cSVD; } \\
\text { DWI: diffusion metrics, } \\
\text { tractography }\end{array}$ \\
\hline $\begin{array}{c}\text { UK Biobank } \\
\text { United Kingdom } \\
\text { Improving prevention, diagnosis and } \\
\text { treatment of life-threatening illnesses. }\end{array}$ & $\begin{array}{c}\text { General } \\
\text { population }\end{array}$ & $\begin{array}{l}\mathrm{N}=500000 \\
\text { age } 40-69 \\
2006-2010 \\
\text { Follow-up ongoing }\end{array}$ & $\begin{array}{l}\text { Structural: volumes, cSVD; } \\
\text { DWI: diffusion metrics, } \\
\text { tractography; } \\
\text { Rs-fMRI: SC; Tb-fMRI: } \\
\text { activation }\end{array}$ \\
\hline $\begin{array}{c}\text { SNAC-K Study } \\
\text { Kungsholmen, Sweden } \\
\text { Detect influence of lifetime } \\
\text { genetic/environmental/ } \\
\text { biological factors on health in late } \\
\text { adulthood. }\end{array}$ & $\begin{array}{c}\text { General } \\
\text { population }\end{array}$ & $\begin{array}{l}\mathrm{N}=555, \text { age } 60+ \\
\text { 2001-2003 } \\
\text { 2004-2019 every } 6 \\
\text { years follow-up }\end{array}$ & Structural: volumes, cSVD \\
\hline $\begin{array}{l}\text { Ages-Reykjavik Study } \\
\text { Reykjavik, Iceland } \\
\text { Examine risk factors in relation to } \\
\text { disease and disability in old age. }\end{array}$ & $\begin{array}{c}\text { General } \\
\text { population }\end{array}$ & $\begin{array}{c}\mathrm{N}=5764, \text { age } 67+ \\
2002-2006\end{array}$ & Structural: volumes, cSVD \\
\hline $\begin{array}{c}\text { SHIP } \\
\text { Northeast Germany } \\
\text { Estimate prevalence/incidence of risk } \\
\text { factors, subclinical disorders, and } \\
\text { diseases and complex associations } \\
\text { among them. }\end{array}$ & $\begin{array}{c}\text { General } \\
\text { population }\end{array}$ & $\begin{array}{c}\mathrm{N}=2500, \text { age } 20-90 \\
1997-2013\end{array}$ & $\begin{array}{c}\text { Structural: volumes, cSVD; } \\
\text { DWI }\end{array}$ \\
\hline $\begin{array}{c}\text { 3C Study } \\
\text { Bordeaux/Dijon/Montpellier, France } \\
\text { Relation between vascular diseases and } \\
\text { dementia. }\end{array}$ & $\begin{array}{c}\text { General } \\
\text { population }\end{array}$ & $\begin{array}{l}\mathrm{N}=3442 \text {, age } 65+ \\
\text { 1999-2001 baseline } \\
\text { 2001-2012 } \\
\text { follow-up }\end{array}$ & Structural: volumes, cSVD \\
\hline
\end{tabular}




\section{The Maastricht Study}

In this thesis, we use population data from The Maastricht Study. The Maastricht Study is an ongoing observational prospective population-based cohort study that focuses on the etiology, pathophysiology, complications, and comorbidities of type 2 diabetes and other chronic diseases (25). Its extensive phenotyping approach is certainly suitable to study the mechanisms and determinants of brain alterations in a population-based setting. Eligible for participation were all individuals aged between 40 and 75 years and living in the southern part of the Netherlands. Participants were recruited through mass media campaigns and from the municipal registries and the regional Diabetes Patient Registry via mailings. Recruitment was stratified according to known type 2 diabetes status, with an oversampling of individuals with type 2 diabetes. This thesis includes cross-sectional data from the first 5083 participants, who completed the baseline survey between November 2010 and December 2017, and with complete MRI data without artifacts (Figure 1.2).

Participants invited for MRI $(n=5547)$

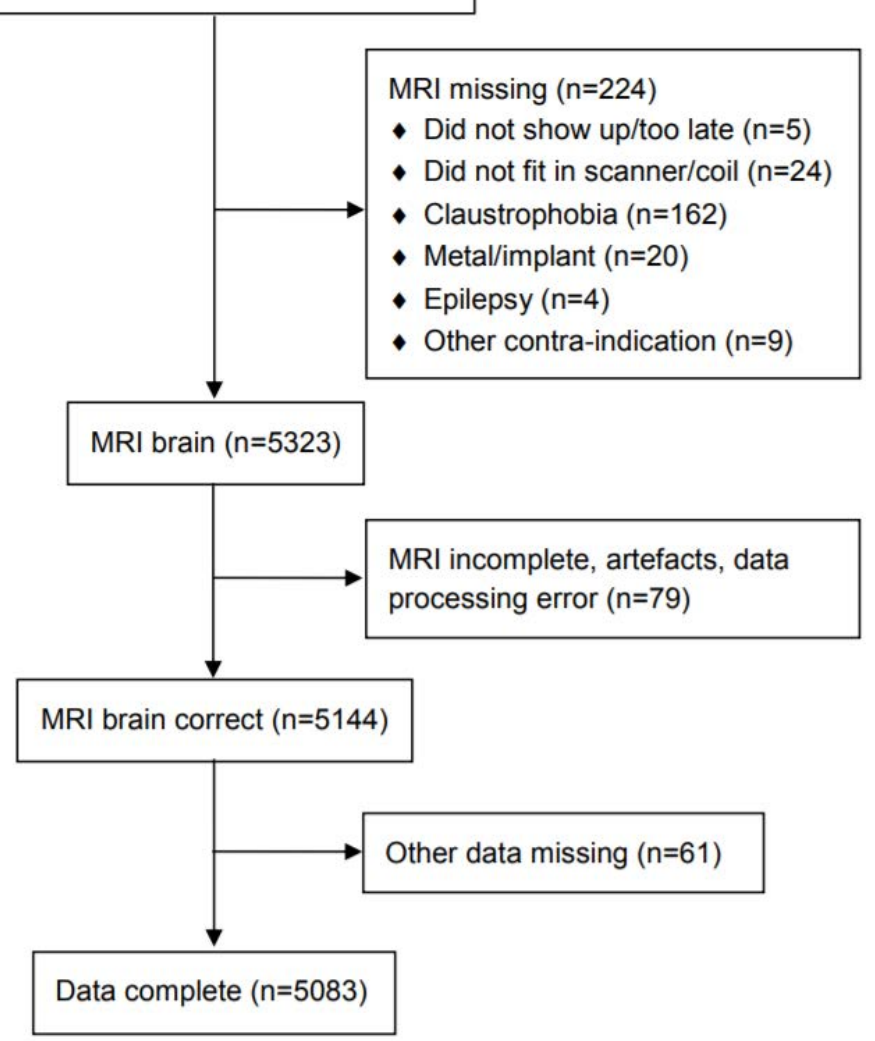

Figure 1.2: Flowchart of the study population 


\section{Objectives}

The main objectives of this thesis are twofold.

1. To unveil novel neuronal imaging associations of cardiometabolic risk factors beyond visible brain lesions or abnormalities.

2. To evaluate the value of structural and functional brain network measures for this purpose.

\section{Outline of thesis}

This thesis first summarizes the existing evidence on associations between cardiometabolic risk factors and subtle brain changes as assessed by structural and advanced imaging methods. Subsequently, we investigate in The Maastricht Study the associations of specific cardiometabolic and lifestyle factors with advanced MRI techniques, as these are thought to uncover more subtle tissue and vascular alterations than macroscopically visible lesions displayed by structural MRI. Finally, we unravel to what extent various systemic physiological influences are associated with the measured BOLD signal. Additionally, we investigate to what extent the BOLD signal components, particularly the neurogenic component, are altered in participants with cardiometabolic risk factors. Figure 1.3 gives a schematic overview of the associations investigated in this thesis. The next section describes the aims of each individual chapter.

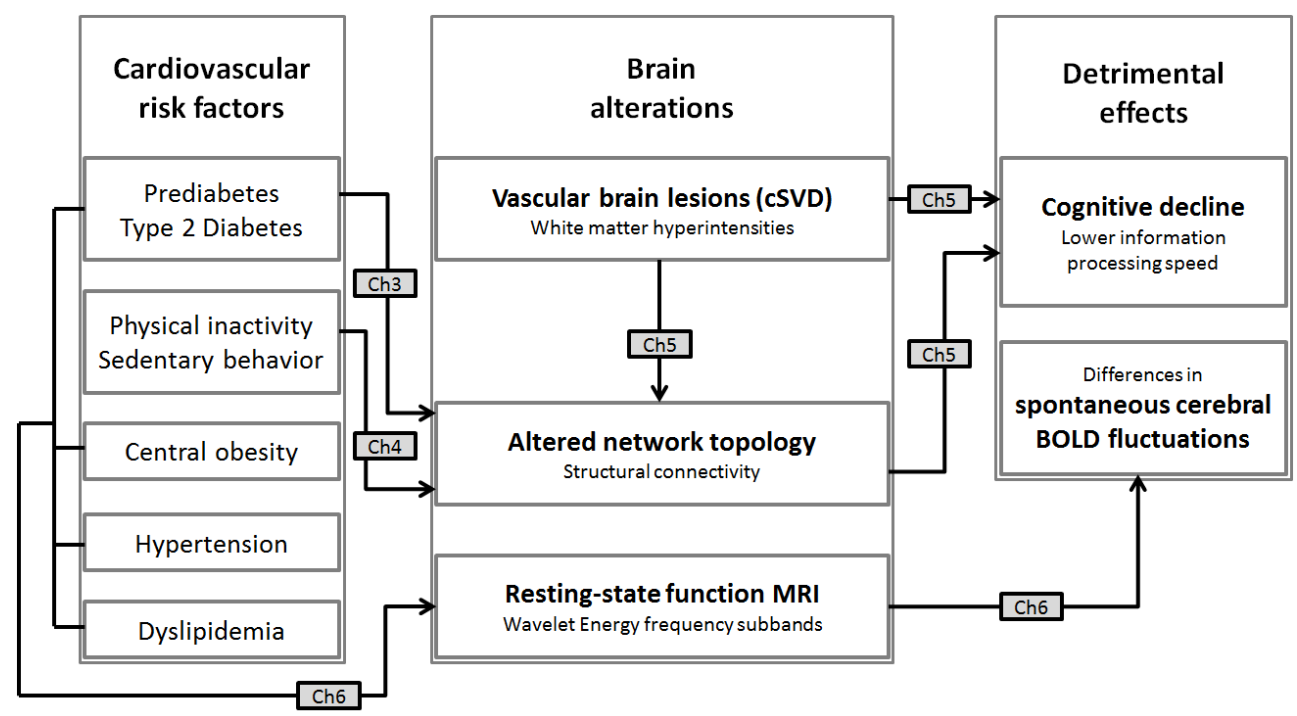

Figure 1.3: Schematic outline of the associations investigated in this thesis

After the general introduction, a narrative review is conducted in Chapter $\mathbf{2}$ to summarize the existing evidence on associations between cardiometabolic risk factors and subtle brain changes as assessed by structural and advanced MRI. First, we introduce the different MRI techniques. Then we discuss the associations of the cardiometabolic risk factors hyperglycemia, physical inactivity, sedentary behavior, 
central obesity, hypertension, and dyslipidemia, with changes on brain MRI. Finally, we discuss the findings and their currently available level of evidence.

In Chapter 3, we investigate the association of prediabetes and type 2 diabetes, with white matter network characteristics, in terms of the number (node degree) and organization (graph measures) of the white matter connections.

In Chapter 4, we investigate the association of objectively measured low- and high-intensity physical activity (LPA and HPA) and sedentary time (ST) with white matter connectivity, both throughout the whole brain, and in brain regions involved in motor function, as a measure of white matter integrity.

In Chapter 5, we investigate if and, if so how, CSVD lesions, measures of the white matter tracts and network, and cognitive function are associated, and whether these associations dependent on cardiometabolic risk factors.

In Chapter 6, we decompose the dynamic resting-state fMRI brain signal into wavelet components and explore whether the various frequency subbands are associated with physiological measures in the physiological frequency subbands cardiac activity, respiration, myogenic activity, neurogenic activity, and endothelial activity.

Finally, in Chapter 7, we combine and discuss the key findings of this thesis. In addition, we address methodological considerations and directions for future research.

\section{References}

1. Organization WH. Health 2020: a European policy framework supporting action across government and society for health and well-being. Copenhagen: World Health Organization Regional Officie for Europe 2012.

2. Bhatnagar $P$, Wickramasinghe $K$, Wilkins $E$, Townsend $N$. Trends in the epidemiology of cardiovascular disease in the UK. Heart 2016;102(24):1945-1952. doi: 10.1136/heartjnl-2016-309573

3. American Diabetes A. Diagnosis and Classification of Diabetes Mellitus. Diabetes Care 2011;34(Suppl 1):S62-S69. doi: $10.2337 / \mathrm{dc11}$-S062

4. Organization WH. Global report on diabetes: World Health Organization, 2016.

5. Barrett EJ, Liu Z, Khamaisi M, King GL, Klein R, Klein BEK, Hughes TM, Craft S, Freedman BI, Bowden DW, Vinik Al, Casellini CM. Diabetic Microvascular Disease: An Endocrine Society Scientific Statement. The Journal of Clinical Endocrinology \& Metabolism 2017;102(12):4343-4410. doi: 10.1210/jc.2017-01922

6. Tyndall AV, Argourd L, Sajobi TT, Davenport MH, Forbes SC, Gill SJ, Parboosingh JS, Anderson TJ, Wilson BJ, Smith EE, Hogan DB, Hill MD, Poulin MJ. Cardiometabolic risk factors predict cerebrovascular health in older adults: results from the Brain in Motion study. Physiological reports 2016;4(8). doi: 10.14814/phy2.12733

7. Friedman JI, Tang CY, de Haas HJ, Changchien L, Goliasch G, Dabas P, Wang V, Fayad ZA, Fuster V, Narula J. Brain Imaging Changes Associated With Risk Factors for Cardiovascular and Cerebrovascular Disease in Asymptomatic Patients. JACC: Cardiovascular Imaging 2014;7(10):1039-1053. doi: https://doi.org/10.1016/j.jcmg.2014.06.014

8. van Bussel FCG, Backes WH, Hofman PAM, van Oostenbrugge RJ, van Boxtel MPJ, Verhey FRJ, Steinbusch HWM, Schram MT, Stehouwer CDA, Wildberger JE, Jansen JFA. Cerebral Pathology and Cognition in Diabetes: The Merits of Multiparametric Neuroimaging. Frontiers in neuroscience 2017;11:188. doi: 10.3389/fnins.2017.00188

9. Kalaria RN. Cerebrovascular Disease and Mechanisms of Cognitive Impairment. Evidence From Clinicopathological Studies in Humans 2012;43(9):2526-2534. doi: 10.1161/strokeaha.112.655803

10. Biessels GJ, Reijmer YD. Brain Changes Underlying Cognitive Dysfunction in Diabetes: What Can We Learn From MRI? Diabetes 2014;63(7):2244-2252. doi: 10.2337/db14-0348 
11. Geijselaers SLC, Sep SJS, Stehouwer CDA, Biessels GJ. Glucose regulation, cognition, and brain MRI in type 2 diabetes: a systematic review. The lancet Diabetes \& endocrinology 2015;3(1):75-89. doi: 10.1016/s22138587(14)70148-2

12. Awad N, Gagnon M, Messier C. The relationship between impaired glucose tolerance, type 2 diabetes, and cognitive function. J Clin Exp Neuropsychol 2004;26(8):1044-1080. doi: 10.1080/13803390490514875

13. Biessels GJ, Staekenborg S, Brunner E, Brayne C, Scheltens P. Risk of dementia in diabetes mellitus: a systematic review. The Lancet Neurology 2006;5(1):64-74. doi: 10.1016/s1474-4422(05)70284-2

14. Schneider ALC, Selvin E, Sharrett AR, Griswold M, Coresh J, Jack CR, Jr., Knopman D, Mosley T, Gottesman RF. Diabetes, Prediabetes, and Brain Volumes and Subclinical Cerebrovascular Disease on MRI: The Atherosclerosis Risk in Communities Neurocognitive Study (ARIC-NCS). Diabetes care 2017;40(11):1514-1521. doi: 10.2337/dc171185

15. van Agtmaal MJM, Houben A, de Wit V, Henry RMA, Schaper NC, Dagnelie PC, van der Kallen CJ, Koster A, Sep SJ, Kroon AA, Jansen JFA, Hofman PA, Backes WH, Schram MT, Stehouwer CDA. Prediabetes Is Associated With Structural Brain Abnormalities: The Maastricht Study. Diabetes care 2018;41(12):2535-2543. doi: 10.2337/dc181132

16. Marseglia A, Fratiglioni L, Kalpouzos G, Wang R, Bäckman L, Xu W. Prediabetes and diabetes accelerate cognitive decline and predict microvascular lesions: A population-based cohort study. Alzheimer's \& Dementia: The Journal of the Alzheimer's Association 2019;15(1):25-33. doi: 10.1016/j.jalz.2018.06.3060

17. Kloppenborg RP, van den Berg E, Kappelle $L$, Biessels GJ. Diabetes and other vascular risk factors for dementia: which factor matters most? A systematic review. Eur J Pharmacol 2008;585(1):97-108. doi:

10.1016/j.ejphar.2008.02.049

18. van den Berg E, Dekker JM, Nijpels G, Kessels RP, Kappelle L, de Haan EH, Heine RJ, Stehouwer CD, Biessels GJ. Blood pressure levels in pre-diabetic stages are associated with worse cognitive functioning in patients with type 2 diabetes. Diabetes/metabolism research and reviews 2009;25(7):657-664. doi: 10.1002/dmrr.1009

19. Dong C, Nabizadeh N, Caunca M, Cheung YK, Rundek T, Elkind MS, DeCarli C, Sacco RL, Stern Y, Wright CB. Cognitive correlates of white matter lesion load and brain atrophy: the Northern Manhattan Study. Neurology 2015;85(5):441-449. doi: 10.1212/wnl.0000000000001716

20. van Dijk EJ, Prins ND, Vrooman HA, Hofman A, Koudstaal PJ, Breteler MM. Progression of cerebral small vessel disease in relation to risk factors and cognitive consequences: Rotterdam Scan study. Stroke 2008;39(10):27122719. doi: 10.1161/strokeaha.107.513176

21. Beason-Held LL, Goh JO, An Y, Kraut MA, O'Brien RJ, Ferrucci L, Resnick SM. Changes in brain function occur years before the onset of cognitive impairment. The Journal of neuroscience: the official journal of the Society for Neuroscience 2013;33(46):18008-18014. doi: 10.1523/JNEUROSCI.1402-13.2013

22. Rubinov $M$, Sporns $O$. Complex network measures of brain connectivity: uses and interpretations. Neurolmage 2010;52(3):1059-1069. doi: 10.1016/j.neuroimage.2009.10.003

23. Girouard H, ladecola C. Neurovascular coupling in the normal brain and in hypertension, stroke, and Alzheimer disease. Journal of Applied Physiology 2006;100(1):328-335. doi: 10.1152/japplphysiol.00966.2005

24. de Pasquale F, Della Penna S, Snyder AZ, Lewis C, Mantini D, Marzetti L, Belardinelli P, Ciancetta L, Pizzella V, Romani GL, Corbetta M. Temporal dynamics of spontaneous MEG activity in brain networks. Proceedings of the National Academy of Sciences 2010;107(13):6040-6045. doi: 10.1073/pnas.0913863107

25. Schram MT, Sep SJ, van der Kallen CJ, Dagnelie PC, Koster A, Schaper N, Henry RM, Stehouwer CD. The Maastricht Study: an extensive phenotyping study on determinants of type 2 diabetes, its complications and its comorbidities. Eur J Epidemiol 2014;29(6):439-451. doi: 10.1007/s10654-014-9889-0 


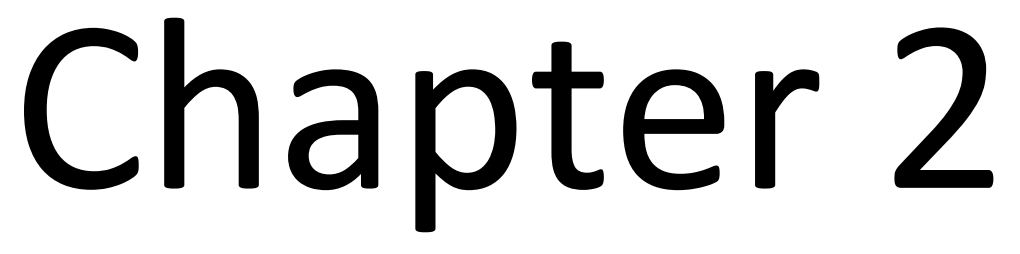

\section{Cardiometabolic determinants of early and advanced brain alterations: Insights from conventional and novel MRI techniques}

Laura W.M. Vergoossen, Jacobus F.A. Jansen,

Walter H. Backes, Miranda T. Schram

Neuroscience and Biobehavioral Reviews 115 (2020) 308-320, doi:

10.1016/j.neubiorev.2020.04.001.
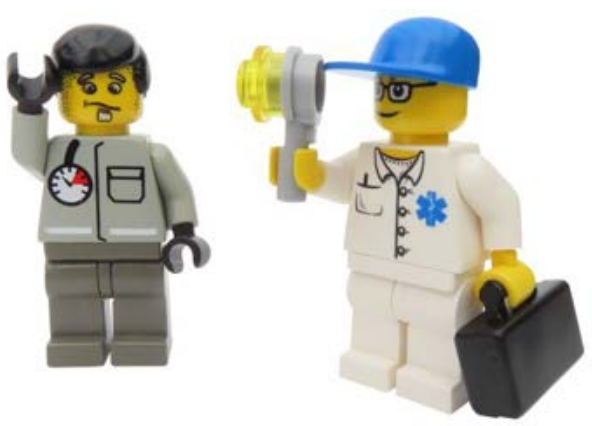


\begin{abstract}
Cardiometabolic risk factors may be of key importance in the development of future brain diseases like dementia or depression. However, it remains unclear how these risk factors exactly affect the brain. Advanced MR imaging methods such as, diffusion weighted and functional MRI, can provide detailed insights into subtle brain changes, and potentially into early development of disease. In this narrative review, we summarize the available evidence on the associations of cardiometabolic risk factors with subtle changes in brain MRI measures. We found clear evidence that hyperglycemia, physical inactivity, central obesity, and hypertension are associated with both structural and functional brain alterations, while the role of dyslipidemia is far less clear. However, longitudinal evidence that assesses temporality of the associations with more advanced and thus more precise brain imaging methods is needed to improve our insights into the complex etiology of brain diseases.
\end{abstract}




\section{Introduction}

Cardiometabolic risk factors may be of key importance in the development of brain diseases like dementia and depression. However, it remains unclear how these risk factors exactly affect the brain. Advanced MR imaging methods can provide detailed insights into subtle brain changes, and thus early development of brain diseases, enhancing our understanding of disease pathology. Subtle brain changes are likely to precede brain dysfunction, and in a later stage, brain diseases (1). Cardiometabolic risk factors, like hyperglycemia, physical inactivity and sedentary behavior, central obesity, hypertension, and dyslipidemia, have been identified as risk factors of dementia and depression $(2,3)$, and their associations have been discussed in previous review articles $(4,5)$. However, no such summary is available on the cardiometabolic determinants of subtle brain alterations as visualized with advanced imaging methods. Therefore, in this narrative review, we summarize the existing evidence on associations between cardiometabolic risk factors and subtle brain changes as assessed by structural and advanced imaging modalities, such as, diffusion weighted MRI (dMRI) and functional MRI (fMRI). These advanced techniques are thought to reflect more subtle tissue and vascular alterations than macroscopically visible lesions displayed by structural MRI.

First, we will introduce the MRI techniques that are presented in literature. Second, we will discuss the association of well-known cardiometabolic risk factors, including hyperglycemia, physical inactivity, sedentary behavior, central obesity, hypertension and dyslipidemia, with structural changes on brain MRI, e.g., with measures of brain atrophy and cerebral small vessel disease (cSVD). Third, their associations with more advanced brain MRI measures, such as diffusion measures and brain connectivity derived from $\mathrm{dMRI}$ and $\mathrm{fMRI}$, will be summarized. Finally, we will discuss the findings and their currently available level of evidence.

\section{Methods}

\section{Literature search and study selection}

We performed an literature search by use of the search terms 'brain' and 'MRI', combined with specific search terms for each category of risk factors, as shown in Supplementary Figure 2.1. The inclusion criteria were: full-article research papers and English-written publications, published from inception to May 1, 2019. The following articles were excluded: animal studies, studies on subjects with a specific disease, with a small sample size (case-control $\mathrm{N}<10$ per group; population-based $\mathrm{N}<100$ ), focused on determinant(s) or outcome measures other than cardiometabolic risk factors or brain MRI, conference abstracts without a full text publication, and research protocols. In case of multiple studies on the same study population, the most recent or largest study was included in this review. When possible, we focused on studies performed in large observational population-based cohort studies to maximize generalizability. 


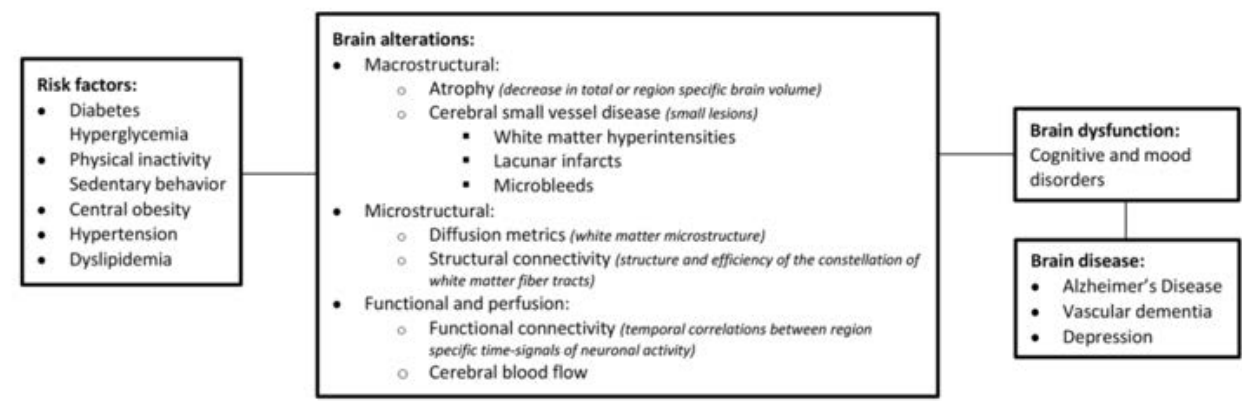

Figure 2.1: Schematic overview of the associations between cardiometabolic risk factors, early brain alterations, brain dysfunction, and brain diseases.

\section{Conventional MRI techniques to detect macrostructural brain changes}

Structural brain MRI techniques can detect macroscopically visible morphological brain abnormalities, of which atrophy and features of CSVD are highly relevant for this review. These macrostructural changes are presumably irreversible, but nonetheless important for understanding development of brain diseases.

\section{Brain atrophy}

Brain atrophy is a decrease in total or regional brain volume, not caused by a specific macroscopic focal injury such as an infarction or trauma. In general, this loss of volume is thought to be the result of neurodegeneration, e.g., the loss of neurons or other brain cells due to cell death and/or apoptosis $(6,7)$.

\section{Cerebral small vessel disease}

CSVD refers to lesions in the brain, such as white matter hyperintensities, microbleeds, and lacunar infarcts. According to previous studies, presence of lacunes, white matter hyperintensities, and microbleeds are jointly indicative of an underlying CSVD state, and each measure has been associated with lower general cognitive ability (8).

\section{White matter hyperintensities}

White matter hyperintensities (WMH) are hyper-intense loci on $\mathrm{T}_{2}$-weighted (TSE and FLAIR) MRI scans (6). Larger WMH volumes are associated with worse cognitive function (9). Like brain atrophy, WMH occur more often in older individuals and are strongly associated with cerebrovascular disease and cognitive decline (10). Wardlaw et al. (11) previously discussed the pathogenesis of cSVD features. The main mechanism underling CSVD-related brain injury, especially $\mathrm{WMH}$, is usually assumed to be ischemia, which results from narrowed or occluded (perforating) arteries. However arterial occlusion might already be a late-stage phenomenon. Currently, earlier phenomena of CSVD pathology are considered to be represented by, systemic endothelium dysfunction (12). For WMH this may be accompanied by demyelinisation and even axonal loss. 


\section{Lacunar infarcts}

Lacunar infarcts, or in short lacunes, are round or oval, subcortical, fluid-filled cavities (3-15 mm in diameter) (6) and occur frequently in asymptomatic elderly individuals (13).

\section{Microbleeds}

Microbleeds are small, mostly 2-5 mm in diameter, hypo-intense lesions seen on $\mathrm{T}_{2}{ }^{*}$ - or susceptibilityweighted (gradient-echo) MRI (14). Microbleeds are generally located in the cortico-subcortical junction and deep gray or white matter in the cerebral hemispheres, brainstem, and cerebellum (6).

\section{Advanced MRI techniques to detect microstructural brain changes}

\section{Diffusion MRI}

The white matter is organized as a complex network of connected fibers, responsible for efficient information exchange between various brain regions. Alterations in one region may thus affect the function of other regions via the connecting white matter tracts. Therefore, it is important to assess the microstructure of the white matter, which can be visualized by use of dMRI. dMRI can probe white matter fiber architecture, based on the diffusion of water molecules, and yields quantitative measures such as the fractional anisotropy (FA), mean diffusivity (MD), axial diffusivity (AD) and radial diffusivity (RD). All these measures reflect microstructural changes related to preferences in diffusion direction relative to the fiber trajectories. It is recommended to analyze a combination of these diffusion metrics, due to their complicated mutual dependence (15).

\section{Fractional anisotropy}

With respect to the detection of brain changes, the FA is a highly sensitive measure for microstructural changes, however, not very specific to the type of change. FA indicates the directionality of a diffusion process (e.g., due to the orientation of white matter fibers). However, alterations in FA are not unambiguous, as reductions in FA can be either due to decreases in $A D$ and increases in RD or vice versa; FA is furthermore highly influenced by the many crossings of fibers and alterations thereof.

\section{Mean diffusivity}

MD indicates the motility of the water molecules. To measure the locally preferred directionality of water diffusion, diffusion-motion sensitized field gradients in multiple angular directions is used, so called High-Angular-Resolution-Diffusion-Imaging (HARDI). The MD represents an inverse measure of membrane or border density, is independent of direction, and sensitive to cellularity, edema, and necrosis. 


\section{Axial and radial diffusivity}

$A D$ reflects diffusion along the (long) fiber axis, and gives information about axonal injury and thus decreases when there is axonal damage. RD reflects the diffusion perpendicular to the fiber orientation, and is often most sensitive to impairment of the fiber structure. The RD is often suggested as a surrogate myelin marker and changes when there is myelin damage, and it can be influenced by the geometric properties of the axons (e.g., diameter and density). An increased RD is consistently found in many white matter pathologies, the $A D$ tends to be more variable (16).

\section{Structural connectivity}

dMRI can be used to analyze the structure and efficiency of the constellation of white matter fiber tracts, the so-called structural network, by applying graph theory analysis. In graph theory, the brain is represented as a graph, which is a network of nodes (i.e., gray matter brain regions) connected by edges (i.e., white matter tracts between brain regions). The sequence of connections in the network which represent potential routes for communication between brain regions is called a path. The number of connections to one node is called the node degree. The organization of a graph can be characterized by use of graph measures, e.g., clustering coefficient, characteristic path length, global efficiency, and local efficiency. These graph measures describe the efficiency of the white matter network architecture (for an overview, see Table 1). In short, structural connectivity refers to the amount and integrity of white matter tracts between brain areas, thus in general, a lower structural connectivity is a marker of brain pathology.

\section{Functional MRI}

$\mathrm{fMRI}$ is sensitive to changes in blood oxygenation through the blood oxygen level-dependent (BOLD) signal, which is related to brain function; more oxygenation (indirectly) reflects higher brain activity. fMRI brain activity is thought to locally reflect the coupling between neuronal activity and microvascular blood supply (17). In contrast to structural connectivity, functional connectivity relies on statistical dependence of the time signals from different brain regions (which may not be structurally connected). Therefore, a lower functional connectivity is suggested to be a marker of brain dysfunction. fMRI can be used to analyze the temporal correlations between measured time-signals of neuronal activity, to assess collaborations between brain regions, the so-called functional connectivity. Functional connectivity can also expressed in terms of graph measures (Table 2.1). Neuronal activity can be measured during brain activation (task-based or stimulus-induced) and in rest (resting-state). The latter is used to determine the so-called resting-state networks, consisting of functionally connected regions, which show a high level of correlated BOLD time-signal activity, such as the default mode network (DMN). In task-based fMRI, a cognitive or behavioral task is performed while sensory stimuli (e.g., auditory or visual) are presented during scanning to visualize the brain regions that are involved in the specific tasks. 
Table 2.1: Glossary - Most used terms and measures in graph theory.

\begin{tabular}{|c|c|}
\hline Graph measure & Description \\
\hline \multicolumn{2}{|l|}{ Of segregation } \\
\hline $\begin{array}{l}\text { Clustering } \\
\text { coefficient }\end{array}$ & $\begin{array}{l}\text { Number of connections between nearest neighbors of a node as a } \\
\text { proportion of the maximum number of possible connections. }\end{array}$ \\
\hline Local efficiency & $\begin{array}{l}\text { Inverse shortest path length of connections to neighbors of a specific node; } \\
\text { related to clustering coefficient. }\end{array}$ \\
\hline \multicolumn{2}{|l|}{ Of integration } \\
\hline $\begin{array}{l}\text { Characteristic path } \\
\text { length }\end{array}$ & $\begin{array}{l}\text { The minimum number of connections that must be traversed on average to } \\
\text { go from one region to another. }\end{array}$ \\
\hline Global efficiency & $\begin{array}{l}\text { Average inverse shortest path length in the network; inversely related to } \\
\text { characteristic path length. }\end{array}$ \\
\hline
\end{tabular}

\section{Perfusion MRI}

Perfusion weighted MRI can be used to investigate the blood perfusion of tissues, including ischemic conditions. Lower brain perfusion is a marker for brain diseases, and is associated with cognitive decline. The most used perfusion weigthed MRI techniques are dynamic susceptibility contrast (DSC), dynamic contrast enhanced (DCE), and arterial spin labeling (ASL) MR perfusion. Both DSC and DCE require administration of the contrast medium gadolinium, while ASL does not need exogenous contrast. ASL imaging is based on signal loss due to magnetization exchange of labeled water molecules in the blood vessels (18).

\section{Results}

\section{Type 2 diabetes and hyperglycemia as risk factor for early brain alterations}

Several large cross-sectional and longitudinal observational cohort studies investigated the association of type 2 diabetes mellitus (T2DM) with brain atrophy. T2DM was found to be consistently associated with global brain atrophy in cross-sectional data of the Utrecht Diabetic Encephalopathy Study (19-22), The Framingham Heart Study $(23,24)$, The SMART MR study (25), The CARDIA Brain MRI study (26), The Mayo Clinic Study of Aging (27), UK Biobank (28), and The ARIC study (29). This has been confirmed in longitudinal analyses of the Utrecht Diabetic Encephalopathy Study (30), the SMART MR study (31), and in the PROSPER study, over 3 to 4 years of follow-up (32).

More specific, T2DM has been associated with smaller gray matter $(24,28,31,33-36)$ and white matter volumes $(36,37)$, larger CSF volumes $(31,34)$, global cortical thinning $(31,38,39)$, and also smaller hippocampus volumes $(23,24,27,36,40-43)$ as compared to normal glucose metabolism (NGM) inthese, (some population-based) cohort studies. These associations have also been confirmed in longitudinal analyses for decreased gray matter volumes (31, 33); increased CSF volumes (31), and with global cortical thinning $(31,39)$. The follow-up duration of these studies ranged from 40 months $(31)$ up to 12 years (39).

T2DM has also been associated with cSVD characteristics. In multiple large cross-sectional cohort studies an association of T2DM with larger WMH $(19-22,24,28,29,31,37,38)$ and ischemic 
lesion volumes $(34,44)$, and more lacunar infarcts (29) has been established. In longitudinal analyses, T2DM has been associated with increased WMH (31), and ischemic lesion volumes (34). Surprisingly, T2DM has not (yet) been associated with microbleeds $(36,45,46)$.

A minority of studies used advanced MRI techniques to investigate the association of T2DM with white matter microstructure and (both structural and functional) brain connectivity. By use of dMRI, several case-control studies observed lower FA (24, 28, 37, 47-53), and higher MD (28, 37, 47, 49-51), which indicate altered or impaired fiber microstructure in T2DM. Furthermore, two case-control studies found higher $A D(47,51)$, and higher $\operatorname{RD}(47,51)$, similarly indicative of injured white matter by axonal injury and disruption of fibre structure.

Van Bussel et al., reported lower structural connectivity, in terms of lower tract volumes between the hippocampi and the frontal lobe, temporal lobe and subcortical gray matter in T2DM compared to NGM as measured by dMRI (50). fMRI findings in subjects with T2DM included altered neuronal activity (54), lower functional connectivity $(51,55-57)$ (mainly in frontal and parietal lobes) and lower degree centrality (DC) (56) compared to NGM. However, in contradiction to expectations, T2DM was associated with lower characteristic path length (58), higher normalized clustering coefficient (CC) $(58,59)$, and higher local efficiency (Elocal) $(59)$ as compared to NGM. A possible explanation for those findings is a compensatory mechanism to counteract (subtle or even subconsciuous) cognitive impairment. The authors hypothesized that this compensation is achieved by mobilizing additional neural resources, such as excessive activation of the network and the efficient networking of multiple brain regions. Furthermore, one study found a weaker FC of the posterior cingulate cortex (PCC) and stronger FC to several brain regions in T2DM compared to controls (60). Finally, T2DM has been associated with lower blood perfusion (61-64) measured by use of perfusion and flow MRI techniques.

Very few studies investigated the association of prediabetes, defined as a disturbed fasting or non-fasting glucose metabolism, but not yet full-blown diabetes, with structural or functional brain MRI measures. In the large cross-sectional ARIC Neurocognitive Study, no association of prediabetes with smaller brain volumes or larger burden of brain vascular pathology was found (29). Meanwhile, in the large cross-sectional population-based Maastricht Study, prediabetes was associated with smaller WM volumes, but not with differences in GM volumes (46). In one case-control study, patients with prediabetes and those with T2DM showed lower GM volumes in the hippocampus, amygdala, and the putamen compared with controls, while no significant differences were found between participants with T2DM and prediabetes (65). This indicates that brain changes in T2DM compared to normal glucose metabolism were already present in prediabetes. Only one study reported an association of prediabetes with larger WMH volumes and presence of lacunar infarcts, but found no significant association with cerebral microbleeds (46). In the case-control study of Liang et al., a lower FA was found in prediabetes compared to controls (53). Using resting-state $\mathrm{fMRI}$, higher normalized local efficiency was found in participants with prediabetes compared to NGM, hinting at reorganization of the functional networks as compensation for potential cognitive decrements (59).

Furthermore, some studies investigated also the association of blood glucose levels on a continuous scale with MRI brain measures. A cross-sectional study reported that higher HbA1c levels were associated with smaller brain volumes and a higher burden of WMH and lacunar infarctions (29). Additionally, elevated glucose levels were associated with lower FA in the right inferior and bilateral superior longitudinal fasciculi (66). In large population-based studies, higher fasting blood glucose levels were associated with lower cortical thickness $(39,46,67,68)$ and lower GM density and FA (24). One of these was a 12-year follow-up study (39). 
In summary, several large cross-sectional and longitudinal population-based studies investigated the association of T2DM with brain changes, and found more atrophy both in gray and white matter, and more severe characteristics of CSVD in T2DM compared to NGM. Fewer studies investigated the association of T2DM with white matter microstructure and connectivity, and found impaired white matter microstructure, and lower structural and functional connectivity in T2DM compared to NGM, which may already be present in prediabetes. Unfortunately, only a few studies investigated continuous glucose measures in relation to brain changes, and most had a cross-sectional design, but did find clear associations. Allthough these results suggest a causal role for hyperglycemia in early brain changes, longitudinal population-based studies using continuous measures of hyperglycemia are needed to confirm a temporal, and thus potential causal, association of hyperglycemia with early brain damage.

\section{Physical inactivity and sedentary behavior as risk factor for early brain}

\section{alterations}

The association of physical inactivity with structural MRI brain measures has been investigated in large cross-sectional population-based studies, e.g., the AGES-Reykjavik (69), SMART-MR (70), Framingham $(71,72)$, LADIS $(73,74)$, SHIP (75), MAP (76), and NOMAS (77) study. These studies found clear associations between physical inactivity and lower cortical thickness $(78,79)$, specifically in the left prefrontal lobe $(78)$, more brain atrophy $(70,72,80-85)$, and smaller white matter $(69,86)$ and gray matter volumes $(69,75,76,84,87-91)$. Most of these studies used self-reported physical activity measures, while some used objective data as measured by accelerometric devices $(69,72,76,79,80$, 82). PA questionnaires only collect subjetive information and may therefore over- or underestimate PA levels. Especially light- to moderate-intensity PA are difficult to measures with questionnaires. The longitudinal population-based AGES-Reykjavik study showed that objectively measured physical inactivity was associated with more 5-year GM and WM atrophy (69). Comparable results were found in the Cardiovascular Health Study, namely, a longitudinal association of lower self-reported physical activity intensity with more loss of total brain volume over a 9-year period (83). The longitudinal Korean Genome and Epidemiology study found that physical inactivity is associated with brain atrophy (92).

Considering cerebral small vessel disease, more physical inactivity has been associated with the presence of silent brain infarcts $(77)$, and larger WMH volumes $(82,88,93)$ in cross-sectional cohort studies. However, others did not find any association of physical activity with WMH $(70,77,84)$. None of these studies on cerebral small vessel disease used objectively measured data on physical activity.

Physical inactivity has also been associated with diffusion MRI metrics, e.g. a significantly higher $\mathrm{FA}$, and lower MD, AD and RD $(80,91,93,94)$. Only one study investigated the association of physical inactivity on structural connectivity measures. Kim et al. (95) found in a cross-sectional study that subjects with a lower level of self-reported physical activity showed significantly lower regional nodal strength in the bilateral middle frontal, bilateral inferior parietal, medial orbitofrontal, and superior and middle temporal gyri, compared to subjects with high levels of self-reported physical activity. In addition, this study found that physical inactivity was associated with lower local efficiency. Using functional MRI measurements, an association of physical inactivity with less fMRI activation was found in a study on obese women after a six-month hypo caloric Mediterranean diet and increased physical activity program (96). In the 1-year, single-blinded, multicenter randomized controlled LIFE-p trial, an intervention to improve physical activity was compared to health education in sedentary elderly. The intervention on PA 
was associated with higher $\mathrm{fMRI}$ signal only in the inferior frontal gyrus as compared to sedentary groups with health education, 2 years after the intervention ended (97).

Recently, sedentary time has been proposed as an independent risk factor for health outcomes $(98,99)$. Evidence on the association of sedentary behavior and MRI measures is still scarce; however, results from the AGEs Reykjavik study indicate that objectively measured PA and sedentary behavior late in life are associated with current and prior cross-sectional measures of white and gray matter atrophy, and that these brain changes over time are associated with PA and sedentary behavior in expected directions (69).

In summary, physical inactivity has been associated with more atrophy, the manifestation of cerebral small vessel disease, and lower structural connectivity. Information on sedentary behavior is scarce, but indicates an association with more brain atrophy. Furthermore, longitudinal studies are needed, to further investigate the brain changes over time, and whether lifestyle changes could improve the condition of the brain.

\section{Central adiposity as risk factor for early brain alterations}

A number of large population-based studies have investigated the association between central adiposity and structural brain changes. The studies included in this section focus on both simple, anthropometric methods, such as waist circumference (WC), and waist-hip-ratio (WHR), and on more advanced, direct measures of central obesity, such as visceral fat accumulation (VFA) as measured with dual-energy X-ray absorptiometry (DXA), computed tomography (CT), and abdominal MRI scans, all in combination with brain MRI measures. In large cross-sectional (100-102) and longitudinal (103-106) population-based cohort studies, larger WC and WHR have been associated with lower total brain volume and lower gray matter volume. The Framingham Heart Study Offspring assessed VFA by use of CT, and found an association of more visceral adipose tissue with lower total brain volumes (100). Higher VFA measured with abdominal MRI was also associated with global cortical thinning in large cross-sectional populationbased studies $(107,108)$. Visceral adiposity has also been associated with lower white matter volumes. More specifically, larger WC and WHR were associated with less frontal lobe volume in cross-sectional studies $(101,102)$, and with lower frontal and temporal lobe volume in one longitudinal study (104). More visceral adipose tissue measured with abdominal MRI was associated with lower hippocampal and larger ventricular volume in a large cross-sectional population-based study (108). Larger WHR was also associated with lower hippocampal volume according to another cross-sectional population-based study $(108,109)$.

Furthermore, several large cross-sectional population-based cohort studies found an association of VFA with markers of cSVD. In these studies, larger WHR, waist circumference, and VFA have been associated with larger WMH volumes (102, 109-112) and lacunar infarcts (110, 112-114). Higher BMI and WHR were associated with larger deep WMH volumes, and to a lower extend with periventricular WMH volumes in the population-based LIFE study (115). A higher visceral-tosubcutaneous fat ratio measured with abdominal CT was associated with cerebral microbleeds (116) in neurologically healthy people. The longitudinal ARIC study found an association of higher WC and WHR with more incident lacunar infarcts after 10-year follow-up, but not with WMH progression (117).

Evidence on the association of VFA with more advanced measures of brain function is scarce, only associations with diffusion metrics were reported. Higher WC has been associated with lower FA in 
cross-sectional population-based $(48,118-122)$ and case-control studies (118); with higher apparent diffusion coefficient (ADC) in one case-control study (48); lower AD in one cross-sectional populationbased study (122); and higher RD in another cross-sectional population-based study (123). In contrast, Birdsill et al. found different results, i.e., an association of higher WC with higher FA, and lower MD, AD, and RD (124).

In short, several large cross-sectional population-based studies assessed the association of central obesity with brain alterations, and found that central obesity was associated with atrophy and markers of cSVD. Only a few longitudinal studies on these associations were conducted, which indicated that central obesity precedes the development of brain atrophy, CSVD, and changes in white matter microstructure. These longitudinal associations need to be investigated further, because this could be a potential target for prevention of brain deterioration. No studies were found that investigated the association of central obesity with structural and functional connectivity, and other functional MRI measures.

\section{Hypertension and high blood pressure as risk factor for early brain}

\section{alterations}

The brain is known to be more vulnerable to elevated blood pressure or hypertension than other organs, because its microcirculation is characterized by low impedance, which allows the pressure load to penetrate deeply into its microvascular bed $(125,126)$. This (pulsatile) pressure load may cause damage to the smallest blood vessels and thereby cause ischemia and neurodegeneration. Hypertension has been cross-sectionally associated with smaller gray matter volumes (127), left hemisphere (128) and total brain atrophy $(129-131)$, thinner cortex $(132,133)$ and larger ventricles $(128,130,131,134)$ in population-based cohort studies. Furthermore, both population-based cohort studies (134-141), casecontrol studies $(142,143)$, and studies on hypertensive patients (144-148) found an association between hypertension and larger WMH volumes. Only two of these studies had a longitudinal population-based design, and could assess temporality. One study found an association of higher mean arterial pressure with increased WMH volumes after a 28-year follow-up period (135), while the other reported progression of periventricular WMHs in participants with hypertension over 4 years of follow-up (146). Hypertension has also been associated with silent cerebral infarctions $(134,143,149,150)$, lacunar infarctions $(134,151)$, and larger perivascular spaces (151) in both cross-sectional (134) and longitudinal (151) population-based studies (134), and large cross-sectional studies including hypertensive patients (149), in addition to smaller case-control studies $(143,150)$.

Evidence on the association of hypertension or blood pressure with more advanced measures of brain function is scarce, only associations with diffusion metrics and changes in cerebral blood flow have been reported. Associations of hypertension with impaired white matter microstructure (152-154), higher MD (152) and lower FA in normal appearing white matter $(152,154,155)$ have been observed. All these studies had a cross-sectional design, three of these had a large sample size $(153,155,156)$, and two were smaller $(n<100)(152,154)$. The study by Gons et al. found a lower FA in both normal appearing white matter and white matter hyperintensities, and higher MD in white matter hyperintensities for both categorical (i.e., based on hypertensive status), and continuous blood pressure measures (i.e., systolic and diastolic)(156). The study by Fennema-Notestine et al., also had data on hypertension status at an earlier time-point (approximately 5.5 years earlier), and used this information to categorize participants 
in groups of recent or longer duration of hypertension (153). However, no differences between these two groups were observed. Furthermore, an association of hypertension with lower FA $(152,156)$, and hypertension and higher systolic and diastolic blood pressure with lower FA and higher MD in WMH (156) was found. Finally, in three case-control studies, hypertension has been associated with lower cerebral blood flow $(63,157-159)$.

Taken together, hypertension and elevated blood pressure have been associated with brain atrophy, lower cortical thickness, and cSVD characteristics mostly in cross-sectional studies. Longitudinal population-based analyses are scarce, but do indicate that higher mean arterial pressure is associated with increased WMH volume over time. Furthermore, hypertension has been associated with impaired white microstructure, and functional changes in cross-sectional studies. No large population-based studies have investigated the association of hypertension with white matter microstructural impairment yet. To increase knowledge about the temporal, and potentially causal aspects of the association between elevated blood pressure and brain changes, longitudinal population-based studies are needed.

\section{Dyslipidemia as risk factor for early brain alterations}

A number of population-based, case-control, and case studies investigated the association of an adverse lipid profile with early brain changes. In most studies, lipid profiles included information on total, LDL and HDL cholesterol levels, and triglycerides, and for brain outcome measures cortical thickness and markers of CSVD, while studies on atrophy were scarce. We here first summarize findings on total and LDL cholesterol, second on HDL cholesterol and finally on triglycerides. The Strong Heart Study investigated the cross-sectional association of LDL cholesterol levels with brain volumes in a population of American Indians, but found no significant association of LDL cholesterol with total brain and hippocampus volume (134). In contrast to what one might expect, lower LDL cholesterol levels have been associated with GM atrophy in the precentral gyrus and insula cortex in a cross-sectional study (160). In agreement with this, in other cross-sectional studies lower LDL cholesterol was associated with cortical thinning in frontoparietal and occipital areas (161), within the (left) caudal-middle frontal cortex (66), and for the total cortex (133). Higher total cholesterol (162-165) was reported to be associated with larger WMH volume, in three large population-based and one smaller cross-sectional study. However, another study found no association of LDL cholesterol with WHH volumes, but the majority of their study population used lipidmodifying medication, which might decrease their cholesterol level-associated risk for cSVD (166). Less information is available on the association of cholesterol profile with lacunar infarctions. However, Bezerra et al. (167) found an association of higher LDL cholesterol with larger lacunes in the crosssectional population-based ARIC study. Several longitudinal studies have investigated the association of levels of LDL cholesterol with the prevalence of microbleeds, but not all found significant associations. In the population-based Rotterdam Study (168), a borderline association of high LDL cholesterol levels with prevalence of lobar microbleeds was found. In addition, Lee et al. (169) found lower concentrations of LDL cholesterol in patients with a severe degree of microbleeds compared to those without, in a longitudinal study with a follow-up period of 1-5 years. However, in the Strong Heart Study, high serum LDL was not significantly associated with WMH volume, (lacunar) infarcts, and microbleeds (134).

In case-control studies by Cohen et al. (170) and Lou et al. (118), obesity-related abnormal plasma cholesterols (both high LDL and low HDL) with lower FA in prefrontal brain regions was found. This might indicate that elevated LDL levels contribute to obesity-associated impairment of white matter 
microstructure. Information on the association of cholesterol levels with functional connectivity is scarce. Only one small cross-sectional study reported a stronger functional connectivity in the DMN in a high total cholesterol group compared to a low cholesterol group, and lower functional connectivity was found in the salience network (SN) (171). With regard to HDL cholesterol, Coutinho et al. (161) reported that lower HDL cholesterol levels were associated with decreased cortical thickness in various brain regions in middle-aged and older adults (40-86 years), which was expected. Lower HDL cholesterol levels were reported to be associated with higher WMH volume, in one large longitudinal and three large crosssectional population-based studies and two smaller cross-sectional studies (111, 172-176). Lower HDL cholesterol was found to be associated with lacunar infarctions, in one large 3-year follow-up populationbased (177), and one smaller cross-sectional study (178). In the longitudinal AGES-Reykjavik Study (179) an association of higher levels of HDL cholesterol with increased risk for lobar, but not deep, microbleeds was found after 5 years. With regard to triglyceride levels, two cross-sectional studies $(161,180)$ found that higher triglyceride levels were associated with thinner cortex in multiple brain regions. Three longitudinal studies investigated the association of triglyceride levels with cerebral small vessel disease. In the population-based Rotterdam Study, lower triglyceride levels were associated with an increased 9year incidence of microbleeds $(168,181)$. This longitudinal association was confirmed in the AGESReykjavik Study (179) over 5-years of follow-up. Furthermore, the multicenter LADIS study reported that higher triglyceride levels could predict the occurrence of new lacunes over a three-year period (177). These differential results for lacunar infarcts and microbleeds may fit with the hypothesis that microbleeds and lacunes have distinct etiologies.

Studies using advanced MRI techniques were scarce. Only one small cross-sectional study found that lower levels of triglycerides were associated with higher levels of cerebral blood flow as measured with ASL (182).

In conclusion, high LDL cholesterol has been associated with thinner cortex, but higher incidence of lacunar infarcts and microbleeds. On the contrary, high HDL cholesterol was associated with thicker cortex and less white matter hyperintensities, but also with incidence of lacunar infarcts and potentially a higher risk for lobar microbleeds. Studies on diffusion or functional MRI measures are scarce. One study found an association of higher total cholesterol with lower functional connectivity, and one study found an association of higher triglyceride levels with lower cerebral blood flow.

\section{Discussion}

\section{Overview and in-depth analysis of the findings}

Table 2.2 provides a condensed systematic overview of the findings in literature about cardiometabolic risk factors in relation to brain volumes and CSVD. The many omissions in the table indicate that not all risk factors have been studied in relation to brain alterations. In general, higher levels of cardiometabolic risk factors considered in this review have been associated to markers of brain atrophy, i.e., smaller total, gray matter and white matter, and larger CSF volumes. Although, the association of altered lipid profile and sedentary behavior with WM, GM, and CSF volumes has been studied too little and needs further investigation. Furthermore, all cardiometabolic risk factors were associated with globally thinner cortex, except for an altered lipid profile. Higher LDL and total cholesterol levels were associated to thicker cortex in some brain regions. With respect to the CSVD characteristics, all cardiometabolic risk factors 
were associated with larger WMH volumes and the presence of lacunar infarctions. Visceral fat accumulation, altered lipid profile, and hypertension were associated with the presence of microbleeds, while hyperglycemia was not, and for PA and sedentary time, no information was found. These results suggest that all cardiometabolic risk factors are associated with early pathological changes in the brain, in particular with brain volumes and the presence of particular CSVD features. This fits with the notion that all risk factors that are harmful for heart and vasculature, are also harmful for the brain.

Table 2.2: Overview of evidence on the associations between cardiometabolic risk factors and markers of brain atrophy and small vessel disease.

\begin{tabular}{|c|c|c|c|c|c|c|c|c|c|}
\hline & \multicolumn{4}{|c|}{ Volume } & \multirow[b]{2}{*}{ Cortical thickness } & \multicolumn{3}{|c|}{ Presence of cSVD } & \multirow[b]{2}{*}{ Other } \\
\hline & $\begin{array}{l}\text { Total } \\
\text { brain }\end{array}$ & GM & WM & $\mathrm{CSF}$ & & WMH & $\mathrm{MB}$ & $\mathrm{LI}$ & \\
\hline \multicolumn{10}{|l|}{ Hyperglycemia } \\
\hline T2DM & $\downarrow$ & $\downarrow$ & $\downarrow$ & $\uparrow$ & $\downarrow$ & $\uparrow$ & $=$ & $\uparrow$ & $\downarrow$ hippocampus \\
\hline Prediabetes & $\downarrow$ & $\downarrow /=$ & $\downarrow$ & $\uparrow$ & n.i. & $\uparrow$ & $=$ & $\uparrow$ & volume \\
\hline Continuous glucose & $\downarrow$ & $\downarrow$ & n.i. & n.i. & $\downarrow$ & $\uparrow$ & n.i. & $\uparrow$ & $\downarrow$ hippocampus \\
\hline Physical inactivity & $\downarrow$ & $\downarrow$ & $\downarrow$ & $\uparrow$ & $\downarrow$ & $\uparrow$ & n.i. & $\uparrow$ & \\
\hline More sedentary time & $\downarrow$ & n.i. & n.i. & n.i. & n.i. & n.i. & n.i. & n.i. & \\
\hline $\begin{array}{l}\text { Visceral fat } \\
\text { accumulation }\end{array}$ & $\downarrow$ & $\downarrow$ & $\downarrow$ & $\uparrow$ & $\downarrow$ & $\uparrow$ & $\uparrow$ & $\uparrow$ & $\downarrow$ hippocampus \\
\hline Hypertension & $\downarrow$ & $\downarrow$ & $\downarrow$ & $\uparrow$ & $\downarrow$ & $\uparrow$ & $\uparrow$ & $\uparrow$ & $\uparrow P V S$ \\
\hline $\begin{array}{r}\text { Dyslipidemia } \\
\text { Total cholesterol } \\
\uparrow \mathrm{LDL} \\
\downarrow \mathrm{HDL} \\
\text { Triglycerides }\end{array}$ & $\begin{array}{c}\text { n.i. } \\
= \\
\text { n.i. } \\
\downarrow\end{array}$ & $\begin{array}{c}\text { n.i. } \\
\downarrow \\
\text { n.i. } \\
\text { n.i. }\end{array}$ & $\begin{array}{l}\text { n.i. } \\
\text { n.i. } \\
\text { n.i. } \\
\text { n.i. }\end{array}$ & $\begin{array}{l}\text { n.i. } \\
\text { n.i. } \\
\text { n.i. } \\
\text { n.i. }\end{array}$ & $\begin{array}{l}\uparrow \\
\uparrow \\
\downarrow \\
\downarrow\end{array}$ & $\begin{array}{c}\uparrow \\
= \\
\uparrow \\
\text { n.i. }\end{array}$ & $\begin{array}{c}\text { n.i. } \\
\uparrow /= \\
= \\
\uparrow\end{array}$ & $\begin{array}{c}\text { n.i. } \\
\uparrow /= \\
\uparrow \\
\uparrow\end{array}$ & = hippocampus \\
\hline \multicolumn{10}{|c|}{$\begin{array}{l}\text { "GM indicated gray matter; WM, white matter; CSF, cerebrospinal fluid; cSVD, cerebral small vessel disease; WMH, white } \\
\text { matter hyperintensities; MB, microbleeds; LI, lacunar infarcts; T2DM, type } 2 \text { diabetes; PVS, perivascular spaces; LDL, low } \\
\text { density lipoprotein; HDL, high density lipoprotein; 'n.i.' means not investigated, ' }=\text { ', no association found; ' } \uparrow ' \text {, increase; ' } \downarrow \text { ', } \\
\text { decrease. }\end{array}$} \\
\hline
\end{tabular}

Table 2.3 provides an overview of the main findings for diffusion measures, structural connectivity, and functional connectivity. All cardiometabolic risk factors were associated with lower FA and MD, indicating microstructural changes. For an adverse lipid profile, an association with lower FA was found, but no information was available on MD. Hyperglycemia, less PA and more sedentary behavior were also associated with higher $A D$ and $R D$, indicating impaired white matter microstructure; and visceral fat accumulation was associated with lower $A D$ and higher RD, indicating axonal and myelin damage. Regarding structural connectivity, limited data were available, as only studies on hyperglycemia and PA were found. Hyperglycemia has been associated with lower overall structural connectivity. In addition, less physical activity and sedentary behavior have been associated to lower nodal strength and local efficiency, indicating less efficient networks. For $\mathrm{fMRI}$, several associations of hyperglycemia with functional MRI measures were found, e.g., lower overall functional connectivity, higher clustering coefficient, higher local efficiency, lower degree centrality, all indications of network alterations, and lower cerebral blood flow. Furthermore, less physical activity and sedentary behavior have been associated to lower fMRI activation, and a higher functional connectivity in the default mode network (DMN). In addition, an adverse lipid profile was associated to a lower decreased functional connectivity in the salience network (SN). Finally, hypertension was associated with lower functional connectivity. Most omissions in Table 2.3 are in the field of structural connectivity. Studies on associations of risk factors with white matter structure could probably lead to more insights in microstructural changes. 
Table 2.3: Overview of evidence on the associations between cardiometabolic risk factors and diffusion measures and structural and functional connectivity.

\begin{tabular}{|c|c|c|c|c|c|c|}
\hline & \multicolumn{4}{|c|}{$\begin{array}{l}\text { Diffusion parameters } \\
\text { in WM tracts }\end{array}$} & \multirow[t]{2}{*}{ Structural connectivity } & \multirow[t]{2}{*}{ Functional connectivity } \\
\hline & $\mathrm{FA}$ & MD & $A D$ & $\mathrm{RD}$ & & \\
\hline $\begin{array}{r}\text { Hyperglycemia } \\
\mathrm{T} 2 \mathrm{DM} \\
\text { Prediabetes } \\
\text { Continuous glucose }\end{array}$ & $\begin{array}{l}\downarrow \\
\downarrow \\
\downarrow\end{array}$ & $\begin{array}{c}\uparrow \\
\text { n.i. } \\
\text { n.i. }\end{array}$ & $\begin{array}{l}\uparrow \\
\text { n.i. } \\
\text { n.i. }\end{array}$ & $\begin{array}{l}\uparrow \\
\text { n.i. } \\
\text { n.i. }\end{array}$ & $\begin{array}{l}\downarrow S C \\
\text { n.i. } \\
\text { n.i. }\end{array}$ & $\begin{array}{c}\downarrow F C / \downarrow D C / \uparrow C C / \uparrow E_{\text {local }} / \downarrow C B F \\
\downarrow E_{\text {local }} \\
\downarrow \text { arterial flow/ } \downarrow \text { cerebral perfusion }\end{array}$ \\
\hline $\begin{array}{r}\text { Less PA } \\
\text { More sedentary time }\end{array}$ & $\begin{array}{l}\downarrow \\
\text { n.i. }\end{array}$ & $\begin{array}{c}\uparrow \\
\text { n.i. }\end{array}$ & $\begin{array}{c}\uparrow \\
\text { n.i. }\end{array}$ & $\begin{array}{c}\uparrow \\
\text { n.i. }\end{array}$ & $\begin{array}{c}\downarrow \text { nodal strength } / \downarrow \mathrm{E}_{\text {local }} \\
\text { n.i. }\end{array}$ & $\begin{array}{c}\downarrow f M R I \text { activation } \\
\text { n.i. }\end{array}$ \\
\hline $\begin{array}{r}\text { Visceral fat } \\
\text { accumulation }\end{array}$ & $\downarrow$ & $\uparrow$ & $\downarrow$ & $\uparrow$ & n.i. & n.i. \\
\hline Hypertension & $\downarrow$ & $\uparrow$ & n.i. & n.i. & n.i. & $\downarrow F C / \downarrow C B F$ \\
\hline $\begin{array}{r}\text { Dyslipidemia } \\
\text { Total cholesterol } \\
\uparrow \mathrm{LDL} \\
\downarrow \mathrm{HDL} \\
\text { Triglycerides }\end{array}$ & $\begin{array}{l}\downarrow \\
\downarrow \\
\downarrow \\
\text { n.i. }\end{array}$ & $\begin{array}{l}\text { n.i. } \\
\text { n.i. } \\
\text { n.i. } \\
\text { n.i. }\end{array}$ & $\begin{array}{l}\text { n.i. } \\
\text { n.i. } \\
\text { n.i. } \\
\text { n.i. }\end{array}$ & $\begin{array}{l}\text { n.i. } \\
\text { n.i. } \\
\text { n.i. } \\
\text { n.i. }\end{array}$ & $\begin{array}{l}\text { n.i. } \\
\text { n.i. } \\
\text { n.i. } \\
\text { n.i. }\end{array}$ & $\begin{array}{c}\text { } F C \text { in } \mathrm{DMN} / \downarrow F C \text { in } \mathrm{SN} \\
\text { n.i. } \\
\text { n.i. } \\
\downarrow \mathrm{CBF}\end{array}$ \\
\hline
\end{tabular}

"SC = structural connectivity; FC = functional connectivity; $\mathrm{DC}=$ degree centrality; $\mathrm{CC}=$ clustering coefficient; $\mathrm{E}_{\text {local }}=$ local efficiency; $\mathrm{CBF}=$ cerebral blood flow; $\mathrm{DMN}=$ default mode network; $\mathrm{SN}$ = salience network; ' $\mathrm{n}$.i.' means not investigated, ' $=$ ' means no association found.

In addition to the overviews in Table 2.2 and 2.3, we visualised the level of evidence of the observed associations by depicting the study designs found in litereature by risk factors in Figure 2.2. This figure shows that despite to what we may think, the evidence that cardiometabolic risk factors have a temporal association with brain atrophy. This has been evaluated in longitudinal data for diabetes and physical inactivity, but not for obesity, hypertension, and dyslipidemia. In addition, the association of physical inactivity with cSVD needs to be investigated in larger longitudinal studies, to investigate temporal associations. Assessing the associations of cardiometabolic risk factors with more advanced MRI measures as diffusion metrics, structural or function connectivity are in their infancy but coming. 


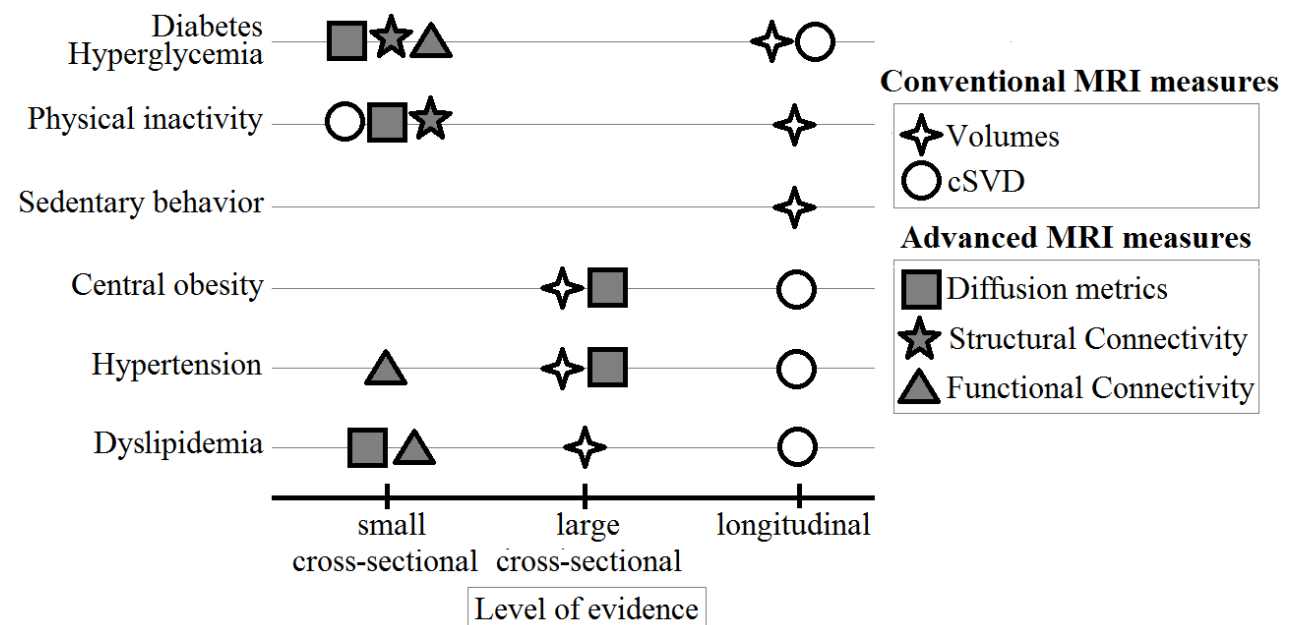

Figure 2.2: Highest level of evidence in the available literature on the associations between cardiometabolic risk factors and conventional (white symbols) and advanced (gray symbols) MRI measures. Large indicates $N>100$; small, $N<100$. The size of the symbols indicates the amount of studies in that category: small indicates 1-4; medium, 5-10; large: $>10$ studies.

\section{Future outlook and clinical relevance}

As we observe several lacunes in this review, there are a number of opportunities for future studies. First, advanced MRI techniques, including microstructural, functional, and perfusion MRI, may provide more detailed insight into underlying mechanisms that lead from cardiometabolic risk factors to brain dysfunction and disease. These insights may help to develop better treatment strategies to delay or even prevent brain alterations and eventual disease. In addition, the longitudinal association of obesity, hypertension and dyslipidemia with volumetric data needs investigation in order to find support for potential causality. Second, reduction of residual confounding is of key importance to interpret the results of studies. The studies included in this review did this to some extent, at least by matching or adjustments for age and sex. However, cardiometabolic risk factors are interrelated, therefore, an integrated approach where cardiometabolic risk factors are taken into account jointly, would advance this field of research. Third, most advanced MRI outcome measures may represent early changes prior to end-organ damage, which makes them potentially more useful as response markers for intervention studies than volumetic data. This is of particular interest, because cardiometabolic risk factors are modifiable. Fourth, early biomarkers for brain disease may enable us to identify people at risk, to prevent further escalation to functional decrements and eventual disease. Thus, future longitudinal studies are needed to address the usefulness of these novel biomarkers in relation to disease outcomes and risk prediction. Finaly, other novel MRI approaches, such as dynamic contrast enhanced (DCE) MRI, to investigate blood-brain-barrier leakage; magnetic resonance spectroscopy (MRS), to investigate the metabolic characteristics of brain alterations; or ultra-high field MRI (>3Tesla) might provide alternative ways to elucidate the early signs and complex pathophysiology of brain diseases. 


\section{Conclusions}

This narrative review indicates clear evidence on the associations of hyperglycemia, central obesity, hypertension, and physical inactivity on brain atrophy, CSVD, and white matter microstructure alterations, although longitudinal data is often lacking. The associations of an adverse lipid profile with MRI markers of the brain are far less clear, as well as the association of relatively novel risk factors as physical inactivity and sedentary behavior. In particular, the evidence from more advanced MRI measures, such as microstructural, functional, and perfusion MRI needs to be applied in longitudinal studies, as insight into more subtle brain alterations, development over time, and subsequent brain dysfunction and disease is needed.

\section{References}

1. Beason-Held LL, Goh JO, An Y, Kraut MA, O'Brien RJ, Ferrucci L, Resnick SM. Changes in Brain Function Occur Years before the Onset of Cognitive Impairment. The Journal of Neuroscience 2013;33(46):18008-18014. doi: 10.1523/JNEUROSCI.1402-13.2013

2. Tyndall AV, Argourd L, Sajobi TT, Davenport MH, Forbes SC, Gill SJ, Parboosingh JS, Anderson TJ, Wilson BJ, Smith EE, Hogan DB, Hill MD, Poulin MJ. Cardiometabolic risk factors predict cerebrovascular health in older adults: results from the Brain in Motion study. Physiological reports 2016;4(8). doi: 10.14814/phy2.12733

3. Friedman JI, Tang CY, de Haas HJ, Changchien L, Goliasch G, Dabas P, Wang V, Fayad ZA, Fuster V, Narula J. Brain Imaging Changes Associated With Risk Factors for Cardiovascular and Cerebrovascular Disease in Asymptomatic Patients. JACC: Cardiovascular Imaging 2014;7(10):1039-1053. doi: https://doi.org/10.1016/j.jcmg.2014.06.014

4. van Bussel FCG, Backes WH, Hofman PAM, van Oostenbrugge RJ, van Boxtel MPJ, Verhey FRJ, Steinbusch HWM, Schram MT, Stehouwer CDA, Wildberger JE, Jansen JFA. Cerebral Pathology and Cognition in Diabetes: The Merits of Multiparametric Neuroimaging. Frontiers in neuroscience 2017;11:188. doi: 10.3389/fnins.2017.00188

5. Kalaria RN. Cerebrovascular Disease and Mechanisms of Cognitive Impairment. Evidence From Clinicopathological Studies in Humans 2012;43(9):2526-2534. doi: 10.1161/strokeaha.112.655803

6. Wardlaw JM, Smith EE, Biessels GJ, Cordonnier C, Fazekas F, Frayne R, Lindley RI, O'Brien JT, Barkhof F, Benavente OR, Black SE, Brayne C, Breteler M, Chabriat H, Decarli C, de Leeuw FE, Doubal F, Duering M, Fox NC, Greenberg S, Hachinski V, Kilimann I, Mok V, Oostenbrugge R, Pantoni L, Speck O, Stephan BC, Teipel S, Viswanathan A, Werring D, Chen C, Smith C, van Buchem M, Norrving B, Gorelick PB, Dichgans M. Neuroimaging standards for research into small vessel disease and its contribution to ageing and neurodegeneration. The Lancet Neurology 2013;12(8):822-838. doi: 10.1016/s1474-4422(13)70124-8

7. Fjell AM, McEvoy L, Holland D, Dale AM, Walhovd KB, Alzheimer's Disease Neuroimaging I. Brain changes in older adults at very low risk for Alzheimer's disease. The Journal of neuroscience : the official journal of the Society for Neuroscience 2013;33(19):8237-8242. doi: 10.1523/JNEUROSCI.5506-12.2013

8. Staals J, Booth T, Morris Z, Bastin ME, Gow AJ, Corley J, Redmond P, Starr JM, Deary IJ, Wardlaw JM. Total MRI load of cerebral small vessel disease and cognitive ability in older people. Neurobiology of aging 2015;36(10):2806-2811. doi: 10.1016/j.neurobiolaging.2015.06.024

9. Tubi MA, Feingold FW, Kothapalli D, Hare ET, King KS, Thompson PM, Braskie MN. White matter hyperintensities and their relationship to cognition: Effects of segmentation algorithm. Neurolmage 2020;206:116327. doi: https://doi.org/10.1016/j.neuroimage.2019.116327

10. Debette $\mathrm{S}, \mathrm{Markus} \mathrm{HS}$. The clinical importance of white matter hyperintensities on brain magnetic resonance imaging: systematic review and meta-analysis. BMJ (Clinical research ed) 2010;341:c3666. doi: 10.1136/bmj.c3666 
11. Wardlaw JM, Valdes Hernandez MC, Munoz-Maniega S. What are white matter hyperintensities made of? Relevance to vascular cognitive impairment. Journal of the American Heart Association 2015;4(6):001140. doi: 10.1161/jaha.114.001140

12. Wardlaw JM, Smith C, Dichgans M. Mechanisms of sporadic cerebral small vessel disease: insights from neuroimaging. The Lancet Neurology 2013;12(5):483-497. doi: 10.1016/s1474-4422(13)70060-7

13. Vermeer SE, Longstreth WT, Jr., Koudstaal PJ. Silent brain infarcts: a systematic review. The Lancet Neurology 2007;6(7):611-619. doi: 10.1016/s1474-4422(07)70170-9

14. Greenberg SM, Vernooij MW, Cordonnier C, Viswanathan A, Al-Shahi Salman R, Warach S, Launer L, Van Buchem MA, Breteler MM. Cerebral microbleeds: a guide to detection and interpretation. The Lancet Neurology 2009;8(2):165-174. doi: 10.1016/s1474-4422(09)70013-4

15. Tae W-S, Ham B-J, Pyun S-B, Kang S-H, Kim B-J. Current Clinical Applications of Diffusion-Tensor Imaging in Neurological Disorders. J Clin Neurol 2018;14(2):129-140.

16. Alexander AL, Hurley SA, Samsonov AA, Adluru N, Hosseinbor AP, Mossahebi P, Tromp DPM, Zakszewski E, Field AS. Characterization of cerebral white matter properties using quantitative magnetic resonance imaging stains. Brain connectivity 2011;1(6):423-446. doi: 10.1089/brain.2011.0071

17. Lee MH, Smyser CD, Shimony JS. Resting-State fMRI: A Review of Methods and Clinical Applications. American Journal of Neuroradiology 2013;34(10):1866-1872. doi: 10.3174/ajnr.A3263

18. Alsop DC, Detre JA, Golay X, Gunther M, Hendrikse J, Hernandez-Garcia L, Lu H, Maclntosh BJ, Parkes LM, Smits $M$, van Osch MJ, Wang DJ, Wong EC, Zaharchuk G. Recommended implementation of arterial spin-labeled perfusion MRI for clinical applications: A consensus of the ISMRM perfusion study group and the European consortium for ASL in dementia. Magnetic resonance in medicine 2015;73(1):102-116. doi: 10.1002/mrm.25197

19. Manschot SM, Biessels GJ, de Valk H, Algra A, Rutten GE, van der Grond J, Kappelle L. Metabolic and vascular determinants of impaired cognitive performance and abnormalities on brain magnetic resonance imaging in patients with type 2 diabetes. Diabetologia 2007;50(11):2388-2397. doi: 10.1007/s00125-007-0792-z

20. Manschot SM, Biessels GJ, Rutten GE, Kessels RP, Gispen WH, Kappelle L. Peripheral and central neurologic complications in type 2 diabetes mellitus: no association in individual patients. Journal of the neurological sciences 2008;264(1-2):157-162. doi: 10.1016/j.jns.2007.08.011

21. Manschot SM, Brands AM, van der Grond J, Kessels RP, Algra A, Kappelle L, Biessels GJ. Brain magnetic resonance imaging correlates of impaired cognition in patients with type 2 diabetes. Diabetes 2006;55(4):11061113.

22. Reijmer YD, van den Berg E, de Bresser J, Kessels RP, Kappelle $L$, Algra A, Biessels GJ. Accelerated cognitive decline in patients with type 2 diabetes: MRI correlates and risk factors. Diabetes/metabolism research and reviews 2011;27(2):195-202. doi: 10.1002/dmrr.1163

23. Debette S, Seshadri S, Beiser A, Au R, Himali JJ, Palumbo C, Wolf PA, DeCarli C. Midlife vascular risk factor exposure accelerates structural brain aging and cognitive decline. Neurology 2011;77(5):461-468. doi: 10.1212/WNL.0b013e318227b227

24. Weinstein G, Maillard P, Himali JJ, Beiser AS, Au R, Wolf PA, Seshadri S, DeCarli C. Glucose indices are associated with cognitive and structural brain measures in young adults. Neurology 2015;84(23):2329-2337. doi: 10.1212/wnl.0000000000001655

25. Tiehuis AM, van der Graaf Y, Mali WP, Vincken K, Muller M, Geerlings MI. Metabolic syndrome, prediabetes, and brain abnormalities on mri in patients with manifest arterial disease: the SMART-MR study. Diabetes care 2014;37(9):2515-2521. doi: 10.2337/dc14-0154

26. Launer L, Lewis CE, Schreiner PJ, Sidney S, Battapady H, Jacobs DR, Lim KO, D'Esposito M, Zhang Q, Reis J, Davatzikos C, Bryan RN. Vascular factors and multiple measures of early brain health: CARDIA brain MRI study. PloS one 2015;10(3):e0122138. doi: 10.1371/journal.pone.0122138

27. Roberts RO, Knopman DS, Przybelski SA, Mielke MM, Kantarci K, Preboske GM, Senjem ML, Pankratz VS, Geda YE, Boeve BF, Ivnik RJ, Rocca WA, Petersen RC, Jack CR, Jr. Association of type 2 diabetes with brain atrophy and cognitive impairment. Neurology 2014;82(13):1132-1141. doi: 10.1212/wnl.0000000000000269 
28. Cox SR, Lyall DM, Ritchie SJ, Bastin ME, Harris MA, Buchanan CR, Fawns-Ritchie C, Barbu MC, de Nooij L, Reus LM, Alloza C, Shen X, Neilson E, Alderson HL, Hunter S, Liewald DC, Whalley HC, McIntosh AM, Lawrie SM, Pell JP, Tucker-Drob EM, Wardlaw JM, Gale CR, Deary IJ. Associations between vascular risk factors and brain MRI indices in UK Biobank. European Heart Journal 2019;40:2290-2299. doi: 10.1093/eurheartj/ehz100

29. Schneider ALC, Selvin E, Sharrett AR, Griswold M, Coresh J, Jack CR, Jr., Knopman D, Mosley T, Gottesman RF. Diabetes, Prediabetes, and Brain Volumes and Subclinical Cerebrovascular Disease on MRI: The Atherosclerosis Risk in Communities Neurocognitive Study (ARIC-NCS). Diabetes care 2017;40(11):1514-1521. doi: 10.2337/dc171185

30. Brundel M, van den Berg E, Reijmer YD, de Bresser J, Kappelle LJ, Biessels GJ. Cerebral haemodynamics, cognition and brain volumes in patients with type 2 diabetes. Journal of diabetes and its complications 2012;26(3):205209. doi: 10.1016/j.jdiacomp.2012.03.021

31. Kooistra M, Geerlings MI, Mali WP, Vincken KL, van der Graaf Y, Biessels GJ. Diabetes mellitus and progression of vascular brain lesions and brain atrophy in patients with symptomatic atherosclerotic disease. The SMART-MR study. Journal of the neurological sciences 2013;332(1-2):69-74. doi: 10.1016/j.jns.2013.06.019

32. van Elderen SG, de Roos A, de Craen AJ, Westendorp RG, Blauw GJ, Jukema JW, Bollen EL, Middelkoop HA, van Buchem MA, van der Grond J. Progression of brain atrophy and cognitive decline in diabetes mellitus: a 3-year follow-up. Neurology 2010;75(11):997-1002. doi: 10.1212/WNL.0b013e3181f25f06

33. Erus G, Battapady H, Zhang T, Lovato J, Miller ME, Williamson JD, Launer L, Bryan RN, Davatzikos C. Spatial patterns of structural brain changes in type 2 diabetic patients and their longitudinal progression with intensive control of blood glucose. Diabetes care 2015;38(1):97-104. doi: 10.2337/dc14-1196

34. Espeland MA, Bryan RN, Goveas JS, Robinson JG, Siddiqui MS, Liu S, Hogan PE, Casanova R, Coker LH, Yaffe K, Masaki K, Rossom R, Resnick SM. Influence of type 2 diabetes on brain volumes and changes in brain volumes: results from the Women's Health Initiative Magnetic Resonance Imaging studies. Diabetes care 2013;36(1):9097. doi: $10.2337 / \mathrm{dc} 12-0555$

35. Mehta D, Pimentel DA, Nunez MZ, Abduljalil A, Novak V. Subclinical albuminuria is linked to gray matter atrophy in type 2 diabetes mellitus. Metabolism: clinical and experimental 2014;63(11):1390-1397. doi: 10.1016/j.metabol.2014.07.008

36. Moran C, Phan TG, Chen J, Blizzard L, Beare R, Venn A, Munch G, Wood AG, Forbes J, Greenaway TM, Pearson S, Srikanth V. Brain atrophy in type 2 diabetes: regional distribution and influence on cognition. Diabetes care 2013;36(12):4036-4042. doi: 10.2337/dc13-0143

37. Raffield LM, Cox AJ, Freedman BI, Hugenschmidt CE, Hsu FC, Wagner BC, Xu J, Maldjian JA, Bowden DW. Analysis of the relationships between type 2 diabetes status, glycemic control, and neuroimaging measures in the Diabetes Heart Study Mind. Acta diabetologica 2016;53(3):439-447. doi: 10.1007/s00592-015-0815-z

38. Brands AM, Biessels GJ, Kappelle $L$, de Haan EH, de Valk HW, Algra A, Kessels RP. Cognitive functioning and brain MRI in patients with type 1 and type 2 diabetes mellitus: a comparative study. Dementia and geriatric cognitive disorders 2007;23(5):343-350. doi: 10.1159/000100980

39. Shaw ME, Nettersheim J, Sachdev PS, Anstey KJ, Cherbuin N. Higher Fasting Plasma Glucose is Associated with Increased Cortical Thinning Over 12 Years: The PATH Through Life Study. Brain topography 2017;30(3):408-416. doi: 10.1007/s10548-017-0544-4

40. den Heijer T, Vermeer SE, van Dijk EJ, Prins ND, Koudstaal PJ, Hofman A, Breteler MM. Type 2 diabetes and atrophy of medial temporal lobe structures on brain MRI. Diabetologia 2003;46(12):1604-1610. doi: 10.1007/s00125-003-1235-0

41. Hilal S, Amin SM, Venketasubramanian N, Niessen WJ, Vrooman H, Wong TY, Chen C, Ikram MK. Subcortical Atrophy in Cognitive Impairment and Dementia. Journal of Alzheimer's disease : JAD 2015;48(3):813-823. doi: 10.3233/jad-150473

42. Hirabayashi N, Hata J, Ohara T, Mukai N, Nagata M, Shibata M, Gotoh S, Furuta Y, Yamashita F, Yoshihara K, Kitazono T, Sudo N, Kiyohara Y, Ninomiya T. Association Between Diabetes and Hippocampal Atrophy in Elderly Japanese: The Hisayama Study. Diabetes care 2016;39(9):1543-1549. doi: 10.2337/dc15-2800 
43. Zhang T, Shaw M, Humphries J, Sachdev P, Anstey KJ, Cherbuin N. Higher fasting plasma glucose is associated with striatal and hippocampal shape differences: the 2sweet project. BMJ open diabetes research \& care 2016;4(1):e000175. doi: 10.1136/bmjdrc-2015-000175

44. Biessels GJ, Koffeman A, Scheltens P. Diabetes and cognitive impairment. Clinical diagnosis and brain imaging in patients attending a memory clinic. Journal of neurology 2006;253(4):477-482. doi: 10.1007/s00415-005-0036-4

45. Brundel M, Reijmer YD, van Veluw SJ, Kuijf HJ, Luijten PR, Kappelle LJ, Biessels GJ. Cerebral microvascular lesions on high-resolution 7-Tesla MRI in patients with type 2 diabetes. Diabetes 2014;63(10):3523-3529. doi: 10.2337/db14-0122

46. van Agtmaal MJM, Houben A, de Wit V, Henry RMA, Schaper NC, Dagnelie PC, van der Kallen CJ, Koster A, Sep SJ, Kroon AA, Jansen JFA, Hofman PA, Backes WH, Schram MT, Stehouwer CDA. Prediabetes Is Associated With Structural Brain Abnormalities: The Maastricht Study. Diabetes care 2018;41(12):2535-2543. doi: 10.2337/dc181132

47. Hsu JL, Chen YL, Leu JG, Jaw FS, Lee CH, Tsai YF, Hsu CY, Bai CH, Leemans A. Microstructural white matter abnormalities in type 2 diabetes mellitus: a diffusion tensor imaging study. Neurolmage 2012;59(2):1098-1105. doi: 10.1016/j.neuroimage.2011.09.041

48. Yau PL, Javier DC, Ryan CM, Tsui WH, Ardekani BA, Ten S, Convit A. Preliminary evidence for brain complications in obese adolescents with type 2 diabetes mellitus. Diabetologia 2010;53(11):2298-2306. doi: 10.1007/s00125010-1857-y

49. Yau PL, Kluger A, Borod JC, Convit A. Neural substrates of verbal memory impairments in adults with type 2 diabetes mellitus. Journal of clinical and experimental neuropsychology 2014;36(1):74-87. doi: 10.1080/13803395.2013.869310

50. van Bussel FC, Backes WH, Hofman PA, van Boxtel MP, Schram MT, Stehouwer CD, Wildberger JE, Jansen JF. Altered Hippocampal White Matter Connectivity in Type 2 Diabetes Mellitus and Memory Decrements. Journal of neuroendocrinology 2016;28(3):12366. doi: 10.1111/jne.12366

51. Sun Q, Chen G-Q, Wang X-B, Yu Y, Hu Y-C, Yan L-F, Zhang X, Yang Y, Zhang J, Liu B, Wang C-C, Ma Y, Wang W, Han Y, Cui G-B. Alterations of White Matter Integrity and Hippocampal Functional Connectivity in Type 2 Diabetes Without Mild Cognitive Impairment. Frontiers in Neuroanatomy 2018;12(21). doi: 10.3389/fnana.2018.00021

52. Xiong $Y$, Zhang S, Shi J, Fan $Y$, Zhang $Q$, Zhu W. Application of neurite orientation dispersion and density imaging to characterize brain microstructural abnormalities in type-2 diabetics with mild cognitive impairment. Journal of magnetic resonance imaging : JMRI 2019. doi: 10.1002/jmri.26687

53. Liang M, Cai X, Tang Y, Yang X-I, Fang J, Li J, Zhang S, Zhou Q. Diffusion tensor imaging of white matter in patients with prediabetes by trace-based spatial statistics. Journal of Magnetic Resonance Imaging 2019;49(4):1105-1112. doi: 10.1002/jmri.26290

54. Cui Y, Jiao Y, Chen YC, Wang K, Gao B, Wen S, Ju S, Teng GJ. Altered spontaneous brain activity in type 2 diabetes: a resting-state functional MRI study. Diabetes 2014;63(2):749-760. doi: 10.2337/db13-0519

55. Liu D, Duan S, Zhang J, Zhou C, Liang M, Yin X, Wei P, Wang J. Aberrant Brain Regional Homogeneity and Functional Connectivity in Middle-Aged T2DM Patients: A Resting-State Functional MRI Study. Frontiers in human neuroscience 2016;10:490. doi: 10.3389/fnhum.2016.00490

56. Liu D, Duan S, Zhou C, Wei P, Chen L, Yin X, Zhang J, Wang J. Altered Brain Functional Hubs and Connectivity in Type 2 Diabetes Mellitus Patients: A Resting-State fMRI Study. Frontiers in aging neuroscience 2018;10:55. doi: 10.3389/fnagi.2018.00055

57. Yang SQ, Xu ZP, Xiong Y, Zhan YF, Guo LY, Zhang S, Jiang RF, Yao YH, Qin YY, Wang JZ, Liu Y, Zhu WZ. Altered Intranetwork and Internetwork Functional Connectivity in Type 2 Diabetes Mellitus With and Without Cognitive Impairment. Scientific reports 2016;6:32980. doi: 10.1038/srep32980

58. Xu J, Chen F, Liu T, Wang T, Zhang J, Yuan H, Wang M. Brain Functional Networks in Type 2 Diabetes Mellitus Patients: A Resting-State Functional MRI Study. Frontiers in neuroscience 2019;13:239-239. doi: 10.3389/fnins.2019.00239

59. van Bussel FC, Backes WH, van Veenendaal TM, Hofman PA, van Boxtel MP, Schram MT, Sep SJ, Dagnelie PC, Schaper N, Stehouwer CD, Wildberger JE, Jansen JF. Functional Brain Networks Are Altered in Type 2 Diabetes 
and Prediabetes: Signs for Compensation of Cognitive Decrements? The Maastricht Study. Diabetes 2016;65(8):2404-2413. doi: 10.2337/db16-0128

60. Tan X, Liang Y, Zeng H, Qin C, Li Y, Yang J, Qiu S. Altered functional connectivity of the posterior cingulate cortex in type 2 diabetes with cognitive impairment. Brain imaging and behavior 2019. doi: 10.1007/s11682-018-0017-8

61. Chen Z, Li J, Sun J, Ma L. Brain expansion in patients with type II diabetes following insulin therapy: a preliminary study with longitudinal voxel-based morphometry. Journal of neuroimaging : official journal of the American Society of Neuroimaging 2014;24(5):484-491. doi: 10.1111/jon.12059

62. Cui Y, Liang X, Gu H, Hu Y, Zhao Z, Yang XY, Qian C, Yang Y, Teng GJ. Cerebral perfusion alterations in type 2 diabetes and its relation to insulin resistance and cognitive dysfunction. Brain imaging and behavior 2017;11(5):1248-1257. doi: 10.1007/s11682-016-9583-9

63. Xia W, Rao H, Spaeth AM, Huang R, Tian S, Cai R, Sun J, Wang S. Blood Pressure is Associated With Cerebral Blood Flow Alterations in Patients With T2DM as Revealed by Perfusion Functional MRI. Medicine 2015;94(48):e2231. doi: 10.1097/md.0000000000002231

64. Bangen KJ, Werhane ML, Weigand AJ, Edmonds EC, Delano-Wood L, Thomas KR, Nation DA, Evangelista ND, Clark AL, Liu TT, Bondi MW. Reduced Regional Cerebral Blood Flow Relates to Poorer Cognition in Older Adults With Type 2 Diabetes. Frontiers in aging neuroscience 2018;10:270. doi: 10.3389/fnagi.2018.00270

65. Cui D, Liu X, Liu M, Cao W, Xue Y, Guo Y, Guo Y, Lu A, Jiao Q. Subcortical gray matter structural alterations in prediabetes and type 2 diabetes. Neuroreport 2019;30(6):441-445. doi: 10.1097/wnr.0000000000001224

66. Gonzales MM, Ajilore O, Charlton RC, Cohen J, Yang S, Sieg E, Bhaumik DK, Kumar A, Lamar M. Divergent Influences of Cardiovascular Disease Risk Factor Domains on Cognition and Gray and White Matter Morphology. Psychosomatic medicine 2017;79(5):541-548. doi: 10.1097/psy.0000000000000448

67. Akintola AA, van den Berg A, Altmann-Schneider I, Jansen SW, van Buchem MA, Slagboom PE, Westendorp RG, van Heemst $D$, van der Grond J. Parameters of glucose metabolism and the aging brain: a magnetization transfer imaging study of brain macro- and micro-structure in older adults without diabetes. Age 2015;37(4):74. doi: 10.1007/s11357-015-9802-0

68. Wennberg AM, Spira AP, Pettigrew C, Soldan A, Zipunnikov V, Rebok GW, Roses AD, Lutz MW, Miller MM, Thambisetty M, Albert MS. Blood glucose levels and cortical thinning in cognitively normal, middle-aged adults. Journal of the neurological sciences 2016;365:89-95. doi: 10.1016/j.jns.2016.04.017

69. Arnardottir NY, Koster A, Domelen DR, Brychta RJ, Caserotti P, Eiriksdottir G, Sverrisdottir JE, Sigurdsson S, Johannsson E, Chen KY, Gudnason V, Harris TB, Launer $U$, Sveinsson T. Association of change in brain structure to objectively measured physical activity and sedentary behavior in older adults: Age, Gene/Environment Susceptibility-Reykjavik Study. Behavioural brain research 2016;296:118-124. doi: 10.1016/j.bbr.2015.09.005

70. Kooistra M, Boss HM, van der Graaf Y, Kappelle $\sqcup$, Biessels GJ, Geerlings MI. Physical activity, structural brain changes and cognitive decline. The SMART-MR study. Atherosclerosis 2014;234(1):47-53. doi: 10.1016/j.atherosclerosis.2014.02.003

71. Tan ZS, Spartano NL, Beiser AS, DeCarli C, Auerbach SH, Vasan RS, Seshadri S. Physical Activity, Brain Volume, and Dementia Risk: The Framingham Study. The journals of gerontology Series A, Biological sciences and medical sciences 2017;72(6):789-795. doi: 10.1093/gerona/glw130

72. Spartano NL, Davis-Plourde KL, Himali JJ, Andersson C, Pase MP, Maillard P, DeCarli C, Murabito JM, Beiser AS, Vasan RS, Seshadri S. Association of Accelerometer-Measured Light-Intensity Physical Activity With Brain Volume: The Framingham Heart Study. JAMA network open 2019;2(4):e192745. doi: 10.1001/jamanetworkopen.2019.2745

73. Frederiksen KS, Verdelho A, Madureira S, Bazner H, O'Brien JT, Fazekas F, Scheltens P, Schmidt R, Wallin A, Wahlund LO, Erkinjunttii T, Poggesi A, Pantoni L, Inzitari D, Waldemar G. Physical activity in the elderly is associated with improved executive function and processing speed: the LADIS Study. International journal of geriatric psychiatry 2015;30(7):744-750. doi: 10.1002/gps.4220

74. Baezner $\mathrm{H}$, Blahak C, Poggesi A, Pantoni L, Inzitari D, Chabriat $H$, Erkinjuntti T, Fazekas F, Ferro JM, Langhorne $P$, O'Brien J, Scheltens P, Visser MC, Wahlund LO, Waldemar G, Wallin A, Hennerici MG. Association of gait and 
balance disorders with age-related white matter changes: the LADIS study. Neurology 2008;70(12):935-942. doi: 10.1212/01.wnl.0000305959.46197.e6

75. Jochem C, Baumeister SE, Wittfeld K, Leitzmann MF, Bahls M, Schminke U, Markus MRP, Felix SB, Volzke H, Hegenscheid K, Dorr M, Jorgen Grabe H. Domains of physical activity and brain volumes: A population-based study. Neurolmage 2017;156:101-108. doi: 10.1016/j.neuroimage.2017.05.020

76. Halloway S, Arfanakis K, Wilbur J, Schoeny ME, Pressler SJ. Accelerometer Physical Activity is Associated with Greater Gray Matter Volumes in Older Adults without Dementia or Mild Cognitive Impairment. The journals of gerontology Series B, Psychological sciences and social sciences 2018. doi: 10.1093/geronb/gby010

77. Willey JZ, Moon YP, Paik MC, Yoshita M, Decarli C, Sacco RL, Elkind MS, Wright CB. Lower prevalence of silent brain infarcts in the physically active: the Northern Manhattan Study. Neurology 2011;76(24):2112-2118. doi: 10.1212/WNL.0b013e31821f4472

78. Afonso RF, Balardin JB, Lazar S, Sato JR, Igarashi N, Santaella DF, Lacerda SS, Amaro E, Jr., Kozasa EH. Greater Cortical Thickness in Elderly Female Yoga Practitioners-A Cross-Sectional Study. Frontiers in aging neuroscience 2017;9:201. doi: 10.3389/fnagi.2017.00201

79. Alosco ML, Brickman AM, Spitznagel MB, Sweet LH, Josephson R, Griffith EY, Narkhede A, Hughes J, Gunstad J. Daily Physical Activity Is Associated with Subcortical Brain Volume and Cognition in Heart Failure. Journal of the International Neuropsychological Society : JINS 2015;21(10):851-860. doi: 10.1017/s1355617715000697

80. Burzynska AZ, Jiao Y, Knecht AM, Fanning J, Awick EA, Chen T, Gothe N, Voss MW, McAuley E, Kramer AF. White Matter Integrity Declined Over 6-Months, but Dance Intervention Improved Integrity of the Fornix of Older Adults. Frontiers in aging neuroscience 2017;9:59. doi: 10.3389/fnagi.2017.00059

81. Carlson MC, Kuo JH, Chuang YF, Varma VR, Harris G, Albert MS, Erickson KI, Kramer AF, Parisi JM, Xue QL, Tan EJ, Tanner EK, Gross AL, Seeman TE, Gruenewald TL, McGill S, Rebok GW, Fried LP. Impact of the Baltimore Experience Corps Trial on cortical and hippocampal volumes. Alzheimer's \& dementia : the journal of the Alzheimer's Association 2015;11(11):1340-1348. doi: 10.1016/j.jalz.2014.12.005

82. Doi T, Makizako H, Shimada H, Tsutsumimoto K, Hotta R, Nakakubo S, Park H, Suzuki T. Objectively measured physical activity, brain atrophy, and white matter lesions in older adults with mild cognitive impairment. Experimental gerontology 2015;62:1-6. doi: 10.1016/j.exger.2014.12.011

83. Braskie MN, Boyle CP, Rajagopalan P, Gutman BA, Toga AW, Raji CA, Tracy RP, Kuller LH, Becker JT, Lopez OL, Thompson PM. Physical activity, inflammation, and volume of the aging brain. Neuroscience 2014;273:199-209. doi: 10.1016/j.neuroscience.2014.05.005

84. Rovio S, Spulber G, Nieminen L, Niskanen E, Winblad B, Tuomilehto J, Nissinen A, Soininen H, Kivipelto M. The effect of midlife physical activity on structural brain changes in the elderly. Neurobiology of aging 2010;31(11):1927-1936. doi: 10.1016/j.neurobiolaging.2008.10.007

85. Zhu N, Jacobs DR, Jr., Schreiner PJ, Launer L, Whitmer RA, Sidney S, Demerath E, Thomas W, Bouchard C, He K, Erus G, Battapady H, Bryan RN. Cardiorespiratory fitness and brain volume and white matter integrity: The CARDIA Study. Neurology 2015;84(23):2347-2353. doi: 10.1212/wnl.0000000000001658

86. Ho AJ, Raji CA, Becker JT, Lopez OL, Kuller LH, Hua X, Dinov ID, Stein JL, Rosano C, Toga AW, Thompson PM. The effects of physical activity, education, and body mass index on the aging brain. Human brain mapping 2011;32(9):1371-1382. doi: 10.1002/hbm.21113

87. Arenaza-Urquijo EM, de Flores R, Gonneaud J, Wirth M, Ourry V, Callewaert W, Landeau B, Egret S, Mezenge F, Desgranges $B$, Chetelat $G$. Distinct effects of late adulthood cognitive and physical activities on gray matter volume. Brain imaging and behavior 2017;11(2):346-356. doi: 10.1007/s11682-016-9617-3

88. Boots EA, Schultz SA, Oh JM, Larson J, Edwards D, Cook D, Koscik RL, Dowling MN, Gallagher CL, Carlsson CM, Rowley HA, Bendlin BB, LaRue A, Asthana S, Hermann BP, Sager MA, Johnson SC, Okonkwo OC. Cardiorespiratory fitness is associated with brain structure, cognition, and mood in a middle-aged cohort at risk for Alzheimer's disease. Brain imaging and behavior 2015;9(3):639-649. doi: 10.1007/s11682-014-9325-9

89. Muller P, Rehfeld K, Schmicker M, Hokelmann A, Dordevic M, Lessmann V, Brigadski T, Kaufmann J, Muller NG. Evolution of Neuroplasticity in Response to Physical Activity in Old Age: The Case for Dancing. Frontiers in aging neuroscience 2017;9:56. doi: 10.3389/fnagi.2017.00056 
90. Zlatar ZZ, McGregor KM, Towler S, Nocera JR, Dzierzewski JM, Crosson B. Self-reported physical activity and objective aerobic fitness: differential associations with gray matter density in healthy aging. Frontiers in aging neuroscience 2015;7:5. doi: 10.3389/fnagi.2015.00005

91. Mueller K, Moller HE, Horstmann A, Busse F, Lepsien J, Bluher M, Stumvoll M, Villringer A, Pleger B. Physical exercise in overweight to obese individuals induces metabolic- and neurotrophic-related structural brain plasticity. Frontiers in human neuroscience 2015;9:372. doi: 10.3389/fnhum.2015.00372

92. Kim RE, Yun CH, Thomas RJ, Oh JH, Johnson HJ, Kim S, Lee S, Seo HS, Shin C. Lifestyle-dependent brain change: a longitudinal cohort MRI study. Neurobiology of aging 2018;69:48-57. doi: 10.1016/j.neurobiolaging.2018.04.017

93. Tseng BY, Gundapuneedi T, Khan MA, Diaz-Arrastia R, Levine BD, Lu H, Huang H, Zhang R. White matter integrity in physically fit older adults. Neurolmage 2013;82:510-516. doi: 10.1016/j.neuroimage.2013.06.011

94. Gons RA, Tuladhar AM, de Laat KF, van Norden AG, van Dijk EJ, Norris DG, Zwiers MP, de Leeuw FE. Physical activity is related to the structural integrity of cerebral white matter. Neurology 2013;81(11):971-976. doi: 10.1212/WNL.0b013e3182a43e33

95. Kim GH, Im K, Kwon H, Seo SW, Ye BS, Cho H, Noh Y, Lee JM, Kim ST, Park SE, Kim H, Hwang JW, Kang SJ, Jeong $\mathrm{JH}, \mathrm{Na}$ DL. Higher Physical Activity Is Associated with Increased Attentional Network Connectivity in the Healthy Elderly. Frontiers in aging neuroscience 2016;8:198. doi: 10.3389/fnagi.2016.00198

96. Garcia-Casares N, Bernal-Lopez MR, Roe-Vellve N, Gutierrez-Bedmar M, Fernandez-Garcia JC, Garcia-Arnes JA, Ramos-Rodriguez JR, Alfaro F, Santamaria-Fernandez S, Steward T, Jimenez-Murcia S, Garcia-Garcia I, Valdivielso P, Fernandez-Aranda F, Tinahones FJ, Gomez-Huelgas R. Brain Functional Connectivity Is Modified by a Hypocaloric Mediterranean Diet and Physical Activity in Obese Women. Nutrients 2017;9(7). doi: $10.3390 /$ nu9070685

97. Rosano C, Venkatraman VK, Guralnik J, Newman AB, Glynn NW, Launer L, Taylor CA, Williamson J, Studenski S, Pahor $\mathrm{M}$, Aizenstein $\mathrm{H}$. Psychomotor speed and functional brain MRI 2 years after completing a physical activity treatment. The journals of gerontology Series A, Biological sciences and medical sciences 2010;65(6):639-647. doi: 10.1093/gerona/glq038

98. Wilmot EG, Edwardson CL, Achana FA, Davies MJ, Gorely T, Gray L, Khunti K, Yates T, Biddle SJ. Sedentary time in adults and the association with diabetes, cardiovascular disease and death: systematic review and metaanalysis. Diabetologia 2012;55(11):2895-2905. doi: 10.1007/s00125-012-2677-z

99. Brocklebank LA, Falconer CL, Page AS, Perry R, Cooper AR. Accelerometer-measured sedentary time and cardiometabolic biomarkers: A systematic review. Preventive medicine 2015;76:92-102. doi: 10.1016/j.ypmed.2015.04.013

100. Debette S, Beiser A, Hoffmann U, Decarli C, O'Donnell CJ, Massaro JM, Au R, Himali JJ, Wolf PA, Fox CS, Seshadri $\mathrm{S}$. Visceral fat is associated with lower brain volume in healthy middle-aged adults. Annals of neurology 2010;68(2):136-144. doi: 10.1002/ana.22062

101. Therkelsen KE, Preis SR, Beiser A, DeCarli C, Seshadri S, Wolf P, Au R, Fox CS. Neck Circumference, Brain Imaging Measures, and Neuropsychological Testing Measures. Journal of stroke and cerebrovascular diseases : the official journal of National Stroke Association 2016;25(7):1570-1581. doi: 10.1016/j.jstrokecerebrovasdis.2016.02.016

102. Debette S, Wolf C, Lambert JC, Crivello F, Soumare A, Zhu YC, Schilling S, Dufouil C, Mazoyer B, Amouyel P, Tzourio C, Elbaz A. Abdominal obesity and lower gray matter volume: a Mendelian randomization study. Neurobiology of aging 2014;35(2):378-386. doi: 10.1016/j.neurobiolaging.2013.07.022

103. Windham BG, Lirette ST, Fornage M, Benjamin EJ, Parker KG, Turner ST, Jack CR, Jr., Griswold ME, Mosley TH. Associations of Brain Structure With Adiposity and Changes in Adiposity in a Middle-Aged and Older Biracial Population. The journals of gerontology Series A, Biological sciences and medical sciences 2017;72(6):825-831. doi: 10.1093/gerona/glw239

104. Driscoll I, Beydoun MA, An Y, Davatzikos C, Ferrucci L, Zonderman AB, Resnick SM. Midlife obesity and trajectories of brain volume changes in older adults. Human brain mapping 2012;33(9):2204-2210. doi: 10.1002/hbm.21353 
105. Janowitz D, Wittfeld K, Terock J, Freyberger HJ, Hegenscheid K, Volzke H, Habes M, Hosten N, Friedrich N, Nauck M, Domanska G, Grabe HJ. Association between waist circumference and gray matter volume in 2344 individuals from two adult community-based samples. Neurolmage 2015;122:149-157. doi:

10.1016/j.neuroimage.2015.07.086

106. Kurth F, Levitt JG, Phillips OR, Luders E, Woods RP, Mazziotta JC, Toga AW, Narr KL. Relationships between gray matter, body mass index, and waist circumference in healthy adults. Human brain mapping 2013;34(7):17371746. doi: 10.1002/hbm.22021

107. Veit R, Kullmann S, Heni M, Machann J, Haring HU, Fritsche A, Preissl H. Reduced cortical thickness associated with visceral fat and BMI. Neurolmage Clinical 2014;6:307-311. doi: 10.1016/j.nicl.2014.09.013

108. Isaac V, Sim S, Zheng H, Zagorodnov V, Tai ES, Chee M. Adverse Associations between Visceral Adiposity, Brain Structure, and Cognitive Performance in Healthy Elderly. Frontiers in aging neuroscience 2011;3:12. doi: 10.3389/fnagi.2011.00012

109. Jagust W, Harvey D, Mungas D, Haan M. Central obesity and the aging brain. Archives of neurology 2005;62(10):1545-1548. doi: 10.1001/archneur.62.10.1545

110. Yamashiro K, Tanaka R, Tanaka Y, Miyamoto N, Shimada Y, Ueno Y, Urabe T, Hattori N. Visceral fat accumulation is associated with cerebral small vessel disease. European journal of neurology 2014;21(4):667-673. doi: 10.1111/ene.12374

111. Anan F, Masaki T, Eto T, Iwao T, Shimomura T, Umeno Y, Eshima N, Saikawa T, Yoshimatsu H. Visceral fat accumulation is a significant risk factor for white matter lesions in Japanese type 2 diabetic patients. European journal of clinical investigation 2009;39(5):368-374. doi: 10.1111/j.1365-2362.2009.02103.x

112. Kim KW, Seo H, Kwak MS, Kim D. Visceral obesity is associated with white matter hyperintensity and lacunar infarct. International journal of obesity (2005) 2017;41(5):683-688. doi: 10.1038/ijo.2017.13

113. Nagura J, Nakagawa Y, Miyanaga M, Matsuoka K, Hayashi K, Ozasa K, Watanabe Y. Relationship between abdominal visceral fat and lacunar infarcts in Japanese men. Circulation journal : official journal of the Japanese Circulation Society 2004;68(11):982-987.

114. Park K, Yasuda N, Toyonaga S, Tsubosaki E, Nakabayashi H, Shimizu K. Significant associations of metabolic syndrome and its components with silent lacunar infarction in middle aged subjects. Journal of neurology, neurosurgery, and psychiatry 2008;79(6):719-721. doi: 10.1136/jnnp.2007.134809

115. Lampe L, Zhang R, Beyer F, Huhn S, Kharabian Masouleh S, Preusser S, Bazin PL, Schroeter ML, Villringer A, Witte AV. Visceral obesity relates to deep white matter hyperintensities via inflammation. Annals of neurology 2019;85(2):194-203. doi: 10.1002/ana.25396

116. Kwon HM, Park JH, Park JH, Jeong HY, Lim JS, Jeong HG, Shin DW, Yun JM, Lee H. Visceral Fat Is an Independent Predictor of Cerebral Microbleeds in Neurologically Healthy People. Cerebrovascular diseases (Basel, Switzerland) 2016;42(1-2):90-96. doi: 10.1159/000445300

117. Dearborn JL, Schneider AL, Sharrett AR, Mosley TH, Bezerra DC, Knopman DS, Selvin E, Jack CR, Coker LH, Alonso A, Wagenknecht LE, Windham BG, Gottesman RF. Obesity, Insulin Resistance, and Incident Small Vessel Disease on Magnetic Resonance Imaging: Atherosclerosis Risk in Communities Study. Stroke 2015;46(11):3131-3136. doi: 10.1161/strokeaha.115.010060

118. Lou B, Chen M, Luo X, Dai Y. Reduced right frontal fractional anisotropy correlated with early elevated plasma LDL levels in obese young adults. PloS one 2014;9(10):e108180. doi: 10.1371/journal.pone.0108180

119. Spieker EA, Kochunov P, Rowland LM, Sprooten E, Winkler AM, Olvera RL, Almasy L, Duggirala R, Fox PT, Blangero J, Glahn DC, Curran JE. Shared genetic variance between obesity and white matter integrity in Mexican Americans. Frontiers in genetics 2015;6:26. doi: 10.3389/fgene.2015.00026

120. Yoon S, Cho H, Kim J, Lee D-W, Kim GH, Hong YS, Moon S, Park S, Lee S, Lee S, Bae S, Simonson DC, Lyoo IK. Brain changes in overweight/obese and normal-weight adults with type 2 diabetes mellitus. Diabetologia 2017;60(7):1207-1217. doi: 10.1007/s00125-017-4266-7

121. Zhang R, Beyer F, Lampe L, Luck T, Riedel-Heller SG, Loeffler M, Schroeter ML, Stumvoll M, Villringer A, Witte AV. White matter microstructural variability mediates the relation between obesity and cognition in healthy adults. Neurolmage 2018;172:239-249. doi: 10.1016/j.neuroimage.2018.01.028 
122. Allen B, Muldoon MF, Gianaros PJ, Jennings JR. Higher Blood Pressure Partially Links Greater Adiposity to Reduced Brain White Matter Integrity. American journal of hypertension 2016;29(9):1029-1037. doi: 10.1093/ajh/hpw026

123. Verstynen TD, Weinstein A, Erickson KI, Sheu LK, Marsland AL, Gianaros PJ. Competing physiological pathways link individual differences in weight and abdominal adiposity to white matter microstructure. Neurolmage 2013;79:129-137. doi: 10.1016/j.neuroimage.2013.04.075

124. Birdsill AC, Oleson S, Kaur S, Pasha E, Ireton A, Tanaka H, Haley A. Abdominal obesity and white matter microstructure in midlife. Human brain mapping 2017;38(7):3337-3344. doi: 10.1002/hbm.23576

125. Mitchell GF. Effects of central arterial aging on the structure and function of the peripheral vasculature: implications for end-organ damage. Journal of applied physiology (Bethesda, Md : 1985) 2008;105(5):1652-1660. doi: 10.1152/japplphysiol.90549.2008

126. O'Rourke MF, Safar ME. Relationship between aortic stiffening and microvascular disease in brain and kidney: cause and logic of therapy. Hypertension (Dallas, Tex : 1979) 2005;46(1):200-204. doi: 10.1161/01.Hyp.0000168052.00426.65

127. Glodzik L, Mosconi L, Tsui W, de Santi S, Zinkowski R, Pirraglia E, Rich KE, McHugh P, Li Y, Williams S, Ali F, Zetterberg $\mathrm{H}$, Blennow K, Mehta $\mathrm{P}$, de Leon MJ. Alzheimer's disease markers, hypertension, and gray matter damage in normal elderly. Neurobiology of aging 2012;33(7):1215-1227. doi: 10.1016/j.neurobiolaging.2011.02.012

128. Salerno JA, Grady C, Mentis M, Gonzalez-Aviles A, Wagner E, Schapiro MB, Rapoport SI. Brain metabolic function in older men with chronic essential hypertension. The journals of gerontology Series A, Biological sciences and medical sciences 1995;50(3):M147-154.

129. Meusel LA, Kansal N, Tchistiakova E, Yuen W, Maclntosh BJ, Greenwood CE, Anderson ND. A systematic review of type 2 diabetes mellitus and hypertension in imaging studies of cognitive aging: time to establish new norms. Frontiers in aging neuroscience 2014;6:148. doi: 10.3389/fnagi.2014.00148

130. Salerno JA, Murphy DG, Horwitz B, DeCarli C, Haxby JV, Rapoport SI, Schapiro MB. Brain atrophy in hypertension. A volumetric magnetic resonance imaging study. Hypertension (Dallas, Tex : 1979) 1992;20(3):340-348.

131. Strassburger TL, Lee HC, Daly EM, Szczepanik J, Krasuski JS, Mentis MJ, Salerno JA, DeCarli C, Schapiro MB, Alexander GE. Interactive effects of age and hypertension on volumes of brain structures. Stroke 1997;28(7):1410-1417.

132. Tchistiakova E, Anderson ND, Greenwood CE, MacIntosh BJ. Combined effects of type 2 diabetes and hypertension associated with cortical thinning and impaired cerebrovascular reactivity relative to hypertension alone in older adults. Neurolmage Clinical 2014;5:36-41. doi: 10.1016/j.nicl.2014.05.020

133. Leritz EC, Salat DH, Williams VJ, Schnyer DM, Rudolph JL, Lipsitz L, FischI B, McGlinchey RE, Milberg WP. Thickness of the human cerebral cortex is associated with metrics of cerebrovascular health in a normative sample of community dwelling older adults. Neurolmage 2011;54(4):2659-2671. doi: 10.1016/j.neuroimage.2010.10.050

134. Shibata D, Suchy-Dicey A, Carty CL, Madhyastha T, Ali T, Best L, Grabowski TJ, Jr., Longstreth WT, Jr., Buchwald D. Vascular Risk Factors and Findings on Brain MRI of Elderly Adult American Indians: The Strong Heart Study. Neuroepidemiology 2019;52(3-4):173-180. doi: 10.1159/000496343

135. Allan CL, Zsoldos E, Filippini N, Sexton CE, Topiwala A, Valkanova V, Singh-Manoux A, Tabak AG, Shipley MJ, Mackay C, Ebmeier KP, Kivimaki M. Lifetime hypertension as a predictor of brain structure in older adults: cohort study with a 28-year follow-up. The British journal of psychiatry : the journal of mental science 2015;206(4):308315. doi: 10.1192/bjp.bp.114.153536

136. de Leeuw FE, de Groot JC, Oudkerk M, Witteman JC, Hofman A, van Gijn J, Breteler MM. Hypertension and cerebral white matter lesions in a prospective cohort study. Brain : a journal of neurology 2002;125(Pt 4):765772.

137. King KS, Peshock RM, Rossetti HC, McColl RW, Ayers CR, Hulsey KM, Das SR. Effect of normal aging versus hypertension, abnormal body mass index, and diabetes mellitus on white matter hyperintensity volume. Stroke 2014;45(1):255-257. doi: 10.1161/strokeaha.113.003602 
138. Kuller LH, Margolis KL, Gaussoin SA, Bryan NR, Kerwin D, Limacher M, Wassertheil-Smoller S, Williamson J, Robinson JG. Relationship of hypertension, blood pressure, and blood pressure control with white matter abnormalities in the Women's Health Initiative Memory Study (WHIMS)-MRI trial. Journal of clinical hypertension (Greenwich, Conn) 2010;12(3):203-212. doi: 10.1111/j.1751-7176.2009.00234.x

139. Park MK, Jo I, Park MH, Kim TK, Jo SA, Shin C. Cerebral white matter lesions and hypertension status in the elderly Korean: the Ansan Study. Archives of gerontology and geriatrics 2005;40(3):265-273. doi: 10.1016/j.archger.2004.09.003

140. Reed T, Kirkwood SC, DeCarli C, Swan GE, Miller BL, Wolf PA, Jack LM, Carmelli D. Relationship of family history scores for stroke and hypertension to quantitative measures of white-matter hyperintensities and stroke volume in elderly males. Neuroepidemiology 2000;19(2):76-86. doi: 26242

141. van Dijk EJ, Breteler MM, Schmidt R, Berger K, Nilsson LG, Oudkerk M, Pajak A, Sans S, de Ridder M, Dufouil C, Fuhrer R, Giampaoli S, Launer L, Hofman A. The association between blood pressure, hypertension, and cerebral white matter lesions: cardiovascular determinants of dementia study. Hypertension (Dallas, Tex : 1979) 2004;44(5):625-630. doi: 10.1161/01.hyp.0000145857.98904.20

142. Greenwald BS, Kramer-Ginsberg E, Krishnan KR, Hu J, Ashtari M, Wu H, Aupperle P, Patel M, Pollack S. A controlled study of MRI signal hyperintensities in older depressed patients with and without hypertension. Journal of the American Geriatrics Society 2001;49(9):1218-1225.

143. Starchina lu A, Parfenov VA, Chazova IE, Pustovitova TS, lakhno NN. [Cognitive disturbances in patients with arterial hypertension]. Zhurnal nevrologii i psikhiatrii imeni SS Korsakova 2008;108(4):19-23.

144. Lee SH, Kim SM, Kim N, Yoon BW, Roh JK. Cortico-subcortical distribution of microbleeds is different between hypertension and cerebral amyloid angiopathy. Journal of the neurological sciences 2007;258(1-2):111-114. doi: 10.1016/j.jns.2007.03.008

145. Scott JA, Braskie MN, Tosun D, Thompson PM, Weiner M, DeCarli C, Carmichael OT. Cerebral Amyloid and Hypertension are Independently Associated with White Matter Lesions in Elderly. Frontiers in aging neuroscience 2015;7:221. doi: 10.3389/fnagi.2015.00221

146. Uiterwijk R, Staals J, Huijts M, de Leeuw PW, Kroon AA, van Oostenbrugge RJ. MRI progression of cerebral small vessel disease and cognitive decline in patients with hypertension. Journal of hypertension 2017;35(6):12631270. doi: 10.1097/hjh.0000000000001294

147. van Boxtel MP, Henskens LH, Kroon AA, Hofman PA, Gronenschild EH, Jolles J, de Leeuw PW. Ambulatory blood pressure, asymptomatic cerebrovascular damage and cognitive function in essential hypertension. Journal of human hypertension 2006;20(1):5-13. doi: 10.1038/sj.jhh.1001934

148. White WB, Jalil F, Wakefield DB, Kaplan RF, Bohannon RW, Hall CB, Moscufo N, Fellows D, Guttmann CRG, Wolfson L. Relationships among clinic, home, and ambulatory blood pressures with small vessel disease of the brain and functional status in older people with hypertension. American heart journal 2018;205:21-30. doi: 10.1016/j.ahj.2018.08.002

149. Eguchi K, Kario K, Shimada K. Greater impact of coexistence of hypertension and diabetes on silent cerebral infarcts. Stroke 2003;34(10):2471-2474. doi: 10.1161/01.str.0000089684.41902.cd

150. Kario K, Ishikawa J, Hoshide S, Matsui Y, Morinari M, Eguchi K, Ishikawa S, Shimada K. Diabetic brain damage in hypertension: role of renin-angiotensin system. Hypertension (Dallas, Tex : 1979) 2005;45(5):887-893. doi: 10.1161/01.HYP.0000163460.07639.3f

151. Shintani S, Shiigai T, Arinami T. Subclinical cerebral lesion accumulation on serial magnetic resonance imaging (MRI) in patients with hypertension: risk factors. Acta neurologica Scandinavica 1998;97(4):251-256.

152. Burgmans S, van Boxtel MP, Gronenschild EH, Vuurman EF, Hofman P, Uylings HB, Jolles J, Raz N. Multiple indicators of age-related differences in cerebral white matter and the modifying effects of hypertension. Neurolmage 2010;49(3):2083-2093. doi: 10.1016/j.neuroimage.2009.10.035

153. Fennema-Notestine C, McEvoy LK, Notestine R, Panizzon MS, Yau WW, Franz CE, Lyons MJ, Eyler LT, Neale MC, Xian $\mathrm{H}$, McKenzie RE, Kremen WS. White matter disease in midlife is heritable, related to hypertension, and shares some genetic influence with systolic blood pressure. Neurolmage Clinical 2016;12:737-745. doi: 10.1016/j.nicl.2016.10.001 
154. Yau PL, Hempel R, Tirsi A, Convit A. Cerebral white matter and retinal arterial health in hypertension and type 2 diabetes mellitus. International journal of hypertension 2013;2013:329602. doi: 10.1155/2013/329602

155. Haight T, Nick Bryan R, Erus G, Hsieh MK, Davatzikos C, Nasrallah I, D'Esposito M, Jacobs DR, Jr., Lewis C, Schreiner $\mathrm{P}$, Sidney S, Meirelles O, Launer L. White matter microstructure, white matter lesions, and hypertension: An examination of early surrogate markers of vascular-related brain change in midlife. Neurolmage Clinical 2018;18:753-761. doi: 10.1016/j.nicl.2018.02.032

156. Gons RA, de Laat KF, van Norden AG, van Oudheusden LJ, van Uden IW, Norris DG, Zwiers MP, de Leeuw FE. Hypertension and cerebral diffusion tensor imaging in small vessel disease. Stroke 2010;41(12):2801-2806. doi: 10.1161/strokeaha.110.597237

157. Dai W, Lopez OL, Carmichael OT, Becker JT, Kuller LH, Gach HM. Abnormal regional cerebral blood flow in cognitively normal elderly subjects with hypertension. Stroke 2008;39(2):349-354. doi: 10.1161/strokeaha.107.495457

158. Jennings JR, Muldoon MF, Ryan C, Price JC, Greer P, Sutton-Tyrrell K, van der Veen FM, Meltzer CC. Reduced cerebral blood flow response and compensation among patients with untreated hypertension. Neurology 2005;64(8):1358-1365. doi: 10.1212/01.wnl.0000158283.28251.3c

159. Wang T, Li Y, Guo X, Huang D, Ma L, Wang DJ, Lou X. Reduced perfusion in normal-appearing white matter in mild to moderate hypertension as revealed by 3D pseudocontinuous arterial spin labeling. Journal of magnetic resonance imaging : JMRI 2016;43(3):635-643. doi: 10.1002/jmri.25023

160. Duan D, Li C, Shen L, Cui C, Shu T, Zheng J. Regional Gray Matter Atrophy Coexistent with Occipital Periventricular White Matter Hyper Intensities. Frontiers in aging neuroscience 2016;8:214. doi:

10.3389/fnagi.2016.00214

161. Coutinho AM, Coutu JP, Lindemer ER, Rosas HD, Rosen BR, Salat DH. Differential associations between systemic markers of disease and cortical thickness in healthy middle-aged and older adults. Neurolmage 2017;146:19-27. doi: 10.1016/j.neuroimage.2016.11.021

162. Breteler MM, van Swieten JC, Bots ML, Grobbee DE, Claus JJ, van den Hout JH, van Harskamp F, Tanghe HL, de Jong PT, van Gijn J, et al. Cerebral white matter lesions, vascular risk factors, and cognitive function in a population-based study: the Rotterdam Study. Neurology 1994;44(7):1246-1252.

163. Schmidt R, Hayn M, Fazekas F, Kapeller P, Esterbauer H. Magnetic resonance imaging white matter hyperintensities in clinically normal elderly individuals. Correlations with plasma concentrations of naturally occurring antioxidants. Stroke 1996;27(11):2043-2047.

164. Willey JZ, Gardener H, Moon YP, Yoshita M, DeCarli C, Cheung YK, Sacco RL, Elkind MS, Wright CB. Lipid profile components and subclinical cerebrovascular disease in the northern Manhattan study. Cerebrovascular diseases (Basel, Switzerland) 2014;37(6):423-430. doi: 10.1159/000362920

165. Del Brutto $\mathrm{OH}$, Mera RM. Understanding the direction of the relationship between white matter hyperintensities of vascular origin, sleep quality, and chronic kidney disease-Results from the Atahualpa Project. Clinical neurology and neurosurgery 2018;165:10-14. doi: 10.1016/j.clineuro.2017.12.019

166. Raz N, Yang Y, Dahle CL, Land S. Volume of white matter hyperintensities in healthy adults: contribution of age, vascular risk factors, and inflammation-related genetic variants. Biochimica et biophysica acta 2012;1822(3):361369. doi: 10.1016/j.bbadis.2011.08.007

167. Bezerra DC, Sharrett AR, Matsushita K, Gottesman RF, Shibata D, Mosley TH, Jr., Coresh J, Szklo M, Carvalho MS, Selvin E. Risk factors for lacune subtypes in the Atherosclerosis Risk in Communities (ARIC) Study. Neurology 2012;78(2):102-108. doi: 10.1212/WNL.0b013e31823efc42

168. Akoudad S, Ikram MA, Portegies ML, Adams HH, Bos D, Hofman A, Koudstaal PJ, Uitterlinden AG, van der Lugt A, van Duijn CM, Vernooij MW. Genetic loci for serum lipid fractions and intracerebral hemorrhage. Atherosclerosis 2016;246:287-292. doi: 10.1016/j.atherosclerosis.2016.01.024

169. Lee SH, Lee ST, Kim BJ, Park HK, Kim CK, Jung KH, Roh JK. Dynamic temporal change of cerebral microbleeds: long-term follow-up MRI study. PloS one 2011;6(10):e25930. doi: 10.1371/journal.pone.0025930

170. Cohen JI, Cazettes F, Convit A. Abnormal cholesterol is associated with prefrontal white matter abnormalities among obese adults, a diffusion tensor imaging study. The neuroradiology journal 2011;1(21):989-997. 
171. Zhang T, Li H, Zhang J, Li X, Qi D, Wang N, Zhang Z. Impacts of High Serum Total Cholesterol Level on Brain Functional Connectivity in Non-Demented Elderly. Journal of Alzheimer's disease : JAD 2016;50(2):455-463. doi: 10.3233/jad-150810

172. Carmelli D, Swan GE, Reed T, Wolf PA, Miller BL, DeCarli C. Midlife cardiovascular risk factors and brain morphology in identical older male twins. Neurology 1999;52(6):1119-1124.

173. de Bruijn RF, Akoudad S, Cremers LG, Hofman A, Niessen WJ, van der Lugt A, Koudstaal PJ, Vernooij MW, Ikram MA. Determinants, MRI correlates, and prognosis of mild cognitive impairment: the Rotterdam Study. Journal of Alzheimer's disease : JAD 2014;42:S239-249. doi: 10.3233/jad-132558

174. Longstreth WT, Jr., Arnold AM, Beauchamp NJ, Jr., Manolio TA, Lefkowitz D, Jungreis C, Hirsch CH, O'Leary DH, Furberg CD. Incidence, manifestations, and predictors of worsening white matter on serial cranial magnetic resonance imaging in the elderly: the Cardiovascular Health Study. Stroke 2005;36(1):56-61. doi: 10.1161/01.str.0000149625.99732.69

175. Dickie DA, Ritchie SJ, Cox SR, Sakka E, Royle NA, Aribisala BS, Valdes Hernandez Mdel C, Maniega SM, Pattie A, Corley J, Starr JM, Bastin ME, Deary IJ, Wardlaw JM. Vascular risk factors and progression of white matter hyperintensities in the Lothian Birth Cohort 1936. Neurobiology of aging 2016;42:116-123. doi: 10.1016/j.neurobiolaging.2016.03.011

176. Aljondi R, Szoeke C, Steward C, Gorelik A, Desmond P. The effect of midlife cardiovascular risk factors on white matter hyperintensity volume and cognition two decades later in normal ageing women. Brain imaging and behavior 2018;14:51-61. doi: 10.1007/s11682-018-9970-5

177. Gouw AA, van der Flier WM, Fazekas F, van Straaten EC, Pantoni L, Poggesi A, Inzitari D, Erkinjuntti T, Wahlund LO, Waldemar G, Schmidt R, Scheltens $P$, Barkhof F. Progression of white matter hyperintensities and incidence of new lacunes over a 3-year period: the Leukoaraiosis and Disability study. Stroke 2008;39(5):1414-1420. doi: 10.1161/strokeaha.107.498535

178. Takashima Y, Yao H, Koga H, Endo K, Matsumoto T, Uchino A, Sadanaga-Akiyoshi F, Yuzuriha T, Kuroda Y. Frontal lobe dysfunction caused by multiple lacunar infarction in community-dwelling elderly subjects. Journal of the neurological sciences 2003;214(1-2):37-41.

179. Ding J, Sigurdsson S, Garcia M, Phillips CL, Eiriksdottir G, Gudnason V, van Buchem MA, Launer L. Risk Factors Associated With Incident Cerebral Microbleeds According to Location in Older People: The Age, Gene/Environment Susceptibility (AGES)-Reykjavik Study. JAMA neurology 2015;72(6):682-688. doi: 10.1001/jamaneurol.2015.0174

180. Krishnadas R, McLean J, Batty GD, Burns H, Deans KA, Ford I, McConnachie A, McGinty A, McLean JS, Millar K, Sattar N, Shiels PG, Velupillai YN, Packard CJ, Cavanagh J. Cardio-metabolic risk factors and cortical thickness in a neurologically healthy male population: Results from the psychological, social and biological determinants of ill health (pSoBid) study. Neurolmage Clinical 2013;2:646-657. doi: 10.1016/j.nicl.2013.04.012

181. Wieberdink RG, Poels MM, Vernooij MW, Koudstaal PJ, Hofman A, van der Lugt A, Breteler MM, Ikram MA. Serum lipid levels and the risk of intracerebral hemorrhage: the Rotterdam Study. Arteriosclerosis, thrombosis, and vascular biology 2011;31(12):2982-2989. doi: 10.1161/atvbaha.111.234948

182. Jennings JR, Heim AF, Kuan DC, Gianaros PJ, Muldoon MF, Manuck SB. Use of total cerebral blood flow as an imaging biomarker of known cardiovascular risks. Stroke 2013;44(9):2480-2485. doi:

10.1161/strokeaha.113.001716 


\section{Supplementary Material}

Search terms: brain AND MRI AND:

1. (hyperglycemi*[Title/Abstract] OR diabetes[Title/Abstract]) NOT (mice OR mouse OR rat OR children OR animal OR infants OR tumor OR metastasis OR cancer OR stroke)

2. "waist circumference" OR "visceral fat"

3. triglycerid*[Title/Abstract] cholesterol*[Title/Abstract] AND ("white matter" OR "gray matter" OR volume OR microbleed* OR lacun* OR connectivity)

4. "physical activity" OR "physical inactivity" OR "sedentary behavior" OR "sedentary time"

5. hypertension*[Title] NOT (mice OR mouse OR rat OR child* OR infant*)

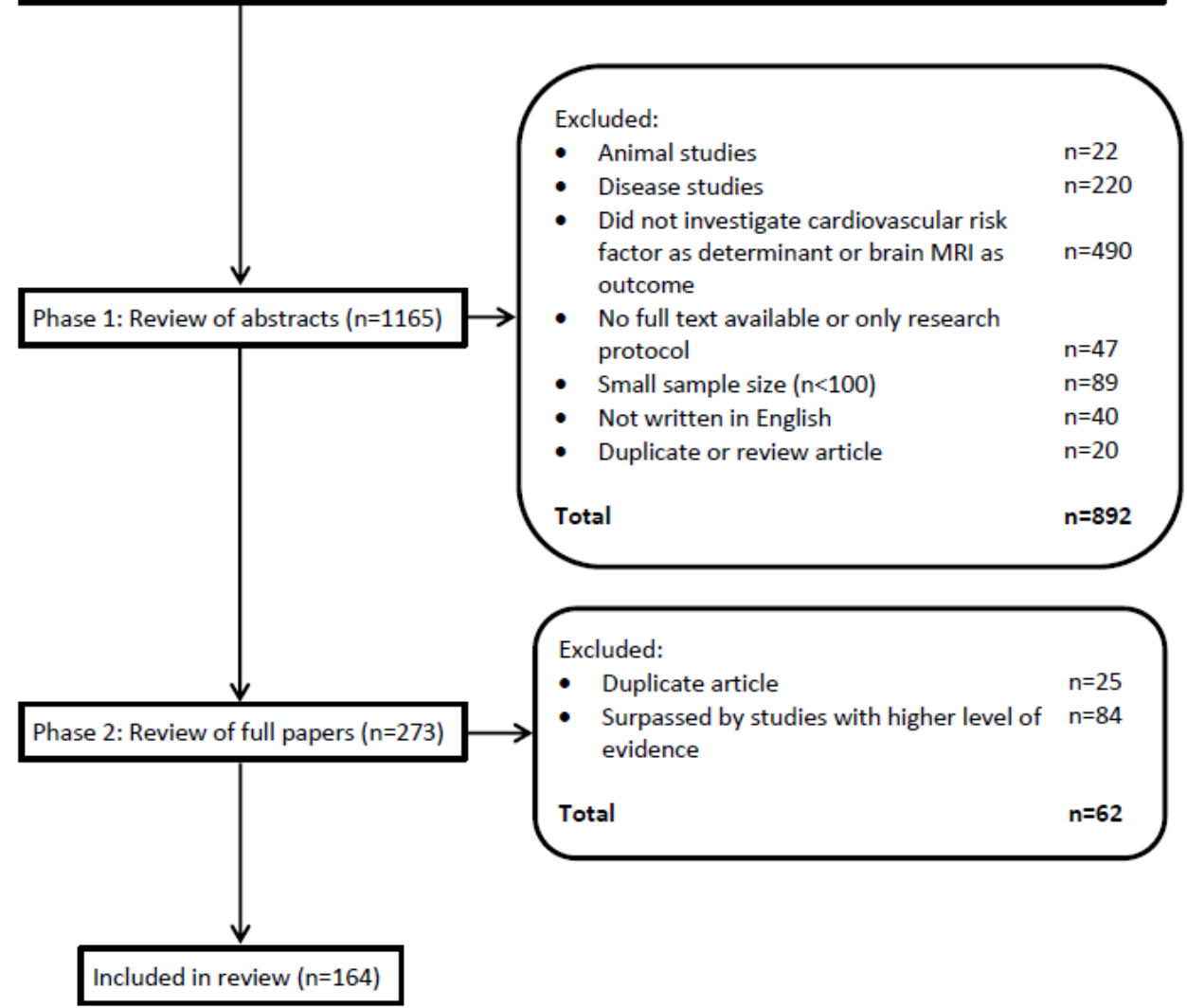

Supplementary Figure 2.1: Flowchart of literature search and study selection. 


\section{Chapter 3}

\section{White Matter Connectivity Abnormalities in Prediabetes and Type 2 Diabetes: The Maastricht Study}

Laura W.M. Vergoossen, Miranda T. Schram, Joost J.A. de Jong, Coen D.A. Stehouwer, Nicolaas C. Schaper, Ronald M.A. Henry, Carla J.H. van der Kallen, Pieter C. Dagnelie, Martin P.J. van Boxtel, Simone J. Eussen, Walter

H. Backes, and Jacobus F.A. Jansen

Diabetes Care. 2020 Jan;43(1):201-208. doi: 10.2337/dc19-0762

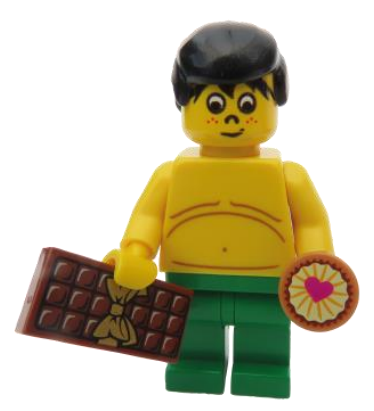




\section{Abstract}

\section{Objective}

Prediabetes and type 2 diabetes are associated with structural brain abnormalities, often observed in cognitive disorders. Besides visible lesions, (pre)diabetes might also be associated with alterations of the intrinsic organization of the white matter. In this population-based cohort-study, the association of prediabetes and type 2 diabetes with white matter network organization was assessed.

\section{Research Design and Methods}

In The Maastricht Study, a type 2 diabetes-enriched population-based cohort-study (1361 normal glucose metabolism, 348 prediabetes, 510 type 2 diabetes assessed by OGTT, $52 \%$ men, aged $59 \pm 8$ years) 3 Tesla structural and diffusion MRI was performed. Whole brain white matter tractography was used to assess the number of connections (node degree) between 94 brain regions and the topology (graph measures). Multivariable linear regression analyses were employed to investigate the associations of glucose metabolism status with network measures. Associations were adjusted for age, sex, education, and cardiovascular risk factors.

\section{Results}

Prediabetes and type 2 diabetes were associated with lower node degree after full adjustment (standardized [st] $\beta$ Prediabetes $[95 \% \mathrm{Cl}]=-0.055[-0.172,-0.062]$, st $\beta$ Type2diabetes $[95 \% \mathrm{Cl}]=-0.256[-0.379$,$0.133]$, Ptrend $<0.001$ ). Prediabetes was associated with lower local efficiency (st $\beta[95 \% \mathrm{Cl}]=-0.084[-0.159$,$0.008], P=0.033$ ) and lower clustering coefficient (st $\beta[95 \% \mathrm{Cl}]=-0.097[-0.189,-0.005], P=0.049$ ), while type 2 diabetes was not. Type 2 diabetes was associated with higher communicability (st $\beta[95 \% \mathrm{Cl}]=0.148[0.042,0.253], \mathrm{P}=0.008)$.

\section{Conclusions}

These findings indicate that prediabetes and type 2 diabetes are associated with fewer white matter connections, and weaker organization of white matter networks. Type 2 diabetes was associated with higher communicability, which was not yet observed in prediabetes, which may reflect the use of alternative white matter connections. 


\section{Introduction}

Type 2 diabetes is associated with cognitive decline (1-3) and poses an increased risk for brain diseases, such as Alzheimer's disease and depression $(4 ; 5)$. As type 2 diabetes is associated with abundant macroand microvascular disease, it may also affect brain vessels leading to cerebral small vessel disease (e.g., white matter lesions (WML)) and neurodegeneration (brain atrophy) $(6 ; 7)$, which represent early features in the pathophysiology of cognitive decline and dementia (8), and can be measured by brain MRI. Some studies even show that prediabetes is already associated with alterations in the brain $(9 ; 10)$, more specifically with presence of lacunar infarcts, larger WML volumes, and smaller white matter volumes, with further deterioration in type 2 diabetes, as previously reported (7). The white matter is organized as a complex network of connected fibers, which is responsible for efficient information exchange between brain regions. Alterations in one region may affect the function of other regions to which they are connected via white matter tracts. Thus, to understand the organization of white matter networks entirely, assessment of regional brain volumes is insufficient. The use of diffusion MRI-derived white matter tracts, in combination with graph theoretical analysis, does address both the regional volumes, and its connections to other regions.

Type 2 diabetes might also be associated with alterations in the intrinsic organization of the white matter (11-14). However, whether changes in the intrinsic network organization of the white matter already occur in prediabetes is currently unknown (15-17). We hypothesize that brain abnormalities comparable to those found in type 2 diabetes are, to a lesser extent, already present in prediabetes, possibly already before onset of cognitive decline. The main objective of this study is to assess the association of prediabetes and type 2 diabetes, with white matter network characteristics, in terms of the number (node degree) and organization (graph measures) of the white matter connections.

\section{Research Design and Methods}

\section{The Maastricht Study: population and design}

We used data from The Maastricht Study, an observational prospective population-based cohort study. The rationale and methodology have been described previously (18). In brief, the study focuses on the etiology, pathophysiology, complications, and comorbidities of type 2 diabetes and is characterized by an extensive phenotyping approach. Eligible for participation were all individuals aged between 40 and 75 years and living in the southern part of the Netherlands. Participants were recruited through mass media campaigns and from the municipal registries and the regional Diabetes Patient Registry via mailings. Recruitment was stratified according to known type 2 diabetes status, with an oversampling of individuals with type 2 diabetes, for reasons of efficiency. Participants with type 1 diabetes or other types of diabetes were excluded from the analysis. The present report includes cross-sectional data from the first 3451 participants, who completed the baseline survey between November 2010 and September 2013. The examinations of each participant were performed within a time window of three months. MRI measurements were implemented from December 2013 onwards until February 2017 and were available in 2318 out of 3451 participants. Of the 2318 participants with MRI measurements available, 2302 subjects had complete data without artifacts [Flowchart in Supplementary material Figure 3.1]. The study has been approved by the institutional medical ethical committee (NL31329.068.10) and the Dutch 
Ministry of Health, Welfare and Sports of the Netherlands (Permit 131088-105234-PG). All participants gave written informed consent.

\section{Glucose metabolism status}

To determine glucose metabolism status, all participants, except those who used insulin, underwent a standardized 2-h 75g oral glucose tolerance test (OGTT) after an overnight fast. For safety reasons, participants with a fasting blood glucose (FBG) level above $11.0 \mathrm{mmol} / \mathrm{L}$, as determined by a finger prick, did not undergo the OGTT. For these individuals, fasting glucose level and information about diabetes medication were used to determine glucose metabolism status. Glucose metabolism status was defined according to the WHO 2006 criteria into NGM, prediabetes, and type 2 diabetes (19). Participants were considered to have type 2 diabetes if they had a fasting blood glucose $\geq 7.0 \mathrm{mmol} / \mathrm{l}$, or a 2 -h post-load blood glucose $\geq 11.1 \mathrm{mmol} / \mathrm{l}$ or used oral glucose-lowering medication or insulin, prediabetes if they had a FBG $\geq 6.1 \mathrm{mmol} / \mathrm{l}$ and/or a 2 -h post-load blood glucose $\geq 7.8 \mathrm{mmol} / \mathrm{l}$, and NGM if they had a FBG $<6.1$ $\mathrm{mmol} / \mathrm{l}$, and a 2 -h post-load blood glucose $<7.8 \mathrm{mmol} / \mathrm{l}$ and no use of diabetes medication.

\section{Magnetic Resonance Imaging}

Magnetic resonance imaging (MRI) was performed on a 3T MRI scanner (MAGNETOM Prisma-fit Syngo MR D13D; Siemens Healthcare, Erlangen, Germany) using a 64-element head/neck coil for parallel imaging with an acceleration factor of two. A 3D T1-weighted magnetization prepared rapid acquisition gradient echo (MPRAGE) sequence (TR/TI/TE 2300/900/2.98 ms, 176 slices, 256×240 matrix size and 1.00 $\mathrm{mm}$ cubic voxel size) was acquired for anatomic reference. Diffusion-weighted MRI (dMRI) data were acquired using a diffusion sensitized echo-planar imaging (EPI) sequence (TR/TE 6100/57 ms, 65 slices, $100 \times 100$ matrix size, $2.00 \mathrm{~mm}$ cubic voxel size, and 64 diffusion sensitizing gradient directions ( $b=1200$ $\mathrm{s} / \mathrm{mm} 2)$ ). In addition, three minimally-diffusion-weighted images ( $b=0 \mathrm{~s} / \mathrm{mm} 2)$ were acquired.

\section{Image preprocessing}

To define $\mathrm{N}=94$ regions, the automatic anatomical labeling 2 (AAL2) atlas (20) was used. The AAL2 volumes of interest were transformed to diffusion space for each individual subject. First, affine registrations of the dMRI image to the T1 image and of the T1 image to T1 MNI-152 standard space (21) were performed. These two transformations were combined and the inverse transformation matrix was applied to the AAL2 template. T1-weighted and Fluid Attenuated Inversion Recovery (FLAIR) images were segmented by use of an ISO13485:2012 certified, automated method (which included visual inspection) $(22 ; 23)$ into white matter, gray matter, cerebrospinal fluid, and WML. Detailed methods are described in (7). dMRI data analysis was performed with the diffusion MR Toolbox ExploreDTI version 4.8.6. (24) The main preprocessing steps were eddy current induced geometric distortions and head motion correction, and estimation of the diffusion tensor. After preprocessing, fiber orientation distributions (FOD) were estimated using constrained spherical deconvolution with a maximum harmonic degree of 8 (25), which allows fiber tracking through regions with crossing fibers. Whole brain deterministic tractography was performed using FOD sampling (26) with a seed point resolution of 2 
$\mathrm{mm} 3$, a step size of $1 \mathrm{~mm}$, and an FOD and maximum deflection angle threshold of 0.1 and $30^{\circ}$, respectively. The next step was performing connectivity analysis to obtain white matter tracts from and to all the segmented regions. A previous study of our group confirmed the robustness of tract volume as a measure for the edge weighting (27), therefore, for each connection, the tract volume was calculated as the number of voxels visited by at least one tract between concerned areas multiplied by the voxel volume (in $\mathrm{mm} 3$ ). The obtained connectivity matrix with tract volumes was normalized to intracranial volume to reduce inter-subject variation (28). When regions were connected by only one or two streamlines, the corresponding tract volumes were removed from the connectivity matrix, as an additional noise filter.

\section{White matter networks}

Network analysis was performed using the Brain Connectivity Toolbox (version 2017-15-01)(29) in MATLAB (Release 2016a; The MathWorks, Inc., Natick, MA). In this method (for an overview, see Figure 3. 1), the brain is represented as a graph, which is a network of nodes (i.e., gray matter brain regions) connected by edges (i.e., white matter connections between brain regions). The organization of such a graph can be characterized by use of graph measures, e.g., clustering coefficient, local efficiency, communicability, and global efficiency. These graph measures describe the efficiency and integrity of the white matter networks.

The node degree is calculated for each AAL2 region and the mean value is defined as the average node degree, which is a measure for the average number of edges connected to a region (node). In a network with a high average node degree, nodes are connected to many other nodes in the network (i.e., strong innervation). The sparsity of a network is the ratio of the number of missing connections in a network to the possible number of connections and is closely, but inversely, related to the node degree. The sparsity ranges from 0 to 1 , the higher the sparsity, the lower the density of the network (29).

\section{Graph measures}

To describe network organization, measures indicative of network segregation, to assess the presence of local densely interconnected groups of brain regions, and indicative of integration, to assess large-scale communication between nodes, were calculated [see Figure 3.1]. Measures of segregation describe the local connectivity properties of a network and comprise clustering and local efficiency. The clustering coefficient quantifies the number of connections between the nearest neighbors of a region as a proportion of the maximum number of possible connections (15). The local efficiency of a region is the inverse of the average shortest path connecting all neighbors of that region (30). Paths are sequences of connections in the network, which represent potential routes for communication between brain regions.

Measures of integration describe the ease with which brain regions communicate in terms of paths and include global efficiency and communicability. The global efficiency is the inverse of the average shortest path length calculated over the entire brain, thus a high global efficiency reflects long paths between regions (30). However, neural communication does not necessarily follow the shortest paths only, but slightly longer paths might also be used (e.g., to bypass affected paths). Therefore an alternative measure of communication, the communicability, was calculated, which includes all possible paths between brain regions, weighted according to their length (31). 


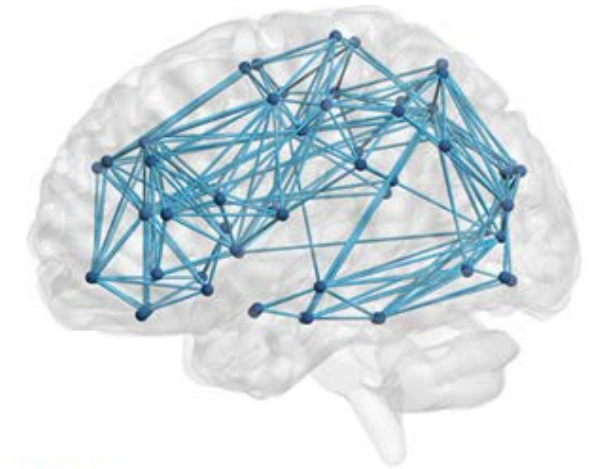

Node $=$ Brain region

Edge $=$ Connection between brain regions

Node degree $=$ \# edges connected to a node

Sparsity $=1-\frac{\text { \# edges }}{\text { \# possible edges }}$

Path = sequence of connections in the network which represent potential routes for communication between brain regions.

Graph $=$ network of nodes connected by edges.

Calculation of graph measures:

- Sparsity thresholded standard network needed, because differences in graph measures calculated in networks with different numbers of edges are not due to differences in topological organization, but due to the difference in number of edges.

- In group-comparison studies connectivity might differ between groups $\rightarrow$ different standard networks needed for each group $\rightarrow$ graph theoretical analysis on most sparse network.

Graph measures of segregation: local connectivity properties

- Clustering coefficient $=$ number of connections between nearest neighbors of a node as a proportion of the maximum number of possible connections.

- Local efficiency = inverse shortest path length of connections to neighbors of a specific node. Graph measures of integration: global connectivity properties

- Characteristic path length = minimum number of connections that must be traversed on average to go from one region to another.

- Global efficiency = average inverse shortest path length in the network.

- Communicability = measure of all possible paths between regions weighted according to their length.

Figure 3.1: Glossary.

\section{White matter structural connectivity}

The node degree was first calculated for the full connectivity matrices of the groups, NGM, prediabetes, and type 2 diabetes, for comparison of the basic network architecture between them. Subsequently, a standard group averaged network was calculated for each group separately (32). Note that these 
standard networks may differ per group comparison. This standard network was proportionally thresholded to a sparsity of 0.80 (only the connections that were present in at least $80 \%$ of the participants in that group will be taken into account in the individual connectivity matrices), resulting in a weighted, undirected network with a sparsity close to the sparsity of the standard network. The standard networks were also thresholded for a range of sparsity values $(0.65-0.9$, step size 0.05$)$ to assess the robustness over different sparsity values. Additionally, connections were identified with a significantly increased or decreased tract volume. First, we applied thresholding by a network based on only the NGM subjects, to check whether differences in basic network architecture were also present after exclusion of connections formed due to noise as opposed to pathology. As the networks of the type 2 diabetes group appeared to be most sparse, subsequently, the organization of this remaining (sub)network was analyzed. Hence, the resulting network contains only the connections of the sparser type 2 diabetes network of which the connections are also present in the other two groups. Otherwise the 'true sparsity' of the subjects with type 2 diabetes would be lower than for the NGM and prediabetes subjects, which again leads to different results in graph measures due to differences in sparsity. To investigate whether prediabetes is already associated with a structural reorganization, for the comparison of prediabetes and NGM, the average prediabetes derived network was applied.

To investigate the structural organization in the white matter networks in type 2 diabetes and prediabetes, graph measures of segregation (i.e., clustering coefficient and local efficiency) and integration (i.e., global efficiency and communicability) $(16 ; 17 ; 33)$ were calculated from the brain graphs. Graph measures were normalized to comparable values from randomly generated networks of equal size and similar connectivity distribution $(\mathrm{N}=100)(34)$, and calculated over a range of six sparsity values, 0.65-0.9 (step size 0.05).

\section{General characteristics and covariates}

Educational level (low, intermediate, high), smoking status (never, current, former) and history of cardiovascular disease were assessed by questionnaires (18). Medication use was assessed in a medication interview where generic name, dose, and frequency were registered. We measured weight, height, BMI, waist circumference, blood pressure (measured in office [705IT; Omron, Kyoto, Japan]), and plasma lipid profile (18).

\section{Statistical analysis}

All statistical analyses were performed by use of the Statistical Package for Social Sciences (SPSS Statistics 23.0; IBM, Chicago, IL). Clinical characteristics of the participants within the three groups of glucose metabolism status were compared using ANOVA and Pearson $\chi^{\wedge} 2$ tests, where appropriate.

Multivariable linear regression was used to investigate the association of glucose metabolism status, with average node degree, and graph measures. For linear trend analyses, the categorical variable glucose metabolism status ( $N G M=0$, prediabetes=1, and type 2 diabetes $=2$ ) was used in the regression models. To assess regression coefficients per glucose metabolism group, analysis with dummy variables for prediabetes and type 2 diabetes with NGM as reference group were used. Analyses were adjusted for potential confounders, notably age, sex, education level and MRI date (Model 1), and additionally adjusted for cardiovascular disease risk factors: BMI, total cholesterol-to-HDL-ratio, lipid-modifying 
medication, office systolic blood pressure, antihypertensive medication, and prior cardiovascular disease (Model 2). Regression coefficients for normal aging (i.e., in participants with normal compared to abnormal glucose metabolism) were determined in the NGM group. Multiple linear regression with falsediscovery-rate $(F D R$ ) correction ( $q$-value $=0.05$ ) was used to correct for multiple comparisons to determine which connections had significantly different tract volumes between groups, and were adjusted for age, sex, education level, and MRI lag time. In the type 2 diabetes-based standard networks, the associations of glucose metabolism groups and continuous measures of blood glucose with graph measures were analyzed by use of multiple regression analyses. Analyses on graph measures were adjusted for age, sex, education level, MRI date, and average node degree (Model 1), and additionally for cardiovascular disease risk factors (Model 2). Furthermore, we investigated the association of HbA1c, FBG, and 2-h post-load glucose levels, with average node degree and graph measures; and adjusted in an additional model for life style factors. Skewed variables (WML volumes) were log10 transformed. Pvalues $<0.05$ were considered statistically significant.

\section{Results}

\section{General characteristics of the study population}

Table 3.1 shows the general characteristics of the study population for subjects with NGM, prediabetes, and type 2 diabetes. The study population consisted of 2219 individuals; 1361 had NGM, 348 had prediabetes, and 510 had type 2 diabetes. Mean age was $59 \pm 8$ years, and $48 \%$ were women. Individuals with prediabetes and type 2 diabetes were older, less often female, more often had an adverse cardiovascular risk profile, and more often had a low educational level [Table 3.1]. Individuals who underwent MRI were younger, less likely to have type 2 diabetes, less often current smokers, and less often had a low education level compared to those that did not undergo MRI [Supplementary Table 3.1].

\section{Structural network characteristics}

After full adjustment, the average node degree for the full connectivity matrices (i.e., before thresholding) was significantly lower for type 2 diabetes subjects compared to NGM (1.3\% lower, standardized $[\mathrm{st}] \beta[95 \% \mathrm{Cl}]=-0.111[-0.220,-0.002], P_{\text {trend }}=0.047$, Supplementary Table 3.2). Subsequent analysis using the standard network based on only NGM subjects, showed significantly different results for type 2 diabetes compared to prediabetes $(0.7 \%$ lower, st $\beta[95 \% \mathrm{CI}]=-0.256[-0.379,-0.133]$, $\left.P_{\text {trend }}<0.001\right)$. Higher HbA1c, FBG, and 2-h post-load glucose levels were also associated with lower node degree in the unthresholded and NGM-based networks (Supplementary Table 3.3). 
Table 3.1: Clinical characteristics of participants according to glucose metabolism status.

\begin{tabular}{|c|c|c|c|c|}
\hline Characteristic & $\begin{array}{c}\text { NGM } \\
(n=1361) \\
\end{array}$ & $\begin{array}{l}\text { Prediabetes } \\
(n=348)\end{array}$ & $\begin{array}{l}\text { Type } 2 \text { diabetes } \\
(n=510)\end{array}$ & $P_{\text {trend }}$ \\
\hline \multicolumn{5}{|l|}{ Demographics } \\
\hline Age (years) & $57.6 \pm 8.1$ & $61.2 \pm 7.5$ & $62.5 \pm 7.6$ & $<0.001$ \\
\hline Sex, male (\%) & 44.2 & 55.2 & 68.6 & $<0.001$ \\
\hline $\begin{array}{l}\text { Education level (\%), } \\
\text { Low/Middle/High }\end{array}$ & $25.4 / 28.1 / 46.4$ & $33.0 / 31.0 / 36.0$ & $41.3 / 30.2 / 28.5$ & $<0.001$ \\
\hline \multicolumn{5}{|l|}{ Glucose metabolism } \\
\hline Fasting blood glucose (mmol/l) & $5.2 \pm 0.4$ & $5.9 \pm 0.6$ & $7.8 \pm 1.9$ & $<0.001$ \\
\hline 2h post-load glucose* $(\mathrm{mmol} / \mathrm{l})$ & $5.4 \pm 1.1$ & $8.1 \pm 1.8$ & $14.2 \pm 4.1$ & $<0.001$ \\
\hline $\mathrm{HbA}_{1 \mathrm{c}}(\%)$ & $5.4 \pm 0.3$ & $5.7 \pm 0.4$ & $6.9 \pm 1.0$ & $<0.001$ \\
\hline $\mathrm{HbA}_{1 \mathrm{c}}(\mathrm{mmol} / \mathrm{mol})$ & $36.0 \pm 3.7$ & $38.6 \pm 4.4$ & $51.4 \pm 11.0$ & $<0.001$ \\
\hline Diabetes duration $^{\dagger}$ (years) & - & - & $6.9 \pm 7.2$ & - \\
\hline \multicolumn{5}{|l|}{ Cardiovascular risk factors } \\
\hline $\mathrm{BMI}\left(\mathrm{kg} / \mathrm{m}^{2}\right)$ & $25.5 \pm 3.5$ & $27.3 \pm 4.0$ & $29.3 \pm 4.6$ & $<0.001$ \\
\hline Waist circumference $(\mathrm{cm})$ & $90.2 \pm 10.9$ & $96.8 \pm 11.3$ & $104.3 \pm 12.9$ & $<0.001$ \\
\hline $\begin{array}{l}\text { Office systolic blood pressure } \\
(\mathrm{mmHg})\end{array}$ & $131 \pm 17$ & $136 \pm 16$ & $141 \pm 17$ & $<0.001$ \\
\hline $\begin{array}{l}\text { Office diastolic blood pressure } \\
\text { (mmHg) }\end{array}$ & $75 \pm 10$ & $78 \pm 10$ & $77 \pm 9$ & $<0.001$ \\
\hline Hypertension, yes (\%) & 39.1 & 59.4 & 82.0 & $<0.001$ \\
\hline Ratio of total cholesterol to HDL & $3.6 \pm 1.2$ & $3.9 \pm 1.2$ & $3.6 \pm 1.1$ & 0.152 \\
\hline $\begin{array}{l}\text { History of cardiovascular disease, } \\
\text { yes (\%) }\end{array}$ & 8.9 & 11.3 & 21.3 & $<0.001$ \\
\hline History of CVA, yes $(\%)^{\ddagger}$ & 1.1 & 2.3 & 3.9 & $<0.001$ \\
\hline \multicolumn{5}{|l|}{ Medication use } \\
\hline Insulin use, yes (\%) ${ }^{+}$ & - & - & 19.6 & - \\
\hline $\begin{array}{l}\text { Antihypertensive medication, yes } \\
\text { (\%) }\end{array}$ & 20.6 & 38.8 & 70.2 & $<0.001$ \\
\hline $\begin{array}{l}\text { Lipid-modifying medication, yes } \\
\text { (\%) }\end{array}$ & 14.8 & 29.0 & 72.5 & $<0.001$ \\
\hline \multicolumn{5}{|l|}{ Lifestyle factors } \\
\hline $\begin{array}{l}\text { Alcohol consumption (\%), } \\
\text { None/Low/High }\end{array}$ & $13.9 / 57.5 / 28.6$ & $16.3 / 53.5 / 30.2$ & $26.4 / 53.1 / 20.5$ & $<0.001$ \\
\hline $\begin{array}{l}\text { Smoking status (\%), } \\
\text { Never/Former/Current }\end{array}$ & $40.9 / 47.9 / 11.1$ & $30.4 / 58.0 / 11.6$ & $32.7 / 53.7 / 13.5$ & 0.001 \\
\hline \multicolumn{5}{|l|}{ Cognitive score } \\
\hline MMSE total score ${ }^{\S}$ & $29.2 \pm 1.1$ & $28.9 \pm 1.1$ & $28.7 \pm 1.3$ & $<0.001$ \\
\hline \multicolumn{5}{|c|}{$\begin{array}{l}\text { Data are presented as means } \pm \text { standard deviation or percentage, and stratified for glucose metabolism status: } \\
\text { normal glucose metabolism (NGM), prediabetes, and type } 2 \text { diabetes. P-values indicate trend analysis over } \\
\text { glucose metabolism status. HbA1c indicates hemoglobin A1c; BP, blood pressure; HDL, high-density lipoprotein; } \\
\text { LDL, low-density lipoprotein; CVA, cerebrovascular accident; MMSE, Mini-Mental State Examination. *2h post- } \\
\text { load glucose values were available in } n=2098 .{ }^{\dagger} \text { Available in } 344 \text { type } 2 \text { diabetes individuals. }{ }^{\ddagger} \text { History of CVA data } \\
\text { was available is } n=2191 .{ }^{\S} \text { Five participants had a MMSE score of } 22 \text { or } 23 \text { (mild cognitive impairment) and none } \\
\text { had dementia. Detailed protocols of the general measurements are presented in the supplementary material. } \\
\text { Characteristics of variables used in the additional models (Supplementary Table } 3.6-3.11 \text { ) are given in } \\
\text { Supplementary Table } 3.12 \text {. }\end{array}$} \\
\hline
\end{tabular}


In Figure 3.2A, the standard network for the NGM group is schematically shown. Figure 3.2B and $3.2 \mathrm{C}$ indicate for which connections the tract volumes were significantly different in prediabetes compared to NGM, and in type 2 diabetes compared to NGM, respectively. These results indicate that in prediabetes, only intra-hemispheric connections had significantly smaller tract volumes. In type 2 diabetes, both inter- and intra-hemispheric connections (of which $66 \%$ were inter-hemispheric) had significantly smaller tract volumes, especially between the frontal lobes and between the frontal and temporal lobe.

A

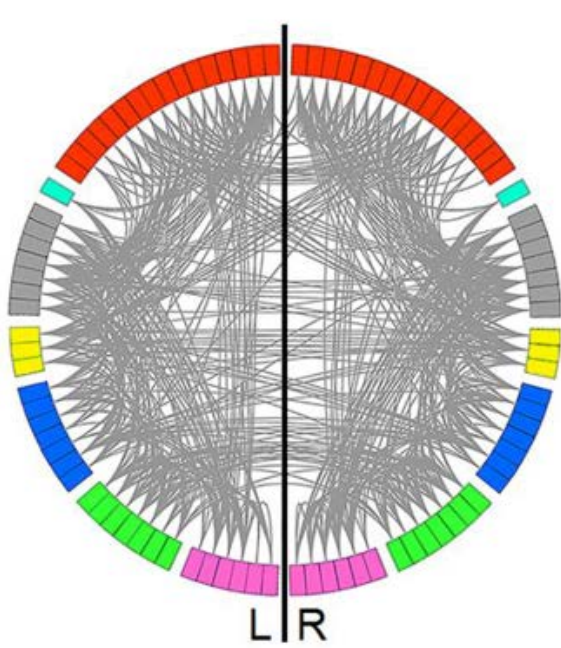

C

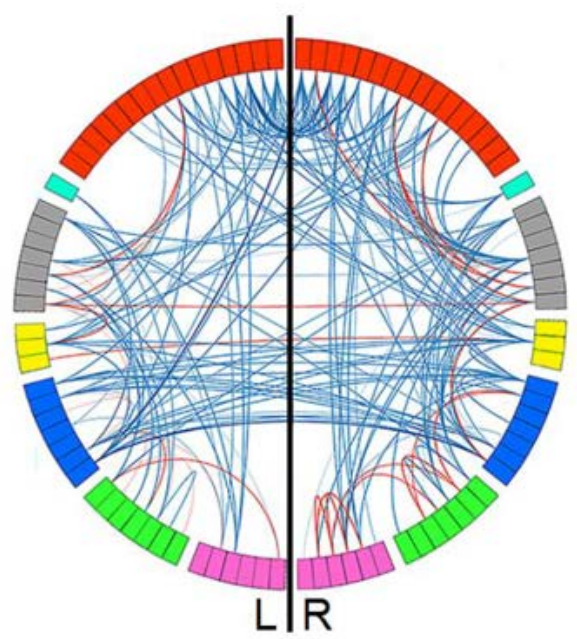

B

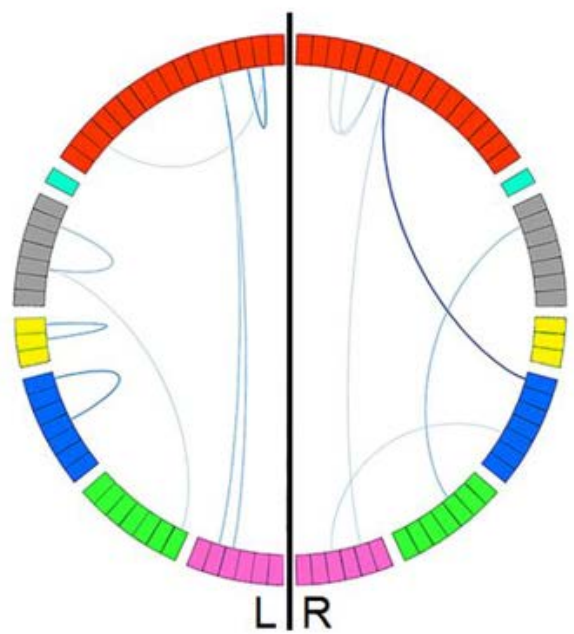

D
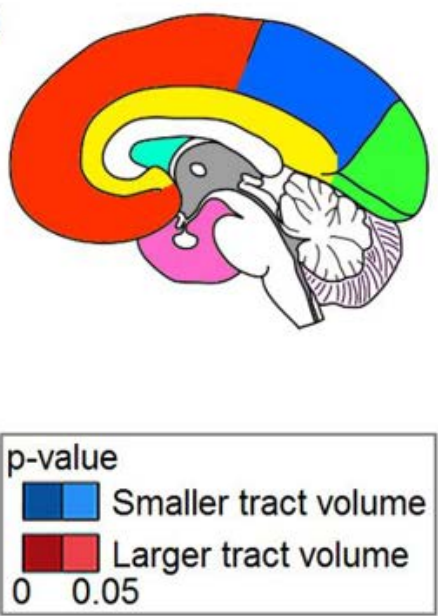

Figure 3.2: Schematic representation of connections between the atlas regions present in the NGM-based standard network (A), and those connections which had a significantly different tract volume in (B) prediabetes or (C) type 2 diabetes compared to NGM subjects. Blue connection lines indicate connections with significantly smaller tract volumes (unstandardized $B<0$ ), and red lines with significantly larger tract volumes (unstandardized $B>0$ ). $P<0.05, F D R$ corrected. Darker blue or red connection lines indicate lower $p$-values. (D) Brain regions that represent the color-coded brain regions. 
As an additional analysis, the association between WML volume and node degree was determined over all subjects. After full adjustment, relative WML volume (in \% of intracranial volume) was negatively associated with the node degree of the NGM-based standard network (st $\beta[95 \% \mathrm{Cl}]=-$ $0.059[-0.101,-0.018], p=0.001)$. This association was not present for the smaller type 2 diabetes-based standard network (st $\beta[95 \% \mathrm{Cl}]=-0.010[-0.035,0.018], p=0.714)$.

\section{Graph measures of the type 2 diabetes-based standard network}

After thresholding all individual networks by use of the prediabetes-, or type 2 diabetes-based networks, graph analysis was performed. In Table 3.2, the associations of these graph measures at a sparsity of 0.8 are shown. In the prediabetes-based standard network, prediabetes was significantly associated with a lower normalized clustering coefficient compared to NGM, which indicates a lower local connectivity. Prediabetes was also associated with a lower normalized average local efficiency. No association was found between prediabetes and the normalized global efficiency and communicability. In addition, type 2 diabetes was associated with higher communicability as compared to NGM, despite the lower node degree. The other three graph measures were not significantly associated with type 2 diabetes. Graph measures for a range of sparsity thresholds are shown in Supplementary Figure 3.2. After full adjustment, only the association with higher communicability in type 2 diabetes remained significant. No associations remained significant for prediabetes. A higher communicability was also found for higher continuous glucose measures and this remained significant after full adjustment (Supplementary Table 3.4).

Table 3.2: Associations of prediabetes and type 2 diabetes with graph network measures at a sparsity value of 0.8 .

\begin{tabular}{|c|c|c|c|c|}
\hline & Prediabetes $^{*}$ & $P$ & Type 2 diabetes $^{\dagger}$ & $P$ \\
\hline \multicolumn{5}{|c|}{ Normalized graph measures, $\beta(95 \% \mathrm{Cl})$} \\
\hline \multicolumn{5}{|l|}{ Clustering coefficient } \\
\hline Model 1 & $-0.097(-0.189,-0.005)$ & 0.049 & $-0.026(-0.111,0.059)$ & 0.562 \\
\hline Model 2 & $-0.066(-0.161,0.028)$ & 0.169 & $0.027(-0.074,0.128)$ & 0.603 \\
\hline \multicolumn{5}{|l|}{ Global efficiency } \\
\hline Model 1 & $0.034(-0.086,0.151)$ & 0.625 & $-0.056(-0.164,0.052)$ & 0.212 \\
\hline Model 2 & $0.032(-0.092,0.156)$ & 0.615 & $-0.051(-0.180,0.077)$ & 0.434 \\
\hline \multicolumn{5}{|l|}{ Local efficiency } \\
\hline Model 1 & $-0.084(-0.159,-0.008)$ & 0.033 & $-0.043(-0.113,0.027)$ & 0.208 \\
\hline Model 2 & $-0.060(-0.137,0.017)$ & 0.128 & $0.010(-0.073,0.093)$ & 0.816 \\
\hline \multicolumn{5}{|l|}{ Communicability } \\
\hline Model 1 & $0.026(-0.092,0.144)$ & 0.475 & $0.148(0.042,0.253)$ & 0.008 \\
\hline Model 2 & $0.043(-0.079,0.165)$ & 0.491 & $0.163(0.037,0.290)$ & 0.011 \\
\hline \multicolumn{5}{|c|}{$\begin{array}{l}\text { *Prediabetes-based standard network. }{ }^{+} \text {Type } 2 \text { diabetes-based standard network. Associations of prediabetes } \\
\text { and type } 2 \text { diabetes with graph measures. Regression coefficients and } 95 \% \mathrm{Cl} \text { indicate the mean difference in } \\
\text { clustering coefficient, global efficiency, local efficiency, and communicability of participants with prediabetes or } \\
\text { type } 2 \text { diabetes compared with NGM. Model } 1 \text { : Adjusted for age, sex, education, average node degree, and MRI } \\
\text { date. Model 2: Model } 1+\text { additionally adjusted for BMI, office systolic blood pressure, total cholesterol-to-HDL- } \\
\text { ratio, antihypertensive medication, lipid-lowering medication, history of cardiovascular disease. Bold values = } \\
\text { p<0.05. }\end{array}$} \\
\hline
\end{tabular}




\section{Diabetes and aging}

Multiple linear regression analysis was employed to determine the relative association of prediabetes and type 2 diabetes with node degree as compared to aging. Node degree was significantly lower in subjects with prediabetes or type 2 diabetes compared to NGM and corresponded to 2.3 or 10.4 years of aging, respectively (Supplementary Table 3.5). Adjustment for potential confounders (i.e., BMI, systolic blood pressure, total cholesterol-to-HDL-ratio, prior cardiovascular disease, and antihypertensive and lipid-lowering medication) did not substantially change these results.

There were also connections where tract volumes were significantly associated with age [Supplementary Figure 3.3A]. Please note the large similarities between connection tract volumes associated with age and type 2 diabetes. However, in type 2 diabetes, the connections between the left and right hippocampus and between right frontal and temporal regions, had significantly smaller tract volumes compared to NGM, but these connections were not associated with age [Supplementary Figure 3.3B].

\section{Discussion}

In this study, we found that both prediabetes and type 2 diabetes were associated with a lower node degree, and thus fewer white matter connections, as compared to NGM. Continuous measures of hyperglycemia (HbA1c, FBG, and 2-h post-load glucose levels) were also associated with lower node degree. Moreover, prediabetes and type 2 diabetes were associated with smaller tract volumes of several connections between cortical regions, which were comparable to those associated with aging. The lower node degree of 0.4 and $1.3 \%$ in subjects with prediabetes and type 2 diabetes, respectively, compared to NGM, was equivalent to 2 and 9 years of aging, which fits with the idea that (pre)diabetes is accompanied by accelerated aging. We also investigated the association between prediabetes and type 2 diabetes with structural organization. In prediabetes compared to NGM, the local efficiency and clustering coefficient were lower, which indicates that there was a weaker local connectivity. In type 2 diabetes compared to NGM, a higher communicability was found, indicating that in type 2 diabetes more alternative white matter connections are used to facilitate structural connectivity between brain regions.

In prediabetes, the clustering coefficient and local efficiency were lower compared to NGM, indicating that structural alterations can be observed already in prediabetes. These findings indicate that brain changes already occur, in prediabetes, before the clinical diagnosis of type 2 diabetes. Therefore, treatment of prediabetes should be considered as a potential target of intervention, for the prevention of complications of type 2 diabetes, including structural brain changes. In type 2 diabetes compared to NGM, a higher communicability was found. Communicability is a measure, which indicates the ease of communication between two brain regions, taking into account not only the shortest path, but also all other possible paths connecting them. A potential explanation for the higher communicability in type 2 diabetes compared to NGM involves the increased WML load in type 2 diabetes and prediabetes (7). The brain might be able to adapt to changing circumstances (to a small extent), and staying physically and mentally fit can possibly promote this effect $(35 ; 36)$. However, the precise pathophysiological basis of white matter alterations in patients with (pre)diabetes remains to be elucidated, and a complex interplay of endocrinological, metabolic, and vascular mechanisms is likely involved $(5 ; 7)$. 
Our findings are in line with previous studies that assessed the association between type 2 diabetes and white matter connectivity. Previous reports showed lower white matter connectivity between the hippocampus and the frontal lobe (13), and microstructural abnormalities in four major white matter tracts connecting the frontal, parietal and temporal lobe (12) in type 2 diabetes compared to a control group. In contrast, a study comparing 55 age-, sex- and education-matched individuals with type 2 diabetes with 50 non-diabetes individuals (11), found that the mean clustering coefficients and global efficiency were lower in type 2 diabetes compared to controls. However, the total number of connections in the network did not differ between the groups, and these between-group differences were independent of vascular lesion load. This difference in observations may be due to the much smaller sample size and the differences in the specific networks, which were analyzed in that study. Interestingly, altered functional connectivity, in terms of a higher clustering coefficient and high local efficiency, was found in type 2 diabetes and at a lower level in prediabetes (37), which was interpreted as a compensatory mechanism in the form of functional reorganization to counteract a decrease in cognitive performance. This is in agreement with the altered structural connectivity observed in the present study, which is indicative of alternative white matter connections in type 2 diabetes.

\section{Study considerations}

Strengths of this study are the sample size and population-based design with an oversampling of participants with type 2 diabetes, which enables an accurate comparison between the three glucose metabolism groups. The large amount of diffusion MRI scans available, were semi-automatically processed blinded to group status, which ensures an objective analysis. Other strengths were the use of HbA1c levels and a 2-hr OGTT to accurately characterize glucose metabolism; and the extensive assessment of potential confounders. In this study, most findings were robust over a large sparsity range and remained statistically significant after adjustment for potential confounders.

There are also some limitations. First, the time between baseline measurements and MRI scan might have influenced the associations observed. However, when we additionally adjusted for this, associations did not significantly change. Second, we used a single OGTT to assess (pre)diabetes status, which may result in misclassification of long-term glucose tolerance status (38). When group sizes and misclassification estimates (38) are taken into account, the net result of this misclassification is likely to be underestimation of brain abnormalities in the prediabetes group. Furthermore, individuals who underwent MRI were younger, were less likely to have type 2 diabetes, were less often current smokers and less often had a low educational level, as compared to the study population which did not undergo MRI. However, as included individuals with MRI data were relatively more healthy compared to those without MRI, our current selection may have caused us to underestimate any of the associations between glucose metabolism status with network measures. And finally, due to the cross-sectional design of the study we cannot infer any conclusion about the causality of this association. Therefore, future longitudinal studies are needed to address if hyperglycemia precedes the development of the observed brain abnormalities, which may infer causality. 


\section{Conclusion}

We showed, in a population-based study, that prediabetes, type 2 diabetes and continuous measures of hyperglycemia are associated with fewer white matter connections, and weaker organization of white matter networks. In addition, type 2 diabetes was associated with higher communicability, which was not yet observed in prediabetes, and which may reflect the use of alternative white matter connections. These findings support the concept that hyperglycemia, even in the prediabetes phase, may be harmful to the brain, and that type 2 diabetes affects the global and local organization of brain structures.

\section{References}

1. van Bussel FCG, Backes WH, Hofman PAM, van Oostenbrugge RJ, van Boxtel MPJ, Verhey FRJ, Steinbusch HWM, Schram MT, Stehouwer CDA, Wildberger JE, Jansen JFA. Cerebral Pathology and Cognition in Diabetes: The Merits of Multiparametric Neuroimaging. Front Neurosci 2017;11:188. doi: 10.3389/fnins.2017.00188

2. Biessels GJ, Reijmer YD. Brain Changes Underlying Cognitive Dysfunction in Diabetes: What Can We Learn From MRI? Diabetes 2014;63(7):2244-2252. doi: 10.2337/db14-0348

3. Geijselaers SLC, Sep SJS, Stehouwer CDA, Biessels GJ. Glucose regulation, cognition, and brain MRI in type 2 diabetes: a systematic review. The lancet Diabetes \& endocrinology 2015;3(1):75-89. doi: 10.1016/s22138587(14)70148-2

4. Awad N, Gagnon M, Messier C. The relationship between impaired glucose tolerance, type 2 diabetes, and cognitive function. J Clin Exp Neuropsychol 2004;26(8):1044-1080. doi: 10.1080/13803390490514875

5. Biessels GJ, Staekenborg S, Brunner E, Brayne C, Scheltens P. Risk of dementia in diabetes mellitus: a systematic review. The Lancet Neurology 2006;5(1):64-74. doi: 10.1016/s1474-4422(05)70284-2

6. Schneider ALC, Selvin E, Sharrett AR, Griswold M, Coresh J, Jack CR, Jr., Knopman D, Mosley T, Gottesman RF. Diabetes, Prediabetes, and Brain Volumes and Subclinical Cerebrovascular Disease on MRI: The Atherosclerosis Risk in Communities Neurocognitive Study (ARIC-NCS). Diabetes care 2017;40(11):15141521. doi: $10.2337 / \mathrm{dc} 17-1185$

7. van Agtmaal MJM, Houben A, de Wit V, Henry RMA, Schaper NC, Dagnelie PC, van der Kallen CJ, Koster A, Sep SJ, Kroon AA, Jansen JFA, Hofman PA, Backes WH, Schram MT, Stehouwer CDA. Prediabetes Is Associated With Structural Brain Abnormalities: The Maastricht Study. Diabetes care 2018;41(12):25352543. doi: $10.2337 /$ dc18-1132

8. Marseglia A, Fratiglioni L, Kalpouzos G, Wang R, Bäckman L, Xu W. Prediabetes and diabetes accelerate cognitive decline and predict microvascular lesions: A population-based cohort study. Alzheimer's \& Dementia: The Journal of the Alzheimer's Association 2019;15(1):25-33. doi: 10.1016/j.jalz.2018.06.3060

9. American Diabetes A. Diagnosis and Classification of Diabetes Mellitus. Diabetes Care 2011;34(Suppl 1):S62-S69. doi: 10.2337/dc11-S062

10. Organization WH. Global report on diabetes: World Health Organization, 2016.

11. Reijmer YD, Leemans A, Brundel M, Kappelle $L$, Biessels GJ. Disruption of the cerebral white matter network is related to slowing of information processing speed in patients with type 2 diabetes. Diabetes 2013;62(6):2112-2115. doi: 10.2337/db12-1644

12. Reijmer YD, Brundel M, de Bresser J, Kappelle $L$, Leemans A, Biessels GJ. Microstructural white matter abnormalities and cognitive functioning in type 2 diabetes: a diffusion tensor imaging study. Diabetes care 2013;36(1):137-144. doi: 10.2337/dc12-0493

13. van Bussel FC, Backes WH, Hofman PA, van Boxtel MP, Schram MT, Stehouwer CD, Wildberger JE, Jansen JF. Altered Hippocampal White Matter Connectivity in Type 2 Diabetes Mellitus and Memory Decrements. Journal of neuroendocrinology 2016;28(3):12366. doi: 10.1111/jne.12366 
14. Hsu JL, Chen YL, Leu JG, Jaw FS, Lee CH, Tsai YF, Hsu CY, Bai CH, Leemans A. Microstructural white matter abnormalities in type 2 diabetes mellitus: a diffusion tensor imaging study. Neurolmage 2012;59(2):10981105. doi: 10.1016/j.neuroimage.2011.09.041

15. Watts DJ, Strogatz SH. Collective dynamics of 'small-world' networks. Nature 1998;393:440. doi: $10.1038 / 30918$

16. Stam CJ, Reijneveld JC. Graph theoretical analysis of complex networks in the brain. Nonlinear biomedical physics 2007;1(1):3. doi: 10.1186/1753-4631-1-3

17. Bullmore E, Sporns O. Complex brain networks: graph theoretical analysis of structural and functional systems. Nature reviews Neuroscience 2009;10(3):186-198. doi: 10.1038/nrn2575

18. Schram MT, Sep SJS, van der Kallen CJ, Dagnelie PC, Koster A, Schaper N, Henry RMA, Stehouwer CDA. The Maastricht Study: an extensive phenotyping study on determinants of type 2 diabetes, its complications and its comorbidities. European Journal of Epidemiology 2014;29(6):439-451. doi: 10.1007/s10654-0149889-0

19. Organization WH. Definition and diagnosis of diabetes mellitus and intermediate hyperglycemia: report of a WHO/IDF consultation. Geneva, Switzerland2006.

20. Tzourio-Mazoyer N, Landeau B, Papathanassiou D, Crivello F, Etard O, Delcroix N, Mazoyer B, Joliot M. Automated anatomical labeling of activations in SPM using a macroscopic anatomical parcellation of the MNI MRI single-subject brain. Neuroimage 2002;15(1):273-289. doi: 10.1006/nimg.2001.0978

21. Fonov V, Evans AC, Botteron K, Almli CR, McKinstry RC, Collins DL. Unbiased average age-appropriate atlases for pediatric studies. Neurolmage 2011;54(1):313-327. doi:

https://doi.org/10.1016/j.neuroimage.2010.07.033

22. Vrooman HA, Cocosco CA, van der Lijn F, Stokking R, Ikram MA, Vernooij MW, Breteler MM, Niessen WJ. Multi-spectral brain tissue segmentation using automatically trained k-Nearest-Neighbor classification. Neurolmage 2007;37(1):71-81. doi: 10.1016/j.neuroimage.2007.05.018

23. de Boer R, Vrooman HA, van der Lijn F, Vernooij MW, Ikram MA, van der Lugt A, Breteler MM, Niessen WJ. White matter lesion extension to automatic brain tissue segmentation on MRI. Neurolmage 2009;45(4):1151-1161. doi: 10.1016/j.neuroimage.2009.01.011

24. Leemans A, Jeurissen B, Sijbers J, Jones D. ExploreDTI: a graphical toolbox for processing, analyzing, and visualizing diffusion MR data. ISMRM 17th Scientific Meeting \& Exhibition2009; p. 3537.

25. Tournier JD, Calamante F, Connelly A. Determination of the appropriate b value and number of gradient directions for high-angular-resolution diffusion-weighted imaging. NMR in Biomedicine 2013;26(12):17751786. doi: 10.1002/nbm.3017

26. Jeurissen B, Leemans A, Jones DK, Tournier J-D, Sijbers J. Probabilistic fiber tracking using the residual bootstrap with constrained spherical deconvolution. Human Brain Mapping 2011;32(3):461-479. doi: 10.1002/hbm.21032

27. Vaessen MJ, Jansen JFA, Vlooswijk MCG, Hofman PAM, Majoie HJM, Aldenkamp AP, Backes WH. White Matter Network Abnormalities Are Associated with Cognitive Decline in Chronic Epilepsy. Cerebral Cortex 2011;22(9):2139-2147. doi: 10.1093/cercor/bhr298

28. Whitwell JL, Crum WR, Watt HC, Fox NC. Normalization of cerebral volumes by use of intracranial volume: implications for longitudinal quantitative MR imaging. AJNR Am J Neuroradiol 2001;22(8):1483-1489.

29. Rubinov M, Sporns O. Complex network measures of brain connectivity: uses and interpretations. Neurolmage 2010;52(3):1059-1069. doi: 10.1016/j.neuroimage.2009.10.003

30. Latora V, Marchiori M. Efficient behavior of small-world networks. Physical review letters 2001;87(19):198701. doi: 10.1103/PhysRevLett.87.198701

31. Estrada E, Hatano N, Benzi M. The physics of communicability in complex networks. Physics Reports 2012;514(3):89-119. doi: https://doi.org/10.1016/j.physrep.2012.01.006

32. de Reus MA, van den Heuvel MP. Estimating false positives and negatives in brain networks. Neurolmage 2013;70:402-409. doi: 10.1016/j.neuroimage.2012.12.066 
33. Watts DJ, Strogatz SH. Collective dynamics of 'small-world' networks. Nature 1998;393(6684):440-442. doi: $10.1038 / 30918$

34. van den Heuvel MP, Sporns O. Rich-Club Organization of the Human Connectome. The Journal of Neuroscience 2011;31(44):15775-15786. doi: 10.1523/jneurosci.3539-11.2011

35. Sexton CE, Betts JF, Demnitz N, Dawes H, Ebmeier KP, Johansen-Berg H. A systematic review of MRI studies examining the relationship between physical fitness and activity and the white matter of the ageing brain. Neurolmage 2016;131:81-90. doi: 10.1016/j.neuroimage.2015.09.071

36. Phillips C. Lifestyle Modulators of Neuroplasticity: How Physical Activity, Mental Engagement, and Diet Promote Cognitive Health during Aging. Neural Plast 2017;2017:3589271-3589271. doi: $10.1155 / 2017 / 3589271$

37. van Bussel FC, Backes WH, van Veenendaal TM, Hofman PA, van Boxtel MP, Schram MT, Sep SJ, Dagnelie PC, Schaper N, Stehouwer CD, Wildberger JE, Jansen JF. Functional Brain Networks Are Altered in Type 2 Diabetes and Prediabetes: Signs for Compensation of Cognitive Decrements? The Maastricht Study. Diabetes 2016;65(8):2404-2413. doi: 10.2337/db16-0128

38. Mooy JM, Grootenhuis PA, de Vries H, Kostense PJ, Popp-Snijders C, Bouter LM, Heine RJ. Intra-individual variation of glucose, specific insulin and proinsulin concentrations measured by two oral glucose tolerance tests in a general Caucasian population: the Hoorn Study. Diabetologia 1996;39(3):298-305. 


\section{Supplementary Material}

\section{Detailed protocols of the measurements performed within The}

\section{Maastricht Study:}

Questionnaires. As described elsewhere (1), we used web-based questionnaires to obtain information regarding smoking status (never/former/current), alcohol consumption, educational level, physical activity, diet, prior CVD and cognitive impairment. Alcohol consumption was classified as none, low (1- 7 glasses/wk for women and 1-14 glasses/wk for men) and high (> 7 glasses/wk for women and $>14$ glasses/wk for men). Educational level was classified as low (no education, primary education, lower vocational education), intermediate (intermediate general secondary education, intermediate vocational education, higher general secondary education), or high (higher vocational education or university). Physical activity was assessed by means of a modified version of the Champs questionnaire. Diet was assessed by a tailor-made FFQ developed by use of the National FFQ Tool. Prior CVD was defined as a history of myocardial infarction; stroke; or vascular surgery (including angioplasty) on coronary, carotid, abdominal aortic, or peripheral arteries, and prior CVA as history of cerebrovascular accident (stroke, or TIA), both based on the Rose questionnaire. Cognitive impairment was measured using the Mini-Mental State Examination (MMSE). Five participants had a MMSE score of 22 or $23(\mathrm{MCl})$ and none had dementia Medication use was assessed in a medication interview where generic name, dose, and frequency were registered.

Laboratory assessments. Plasma glucose is measured with a standard enzymatic hexokinase reference method, and serum total cholesterol, HDL cholesterol, and triglycerides are measured with standard (enzymatic and/or colorimetric) methods by an automatic analyzer (until 9 May 2012: Beckman Synchron LX20, Beckman Coulter Inc., Brea, USA; after 9 May 2012: Cobas 6000, Roche diagnostics, Mannheim, Germany). When appropriate LDL cholesterol is calculated according to the Friedewald formula (2). $\mathrm{HbA1C}$ is measured with ion-exchange high performance liquid chromatography (HPLC) (Variant tm II, Bio-Rad, Hercules, California, USA).

Physical examination. Weight and height are measured without shoes and wearing light clothing using a scale and stadiometer to the nearest $0.5 \mathrm{~kg}$ or $0.1 \mathrm{~cm}$ (Seca, Hamburg, Germany). Waist circumference is measured with a flexible plastic tape measure (Seca, Hamburg, Germany) in a duplicate midway between the lower rib margin and the iliac crest at the end of expiration, to the nearest $0.5 \mathrm{~cm}$.

Blood pressure. Office blood pressure is determined three times on the right arm after a 10-minute rest period, using a non-invasive blood pressure monitor (Omron 705IT, Japan). When the difference between measurement two and three is more than $10 \mathrm{mmHg}$, a fourth measurement is performed. All available measurements are used to calculate the average blood pressure. Ambulatory 24-h blood pressure (WatchBP 03, Microlife, Switzerland, respectively) is measured at the non-dominant arm, using an ambulatory device that is programmed to take blood pressure readings every 15 minutes from $8.00-$ 23.00 and every 30 minutes from $23.00-8.00$. 


\section{Additional analyses}

With regard to the node degree analyses, the associations of prediabetes and type 2 diabetes, remained unchanged when substituting office systolic blood pressure for 24 - hour ambulatory systolic blood pressure (24-hour ambulatory blood pressure was available in $n=1888$ individuals; Supplementary Table 6) or substituting BMI for waist circumference (Supplementary Table 7), or further adjustment for lifestyle factors, i.e., smoking status, alcohol use, physical activity, and diet score (data available for $n=1825$, Supplementary Table 8). Furthermore, in the analyses of graph measures, the association of prediabetes and type 2 diabetes remained also unchanged when substituting office systolic blood pressure for 24- hour ambulatory systolic blood pressure (24-hour ambulatory blood pressure was available in $\mathrm{n}=1888$ individuals; Supplementary Table 9) or substituting BMI for waist circumference (Supplementary Table 10), or further adjustment for lifestyle factors (data available for $n=1825$, Supplementary Table 10).

\section{Commentary on Supplementary Figure 2}

We want to emphasize that we depicted the normalized graph measures in the figure. These normalized graph measured show a different behavior with varying sparsity values compared to the not normalized graph measures, and are more different to interpret. However, normalization is necessary for comparisons between groups (3). In more detail: Normalized clustering coefficient increased with sparsity, with the removal of connections at increasing sparsity, the proportion of connections between the nodes within its neighborhood divided by the number of connections that theoretically could exist between them, will decrease. However, since the clustering coefficient is normalized to a random network, for which the proportional decrease is larger, the normalized clustering coefficient thus increases at increasing sparsity (this was also found in the study of van Wijk et al. (4)). The normalized local efficiency is related to the normalized clustering coefficient, and will therefore show the same behavior. Since the connection-weights represent tract volumes, and since the structural connections taken into account are mostly short (intra-hemispheric) tracts with a small volume, the structural global efficiency is calculated using low connection strengths that increases with sparsity.

\section{Supplemental References}

1. Schram MT, Sep SJ, van der Kallen CJ, Dagnelie PC, Koster A, Schaper N, Henry RM, Stehouwer CD. The Maastricht Study: an extensive phenotyping study on determinants of type 2 diabetes, its complications and its comorbidities. Eur J Epidemiol 2014;29(6):439-451. doi: 10.1007/s10654-014-9889-0

2. Friedewald WT, Levy RI, Fredrickson DS. Estimation of the concentration of low-density lipoprotein cholesterol in plasma, without use of the preparative ultracentrifuge. Clin Chem 1972;18(6):499-502.

3. Maslov S, Sneppen K. Specificity and stability in topology of protein networks. Science (New York, NY) 2002;296(5569):910-913. doi: 10.1126/science.1065103

4. van Wijk BC, Stam CJ, Daffertshofer A. Comparing brain networks of different size and connectivity density using graph theory. PloS one 2010;5(10):e13701. doi: 10.1371/journal.pone.0013701 


\section{Supplementary Figures}

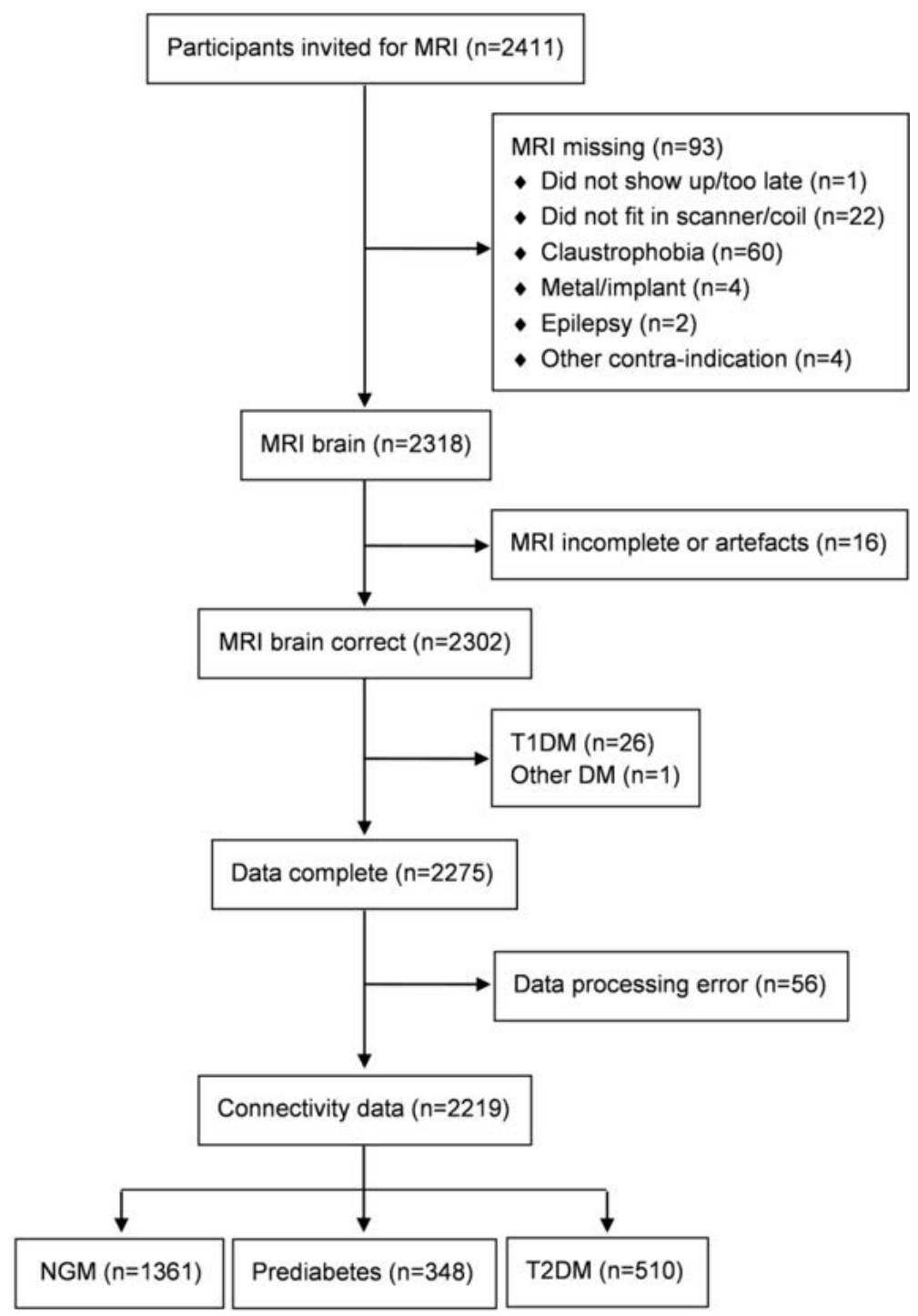

Supplementary Figure 3.1: Flowchart of the study population. The time lag between baseline assessment and MRI was $2.3 \pm 1.3$ years (mean \pm standard deviation). 

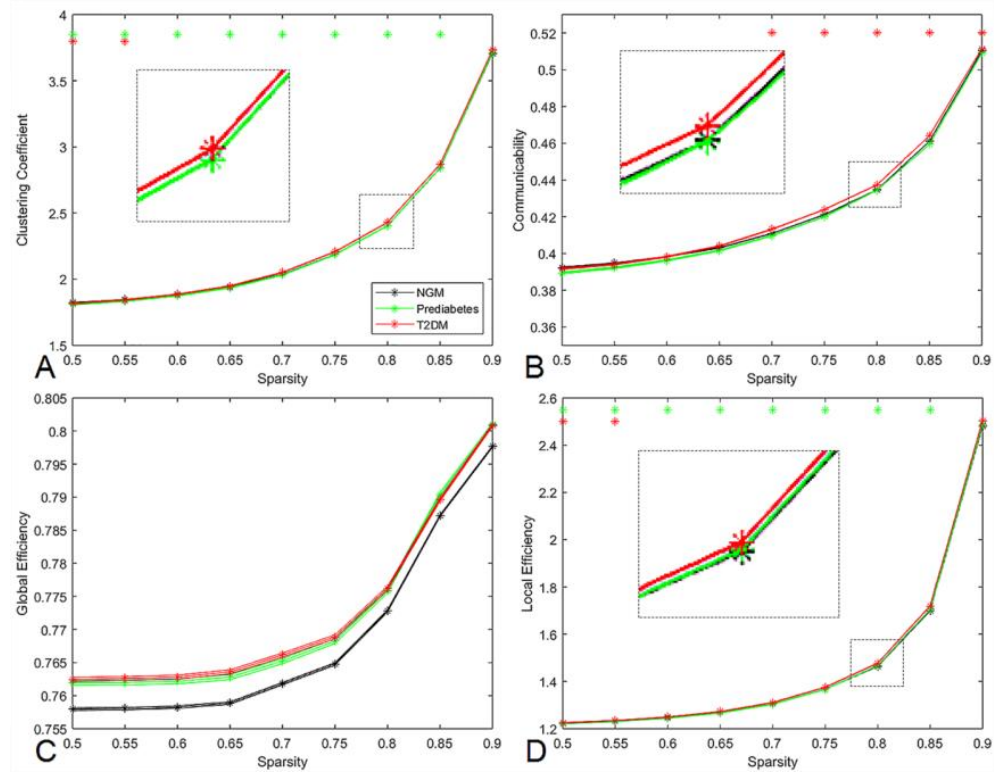

Supplementary Figure 3.2: Normalized graph measures over a range a sparsity values for participants with type 2 diabetes, prediabetes, and NGM. SEM = standard error of mean. *= sparsity values analyzed. All graph measures were normalized to random networks (see additional comment in the Supplementary Material on page 3). * = p-value $<0.05$, red for type 2 diabetes compared to NGM and green for prediabetes compared to NGM. (A) Clustering coefficient. (B) Communicability. (C) Global efficiency, and (D) Local efficiency.
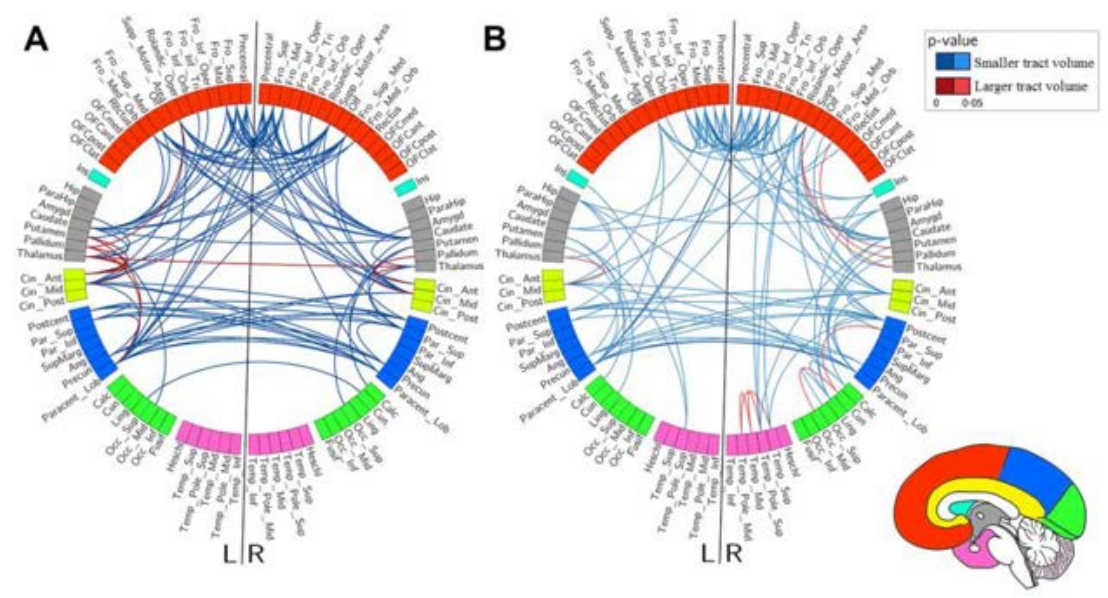

Supplementary Figure 3.3: Schematic representation of connections between the atlas regions which had a significantly different tract volume for (A) higher age, and (B) in type 2 diabetes compared to NGM. Blue lines indicate connections with significantly lower tract volumes (unstandardized $B<0$ ), and red lines with significantly higher tract volumes (unstandardized $B>0$ ). For the comparison of type 2 diabetes with normal aging only the 100 connections with the lowest $p$-values (all $p$-values were $<0.05$ ) were visualized. Darker blue or red lines indicate lower p-values. 


\section{Supplementary Tables}

Supplementary Table 3.1: General characteristics of the study population with and without brain MRI data.

\begin{tabular}{|c|c|c|c|}
\hline Characteristic & $\begin{array}{l}\text { Study population } \\
(n=2219)\end{array}$ & $\begin{array}{l}\text { No brain MRI } \\
\text { data available } \\
(n=1232)\end{array}$ & $P$ value \\
\hline \multicolumn{4}{|l|}{ Demographics } \\
\hline Age (years) & $59.3 \pm 8.2$ & $60.6 \pm 8.3$ & $<0.001$ \\
\hline Sex, male (\%) & 51.5 & 51.3 & 0.905 \\
\hline Education level (\%), Low/Middle/High & $30.2 / 29.0 / 40.7$ & $39.7 / 26.8 / 33.5$ & $<0.001$ \\
\hline \multicolumn{4}{|l|}{ Glucose metabolism } \\
\hline Type 2 diabetes (\%) & 23.0 & 37.7 & $<0.001$ \\
\hline Fasting blood glucose (mmol/l) & $5.9 \pm 1.5$ & $6.5 \pm 2.2$ & $<0.001$ \\
\hline $2 \mathrm{~h}$ post-load glucose $(\mathrm{mmol} / \mathrm{l})$ & $7.5 \pm 4.0$ & $8.8 \pm 4.6$ & $<0.001$ \\
\hline $\mathrm{HbA}_{1 \mathrm{c}}(\%)$ & $5.8 \pm 0.8$ & $6.2 \pm 1.1$ & $<0.001$ \\
\hline $\mathrm{HbA}_{1 \mathrm{c}}(\mathrm{mmol} / \mathrm{mol})$ & $40.0 \pm 8.9$ & $43.9 \pm 12.0$ & $<0.001$ \\
\hline Diabetes duration* (years) & $6.9 \pm 7.2$ & $7.3 \pm 1.1$ & 0.449 \\
\hline \multicolumn{4}{|l|}{ Cardiovascular risk factors } \\
\hline $\mathrm{BMI}\left(\mathrm{kg} / \mathrm{m}^{2}\right)$ & $26.6 \pm 4.2$ & $27.9 \pm 5.1$ & $<0.001$ \\
\hline Waist circumference $(\mathrm{cm})$ & $94.5 \pm 12.8$ & $98.5 \pm 15.1$ & $<0.001$ \\
\hline Office systolic blood pressure (mmHg) & $133 \pm 17$ & $137 \pm 20$ & $<0.001$ \\
\hline Office diastolic blood pressure (mmHg) & $76 \pm 10$ & $76 \pm 10$ & 0.320 \\
\hline Hypertension, yes (\%) & 52.1 & 61.0 & $<0.001$ \\
\hline Total cholesterol (mmol/L) & $5.3 \pm 1.1$ & $5.0 \pm 1.2$ & $<0.001$ \\
\hline HDL cholesterol ( $\mathrm{mmol} / \mathrm{L})$ & $1.6 \pm 0.5$ & $1.5 \pm 0.5$ & $<0.001$ \\
\hline LDL cholesterol (mmol/L) & $3.2 \pm 1.0$ & $2.9 \pm 1.0$ & $<0.001$ \\
\hline Triglyceride levels (mmol/L) & $1.4 \pm 0.8$ & $1.5 \pm 0.9$ & $<0.001$ \\
\hline Total cholesterol-to-HDL-ratio & $3.7 \pm 1.2$ & $3.7 \pm 1.2$ & 0.283 \\
\hline History of cardiovascular disease, yes (\%) & 12.1 & 25.1 & $<0.001$ \\
\hline \multicolumn{4}{|l|}{ Medication use } \\
\hline Insulin use, yes $(\%)^{*}$ & 19.6 & 33.8 & $<0.001$ \\
\hline Antihypertensive medication, yes (\%) & 34.9 & 49.2 & $<0.001$ \\
\hline Lipid-modifying medication, yes (\%) & 30.7 & 47.0 & $<0.001$ \\
\hline \multicolumn{4}{|l|}{ Lifestyle factors } \\
\hline Alcohol consumption (\%), None/Low/High & $17.1 / 55.9 / 27.9$ & $21.3 / 54.6 / 24.1$ & 0.003 \\
\hline Smoking status (\%), Never/Former/Current & $37.4 / 50.8 / 11.8$ & $29.3 / 53.1 / 17.7$ & $<0.001$ \\
\hline \multicolumn{4}{|l|}{ Cognitive score } \\
\hline MMSE total score & $29.0 \pm 1.2$ & $28.7 \pm 1.4$ & $<0.001$ \\
\hline
\end{tabular}


Supplementary Table 3.2: Associations of prediabetes and type 2 diabetes with node degree.

\begin{tabular}{|c|c|c|c|}
\hline & Prediabetes & Type 2 diabetes & $P_{\text {trend }}$ \\
\hline Node degree & standardized $\beta(95 \% \mathrm{Cl})$ & standardized $\beta(95 \% \mathrm{Cl})$ & \\
\hline \multicolumn{4}{|l|}{ Unthresholded network } \\
\hline Model 1 & $-0.044(-0.164,0.076)$ & $-0.111(-0.220,-0.002)$ & 0.047 \\
\hline Model 2 & $-0.060(-0.183,0.063)$ & $-0.151(-0.280,-0.022)$ & 0.022 \\
\hline \multicolumn{4}{|l|}{ NGM-based network } \\
\hline Model 1 & $-0.066(-0.181,0.048)$ & $-0.296(-0.400,-0.191)$ & $<0.001$ \\
\hline Model 2 & $-0.055(-0.172,0.062)$ & $-0.256(-0.379,-0.133)$ & $<0.001$ \\
\hline \multicolumn{4}{|l|}{ Type 2 diabetes-based network } \\
\hline Model 1 & $-0.055(-0.174,0.064)$ & $-0.135(-0.243,-0.027)$ & 0.015 \\
\hline Model 2 & $-0.071(-0.193,0.050)$ & $-0.168(-0.296,-0.040)$ & 0.010 \\
\hline \multicolumn{4}{|c|}{$\begin{array}{l}\text { Associations of prediabetes and type } 2 \text { diabetes with node degree, with NGM as reference. Regression } \\
\text { coefficients and } 95 \% \mathrm{Cl} \text { indicate the mean difference in node degree of participants with prediabetes or type } 2 \\
\text { diabetes compared with NGM. Model } 1 \text { : Adjusted for age, sex, education, and MRI date. Model 2: Model } 1+ \\
\text { additionally adjusted for BMI, office systolic blood pressure, total cholesterol-to-HDL-ratio, antihypertensive } \\
\text { medication, lipid-lowering medication, history of cardiovascular disease. Bold values }=p<0.05 \text {. }\end{array}$} \\
\hline
\end{tabular}




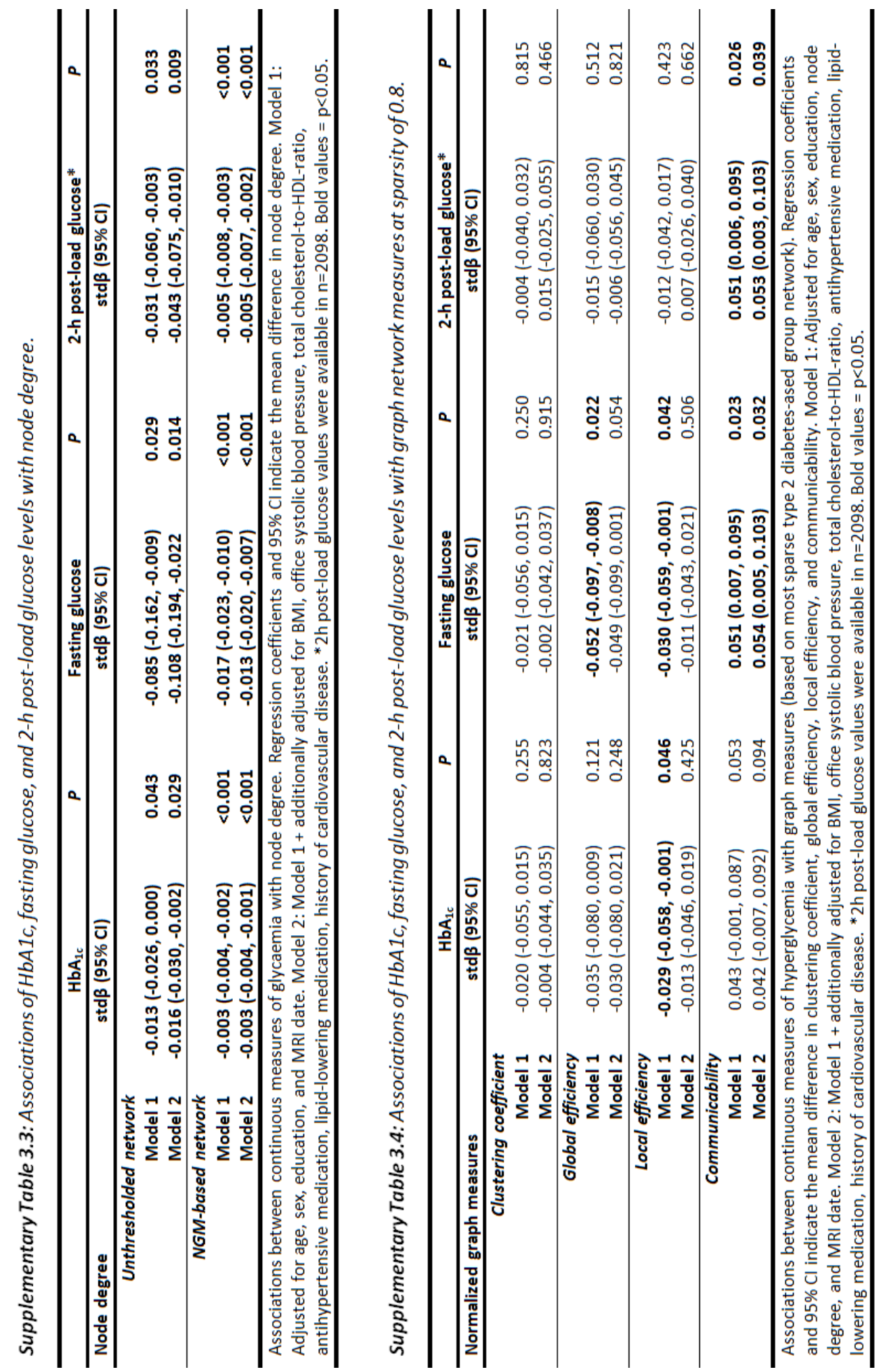


Supplementary Table 3.5: Relative change for (pre)diabetes and age in node degree.

\begin{tabular}{|c|c|c|c|c|}
\hline & & & \multicolumn{2}{|l|}{ Node degree* $^{*}$} \\
\hline & & & standardized $\beta$ (95\%) & p-value \\
\hline \multirow[t]{7}{*}{ Model $1^{+}$} & Prediabetes & & $-0.024(-0.065,0.017)$ & 0.258 \\
\hline & Type 2 diab & petes & $-0.134(-0.181,-0.086)$ & $<0.001$ \\
\hline & Age & & $-0.236(-0.279,-0.194)$ & $<0.001$ \\
\hline & $\underline{\beta_{\text {Prediabetes }} .}$. & $S D_{\text {Age }}$ & \multirow{2}{*}{\multicolumn{2}{|c|}{2.3 years }} \\
\hline & $\beta_{\text {Age }}$ & $\overline{S D_{\text {Prediabetes }}}$ & & \\
\hline & $\underline{\beta_{\text {Type2diabetes }}}$ & $\underline{s} \cdot \underline{S D_{A g e}}$ & \multirow{2}{*}{10.4 years } & \\
\hline & $\beta_{\text {Age }}$ & $\overline{S D_{\text {Type2diabetes }}}$ & & \\
\hline \multirow[t]{7}{*}{ Model $2^{\ddagger}$} & Prediabetes & & $-0.020(-0.061,0.022)$ & 0.357 \\
\hline & Type 2 diab & petes & $-0.116(-0.171,-0.060)$ & $<0.001$ \\
\hline & Age & & $-0.219(-0.264,-0.174)$ & $<0.001$ \\
\hline & $\underline{\beta_{\text {Prediabetes }}}$. & $S D_{\text {Age }}$ & \multirow{2}{*}{\multicolumn{2}{|c|}{2.1 years }} \\
\hline & $\beta_{\text {Age }}$ & $\overline{S D_{\text {Prediabetes }}}$ & & \\
\hline & $\underline{\beta_{\text {Type } 2 \text { diabetes }}}$ & $S D_{\text {Age }}$ & \multirow{2}{*}{9.7 years } & \\
\hline & $\beta_{\text {Age }}$ & $\overline{S D_{\text {Type2diabetes }}}$ & & \\
\hline \multicolumn{5}{|c|}{$\begin{array}{l}{ }^{*} \text { Node degree for entire dataset }(\mathrm{n}=2219) \text {, calculated in NGM-based standard network. } \\
{ }^{+} \text {Additionally adjusted for sex, education, and MRI date. }{ }^{\ddagger} \text { Model } 1+\text { additionally adjusted } \\
\text { for BMI, office systolic blood pressure, total-cholesterol-to-HDL-ratio, antihypertensive } \\
\text { medication, lipid-lowering medication, history of cardiovascular disease. Bold values }=\mathrm{p}<0.05 \text {. }\end{array}$} \\
\hline
\end{tabular}

Supplementary Table 3.6: Associations of prediabetes and type 2 diabetes with node degree, with replacement of office by 24-h systolic ambulatory blood pressure in regression models.

\begin{tabular}{|c|c|c|c|}
\hline & Prediabetes & Type 2 diabetes & $P_{\text {trend }}$ \\
\hline Node degree & standardized $\beta(95 \% \mathrm{Cl})$ & standardized $\beta(95 \% \mathrm{Cl})$ & \\
\hline \multicolumn{4}{|l|}{ Unthresholded network } \\
\hline Model 1 & $-0.058(-0.189,0.072)$ & $-0.169(-0.287,-0.051)$ & 0.005 \\
\hline Model 2 & $-0.078(-0.211,0.055)$ & $-0.234(-0.371,-0.097)$ & 0.001 \\
\hline \multicolumn{4}{|l|}{ NGM-based network } \\
\hline Model 1 & $-0.068(-0.194,0.058)$ & $-0.279(-0.393,-0.166)$ & $<0.001$ \\
\hline Model 2 & $-0.063(-0.192,0.065)$ & $-0.259(-0.392,-0.127)$ & $<0.001$ \\
\hline \multicolumn{4}{|l|}{ Type 2 diabetes-based network } \\
\hline Model 1 & $-0.057(-0.189,0.074)$ & $-0.150(-0.269,-0.032)$ & 0.013 \\
\hline Model 2 & $-0.077(-0.211,0.057)$ & $-0.201(-0.340,-0.063)$ & 0.004 \\
\hline \multicolumn{4}{|c|}{$\begin{array}{l}\text { Associations of prediabetes and type } 2 \text { diabetes with node degree, with NGM as reference. Regression } \\
\text { coefficients and } 95 \% \mathrm{Cl} \text { indicate the mean difference in node degree of participants with prediabetes or type } 2 \\
\text { diabetes compared with NGM. Model } 1 \text { : Adjusted for age, sex, education, and MRI date. Model } 2 \text { : Model } 1+ \\
\text { additionally adjusted for BMI, 24-h systolic ambulatory blood pressure, total cholesterol-to-HDL-ratio, } \\
\text { antihypertensive medication, lipid-lowering medication, history of cardiovascular disease. Data were available } \\
\text { in } \mathrm{n}=1888 \text { individuals (type } 2 \text { diabetes/prediabetes/NGM, } 437 / 293 / 1158 \text {, respectively). Bold values }=p<0.05 \text {. }\end{array}$} \\
\hline
\end{tabular}


Supplementary Table 3.7: Associations of prediabetes and type 2 diabetes with node degree, with replacement of $B M I$ by waist circumference in regression models.

\begin{tabular}{|c|c|c|c|}
\hline & Prediabetes & Type 2 diabetes & $P_{\text {trend }}$ \\
\hline Node degree & standardized $\beta(95 \% \mathrm{Cl})$ & standardized $\beta(95 \% \mathrm{Cl})$ & \\
\hline \multicolumn{4}{|l|}{ Unthresholded network } \\
\hline Model 1 & $-0.043(-0.163,0.077)$ & $-0.111(-0.220,-0.002)$ & 0.047 \\
\hline Model 2 & $-0.054(-0.177,0.069)$ & $-0.139(-0.270,-0.009)$ & 0.037 \\
\hline \multicolumn{4}{|l|}{ NGM-based network } \\
\hline Model 1 & $-0.066(-0.181,0.049)$ & $-0.296(-0.400,-0.191)$ & $<0.001$ \\
\hline Model 2 & $-0.055(-0.172,0.062)$ & $-0.256(-0.380,-0.131)$ & $<0.001$ \\
\hline \multicolumn{4}{|l|}{ Type 2 diabetes-based network } \\
\hline Model 1 & $-0.054(-0.173,0.065)$ & $-0.135(-0.243,-0.027)$ & 0.015 \\
\hline Model 2 & $-0.070(-0.192,0.052)$ & $-0.168(-0.295,-0.037)$ & 0.012 \\
\hline
\end{tabular}

Associations of prediabetes and type 2 diabetes with node degree, with NGM as reference. Regression coefficients and $95 \% \mathrm{Cl}$ indicate the mean difference in node degree of participants with prediabetes or type 2 diabetes compared with NGM. Model 1: Adjusted for age, sex, education, and MRI date. Model 2: Model $1+$ additionally adjusted for waist circumference, office systolic blood pressure, total cholesterol-to-HDL-ratio, antihypertensive medication, lipid-lowering medication, history of cardiovascular disease. Data were available in $n=2218$ individuals (type 2 diabetes/prediabetes/NGM, 510/348/1360, respectively). Bold values $=p<0.05$.

Supplementary Table 3.8: Associations of prediabetes and type 2 diabetes with node degree, additionally adjusted for lifestyle factors.

\begin{tabular}{|c|c|c|c|}
\hline & Prediabetes & Type 2 diabetes & $P_{\text {trend }}$ \\
\hline Node degree & standardized $\beta(95 \% \mathrm{Cl})$ & standardized $\beta(95 \% \mathrm{Cl})$ & \\
\hline \multicolumn{4}{|l|}{ Unthresholded network } \\
\hline Model 1 & $-0.009(-0.139,0.120)$ & $-0.126(-0.246,-0.006)$ & 0.054 \\
\hline Model 2 & $-0.030(-0.162,0.103)$ & $-0.179(-0.321,-0.037)$ & 0.020 \\
\hline Model 3 & $-0.027(-0.160,0.106)$ & $-0.174(-0.318,-0.031)$ & 0.026 \\
\hline \multicolumn{4}{|l|}{ NGM-based network } \\
\hline Model 1 & $-0.066(-0.188,0.055)$ & $-0.320(-0.433,-0.207)$ & $<0.001$ \\
\hline Model 2 & $-0.047(-0.171,0.078)$ & $-0.264(-0.397,-0.130)$ & $<0.001$ \\
\hline Model 3 & $-0.041(-0.165,0.084)$ & $-0.253(-0.388,-0.118)$ & 0.001 \\
\hline \multicolumn{4}{|l|}{ Type 2 diabetes-based network } \\
\hline Model 1 & $-0.035(-0.163,0.093)$ & $-0.168(-0.287,-0.049)$ & 0.008 \\
\hline Model 2 & $-0.048(-0.179,0.083)$ & $-0.188(-0.329,-0.047)$ & 0.012 \\
\hline Model 3 & $-0.044(-0.175,0.087)$ & $-0.176(-0.318,-0.034)$ & 0.020 \\
\hline
\end{tabular}

Associations of prediabetes and type 2 diabetes with node degree, with NGM as reference. Regression coefficients and $95 \% \mathrm{Cl}$ indicate the mean difference in node degree of participants with prediabetes or type 2 diabetes compared with NGM. Model 1: Adjusted for age, sex, education, and MRI date. Model 2: Model $1+$ additionally adjusted for BMI, office systolic blood pressure, total cholesterol-to-HDL-ratio, antihypertensive medication, lipid-lowering medication, history of cardiovascular disease. Model 3: Model 2 + additionally adjusted for smoking status, alcohol use, physical activity and diet score. Bold values $=p<0.05$. Physical activity and diet score data were available in $n=1825$ individuals (388/294/1143 for type 2 diabetes/prediabetes/NGM, respectively). 
Supplementary Table 3.9: Associations of prediabetes and type 2 diabetes with graph network measures at a sparsity value of 0.8 , with replacement of office by 24-h systolic ambulatory blood pressure in regression models.

\begin{tabular}{|c|c|c|c|c|}
\hline & Prediabetes* & $P$ & Type 2 diabetes $^{\dagger}$ & $P$ \\
\hline \multicolumn{5}{|c|}{ Normalized graph measures, $\beta$ (95\% Cl) } \\
\hline \multicolumn{5}{|l|}{ Clustering coefficient } \\
\hline Model 1 & $-0.110(-0.210,-0.009)$ & 0.032 & $-0.036(-0.128,0.056)$ & 0.448 \\
\hline Model 2 & $-0.085(-0.188,0.017)$ & 0.103 & $0.024(-0.083,0.131)$ & 0.665 \\
\hline \multicolumn{5}{|l|}{ Global efficiency } \\
\hline Model 1 & $0.015(-0.117,0.147)$ & 0.820 & $-0.071(-0.188,0.046)$ & 0.235 \\
\hline Model 2 & $0.028(-0.107,0.163)$ & 0.683 & $-0.021(-0.158,0.116)$ & 0.762 \\
\hline \multicolumn{5}{|l|}{ Local efficiency } \\
\hline Model 1 & $-0.093(-0.175,-0.011)$ & 0.027 & $-0.050(-0.126,0.025)$ & 0.191 \\
\hline Model 2 & $-0.073(-0.157,0.011)$ & 0.087 & $0.012(-0.076,0.099)$ & 0.794 \\
\hline \multicolumn{5}{|l|}{ Communicability } \\
\hline Model 1 & $0.032(-0.097,0.162)$ & 0.622 & $0.165(0.048,0.282)$ & 0.006 \\
\hline Model 2 & $0.047(-0.086,0.179)$ & 0.490 & $0.173(0.037,0.310)$ & 0.013 \\
\hline \multicolumn{5}{|c|}{$\begin{array}{l}\text { *Prediabetes-based standard network. }{ }^{+} \text {Type } 2 \text { diabetes-based standard network. Associations of prediabetes and type } \\
2 \text { diabetes with graph measures. Regression coefficients and } 95 \% \mathrm{Cl} \text { indicate mean difference in clustering coefficient, } \\
\text { global efficiency, local efficiency, and communicability of participants with prediabetes or type } 2 \text { diabetes compared } \\
\text { with NGM. Model 1: Adjusted for age, sex, education, node degree, and MRI date. Model } 2 \text { : additionally adjusted for } \\
\text { BMI, } 24 \text {-h systolic ambulatory blood pressure, total cholesterol-to-HDL-ratio, antihypertensive medication, lipid- } \\
\text { lowering medication, history of cardiovascular disease. Data were available in n=1888 individuals (type } 2 \\
\text { diabetes/prediabetes/NGM, } 437 / 293 / 1158 \text {, respectively). Bold values } p<0.05 \text {. }\end{array}$} \\
\hline
\end{tabular}

Supplementary Table 3.10: Associations of prediabetes and type 2 diabetes with graph network measures at a sparsity value of 0.8 , with replacement of $B M I$ by waist circumference in regression models.

\begin{tabular}{|c|c|c|c|c|}
\hline & Prediabetes ${ }^{*}$ & $\mathrm{P}$ & Type 2 diabetes ${ }^{\dagger}$ & $\mathrm{P}$ \\
\hline \multicolumn{5}{|c|}{ Normalized graph measures, $\beta$ (95\% Cl) } \\
\hline \multicolumn{5}{|l|}{ Clustering coefficient } \\
\hline Model 1 & $-0.092(-0.185,0.000)$ & 0.050 & $-0.025(-0.112,0.061)$ & 0.562 \\
\hline Model 2 & $-0.067(-0.162,0.028)$ & 0.168 & $0.035(-0.067,0.137)$ & 0.500 \\
\hline \multicolumn{5}{|l|}{ Global efficiency } \\
\hline Model 1 & $0.030(-0.091,0.151)$ & 0.624 & $-0.069(-0.178,0.040)$ & 0.212 \\
\hline Model 2 & $0.049(-0.076,0.173)$ & 0.445 & $-0.014(-0.144,0.116)$ & 0.836 \\
\hline \multicolumn{5}{|l|}{ Local efficiency } \\
\hline Model 1 & $-0.082(-0.157,-0.006)$ & 0.034 & $-0.045(-0.116,0.025)$ & 0.208 \\
\hline Model 2 & $-0.057(-0.135,0.020)$ & 0.148 & $0.022(-0.062,0.105)$ & 0.615 \\
\hline \multicolumn{5}{|l|}{ Communicability } \\
\hline Model 1 & $0.029(-0.090,0.147)$ & 0.475 & $0.146(0.039,0.253)$ & 0.008 \\
\hline Model 2 & $0.035(-0.087,0.157)$ & 0.577 & $0.154(0.026,0.282)$ & 0.018 \\
\hline \multicolumn{5}{|c|}{$\begin{array}{l}\text { *Prediabetes-based standard network. }{ }^{\dagger} \text { Type } 2 \text { diabetes-based standard network. Associations of prediabetes and type } \\
2 \text { diabetes with graph measures. Regression coefficients and } 95 \% \mathrm{Cl} \text { indicate mean difference in clustering coefficient, } \\
\text { global efficiency, local efficiency, and communicability of participants with prediabetes or type } 2 \text { diabetes compared } \\
\text { with NGM. Model } 1 \text { : Adjusted for age, sex, education, node degree, MRI date. Model } 2 \text { : additionally adjusted for waist } \\
\text { circumference, office systolic blood pressure, total cholesterol-to-HDL-ratio, antihypertensive medication, lipid- } \\
\text { lowering medication, history of cardiovascular disease. Data were available in } n=2218 \text { individuals (type } 2 \\
\text { diabetes/prediabetes/NGM, 510/348/1360, respectively). Bold values } p<0.05 \text {. }\end{array}$} \\
\hline
\end{tabular}


Supplementary Table 3.11: Associations of prediabetes and type 2 diabetes with graph network measures at a sparsity value of 0.8 , additionally adjusted for lifestyle factors.

\begin{tabular}{|c|c|c|c|c|}
\hline & Prediabetes $^{*}$ & $\mathrm{P}$ & Type 2 diabetes $^{\dagger}$ & $\mathrm{P}$ \\
\hline \multicolumn{5}{|c|}{ Normalized graph measures, $\beta(95 \% \mathrm{Cl})$} \\
\hline \multicolumn{5}{|l|}{ Clustering coefficient } \\
\hline Model 1 & $-0.077(-0.177,0.023)$ & 0.130 & $-0.014(-0.109,0.081)$ & 0.771 \\
\hline Model 2 & $-0.047(-0.150,0.056)$ & 0.371 & $0.046(-0.066,0.158)$ & 0.425 \\
\hline Model 3 & $-0.049(-0.152,0.054)$ & 0.349 & $0.034(-0.079,0.146)$ & 0.560 \\
\hline \multicolumn{5}{|l|}{ Global efficiency } \\
\hline Model 1 & $0.023(-0.107,0.152)$ & 0.733 & $-0.042(-0.161,0.077)$ & 0.490 \\
\hline Model 2 & $0.021(-0.113,0.155)$ & 0.755 & $-0.014(-0.155,0.128)$ & 0.847 \\
\hline Model 3 & $0.023(-0.111,0.157)$ & 0.737 & $-0.015(-0.157,0.128)$ & 0.839 \\
\hline \multicolumn{5}{|l|}{ Local efficiency } \\
\hline Model 1 & $-0.072(-0.154,0.009)$ & 0.083 & $-0.039(-0.117,0.039)$ & 0.326 \\
\hline Model 2 & $-0.048(-0.132,0.036)$ & 0.259 & $0.017(-0.075,0.109)$ & 0.712 \\
\hline Model 3 & $-0.049(-0.133,0.035)$ & 0.252 & $0.010(-0.082,0.103)$ & 0.828 \\
\hline \multicolumn{5}{|l|}{ Communicability } \\
\hline Model 1 & $0.082(-0.046,0.211)$ & 0.208 & $0.171(0.052,0.290)$ & 0.005 \\
\hline Model 2 & $0.103(-0.030,0.235)$ & 0.128 & $0.199(0.059,0.340)$ & 0.005 \\
\hline Model 3 & $0.097(-0.036,0.229)$ & 0.154 & $0.184(0.042,0.326)$ & 0.011 \\
\hline \multicolumn{5}{|c|}{$\begin{array}{l}{ }^{*} \text { Prediabetes-based standard network. }{ }^{\dagger} \text { Type } 2 \text { diabetes-based standard network. Associations of prediabetes and type } \\
2 \text { diabetes with graph measures. Regression coefficients and } 95 \% \mathrm{Cl} \text { indicate the mean difference in clustering } \\
\text { coefficient, global efficiency, local efficiency, and communicability of participants with prediabetes or type } 2 \text { diabetes } \\
\text { compared with NGM. Model } 1 \text { : Adjusted for age, sex, education, node degree, and MRI date. Model } 2 \text { : Model } 1+ \\
\text { additionally adjusted for BMI, office systolic blood pressure, total cholesterol-to-HDL-ratio, antihypertensive } \\
\text { medication, lipid-lowering medication, history of cardiovascular disease. Model } 3: \text { Model } 2+\text { additionally adjusted for } \\
\text { smoking status, alcohol use, physical activity, and diet score. Bold values }=p<0.05 \text {. Physical activity and diet score data } \\
\text { were available in } n=1825 \text { individuals ( } 388 / 294 / 1143 \text { for type } 2 \text { diabetes/prediabetes/NGM, respectively). }\end{array}$} \\
\hline
\end{tabular}

Supplementary Table 3.12: Additional clinical characteristics of participants according to glucose metabolism status.

\begin{tabular}{|c|c|c|c|c|}
\hline Characteristic & $\begin{array}{l}\text { NGM } \\
(n=1361)\end{array}$ & $\begin{array}{l}\text { Prediabetes } \\
(n=348)\end{array}$ & $\begin{array}{l}\text { Type } 2 \text { diabetes } \\
(n=510)\end{array}$ & Ptrend \\
\hline \multicolumn{5}{|l|}{ Cardiovascular risk factors } \\
\hline 24-h ambulatory systolic BP $(\mathrm{mmHg})^{*}$ & $118 \pm 11$ & $121 \pm 12$ & $123 \pm 11$ & $<0.001$ \\
\hline 24-h ambulatory diastolic BP $(\mathrm{mmHg})^{*}$ & $75 \pm 7$ & $76 \pm 7$ & $74 \pm 7$ & 0.114 \\
\hline Total cholesterol (mmol/L) & $5.6 \pm 1.0$ & $5.5 \pm 1.1$ & $4.5 \pm 1.0$ & $<0.001$ \\
\hline HDL cholesterol (mmol/L) & $1.7 \pm 0.5$ & $1.5 \pm 0.4$ & $1.3 \pm 0.4$ & $<0.001$ \\
\hline LDL cholesterol (mmol/L) & $3.4 \pm 0.9$ & $3.3 \pm 1.0$ & $2.4 \pm 0.9$ & $<0.001$ \\
\hline Triglyceride levels (mmol/L) & $1.2 \pm 0.7$ & $1.6 \pm 1.0$ & $1.7 \pm 1.0$ & $<0.001$ \\
\hline \multicolumn{5}{|l|}{ Lifestyle factors } \\
\hline Physical activity (hours/week) $^{\dagger}$ & $15.2 \pm 8.1$ & $14.4 \pm 7.7$ & $12.1 \pm 7.1$ & $<0.001$ \\
\hline Diet (Greek Mediterranean diet score, $1-9)^{\ddagger}$ & $4.6 \pm 1.7$ & $4.5 \pm 1.7$ & $4.1 \pm 1.6$ & $<0.001$ \\
\hline \multicolumn{5}{|c|}{$\begin{array}{l}\text { Data are presented as means } \pm \text { standard deviation or percentage, and stratified for glucose metabolism status: norma } \\
\text { glucose metabolism (NGM), prediabetes, and type } 2 \text { diabetes. P-values indicate trend analysis over glucose } \\
\text { metabolism status. BP indicates blood pressure; HDL, high-density lipoprotein; LDL, low-density lipoprotein. }{ }^{*} 24-\mathrm{h} \\
\text { ambulatory blood pressure data was available in } n=1888 \text {. }{ }^{\dagger} \text { Physical activity data was available in } n=1969 .{ }^{\ddagger} \text { Diet score } \\
\text { was available in } n=2104 \text {. Detailed protocols of the general measurements are presented in the supplementary } \\
\text { material. }\end{array}$} \\
\hline
\end{tabular}




\section{Chapter 4}

\section{Association of physical activity and sedentary time with structural brain networks - The Maastricht Study}

Laura W.M. Vergoossen, J.F.A. Jansen, J.J.A. de Jong, C.D.A. Stehouwer, N.C. Schaper, H.H.C.M. Savelberg, A. Koster, W.H. Backes, M.T. Schram

Geroscience (2020); Oct 9. doi: 10.1007/s11357-020-00276-z

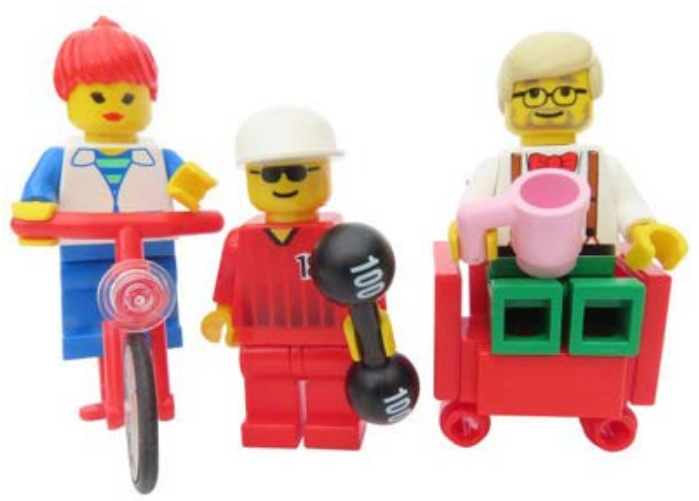




\section{Abstract}

\section{Objective}

We assessed whether objectively measured low- and high-intensity physical activity (LPA and HPA) and sedentary time (ST) were associated with white matter connectivity, both throughout the whole brain, and in brain regions involved in motor function.

\section{Methods}

In the large population-based Maastricht Study ( $n=1715$, age 59.6 \pm 8.1 (mean \pm standard deviation) years, and $48 \%$ woman), the amounts of LPA, HPA, and ST were objectively measured during 7 days by an activPAL accelerometer. In addition, using 3 T structural and diffusion MRI, we calculated whole brain node degree, and node degree of the basal ganglia and primary motor cortex. Multivariable linear regression analysis was performed and we report standardized regression coefficients (st $\beta$ ) adjusted for age, sex, education level, wake time, diabetes status, BMI, office systolic blood pressure, antihypertensive medication, total-cholesterol-to-HDL-cholesterol ratio, and lipid-modifying medication, alcohol use, smoking status, and history of cardiovascular disease.

\section{Results}

Lower HPA was associated with lower whole brain node degree after full adjustment (st $\beta[95 \% \mathrm{Cl}]=-0.062$ $[-0.101,-0.013] ; p=0.014)$, whereas lower LPA (st $\beta[95 \% \mathrm{Cl}]=-0.013[-0.061,0.034] ; p=0.580)$ and higher ST (st $\beta[95 \% \mathrm{Cl}]=-0.030[-0.081,0.021] ; p=0.250$ ) were not. In addition, lower HPA was associated with lower node degree of the basal ganglia after full adjustment (st $\beta[95 \% \mathrm{Cl}]=-0.070[-0.121,-0.018] ; p=0.009$ ).

\section{Conclusions}

Objectively measured lower HPA, but not lower LPA and higher ST, were associated with lower whole brain node degree and node degree in specific brain regions highly specialized in motor function. Further research is needed to establish whether more HPA may preserve structural brain connectivity. 


\section{Introduction}

It is increasingly acknowledged that low physical activity is not only harmful for general health (1), but also for the brain (2-4). In addition, sedentary behavior, which is a risk factor independent of physical activity, may also be associated with cognitive decline $(5,6)$. However, how both physical activity and sedentary behavior exactly affect early changes in brain function is not yet clear.

A growing body of evidence shows a clear association between low physical activity and sedentary behavior and structural brain changes, such as brain atrophy (7-10) and cerebral small vessel disease (CSVD) (11) at the population level. However, both atrophy and CSVD are likely to represent irreversible damage, while novel markers of early reversible brain changes may be available. Previous studies have indicated that the structural organization of brain networks, also named connectivity, may represent such a marker, which is also affected in dementia (12). However, data on the association between physical activity and structural brain networks are scarce (13), while the association of sedentary behavior and structural brain networks have not been reported yet.

In this study, we hypothesize that both whole brain structural organization of brain networks and the organization of specific regions involved in motor function, as the basal ganglia and the primary motor cortex (14), are affected by low physical activity and high levels of sedentary time. Therefore, we assessed the association of objectively measured low- and high-intensity physical activity and sedentary time with both whole brain and regional white matter structural connectivity within the populationbased Maastricht Study.

\section{Research Design and Methods}

\section{The Maastricht Study: population and design}

We used data from The Maastricht Study, an observational prospective population-based cohort study. The rationale and methodology have been described previously (15). In brief, the study focuses on the etiology, pathophysiology, complications, and comorbidities of type 2 diabetes mellitus (T2DM), and is characterized by an extensive phenotyping approach. Eligible for participation were all individuals aged between 40 and 75 years and living in the southern part of the Netherlands. Participants were recruited through mass media campaigns and from the municipal registries and the regional Diabetes Patient Registry via mailings. Recruitment was stratified according to known T2DM status, with an oversampling of individuals with T2DM, for reasons of efficiency. The present report considered cross-sectional data from the first 3451 participants, who completed the baseline survey between November 2010 and September 2013. The examinations of each participant were performed within a time window of three months [Supplementary Figure 4.1]. MRI measurements were implemented from December 2013 onwards until February 2017 and were available in 2318 out of 3451 participants. Of the 2318 participants with MRI measurements available, 2302 participants had complete data without artifacts, and 1715 participants of those also had objectively measured physical activity data available [Flowchart in Supplementary material Figure 4.2]. The study has been approved by the institutional medical ethical committee (NL31329.068.10) and the Minister of Health, Welfare and Sports of the Netherlands (Permit 131088-105234-PG). All participants gave written informed consent. 


\section{Physical activity and sedentary time measures}

Daily activity levels were measured using the activPAL $3^{\text {TM }}$ physical activity monitor (PAL Technologies, Glasgow, UK). This device is a small $(53 \times 35 \times 7 \mathrm{~mm})$, lightweight $(15 \mathrm{~g})$ triaxial accelerometer that records movement in the vertical, anterio-posterior and mediolateral axes, and also determines posture (sitting or lying, standing and stepping) based on acceleration information. The device was attached directly to the skin on the front of the right thigh with (transparent $3 \mathrm{M}$ Tegaderm ${ }^{\mathrm{TM}}$ ) tape, after the device had been waterproofed using a nitrile sleeve. Participants were asked to wear the accelerometer for 8 consecutive days, without removing it at any time. To avoid inaccurately identifying non-wear time, participants were asked not to replace the device once removed. The method for determining the waking time has been described elsewhere (16). Data were uploaded using the activPAL software and processed using customized software (MATLAB R2013b, MathWorks, Natick, MA, USA). Data from the first day were excluded from the analysis because participants performed physical function tests at the research center after the device was attached. In addition, data from the final wear day providing $\leq 14$ waking hours of data were excluded from the analysis. Participants were included if they provided at least one valid day ( $\geq 10 \mathrm{~h}$ of waking data).

The total amount of stepping time was based on the stepping posture, and calculated as the mean time spent in that position during waking time per day (17). The total stepping time was further classified into high-intensity physical activity (HPA, minutes with a step frequency $>110$ steps/min during waking time) (18) and low-intensity physical activity (LPA, minutes with a step frequency $\leq 110$ steps/min during waking time). In this study, we aimed to identify risk factors for brain alterations. As physical activity may be protective and sedentary time a risk, we choose to consider high physical inactivity (low physical activity) and high sedentary time as risk factors. Therefore we inversed the physical activity data (e.g., multiplied by -1 , and used the inverse of total, low-intensity, and high-intensity physical activity was used in statistical analyses, to represent low physical activity levels. The total amount of sedentary time (ST) was based on the sedentary posture (sitting or lying), and calculated as the mean time spent in a sedentary position during waking time per day.

For descriptive purposes, we present the data in Table 4.1 according to the recently published physical activity guidelines $(19,20)$. These guidelines both recommend at least 150 minutes of highintensity physical activity per week for considerable health benefits, including brain health. Participants that were compliant with these guidelines were indicated as the high HPA group, and those that were not compliant as the low HPA group. We used these categories to assess the reference networks for white matter integrity, to address potential differences in connectivity between active and inactive participants.

\section{Magnetic Resonance Imaging}

Magnetic resonance imaging (MRI) was performed on a 3T MRI scanner (MAGNETOM Prisma-fit Syngo MR D13D, Siemens Healthcare, Erlangen, Germany) by use of a 64-element head/neck coil for parallel imaging with an acceleration factor of two. A 3D T1-weighted magnetization prepared rapid acquisition gradient echo (MPRAGE) sequence (TR/TI/TE 2300/900/2.98 ms, 176 slices, 256×240 matrix size and 1.00 $\mathrm{mm}$ cubic voxel size) was acquired for anatomic reference. Diffusion-weighted MRI (dMRI) data were acquired with a diffusion sensitized echo-planar imaging (EPI) sequence (TR/TE 6100/57 ms, 65 slices, 
$100 \times 100$ matrix size, $2.00 \mathrm{~mm}$ cubic voxel size, and 64 diffusion sensitizing gradient directions $(b=1200$ $\left.\mathrm{s} / \mathrm{mm}^{2}\right)$ ). In addition, three minimally-diffusion-weighted images $\left(b=0 \mathrm{~s} / \mathrm{mm}^{2}\right)$ were acquired.

\section{Image preprocessing}

To define $\mathrm{N}=120$ brain regions, the Automatic Anatomical Labeling (AAL2) atlas (21) was used. The atlas volumes of interest were transformed to diffusion image space for each individual subject. First, affine registrations of the dMRI image to the T1 image and of the T1 image to T1 Montreal Neurological Institute-152 standard space (22) were performed. These two transformations were combined and the inverse transformation matrix was applied to the AAL2 template. T1-weighted images were segmented by use of a certified (ISO13485:2012), automated method (which included visual inspection) (23, 24). $\mathrm{T}_{1^{-}}$ weighted images were segmented into gray matter, white matter and cerebrospinal fluid volumes (1 voxel $=1.00 \mathrm{~mm}^{3}=0.001 \mathrm{ml}$ ) (23). Intracranial volume was calculated as the sum of gray matter, white and cerebrospinal fluid volumes. Total brain parenchyma volume was calculated as the sum of gray and white matter volumes. dMRI (pre)processing was performed with the diffusion MR Toolbox ExploreDTI version 4.8.6 (25). The main preprocessing steps were eddy current induced geometric distortions and head motion correction, and estimation of the diffusion tensor. After preprocessing, fiber orientation distributions (FOD) were estimated using constrained spherical deconvolution with a maximum harmonic degree of 8 , which allows fiber tracking through regions with crossing fibers (26). Whole brain deterministic tractography was performed using FOD sampling (27) with a seed point resolution of 2 $\mathrm{mm}^{3}$, a step size of $1 \mathrm{~mm}$, and FOD and maximum deflection angle threshold of 0.1 and $30^{\circ}$, respectively. The next step was to perform connectivity analysis to obtain white matter tracts from and to all the AAL2 brain regions. A previous study of our group confirmed the robustness of tract volume as a measure for the edge weighting (28), therefore, for each connection, the tract volume was calculated as the number of voxels visited by at least one tract between the areas concerned multiplied by the voxel volume (in $\mathrm{mm}^{3}$ ) (as previously described (29)). The obtained connectivity matrix with tract volumes was normalized to intracranial volume to reduce inter-subject variation (30). When regions were connected by only one or two streamlines, the corresponding tract volumes were removed from the connectivity matrix, as an additional noise filter.

\section{White matter networks}

Network analysis was performed using the Brain Connectivity Toolbox (version 2017-15-01) (31) in MATLAB (Release 2016a, The MathWorks, Inc., Natick, Massachusetts, United States). In this method, the brain was represented as a graph, which is a network of nodes (i.e., gray matter brain regions) connected by edges (i.e., white matter connections between brain regions). The node degree was calculated for each atlas region and the mean value was defined as the whole brain node degree, which is a measure for the average number of edges connected to a node. In a network with a high whole brain node degree, brain regions are connected to many other brain regions in the network (i.e., strong innervation). The sparsity of a network is the ratio of the number of missing connections in a network to the possible number of connections and is closely, but inversely, related to the node degree. The sparsity ranges from 0 to 1 , the higher the sparsity, the lower the density of the network (31). 
Subsequently, reference networks were calculated (32) based on predefined levels of physical activity and sedentary time. Note that these reference networks may differ per group comparison. The reference networks were proportionally thresholded to a sparsity of 0.80 (only the $20 \%$ connections with the highest occurrence in the individual connectivity matrices of the participants in that group), resulting in a weighted, undirected network with a sparsity close to the sparsity of the standard network (more detailed information can be found in the Supplementary Material).

The first reference network was based on the high HPA group (participants who met the physical activity guidelines $(19,20)$, i.e., at least 150 minutes of high-intensity physical activity per week (21.4 minutes per day)). With regard to sedentary behavior, as mentioned above, the guidelines only advise reducing sitting without providing numbers. Therefore, the sedentary behavior reference network was based on the tertile of the participants with the lowest sedentary time (i.e., less than 512 minutes of sedentary time per day). Thereafter, we calculated the whole brain node degree for both reference networks. To investigate local connectivity changes we calculated the node degree for brain regions important for physical activity and motor functions (i.e., the basal ganglia (i.e., caudate nucleus, putamen, pallidum, and thalamus as defined by the AAL2 atlas) (Figure 4.1A)) and the primary motor cortex (Figure 4.1B), and for the four brain lobes (i.e., the frontal (without primary motor cortex), temporal, parietal, and occipital lobe).
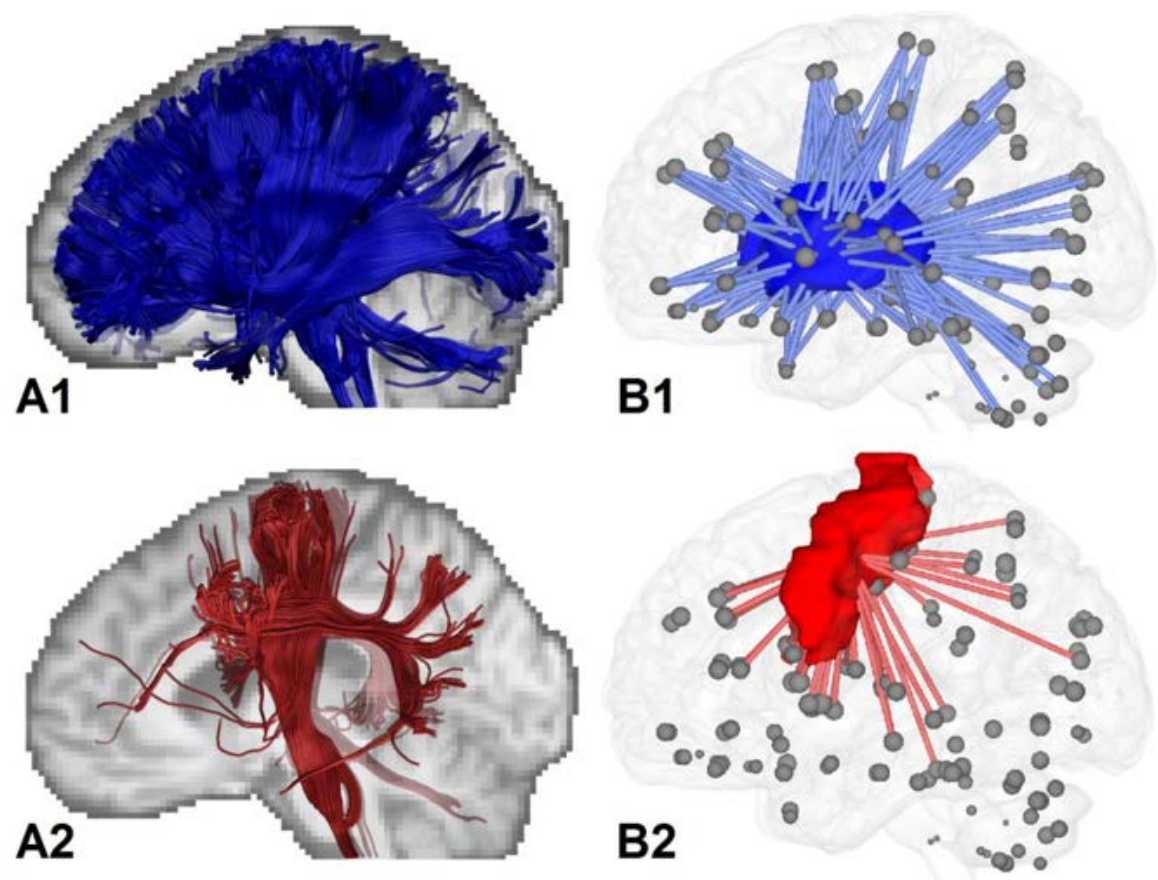

Figure 4.1: White matter tracts crossing the basal ganglia and primary motor cortex. Tracts crossing the basal ganglia (A1) are mainly projection fibers, and crossing the primary motor cortex (A2) pyramidal tracts (e.g., the cortico-spinal tract). Blue and red volumes indicate the locations of the basal ganglia (B1) and primary motor cortex (B2), respectively. The gray dots represent the centers of 120 atlas regions. Lines indicate connections from a subset of brain regions to these two volumes; the number of lines is equal to the node degree. 


\section{General characteristics and covariates}

Educational level (low, intermediate, high), smoking status (never, current, former) and history of cardiovascular disease were assessed by questionnaires (33). Medication use was assessed in an interview where generic name, dose, and frequency were registered. We measured weight, height, BMI, waist circumference, blood pressure (measured in office [Omron 705IT, Japan]), and plasma lipid profile(33).

\section{Statistical analysis}

All statistical analyses were performed by use of the Statistical Package for Social Sciences (SPSS Statistics 23.0, IBM, Chicago, IL, USA). Multivariable linear regression analysis was used to investigate the association of physical activity and sedentary behavior, with whole brain node degree, node degree of the basal ganglia (BG), and the primary motor cortex (PMC). Analyses were adjusted for potential confounders, notably age, sex, education level, MRI lag time, and wake time (model 1), additionally adjusted for diabetes status (model 2), and additionally adjusted for cardiovascular risk factors: BMI, office systolic blood pressure, antihypertensive medication, total-cholesterol-to-HDL-cholesterol ratio, and lipid-modifying medication, alcohol use, smoking status, and history of CVD (model 3). P-values $<0.05$ were considered statistically significant. Interaction terms (e.g., HPA time*sex, and HPA time*diabetes) were incorporated in the regression models to test for interaction among, on the one hand, physical activity and sedentary time, and on the other hand, sex and diabetes status, on node degree. For interaction terms a $\mathrm{P}$ value $\leq 0.10$ was considered statistically significant.

\section{Results}

\section{General characteristics of the study population}

Table 4.1 shows the general characteristics of the study population stratified for low or high HPA. The study population consisted of 1715 participants, mean age was $59.6 \pm 8.1$ years, and $48 \%$ were woman. The low HPA groups was older, had a higher BMI and waist circumference, more often had an adverse cardiovascular risk profile, and were more often smoker. Education levels did not differ significantly for individuals with different levels of physical activity [Table 4.1]. 
Table 4.1: General characteristics of participants stratified by low or high HPA measured by the ActivPAL.

\begin{tabular}{|c|c|c|c|c|}
\hline Characteristic & $\begin{array}{l}\text { Total } \\
(n=1715)\end{array}$ & $\begin{array}{l}\text { High HPA } \\
(n=780)\end{array}$ & $\begin{array}{l}\text { Low HPA } \\
(n=935)\end{array}$ & $P$ \\
\hline \multicolumn{5}{|l|}{ Demographics } \\
\hline Age (years) & $59.6 \pm 8.1$ & $58.0 \pm 7.9$ & $60.9 \pm 8.0$ & $<0.001$ \\
\hline Sex, female (No. [\%]) & $830[48.4]$ & $447[57.3]$ & $383[41.0]$ & $<0.001$ \\
\hline Education level (No. [\%]), & $523 / 497 / 695$ & $225 / 224 / 331$ & $297 / 274 / 364$ & \multirow{2}{*}{0.283} \\
\hline Low/Middle/High & {$[30.5 / 29.0 / 40.5]$} & {$[28.9 / 28.7 / 42.4]$} & {$[31.8 / 29.3 / 38.9]$} & \\
\hline \multicolumn{5}{|l|}{ Cardiovascular risk factors } \\
\hline BMI $\left(\mathrm{kg} / \mathrm{m}^{2}\right)$ & $26.6 \pm 4.2$ & $25.5 \pm 3.7$ & $27.6 \pm 4.4$ & $<0.001$ \\
\hline Waist circumference $(\mathrm{cm})$ & $94.4 \pm 12.7$ & $89.8 \pm 11.0$ & $98.2 \pm 12.8$ & $<0.001$ \\
\hline Systolic blood pressure (mmHg) & $134.0 \pm 17.3$ & $131.8 \pm 16.9$ & $135.8 \pm 17.4$ & $<0.001$ \\
\hline Diastolic blood pressure $(\mathrm{mmHg})$ & $76.1 \pm 9.7$ & $75.3 \pm 9.8$ & $76.7 \pm 9.6$ & 0.003 \\
\hline T2DM (No. [\% of T2DM]) & $400[23.6]$ & 99 [12.9] & $301[32.6]$ & $<0.001$ \\
\hline Hypertension, yes (No. [\%]) & $914[53.3]$ & $345[44.2]$ & $569[60.8]$ & $<0.001$ \\
\hline Total-to-HDL-cholesterol-ratio & $3.6 \pm 1.1$ & $3.3 \pm 1.0$ & $3.7 \pm 1.2$ & $<0.001$ \\
\hline History of CVD, yes (No. [\%]) & $218[12.7]$ & $57[7.3]$ & $161[17.2]$ & $<0.001$ \\
\hline \multicolumn{5}{|l|}{ Medication use } \\
\hline Diabetes medication, yes (No. [\%]) & $308[18.0]$ & $72[9.2]$ & $236[25.2]$ & $<0.001$ \\
\hline $\begin{array}{l}\text { Antihypertensive medication, yes (No. } \\
{[\%] \text { ) }}\end{array}$ & $619[36.1]$ & $199[25.6]$ & $420[44.9]$ & $<0.001$ \\
\hline $\begin{array}{l}\text { Lipid-modifying medication, yes (No. } \\
\text { [\%]) }\end{array}$ & $540[31.5]$ & 178 [22.9] & $362[38.7]$ & $<0.001$ \\
\hline \multicolumn{5}{|l|}{ Lifestyle factors } \\
\hline Alcohol (No. [\%]), & $291 / 980 / 444$ & $108 / 452 / 220$ & $183 / 528 / 224$ & \multirow{2}{*}{0.003} \\
\hline None/Low/High & {$[17.0 / 57.2 / 25.9]$} & {$[13.8 / 58.0 / 28.2]$} & {$[19.6 / 56.5 / 23.9]$} & \\
\hline Smoking (No. [\%]), & $651 / 854 / 210$ & $326 / 380 / 74$ & $325 / 474 / 136$ & \multirow{2}{*}{0.001} \\
\hline Never/Former/Current & {$[38.0 / 49.8 / 12.3]$} & {$[41.7 / 48.8 / 9.6]$} & {$[34.8 / 50.7 / 14.5]$} & \\
\hline Diet (Dutch Healthy Diet, 0-100)‡ & $85.6 \pm 14.3$ & $83.1 \pm 14.8$ & $82.3 \pm 14.0$ & $<0.001$ \\
\hline Total PA (min/day) & $124 \pm 41$ & $145 \pm 37$ & $106 \pm 35$ & $<0.001$ \\
\hline LPA (min/day) & $100 \pm 33$ & $106 \pm 31$ & $95 \pm 34$ & $<0.001$ \\
\hline HPA (min/day) & $24 \pm 19$ & $39 \pm 18$ & $11 \pm 6$ & $<0.001$ \\
\hline Sedentary time (min/day) & $558 \pm 99$ & $530 \pm 93$ & $581 \pm 99$ & $<0.001$ \\
\hline Wake time (min/day) & $945 \pm 53$ & $951 \pm 50$ & $940 \pm 54$ & $<0.001$ \\
\hline \multicolumn{5}{|l|}{ Cognitive score } \\
\hline MMSE total score & $29.0 \pm 1.2$ & $29.2 \pm 1.1$ & $28.9 \pm 1.2$ & $<0.001$ \\
\hline \multicolumn{5}{|l|}{ Node degree } \\
\hline Whole brain & $20.9 \pm 0.8$ & $21.1 \pm 0.7$ & $20.8 \pm 0.8$ & $<0.001$ \\
\hline Frontal lobe & $17.8 \pm 0.9$ & $17.9 \pm 0.9$ & $17.7 \pm 1.0$ & $<0.001$ \\
\hline Temporal lobe & $19.8 \pm 0.9$ & $19.9 \pm 0.8$ & $19.7 \pm 0.9$ & $<0.001$ \\
\hline Parietal lobe & $20.3 \pm 0.8$ & $20.3 \pm 0.8$ & $20.4 \pm 0.9$ & 0.150 \\
\hline Occipital lobe & $24.4 \pm 1.3$ & $24.4 \pm 1.3$ & $24.3 \pm 1.3$ & 0.354 \\
\hline Basal ganglia & $42.0 \pm 2.0$ & $42.3 \pm 2.0$ & $41.8 \pm 2.0$ & $<0.001$ \\
\hline Primary motor cortex & $25.0 \pm 2.7$ & $25.3 \pm 2.6$ & $24.8 \pm 2.8$ & 0.001 \\
\hline \multicolumn{5}{|l|}{ Other } \\
\hline MRI lag time (years) & $2.0 \pm 1.2$ & $2.0 \pm 1.2$ & $2.1 \pm 1.2$ & 0.097 \\
\hline \multicolumn{5}{|c|}{$\begin{array}{l}\text { General characteristics of the study population were evaluated by ANOVA (continuous variables with a normal } \\
\text { distribution) or } \chi 2 \text { tests (categorical variables). Data are presented as means } \pm \text { standard deviation, or percentages for } \\
\text { categorical variables. No. indicates number; PA. physical activity; T2DM, type } 2 \text { diabetes mellitus; HDL, high-density } \\
\text { lipoprotein; CVD, cardiovascular disease; MMSE, Mini-Mental State Examination. High HPA was defined as at least } 150 \\
\text { minutes of high-intensity physical activity per week ( } 21.4 \text { minutes per day). } ¥ D i e t \text { score was available in } n=1613 \text {. }\end{array}$} \\
\hline
\end{tabular}


Table 4.2 shows the associations of physical activity and sedentary time with total brain volume and white matter volume. None of these associations remained significant after adjustment for demographics and cardiovascular risk factors. Participants without MRI or accelerometry data ( $\mathrm{N}=1736)$ had a higher BMI, more often had T2DM, a history of CVD and mobility (Supplementary Table 4.1), compared with the study population.

Table 4.2: Associations of subtypes of PA and ST with volumes of the total brain, and white matter.

\begin{tabular}{|c|c|c|c|c|}
\hline & Total brain volume & & White matter volume & \\
\hline LPA time (high to low) & st $\beta(95 \% \mathrm{Cl})$ & $P$ & $\operatorname{st} \beta(95 \% \mathrm{Cl})$ & $P$ \\
\hline Model 1 & $-0.019(-0.033,-0.006)$ & 0.005 & $0.003(-0.019,0.025)$ & 0.784 \\
\hline Model 2 & $-0.012(-0.025,0.002)$ & 0.092 & $0.011(-0.012,0.033)$ & 0.353 \\
\hline Model 3 & $-0.008(-0.022,0.005)$ & 0.230 & $0.010(-0.013,0.033)$ & 0.395 \\
\hline HPA time (high to low) & st $\beta(95 \% \mathrm{Cl})$ & $P$ & $\operatorname{st} \beta(95 \% \mathrm{Cl})$ & $P$ \\
\hline Model 1 & $-0.013(-0.027,0.001)$ & 0.065 & $0.003(-0.020,0.026)$ & 0.821 \\
\hline Model 2 & $-0.005(-0.019,0.009)$ & 0.506 & $0.011(-0.013,0.034)$ & 0.365 \\
\hline Model 3 & $-0.003(-0.017,0.011)$ & 0.687 & $0.010(-0.014,0.034)$ & 0.423 \\
\hline Sedentary time (low to high) & $\operatorname{st} \beta(95 \% \mathrm{Cl})$ & $P$ & $\operatorname{st} \beta(95 \% \mathrm{Cl})$ & $P$ \\
\hline Model 1 & $-0.022(-0.037,-0.008)$ & 0.002 & $-0.008(-0.032,0.016)$ & 0.492 \\
\hline Model 2 & $-0.013(-0.028,0.001)$ & 0.073 & $0.001(-0.024,0.025)$ & 0.963 \\
\hline Model 3 & $-0.010(-0.024,0.005)$ & 0.200 & $0.001(-0.024,0.026)$ & 0.944 \\
\hline \multicolumn{5}{|c|}{$\begin{array}{l}\text { Associations between physical activity measures (minutes/day) with brain volumes. } \\
\text { Regression coefficients and } 95 \% \mathrm{Cl} \text { indicate the mean difference in volume per SD } \\
\text { Higher LPA, HPA or lower sedentary time. Model 1: Adjusted for age, sex, } \\
\text { education level, MRI lag time, wake time, and ICV. Model 2: additionally adjusted for } \\
\text { diabetes status. Model 3: additionally adjusted for BMI, systolic blood pressure, } \\
\text { antihypertensive medication, total-to-HDL-cholesterol-ratio, lipid-modifying medication, } \\
\text { smoking status, alcohol use, and history of cardiovascular disease. }\end{array}$} \\
\hline
\end{tabular}

Figure 4.2 shows the node degree of the four lobes and specific motor regions for participants with high and low HPA. The low HPA group had a slightly, but significantly lower node degree of the frontal lobe (1.1\%), temporal lobe (1.0\%), basal ganglia (1.2\%), and primary motor cortex $(2.0 \%)$, compared to the high HPA group. The highest node degree was found in the basal ganglia, because these structures are centrally located in the brain and therefore connected to many other regions (Figure 4.1A and 4.1B). 


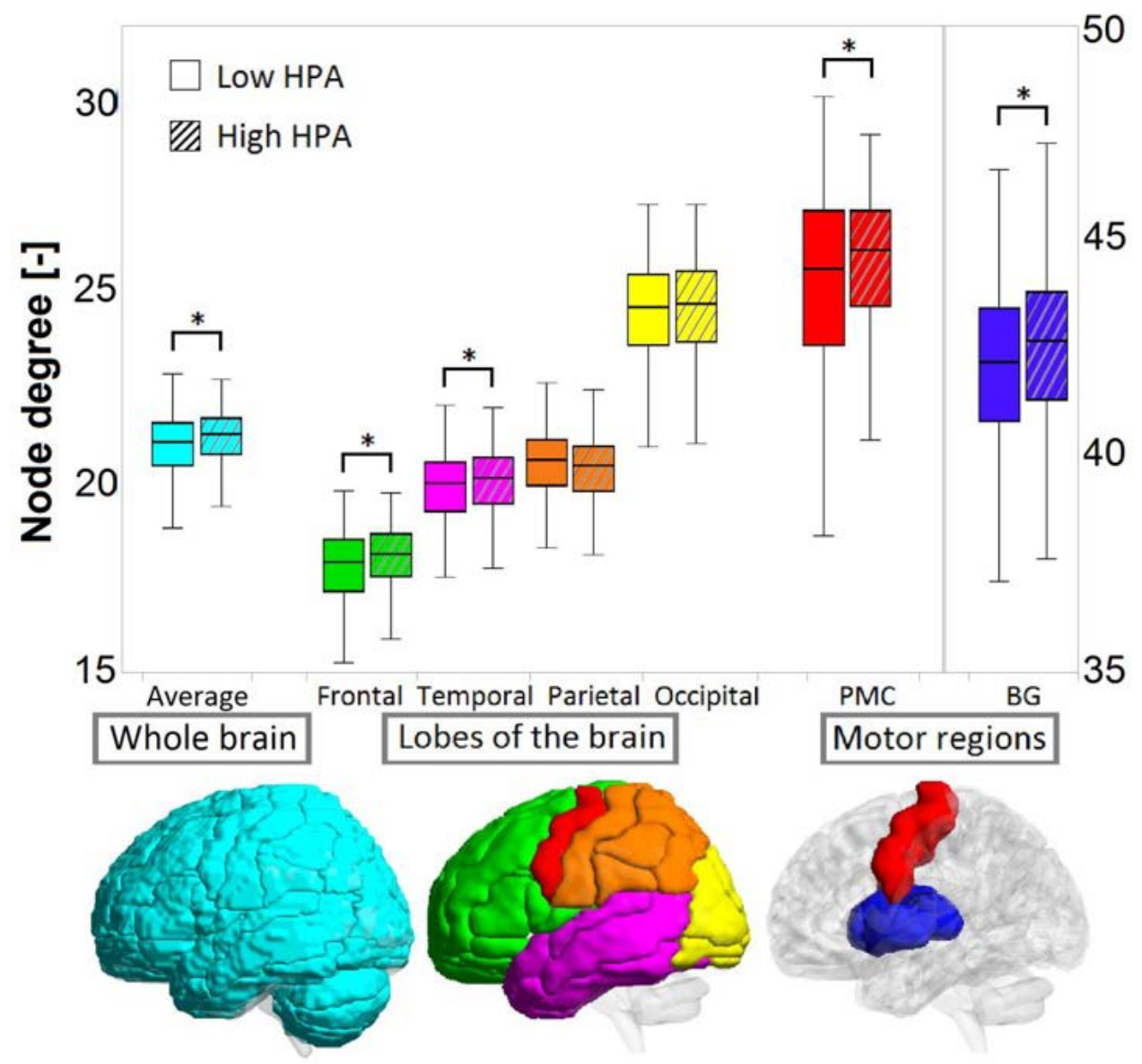

Figure 4.2: Boxplot for the node degree of the whole brain, the four lobes, and the motor regions of the brain for participants with high (dashed) and low HPA time. Note the different scale for the node degree of the basal ganglia (BG).

\section{Physical activity, sedentary behavior and whole brain node degree}

Table 4.3 shows the associations of physical activity and sedentary time with whole brain node degree. Lower levels of HPA and higher amount of sedentary time were associated with lower whole brain node degree in model 1. After adjustment for diabetes status, the association between sedentary time and whole brain node degree was attenuated (model 2). After full adjustment for cardiovascular risk factors, the association of HPA with whole brain node degree remained statistically significant (model 3). 
Table 4.3: Associations of low and high-intensity physical activity time, and high sedentary time with whole brain node degree.

\begin{tabular}{|c|c|c|}
\hline \multicolumn{3}{|c|}{ Whole brain node degree } \\
\hline LPA time (high to low) & $\operatorname{st} \beta(95 \% \mathrm{Cl})$ & $P$-value \\
\hline Model 1 & $-0.035(-0.081,0.011)$ & 0.137 \\
\hline Model 2 & $-0.022(-0.069,0.025)$ & 0.356 \\
\hline Model 3 & $-0.013(-0.061,0.034)$ & 0.580 \\
\hline HPA time (high to low) & st $\beta(95 \% \mathrm{Cl})$ & $P$-value \\
\hline Model 1 & $-0.081(-0.128,-0.033)$ & 0.001 \\
\hline Model 2 & $-0.068(-0.116,-0.021)$ & 0.005 \\
\hline Model 3 & $-0.062(-0.112,-0.013)$ & 0.014 \\
\hline Sedentary time (low to high) & st $\beta(95 \% \mathrm{Cl})$ & $P$-value \\
\hline Model 1 & $-0.052(-0.101,-0.002)$ & 0.039 \\
\hline Model 2 & $-0.037(-0.087,0.013)$ & 0.152 \\
\hline Model 3 & $-0.030(-0.081,0.021)$ & 0.250 \\
\hline \multicolumn{3}{|c|}{$\begin{array}{l}\text { Associations of physical activity measures with whole brain node degree. } \\
\text { Standardized regression coefficients and } 95 \% \mathrm{Cl} \text { indicate the mean difference in node } \\
\text { degree per SD lower physical activity and higher sedentary time. Model } 1 \text { : Adjusted for } \\
\text { age, sex, education level, MRI lag time, and wake time. Model } 2 \text { : additionally adjusted } \\
\text { for diabetes status. Model 3: additionally adjusted for BMI, systolic blood pressure, } \\
\text { antihypertensive medication, total-to-HDL-cholesterol-ratio, lipid-modifying } \\
\text { medication, smoking status, alcohol use, and history of cardiovascular disease. }\end{array}$} \\
\hline
\end{tabular}

Lower HPA was also associated with lower node degree of the temporal and frontal lobe in fully adjusted analyses, but not with node degree of the parietal and occipital lobe (Table 4.4).

To put this into perspective, the difference in whole brain node degree associated with lower HPA time equivalent to one year of aging was 5.0 minutes less HPA time per day (Supplementary Table 4.6).

\section{Physical activity, sedentary behavior and regional node degree}

Table 4.5 shows the associations of physical activity and sedentary time with specific node degree of the motor regions, i.e., the basal ganglia, and the primary motor cortex. Lower LPA and HPA, and higher sedentary time were associated with lower node degree of the basal ganglia (model 1). These associations remained statistically significant after adjustment for diabetes status, except for higher sedentary time (model 2). Lower HPA remained statistically significantly associated with lower node degree of the basal ganglia after additional adjustment for cardiovascular risk factors (model 3). Lower HPA was also associated with a lower node degree of the primary motor cortex in model 1 , but this association attenuated after adjustment for diabetes status and other cardiovascular risk factors (model 2 and 3). LPA and sedentary time were not associated with node degree of the primary motor cortex. 


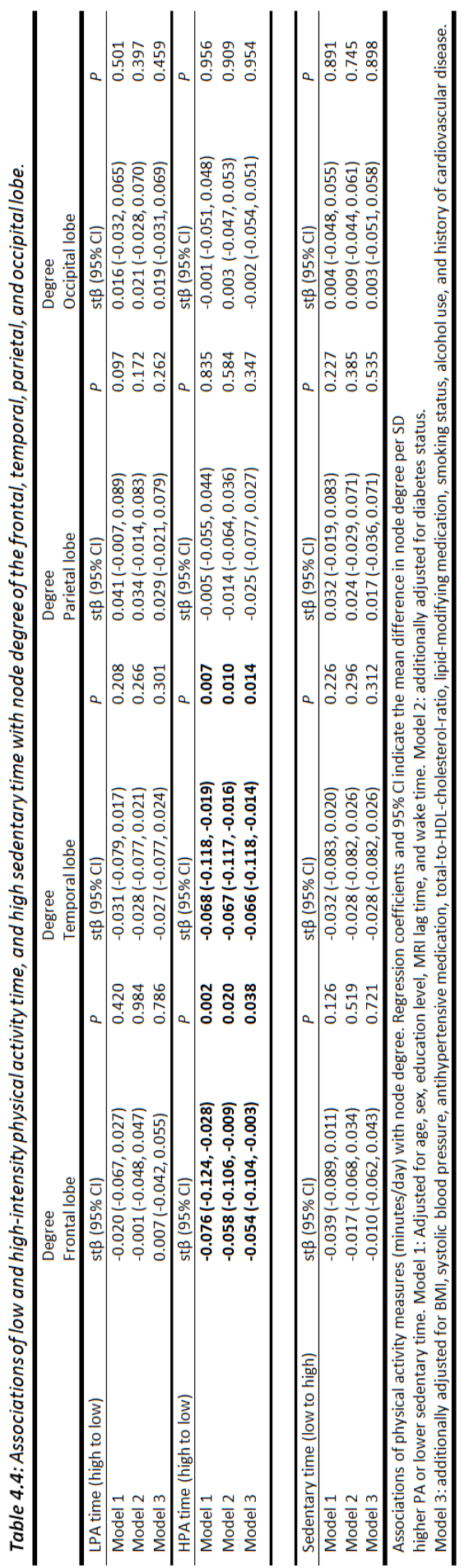


Table 4.5: Associations of low- and high-intensity physical activity time, and high sedentary time with node degree of the basal ganglia and the primary motor cortex.

\begin{tabular}{|c|c|c|c|c|}
\hline & $\begin{array}{l}\text { Degree } \\
\text { Basal Ganglia }\end{array}$ & & $\begin{array}{l}\text { Degree } \\
\text { Primary Motor Cortex }\end{array}$ & \\
\hline LPA time (high to low) & st $\beta(95 \% \mathrm{Cl})$ & $P$ & $\operatorname{st} \beta(95 \% \mathrm{Cl})$ & $P$ \\
\hline Model 1 & $-0.067(-0.116,-0.019)$ & 0.006 & $-0.038(-0.085,0.010)$ & 0.118 \\
\hline Model 2 & $-0.053(-0.102,-0.004)$ & 0.032 & $-0.017(-0.065,0.031)$ & 0.487 \\
\hline Model 3 & $-0.049(-0.098,0.001)$ & 0.056 & $-0.017(-0.066,0.032)$ & 0.489 \\
\hline HPA time (high to low) & st $\beta(95 \% \mathrm{Cl})$ & $P$ & $\operatorname{st} \beta(95 \% \mathrm{Cl})$ & $P$ \\
\hline Model 1 & $-0.085(-0.134,-0.035)$ & 0.001 & $-0.052(-0.101,-0.003)$ & 0.037 \\
\hline Model 2 & $-0.070(-0.121,-0.020)$ & 0.006 & $-0.030(-0.079,0.019)$ & 0.232 \\
\hline Model 3 & $-0.070(-0.121,-0.018)$ & 0.009 & $-0.035(-0.086,0.016)$ & 0.178 \\
\hline Sedentary time (low to high) & st $\beta(95 \% \mathrm{Cl})$ & $P$ & st $\beta(95 \% \mathrm{Cl})$ & $P$ \\
\hline Model 1 & $-0.052(-0.103,0.000)$ & 0.049 & $-0.033(-0.084,0.017)$ & 0.197 \\
\hline Model 2 & $-0.034(-0.087,0.018)$ & 0.203 & $-0.008(-0.060,0.044)$ & 0.761 \\
\hline Model 3 & $-0.029(-0.082,0.025)$ & 0.295 & $-0.008(-0.061,0.045)$ & 0.759 \\
\hline \multicolumn{5}{|c|}{$\begin{array}{l}\text { Associations of physical activity measures with node degree of the basal ganglia and primary motor cortex. } \\
\text { Regression coefficients and } 95 \% \mathrm{Cl} \text { indicate the mean difference in node degree per SD lower physical activity } \\
\text { and higher sedentary time. Model } 1 \text { : Adjusted for wake time, age, sex, education level, MRI lag time. Model } 2 \text { : } \\
\text { additionally adjusted for diabetes status. Model 3: additionally adjusted for BMI, systolic blood pressure, } \\
\text { antihypertensive medication, total-to-HDL-cholesterol-ratio, lipid-modifying medication, smoking status, } \\
\text { alcohol use, and history of cardiovascular disease. }\end{array}$} \\
\hline
\end{tabular}

\section{Additional analyses}

Qualitatively similar associations of physical activity and sedentary time with node degree were observed in a range of additional analyses; when we used total PA (Supplementary Table 4.2), when we used PA data measured with questionnaires instead of accelerometry (Supplementary Table 4.3), when model 3 was additionally adjusted for MRI quality, diet, (available in a smaller sample size), MMSE score, or white matter hyperintensity volume, and when we replaced BMI with waist circumference, or replaced office with $24 \mathrm{~h}$ ambulatory blood pressure (available in a smaller sample size; Supplementary Table 4.4 and 4.5). No interactions were observed with sex and diabetes status ( $P$ interaction $>0.10$ for all analyses).

\section{Discussion}

In this study, we found an association of lower HPA with lower whole brain node degree, independent of major demographic, cardiovascular and lifestyle risk factors. In other words, the difference in whole brain node degree associated with lower HPA time equivalent to one year of aging was 5.0 minutes less HPA time per day. LPA and ST were not significantly associated with whole brain node degree. In analyses on regional node degree, we found that lower HPA was associated with low node degree of the basal ganglia, but not of the primary motor cortex, independent of major demographic, cardiovascular and lifestyle risk factors. LPA and sedentary time were not associated with markers of regional node degree.

We found that objectively measured lower HPA was associated with lower whole brain node degree. Our finding is in agreement with, and extends a prior cross-sectional study, which observed an association between lower levels of self-reported physical activity and lower regional connectivity (nodal 
strength) in several frontal, parietal, temporal brain regions(13), and lower local white matter organization (local efficiency). We also found an association of lower physical activity with lower node degree in the primary motor cortex (which is located in the frontal lobe), other motor regions (i.e., the basal ganglia), and in the frontal and temporal lobe (Table 4.4). However, we did not find such an association for the parietal lobe. Our findings are also in line with a study, where lower aerobic fitness has been associated with lower structural connectivity in multiple cortical areas involving frontal, temporal, and motor regions (34).

We found no association of sedentary time with whole brain or regional node degree after adjustment for cardiovascular and lifestyle risk factors. This may mean that the association between sedentary time and regional connectivity is mediated by up or down stream factors like BMI, blood pressure, lipid profile, prior cardiovascular disease and/or lifestyle risk factors. In addition, our findings may indicate that potential prevention strategies for preservation of brain function on increasing physical activity, in particular HPA, may be more beneficial to the brain, as opposed to reduction of sedentary time. However, standardized regression coefficient were very similar for HPA and ST in model 1, which may indicate that the association between ST and connectivity is more strongly affected by mediating factors. Furthermore, reducing sedentary time might be easier to achieve, than engaging in HPA. Therefore, studies on sedentary time remain of high relevance for the development of easy applicable prevention strategies. In addition, our study population consists of relatively healthy participants, with adequate cognitive function and relatively low cerebral small vessel disease load (35). Therefore, analyses in more diseased populations may yield differential results.

In general, physical activity periodically increases blood flow to the brain, resulting in increased vascularization of the brain, improved supply of nutrients and removal of metabolic waste. More specifically, higher levels of physical activity or cardiorespiratory fitness have been associated with an increase in cerebral perfusion and cerebral oxygen supply to the prefrontal cortex (36), which is an area involved in motor function (37). Higher levels of physical activity stimulate processes of neurogenesis (formation of new neurons) and angiogenesis (formation of blood vessels), and reduce inflammation (38). Furthermore, being physically active has been shown to reduce cardiovascular risk factors such as type 2 diabetes and hypertension through increasing neurotrophic factors, reducing oxidative stress, and/or reducing beta-amyloid formation (39). These mechanisms may reduce the incidence of mild cognitive impairment and dementia $(2,3)$.

Strengths of this study are the large sample size, the population-based design, the objective measurement of physical activity and sedentary behavior, the extensive assessment of potential confounders which enabled us to substantially reduce potential residual confounding, and the broad array of additional analyses, which all gave consistent results. Furthermore, the use of diffusion MRI scans to study structural connectivity measures, enabled us to find more subtle brain alterations, as we did not find associations with brain volumes in this population. The large number of diffusion MRI scans, were semi-automatically processed blinded to group status, which ensures an objective analysis.

There are also some limitations. First, the cross-sectional design of the study implies that any conclusion about causality should be made with caution. Further longitudinal studies and intervention trials may be prompted to investigate whether specific connectivity loss can be reversed or prevented by increasing high-intensity physical activity. Second, the study population was oversampled for type 2 diabetes. However, analyses were adjusted for diabetes status, and no consistent interaction with diabetes status was observed. Third, participants with missing data had a more adverse cardiovascular risk profile, which might have led to an underestimation of our findings. Fourth, although we cannot 
exclude the possibility of residual confounding by variables not included in this study, we have adjusted for many known confounding factors, which may have resulted in overadjustment, and thus underestimate the association of physical activity and sedentary time with node degree.

We showed that objectively measured lower HPA, but not LPA and ST, were associated with lower whole brain node degree and node degree in specific brain regions highly specialized in motor function. Further research is needed to establish whether more HPA may preserve structural brain connectivity.

\section{References}

1. Scherder EJA, Van Paasschen J, Deijen JB, Van Der Knokke S, Orlebeke JFK, Burgers I, Devriese PP, Swaab DF, Sergeant JA. Physical activity and executive functions in the elderly with mild cognitive impairment. Aging \& Mental Health 2005;9(3):272-280. doi: 10.1080/13607860500089930

2. Kennedy G, Hardman RJ, Macpherson H, Scholey AB, Pipingas A. How Does Exercise Reduce the Rate of AgeAssociated Cognitive Decline? A Review of Potential Mechanisms. Journal of Alzheimer's disease : JAD 2017;55(1):1-18. doi: 10.3233/jad-160665

3. Gallaway PJ, Miyake H, Buchowski MS, Shimada M, Yoshitake Y, Kim AS, Hongu N. Physical Activity: A Viable Way to Reduce the Risks of Mild Cognitive Impairment, Alzheimer's Disease, and Vascular Dementia in Older Adults. Brain Sci 2017;7(2). doi: 10.3390/brainsci7020022

4. Mekari S, Dupuy O, Martins R, Evans K, Kimmerly DS, Fraser S, Neyedli HF. The effects of cardiorespiratory fitness on executive function and prefrontal oxygenation in older adults. GeroScience 2019;41(5):681-690. doi: 10.1007/s11357-019-00128-5

5. Wheeler MJ, Dempsey PC, Grace MS, Ellis KA, Gardiner PA, Green DJ, Dunstan DW. Sedentary behavior as a risk factor for cognitive decline? A focus on the influence of glycemic control in brain health. Alzheimer's \& Dementia: Translational Research \& Clinical Interventions 2017;3(3):291-300. doi: https://doi.org/10.1016/j.trci.2017.04.001

6. Falck RS, Davis JC, Liu-Ambrose T. What is the association between sedentary behaviour and cognitive function? A systematic review. British journal of sports medicine 2017;51(10):800-811. doi: 10.1136/bjsports-2015-095551

7. Doi T, Makizako H, Shimada H, Tsutsumimoto K, Hotta R, Nakakubo S, Park H, Suzuki T. Objectively measured physical activity, brain atrophy, and white matter lesions in older adults with mild cognitive impairment. Experimental gerontology 2015;62:1-6. doi: 10.1016/j.exger.2014.12.011

8. Spartano NL, Davis-Plourde KL, Himali JJ, Andersson C, Pase MP, Maillard P, DeCarli C, Murabito JM, Beiser AS, Vasan RS, Seshadri S. Association of Accelerometer-Measured Light-Intensity Physical Activity With Brain Volume: The Framingham Heart StudyAssociation of Accelerometer-Measured Light-Intensity Physical Activity With Brain VolumeAssociation of Accelerometer-Measured Light-Intensity Physical Activity With Brain Volume. JAMA Network Open 2019;2(4):e192745-e192745. doi: 10.1001/jamanetworkopen.2019.2745

9. Hamer M, Sharma N, Batty GD. Association of objectively measured physical activity with brain structure: UK Biobank study. Journal of internal medicine 2018;284(4):439-443. doi: 10.1111/joim.12772

10. Arnardottir NY, Koster A, Domelen DR, Brychta RJ, Caserotti P, Eiriksdottir G, Sverrisdottir JE, Sigurdsson S, Johannsson E, Chen KY, Gudnason V, Harris TB, Launer L, Sveinsson T. Association of change in brain structure to objectively measured physical activity and sedentary behavior in older adults: Age, Gene/Environment Susceptibility-Reykjavik Study. Behavioural brain research 2016;296:118-124. doi: 10.1016/j.bbr.2015.09.005

11. Willey JZ, Moon YP, Paik MC, Yoshita M, Decarli C, Sacco RL, Elkind MS, Wright CB. Lower prevalence of silent brain infarcts in the physically active: the Northern Manhattan Study. Neurology 2011;76(24):2112-2118. doi: 10.1212/WNL.0b013e31821f4472

12. Tucholka A, Grau-Rivera O, Falcon C, Rami L, Sánchez-Valle R, Lladó A, Gispert JD, Molinuevo JL, Alzheimer's Disease Neuroimaging I. Structural Connectivity Alterations Along the Alzheimer's Disease Continuum: 
Reproducibility Across Two Independent Samples and Correlation with Cerebrospinal Fluid Amyloid- $\beta$ and Tau. Journal of Alzheimer's disease : JAD 2018;61(4):1575-1587. doi: 10.3233/JAD-170553

13. Kim GH, Im K, Kwon H, Seo SW, Ye BS, Cho H, Noh Y, Lee JM, Kim ST, Park SE, Kim H, Hwang JW, Kang SJ, Jeong $\mathrm{JH}, \mathrm{Na}$ DL. Higher Physical Activity Is Associated with Increased Attentional Network Connectivity in the Healthy Elderly. Frontiers in aging neuroscience 2016;8:198. doi: 10.3389/fnagi.2016.00198

14. Brooks DJ. The role of the basal ganglia in motor control: contributions from PET. Journal of the neurological sciences 1995;128(1):1-13. doi: 10.1016/0022-510x(94)00206-4

15. Schram MT, Sep SJ, van der Kallen CJ, Dagnelie PC, Koster A, Schaper N, Henry RM, Stehouwer CD. The Maastricht Study: an extensive phenotyping study on determinants of type 2 diabetes, its complications and its comorbidities. Eur J Epidemiol 2014;29(6):439-451. doi: 10.1007/s10654-014-9889-0

16. van der Berg JD, Willems PJ, van der Velde JH, Savelberg HH, Schaper NC, Schram MT, Sep SJ, Dagnelie PC, Bosma $\mathrm{H}$, Stehouwer CD, Koster A. Identifying waking time in 24-h accelerometry data in adults using an automated algorithm. Journal of sports sciences 2016;34(19):1867-1873. doi: 10.1080/02640414.2016.1140908

17. van der Berg JD, Stehouwer CDA, Bosma H, van der Velde JHPM, Willems PJB, Savelberg HHCM, Schram MT, Sep SJS, van der Kallen CJH, Henry RMA, Dagnelie PC, Schaper NC, Koster A. Associations of total amount and patterns of sedentary behaviour with type 2 diabetes and the metabolic syndrome: The Maastricht Study. Diabetologia 2016;59(4):709-718. doi: 10.1007/s00125-015-3861-8

18. Tudor-Locke C, Rowe DA. Using cadence to study free-living ambulatory behaviour. Sports medicine (Auckland, NZ) 2012;42(5):381-398. doi: 10.2165/11599170-000000000-00000

19. Weggemans RM, Backx FJG, Borghouts L, Chinapaw M, Hopman MTE, Koster A, Kremers S, van Loon LIC, May A, Mosterd A, van der Ploeg HP, Takken T, Visser M, Wendel-Vos GCW, de Geus EJC. The 2017 Dutch Physical Activity Guidelines. The international journal of behavioral nutrition and physical activity 2018;15(1):58. doi: 10.1186/s12966-018-0661-9

20. Piercy KL, Troiano RP, Ballard RM, Carlson SA, Fulton JE, Galuska DA, George SM, Olson RD. The Physical Activity Guidelines for Americans. Jama 2018;320(19):2020-2028. doi: 10.1001/jama.2018.14854

21. Tzourio-Mazoyer N, Landeau B, Papathanassiou D, Crivello F, Etard O, Delcroix N, Mazoyer B, Joliot M. Automated anatomical labeling of activations in SPM using a macroscopic anatomical parcellation of the MNI MRI single-subject brain. Neuroimage 2002;15(1):273-289. doi: 10.1006/nimg.2001.0978

22. Fonov V, Evans AC, Botteron K, Almli CR, McKinstry RC, Collins DL. Unbiased average age-appropriate atlases for pediatric studies. Neurolmage 2011;54(1):313-327. doi: https://doi.org/10.1016/j.neuroimage.2010.07.033

23. Vrooman HA, Cocosco CA, van der Lijn F, Stokking R, Ikram MA, Vernooij MW, Breteler MM, Niessen WJ. Multispectral brain tissue segmentation using automatically trained k-Nearest-Neighbor classification. Neurolmage 2007;37(1):71-81. doi: 10.1016/j.neuroimage.2007.05.018

24. de Boer R, Vrooman HA, van der Lijn F, Vernooij MW, Ikram MA, van der Lugt A, Breteler MM, Niessen WJ. White matter lesion extension to automatic brain tissue segmentation on MRI. Neurolmage 2009;45(4):1151-1161. doi: 10.1016/j.neuroimage.2009.01.011

25. Leemans A, Jeurissen B, Sijbers J, Jones D. ExploreDTI: a graphical toolbox for processing, analyzing, and visualizing diffusion MR data. ISMRM 17th Scientific Meeting \& Exhibition2009; p. 3537.

26. Tournier JD, Calamante F, Connelly A. Determination of the appropriate $b$ value and number of gradient directions for high-angular-resolution diffusion-weighted imaging. NMR in Biomedicine 2013;26(12):1775-1786. doi: 10.1002/nbm.3017

27. Jeurissen B, Leemans A, Jones DK, Tournier J-D, Sijbers J. Probabilistic fiber tracking using the residual bootstrap with constrained spherical deconvolution. Human Brain Mapping 2011;32(3):461-479. doi: 10.1002/hbm.21032

28. Vaessen MJ, Jansen JFA, Vlooswijk MCG, Hofman PAM, Majoie HJM, Aldenkamp AP, Backes WH. White Matter Network Abnormalities Are Associated with Cognitive Decline in Chronic Epilepsy. Cerebral Cortex 2011;22(9):2139-2147. doi: 10.1093/cercor/bhr298

29. Vergoossen LW, Schram MT, de Jong JJ, Stehouwer CD, Schaper NC, Henry RM, van der Kallen CJ, Dagnelie PC, van Boxtel MP, Eussen SJ, Backes WH, Jansen JF. White Matter Connectivity Abnormalities in Prediabetes and Type 2 Diabetes: The Maastricht Study. Diabetes care 2019:dc190762. doi: 10.2337/dc19-0762 
30. Whitwell JL, Crum WR, Watt HC, Fox NC. Normalization of cerebral volumes by use of intracranial volume: implications for longitudinal quantitative MR imaging. AJNR Am J Neuroradiol 2001;22(8):1483-1489.

31. Rubinov M, Sporns O. Complex network measures of brain connectivity: uses and interpretations. Neurolmage 2010;52(3):1059-1069. doi: 10.1016/j.neuroimage.2009.10.003

32. de Reus MA, van den Heuvel MP. Estimating false positives and negatives in brain networks. Neurolmage 2013;70:402-409. doi: 10.1016/j.neuroimage.2012.12.066

33. Schram MT, Sep SJS, van der Kallen CJ, Dagnelie PC, Koster A, Schaper N, Henry RMA, Stehouwer CDA. The Maastricht Study: an extensive phenotyping study on determinants of type 2 diabetes, its complications and its comorbidities. European Journal of Epidemiology 2014;29(6):439-451. doi: 10.1007/s10654-014-9889-0

34. Voss MW, Heo S, Prakash RS, Erickson KI, Alves H, Chaddock L, Szabo AN, Mailey EL, Wójcicki TR, White SM, Gothe N, McAuley E, Sutton BP, Kramer AF. The influence of aerobic fitness on cerebral white matter integrity and cognitive function in older adults: results of a one-year exercise intervention. Human brain mapping 2013;34(11):2972-2985. doi: 10.1002/hbm.22119

35. van Agtmaal MJM, Houben A, de Wit V, Henry RMA, Schaper NC, Dagnelie PC, van der Kallen CJ, Koster A, Sep SJ, Kroon AA, Jansen JFA, Hofman PA, Backes WH, Schram MT, Stehouwer CDA. Prediabetes Is Associated With Structural Brain Abnormalities: The Maastricht Study. Diabetes care 2018;41(12):2535-2543. doi: 10.2337/dc181132

36. Dupuy O, Gauthier CJ, Fraser SA, Desjardins-Crèpeau L, Desjardins M, Mekary S, Lesage F, Hoge RD, Pouliot P, Bherer $L$. Higher levels of cardiovascular fitness are associated with better executive function and prefrontal oxygenation in younger and older women. Frontiers in human neuroscience 2015;9(66). doi: 10.3389/fnhum.2015.00066

37. Goldman-Rakic PS. Motor control function of the prefrontal cortex. Ciba Found Symp 1987;132:187-200. doi: 10.1002/9780470513545.ch12

38. Trigiani $\amalg$, Hamel E. An endothelial link between the benefits of physical exercise in dementia. Journal of Cerebral Blood Flow \& Metabolism 2017;37(8):2649-2664. doi: 10.1177/0271678x17714655

39. Zimmerman B, Sutton B, Low K, Fletcher M, Tan CH, Schneider-Garces N, Li Y, Ouyang C, Maclin E, Gratton G, Fabiani M. Cardiorespiratory fitness mediates the effects of aging on cerebral blood flow. Frontiers in aging neuroscience 2014;6(59). doi: 10.3389/fnagi.2014.00059 


\section{Supplementary Material}

\section{Detailed protocols of the measurements performed within The Maastricht}

\section{Study:}

Questionnaires. As described elsewhere (1), we used web-based questionnaires to obtain information regarding smoking status (never/former/current), alcohol consumption, educational level, physical activity, diet, prior CVD and cognitive impairment. Alcohol consumption was classified as none, low (1- 7 glasses/wk for women and 1-14 glasses/wk for men) and high (> 7 glasses/wk for women and $>14$ glasses/wk for men). Educational level was classified as low (no education, primary education, lower vocational education), intermediate (intermediate general secondary education, intermediate vocational education, higher general secondary education), or high (higher vocational education or university). Diet was assessed by a tailor-made FFQ developed by use of the National FFQ Tool. Prior CVD was defined as a history of myocardial infarction; stroke; or vascular surgery (including angioplasty) on coronary, carotid, abdominal aortic, or peripheral arteries based on the Rose questionnaire. Cognitive impairment was measured using the Mini-Mental State Examination (MMSE). Medication use was assessed in a medication interview where generic name, dose, and frequency were registered. Subjective physical activity was assessed by means of a modified version of the Champs questionnaire.

Laboratory assessments. Plasma glucose is measured with a standard enzymatic hexokinase reference method, and serum total cholesterol, HDL cholesterol, and triglycerides are measured with standard (enzymatic and/or colorimetric) methods by an automatic analyzer (until 9 May 2012: Beckman Synchron LX20, Beckman Coulter Inc., Brea, USA; after 9 May 2012: Cobas 6000, Roche diagnostics, Mannheim, Germany). When appropriate LDL cholesterol is calculated according to the Friedewald formula(2). HbA1c is measured with ion-exchange high performance liquid chromatography (HPLC) (Variant tm II, Bio-Rad, Hercules, California, USA).

Glucose metabolism status. To determine glucose metabolism status, all participants, except those who used insulin, underwent a standardized 2-h $75 \mathrm{~g}$ oral glucose tolerance test (OGTT) after an overnight fast. For safety reasons, participants with a fasting glucose level above $11.0 \mathrm{mmol} / \mathrm{L}$, as determined by a finger prick, did not undergo the OGTT. For these individuals, fasting glucose level and information about diabetes medication were used to determine glucose metabolism status. Glucose metabolism status was defined according to the WHO 2006 criteria into NGM, prediabetes, and T2DM(3). Participants were considered to have T2DM if they had a fasting blood glucose (FBG) $\geq 7.0 \mathrm{mmol} / \mathrm{l}$, or a $2 \mathrm{hr}$ post-load blood glucose $\geq 11.1 \mathrm{mmol} / \mathrm{l}$ or used oral glucose-lowering medication or insulin, prediabetes if they had a FBG $\geq 6.1 \mathrm{mmol} / \mathrm{l}$ and/or a $2 \mathrm{hr}$ post-load blood glucose $\geq 7.8 \mathrm{mmol} / \mathrm{l}$, and NGM if they had a FBG $<6.1 \mathrm{mmol} / \mathrm{l}$, and a $2 \mathrm{hr}$ post-load blood glucose $<7.8 \mathrm{mmol} / \mathrm{l}$ and no use of diabetes medication. Participants with type 1 diabetes or other types of diabetes were excluded from the analysis.

Physical examination. Weight and height are measured without shoes and wearing light clothing using a scale and stadiometer to the nearest $0.5 \mathrm{~kg}$ or $0.1 \mathrm{~cm}$ (Seca, Hamburg, Germany). Waist circumference is 
measured with a flexible plastic tape measure (Seca, Hamburg, Germany) in a duplicate midway between the lower rib margin and the iliac crest at the end of expiration, to the nearest $0.5 \mathrm{~cm}$.

Blood pressure. Office blood pressure is determined three times on the right arm after a 10-minute rest period, using a non-invasive blood pressure monitor (Omron 705IT, Japan). When the difference between measurement two and three is more than $10 \mathrm{mmHg}$, a fourth measurement is performed. All available measurements are used to calculate the average blood pressure. Ambulatory 24-h blood pressure (WatchBP O3, Microlife, Switzerland, respectively) is measured at the non-dominant arm, using an ambulatory device that is programmed to take blood pressure readings every 15 minutes from $8.00-23.00$ and every 30 minutes from $23.00-8.00$.

\section{Detailed methods for calculation of reference networks and sparsity:}

In structural connectivity analysis, connectivity matrices are based on tractography. As a result, not all pairs of nodes will have white matter connections, which leads to 'sparse' connectivity matrices. The measure sparsity reflects the extent of a graph's deviation from the corresponding fully connected graph. However, this differs between subjects and is also influenced by scan quality. Therefore, thresholding is applied, which ensures that each subject has the same number of nodes and edges. The reference network was calculated from all individual binarized connectivity matrices, for a specific subset of participants (e.g., the physical activity network was based on the participants who met the physical activity guidelines). This is illustrated in a simplified example, not a real network (Supplementary Figure 4.3). First, all individual binarized connectivity matrices were summed (Step 1 in Supplementary Figure 4.3). This reference network was proportionally thresholded to a sparsity of 0.80 (Step 2 in Supplementary Figure 4.3). This means that the $20 \%$ connections that were present in most of the participants were selected, in other words, the $20 \%$ of the nodes with the highest sum score. These $20 \%$ nodes were used to create a binary mask (Step 3 in Supplementary Figure 4.3) that was used to select for each participant a weighted, undirected network with a sparsity, close to the sparsity of the reference network (Step 4 in Supplementary Figure 4.3). The actual sparsity in the individuals is a bit higher than 0.80 , because not each individual has a white matter tract at each connection in the reference network.

\section{Supplemental References}

1. Schram MT, Sep SJ, van der Kallen CJ, Dagnelie PC, Koster A, Schaper N, Henry RM, Stehouwer CD. The Maastricht Study: an extensive phenotyping study on determinants of type 2 diabetes, its complications and its comorbidities. Eur J Epidemiol 2014;29(6):439-451. doi: 10.1007/s10654-014-9889-0

2. Friedewald WT, Levy RI, Fredrickson DS. Estimation of the concentration of low-density lipoprotein cholesterol in plasma, without use of the preparative ultracentrifuge. Clin Chem 1972;18(6):499-502.

3. Organization WH. Definition and diagnosis of diabetes mellitus and intermediate hyperglycemia: report of a WHO/IDF consultation. Geneva, Switzerland2006. 


\section{Supplementary Figures}

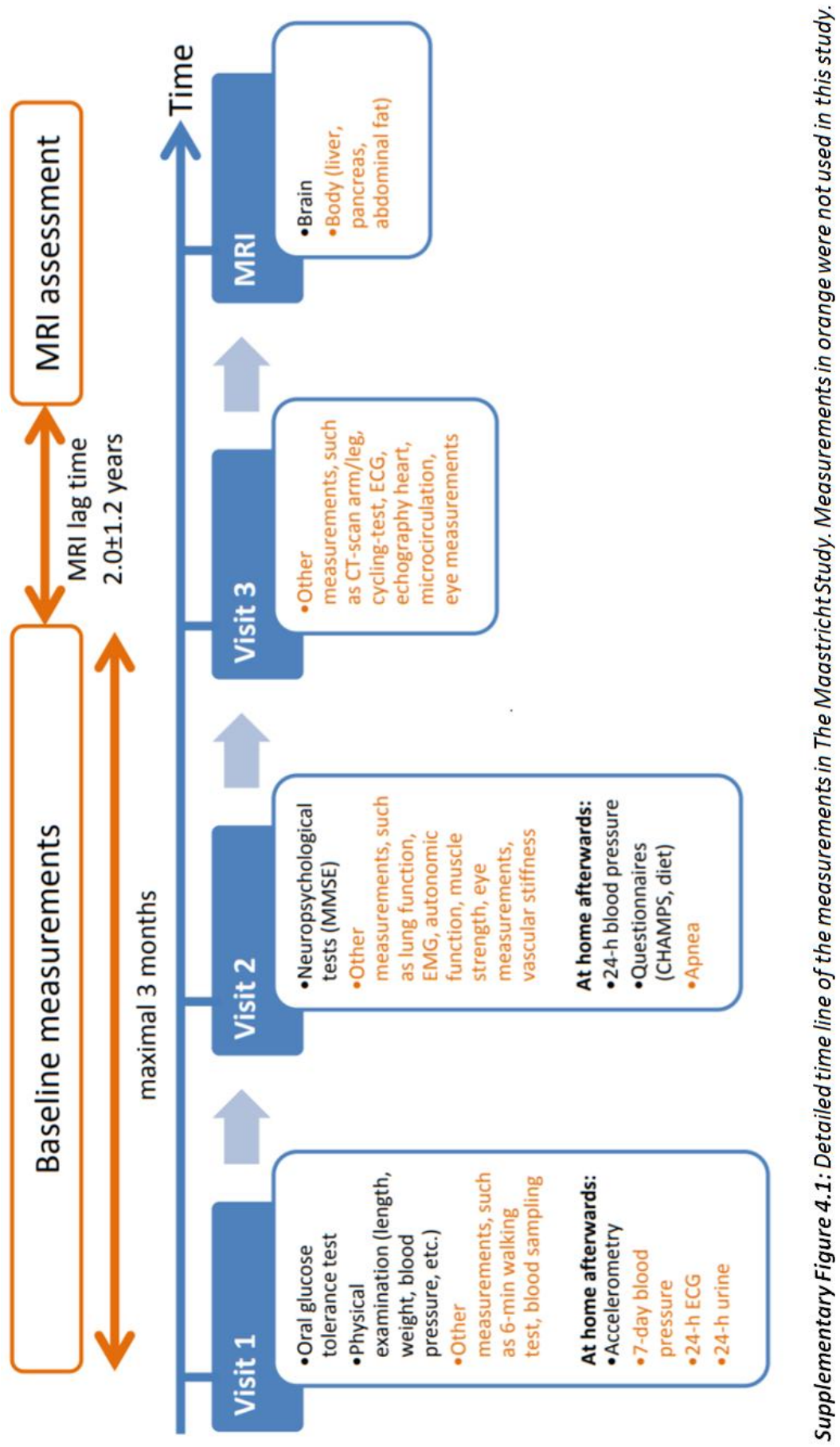


The Maastricht Study population $(n=3451)$

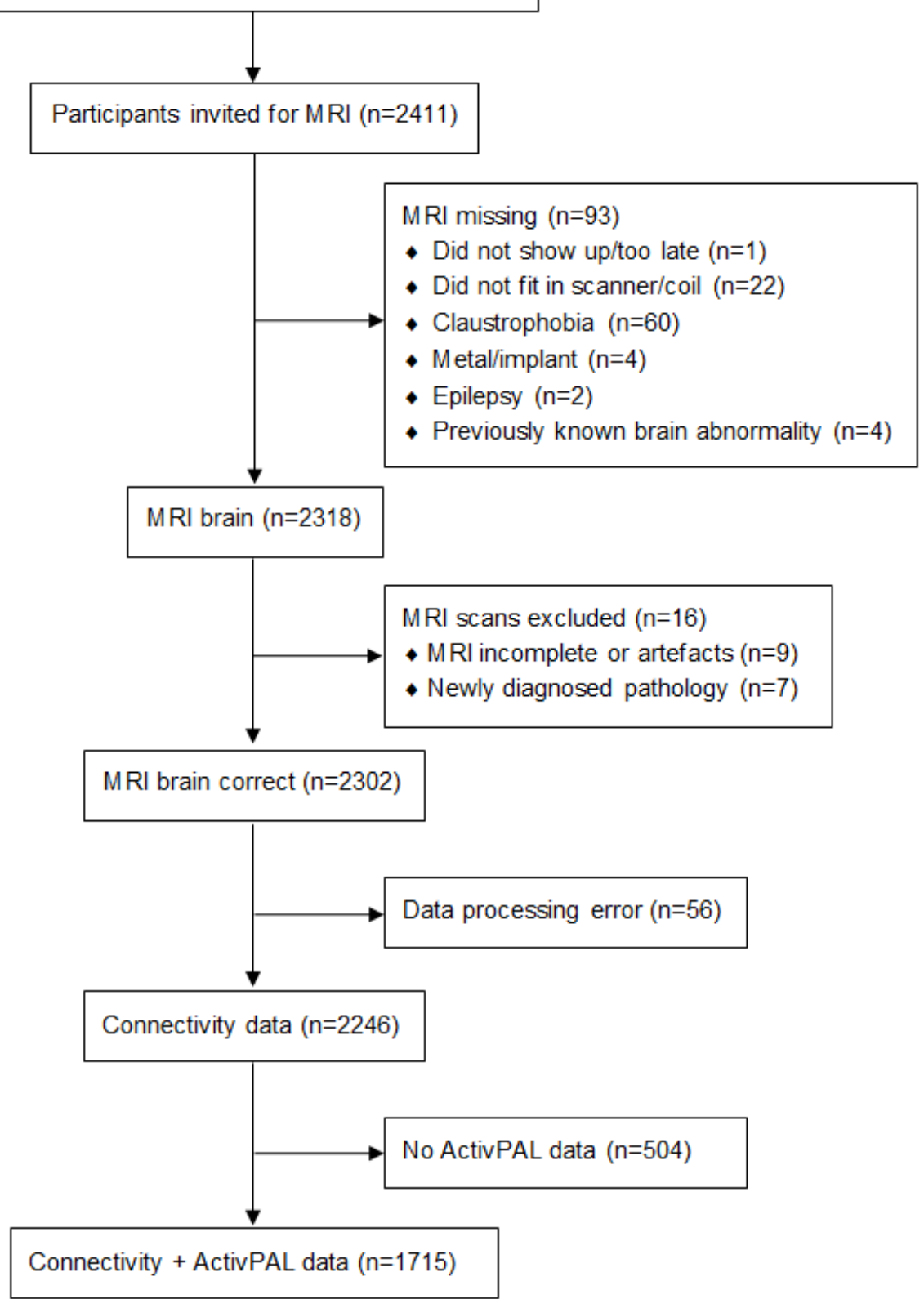

Supplementary Figure 4.2: Flowchart of the study population. 

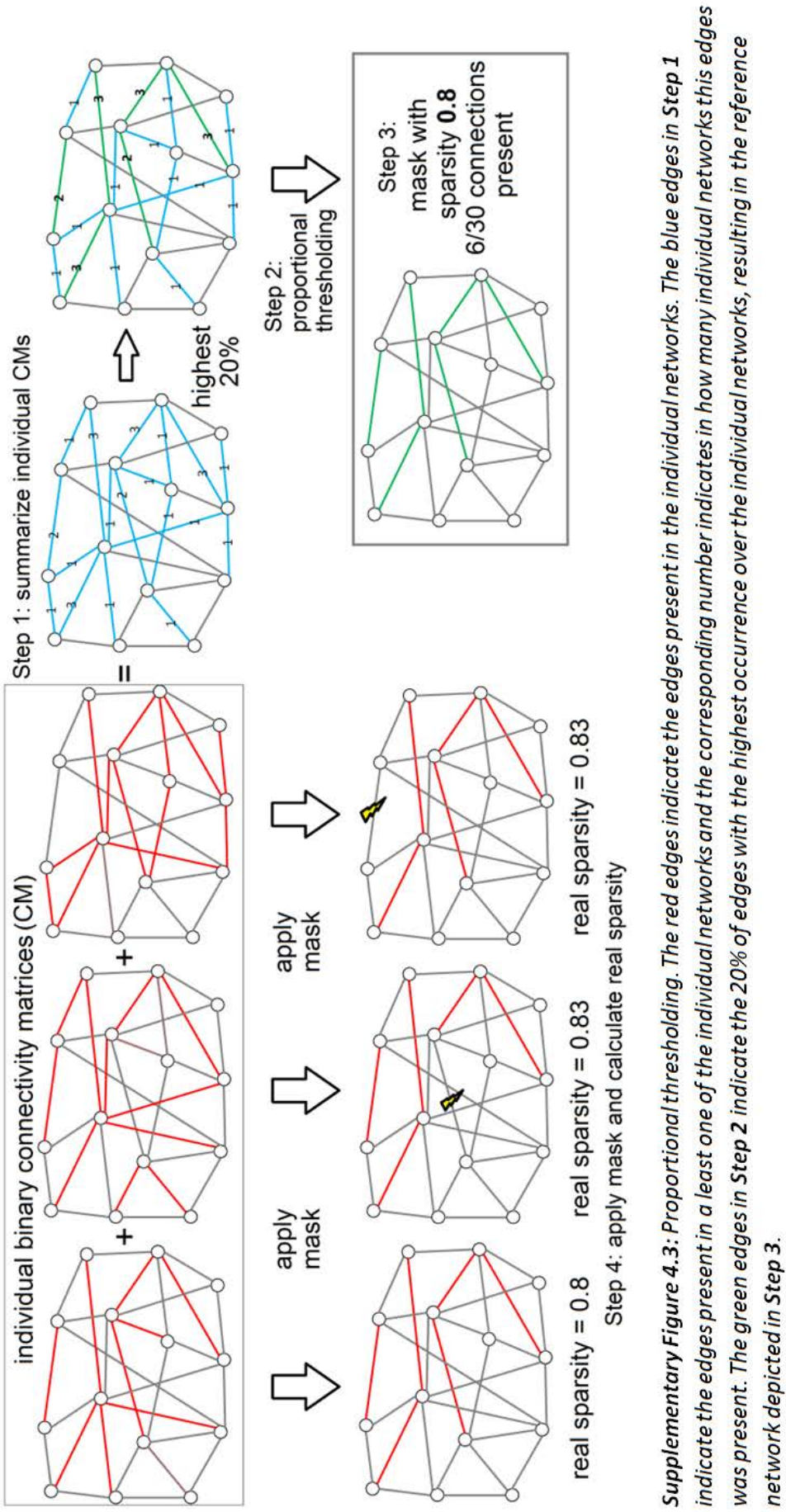


\section{Supplementary Tables}

Supplementary Table 4.1: General characteristics of participants stratified by availability of physical activity and/or brain MRI data.

\begin{tabular}{|c|c|c|c|c|}
\hline Characteristic & $\begin{array}{c}\text { Total } \\
(n=3451)\end{array}$ & $\begin{array}{l}\text { Physical activity and } \\
\text { MRI data available } \\
(n=1715) \\
\end{array}$ & $\begin{array}{l}\text { Physical activity and/or } \\
\text { MRI data not available } \\
(n=1736)\end{array}$ & $P$ \\
\hline \multicolumn{5}{|l|}{ Demographics } \\
\hline Age (years) & $59.8 \pm 8.3$ & $59.6 \pm 8.1$ & $60.0 \pm 8.5$ & 0.183 \\
\hline Sex, female (\%) & 48.6 & 48.4 & 48.7 & 0.843 \\
\hline $\begin{array}{l}\text { Education level (\%), } \\
\text { Low/Middle/High }\end{array}$ & $33.6 / 28.2 / 38.2$ & $30.5 / 29.0 / 40.5$ & $36.6 / 27.5 / 35.9$ & $<0.001$ \\
\hline \multicolumn{5}{|l|}{ Cardiovascular risk factors } \\
\hline $\mathrm{BMI}\left(\mathrm{kg} / \mathrm{m}^{2}\right)$ & $27.1 \pm 4.6$ & $26.6 \pm 4.2$ & $27.5 \pm 4.8$ & $<0.001$ \\
\hline Waist circumference $(\mathrm{cm})$ & $95.9 \pm 13.8$ & $94.4 \pm 12.7$ & $97.5 \pm 14.6$ & $<0.001$ \\
\hline $\begin{array}{l}\text { Systolic blood pressure } \\
\text { (mmHg) }\end{array}$ & $135.1 \pm 18.2$ & $134.0 \pm 17.3$ & $136.1 \pm 19.0$ & 0.001 \\
\hline $\begin{array}{l}\text { Diastolic blood pressure } \\
(\mathrm{mmHg})\end{array}$ & $76.1 \pm 9.9$ & $76.1 \pm 9.7$ & $76.2 \pm 10$ & 0.634 \\
\hline T2DM (\%) & 23.0 & 23.7 & 20.9 & $<0.001$ \\
\hline Hypertension, yes (\%) & 56.4 & 53.3 & 59.4 & $<0.001$ \\
\hline $\begin{array}{l}\text { Total cholesterol-to-HDL- } \\
\text { ratio }\end{array}$ & $3.6 \pm 1.2$ & $3.6 \pm 1.1$ & $3.9 \pm 1.3$ & $<0.001$ \\
\hline History of CVD, yes (\%) & 16.7 & 12.7 & 20.7 & $<0.001$ \\
\hline \multicolumn{5}{|l|}{ Medication use } \\
\hline $\begin{array}{l}\text { Diabetes medication, yes } \\
\text { (\%) }\end{array}$ & 19.7 & 18.0 & 60.6 & $<0.001$ \\
\hline $\begin{array}{l}\text { Antihypertensive } \\
\text { medication, yes (\%) }\end{array}$ & 35.1 & 36.1 & 32.1 & 0.079 \\
\hline $\begin{array}{l}\text { Lipid-modifying medication, } \\
\text { yes (\%) }\end{array}$ & 31.1 & 31.5 & 30.1 & 0.546 \\
\hline \multicolumn{5}{|l|}{ Lifestyle factors } \\
\hline Alcohol (\%), None/Low/High & $18.6 / 55.4 / 26.0$ & $17.0 / 57.2 / 25.9$ & $20.2 / 53.7 / 26.1$ & 0.001 \\
\hline $\begin{array}{l}\text { Smoking (\%), } \\
\text { Never/Former/Current }\end{array}$ & $34.5 / 51.6 / 13.8$ & $38.0 / 49.8 / 12.3$ & $31.1 / 51.9 / 15.4$ & $<0.001$ \\
\hline \multicolumn{5}{|l|}{ Cognitive score } \\
\hline MMSE total score & $28.9 \pm 1.3$ & $29.0 \pm 1.2$ & $28.9 \pm 1.4$ & $<0.001$ \\
\hline \multicolumn{5}{|l|}{ Other } \\
\hline MRI lag time & $2.3 \pm 1.3$ & $2.0 \pm 1.2$ & $2.9 \pm 1.4^{*}$ & $<0.001$ \\
\hline $\begin{array}{l}\text { Data are presented as means } \\
\text { indicates type } 2 \text { diabetes mel } \\
\text { Mini-Mental State Examinati }\end{array}$ & $\begin{array}{l}\text { andard deviati } \\
\text {; HDL, high-de } \\
n=699 \text { (physic }\end{array}$ & $\begin{array}{l}\text { percentages for cat } \\
\text { poprotein; CVD, cal } \\
\text { ity data not availak }\end{array}$ & $\begin{array}{l}\text { ical variables. T2DM, } \\
\text { ascular disease; MMSE, }\end{array}$ & \\
\hline
\end{tabular}


Supplementary Table 4.2a: Associations of total physical activity time with whole brain node degree and node degree of the basal ganglia and primary motor cortex.

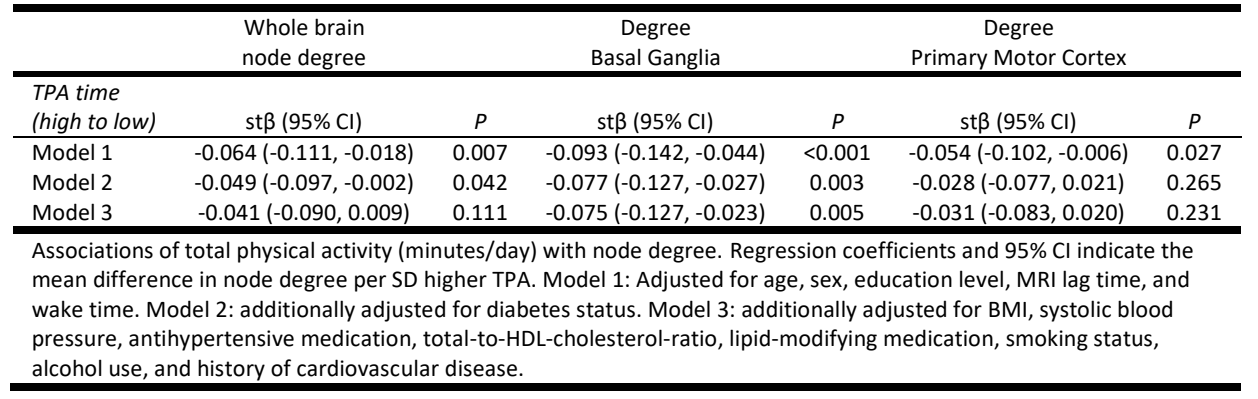

Supplementary Table 4.2b: Associations of total physical activity time with total brain and white matter volume.

\begin{tabular}{|c|c|c|c|c|}
\hline & \multicolumn{2}{|l|}{ Total brain volume } & \multicolumn{2}{|l|}{ WM volume } \\
\hline TPA time (high to low) & st $\beta(95 \% \mathrm{Cl})$ & $P$ & st $\beta(95 \% \mathrm{Cl})$ & $P$ \\
\hline Model 1 & $-0.022(-0.035,-0.008)$ & 0.001 & $0.004(-0.019,0.026)$ & 0.746 \\
\hline Model 2 & $-0.012(-0.026,0.012)$ & 0.092 & $0.014(-0.009,0.037)$ & 0.241 \\
\hline Model 3 & $-0.009(-0.024,0.005)$ & 0.189 & $0.013(-0.011,0.037)$ & 0.280 \\
\hline \multicolumn{5}{|c|}{$\begin{array}{l}\text { Associations between physical activity measures (minutes/day) with brain volumes. } \\
\text { Regression coefficients and } 95 \% \mathrm{Cl} \text { indicate the mean difference in volume per SD } \\
\text { higher TPA time. Model 1: Adjusted for age, sex, education level, MRI lag time, wake time, } \\
\text { and ICV. Model 2: additionally adjusted for diabetes status. Model 3: additionally } \\
\text { adjusted for BMI, systolic blood pressure, antihypertensive medication, } \\
\text { total-to-HDL-cholesterol-ratio, lipid-modifying medication, smoking status, alcohol use, } \\
\text { and history of cardiovascular disease. }\end{array}$} \\
\hline
\end{tabular}

Supplementary Table 4.2c: Associations of total physical activity time with node degree of the frontal, temporal, parietal and occipital lobe.

\begin{tabular}{|c|c|c|c|c|}
\hline & $\begin{array}{c}\text { Degree } \\
\text { Frontal lobe }\end{array}$ & $\begin{array}{c}\text { Degree } \\
\text { Temporal lobe }\end{array}$ & $\begin{array}{c}\text { Degree } \\
\text { Parietal lobe }\end{array}$ & $\begin{array}{c}\text { Degree } \\
\text { Occipital lobe }\end{array}$ \\
\hline $\begin{array}{l}\text { TPA time } \\
\text { (high to low) }\end{array}$ & st $\beta(95 \% \mathrm{Cl})$ & st $\beta(95 \% \mathrm{Cl})$ & st $\beta(95 \% \mathrm{Cl})$ & st $\beta(95 \% \mathrm{Cl})$ \\
\hline Model 1 & $-0.050(-0.098,-0.003)$ & $-0.056(-0.105,-0.007)$ & $0.031(-0.017,0.080)$ & $0.013(-0.036,0.062)$ \\
\hline Model 2 & $-0.027(-0.075,0.022)$ & $-0.054(-0.104,-0.003)$ & $0.022(-0.027,0.072)$ & $0.019(-0.031,0.069)$ \\
\hline Model 3 & $-0.019(-0.070,0.032)$ & $-0.054(-0.106,-0.001)$ & $0.014(-0.038,0.066)$ & $0.016(-0.037,0.068)$ \\
\hline \multicolumn{5}{|c|}{$\begin{array}{l}\text { Associations of physical activity measures (minutes/day) with node degree. Regression coefficients and } 95 \% \mathrm{Cl} \text { indicate the mean } \\
\text { difference in node degree per SD higher PA time. Model 1: Adjusted for age, sex, education level, MRI lag time, and wake time. M } \\
\text { 2: additionally adjusted for diabetes status. Model 3: additionally adjusted for BMI, systolic blood pressure, antihypertensive } \\
\text { medication, total-to-HDL-cholesterol-ratio, lipid-modifying medication, smoking status, alcohol use, and history of cardiovascular } \\
\text { disease. }\end{array}$} \\
\hline
\end{tabular}


Supplementary Table 4.3: Associations of physical activity time determined with CHAMPS questionnaire with whole brain node degree and node degree of the basal ganglia and primary motor cortex.

\begin{tabular}{|c|c|c|c|c|c|c|}
\hline \multicolumn{3}{|c|}{$\begin{array}{l}\text { Whole brain } \\
\text { node degree }\end{array}$} & \multirow[t]{2}{*}{$\begin{array}{c}\text { Degree } \\
\text { Basal Ganglia }\end{array}$} & \multicolumn{3}{|c|}{$\begin{array}{c}\text { Degree } \\
\text { Primary Motor Cortex }\end{array}$} \\
\hline \multicolumn{6}{|c|}{ Total PA time (high to low) } & \\
\hline & st $\beta(95 \% \mathrm{Cl})$ & $P$ & st $\beta(95 \% \mathrm{Cl})$ & $P$ & st $\beta(95 \% \mathrm{Cl})$ & $P$ \\
\hline Model 1 & $-0.032(-0.081,0.016)$ & 0.188 & $-0.055(-0.106,-0.004)$ & 0.033 & $-0.069(-0.119,-0.020)$ & 0.006 \\
\hline Model 2 & $-0.023(-0.072,0.025)$ & 0.343 & $-0.045(-0.096,0.006)$ & 0.081 & $-0.056(-0.106,-0.006)$ & 0.027 \\
\hline Model 3 & $-0.019(-0.068,0.029)$ & 0.433 & $-0.041(-0.092,0.010)$ & 0.113 & $-0.057(-0.107,-0.007)$ & 0.025 \\
\hline \multicolumn{7}{|c|}{ MVPA time (high to low) } \\
\hline & st $\beta(95 \% \mathrm{Cl})$ & $P$ & st $\beta(95 \% \mathrm{Cl})$ & $P$ & st $\beta(95 \% \mathrm{Cl})$ & $P$ \\
\hline Model 1 & $-0.065(-0.111,-0.018)$ & 0.007 & $-0.104(-0.153,-0.055)$ & $<0.001$ & $-0.102(-0.150,-0.054)$ & $<0.001$ \\
\hline Model 2 & $-0.054(-0.101,-0.007)$ & 0.026 & $-0.093(-0.142,-0.044)$ & $<0.001$ & $-0.087(-0.135,-0.038)$ & $<0.001$ \\
\hline Model 3 & $-0.049(-0.097,0.001)$ & 0.043 & $-0.075(-0.140,-0.040)$ & $<0.001$ & $-0.091(-0.140,-0.041)$ & $<0.001$ \\
\hline \multicolumn{7}{|c|}{$\begin{array}{l}\text { Associations of physical activity (CHAMPS questionnaire) with node degree. Regression coefficients and } 95 \% \mathrm{Cl} \text { indicate the me an } \\
\text { difference in node degree per SD higher PA. Model 1: Adjusted for age, sex, education level, and MRI lag time. Model } 2 \text { : additionally } \\
\text { adjusted for diabetes status. Model 3: additionally adjusted for BMI, systolic blood pressure, antihypertensive medication, total-to- } \\
\text { HDL-cholesterol-ratio, lipid-modifying medication, smoking status, alcohol use, and history of cardiovascular disease. MVPA indicates } \\
\text { mild-to-vigorous physical activity (hours/week). CHAMPS questionnaire information available in n=1486. }\end{array}$} \\
\hline
\end{tabular}

Supplementary Table 4.4: Associations of low and high-intensity physical activity time, and high sedentary time with whole brain node degree, additionally corrected for waist circumference, $24 \mathrm{~h}$ blood pressure, MRI quality, diet, or white matter hyperintensity volume.

\begin{tabular}{|c|c|c|}
\hline \multicolumn{3}{|c|}{ Whole brain node degree } \\
\hline LPA time (high to low) & st $\beta(95 \% \mathrm{Cl})$ & P-value \\
\hline Model 3 & $-0.013(-0.061,0.034)$ & 0.580 \\
\hline Model 3 + waist circ. for BMI & $-0.012(-0.060,0.036)$ & 0.621 \\
\hline Model $3+24$ h for office BP & $-0.010(-0.062,0.042)$ & 0.705 \\
\hline Model 3 + MRI quality & $-0.007(-0.052,0.038)$ & 0.757 \\
\hline Model 3 + DHD score & $-0.008(-0.057,0.041)$ & 0.736 \\
\hline Model $3+$ WMH* $^{*}$ ICV & $-0.008(-0.056,0.039)$ & 0.725 \\
\hline HPA time (high to low) & st $\beta(95 \% \mathrm{Cl})$ & P-value \\
\hline Model 3 & $-0.062(-0.112,-0.013)$ & 0.014 \\
\hline Model 3 + waist circ. for BMI & $-0.056(-0.107,-0.006)$ & 0.027 \\
\hline Model $3+24 h$ for office BP & $-0.070(-0.124,-0.015)$ & 0.012 \\
\hline Model 3 + MRI quality & $-0.054(-0.102,-0.007)$ & 0.023 \\
\hline Model 3 + DHD score & $-0.064(-0.115,-0.014)$ & 0.013 \\
\hline Model $3+\mathrm{WMH}^{*}+\mathrm{ICV}$ & $-0.061(-0.110,-0.012)$ & 0.015 \\
\hline Sedentary time (low to high) & st $\beta(95 \% \mathrm{Cl})$ & P-value \\
\hline Model 3 & $-0.030(-0.081,0.021)$ & 0.250 \\
\hline Model 3 + waist circ. for BMI & $-0.019(-0.070,0.033)$ & 0.478 \\
\hline Model $3+24 \mathrm{~h}$ for office BP & $-0.026(-0.083,0.030)$ & 0.362 \\
\hline Model 3 + MRI quality & $-0.019(-0.068,0.030)$ & 0.448 \\
\hline Model 3 + DHD score & $-0.022(-0.075,0.031)$ & 0.414 \\
\hline Model $3+\mathrm{WMH}^{*}+\mathrm{ICV}$ & $-0.025(-0.076,0.026)$ & 0.327 \\
\hline \multicolumn{3}{|c|}{ 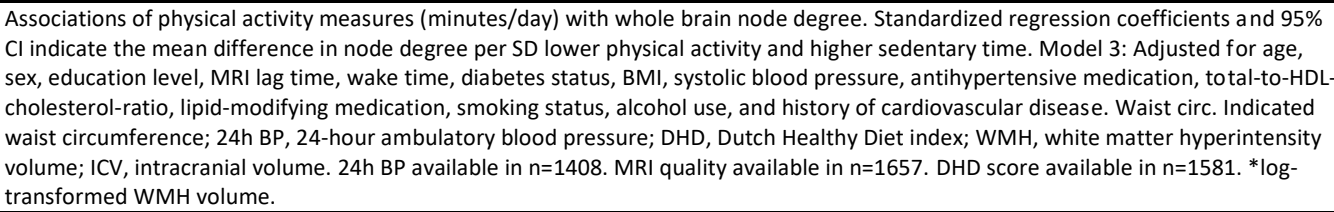 } \\
\hline
\end{tabular}


Supplementary Table 4.5: Associations of low-and high-intensity physical activity time, and high sedentary time with node degree of the basal ganglia and the primary motor cortex.

\begin{tabular}{|c|c|c|c|c|}
\hline & $\begin{array}{c}\text { Degree } \\
\text { Basal Ganglia }\end{array}$ & & $\begin{array}{c}\text { Degree } \\
\text { Primary Motor Cortex }\end{array}$ & \\
\hline LPA time (high to low) & st $\beta(95 \% \mathrm{Cl})$ & & st $\beta(95 \% \mathrm{Cl})$ & \\
\hline Model 3 & $-0.049(-0.098,0.001)$ & 0.056 & $-0.017(-0.066,0.032)$ & 0.489 \\
\hline Model 3 + waist circ. for BMI & $-0.048(-0.098,0.002)$ & 0.059 & $-0.017(-0.066,0.032)$ & 0.490 \\
\hline Model $3+24 h$ for office BP & $-0.062(-0.116,-0.009)$ & 0.022 & $-0.015(-0.068,0.038)$ & 0.574 \\
\hline Model $3+$ MRI quality & $-0.045(-0.094,0.004)$ & 0.074 & $-0.018(-0.067,0.031)$ & 0.475 \\
\hline Model 3 + DHD score & $-0.044(-0.096,0.007)$ & 0.092 & $-0.005(-0.056,0.046)$ & 0.838 \\
\hline HPA time (high to low) & st $\beta(95 \% \mathrm{Cl})$ & & st $\beta(95 \% \mathrm{Cl})$ & \\
\hline Model 3 & $-0.070(-0.121,-0.018)$ & 0.009 & $-0.035(-0.086,0.016)$ & 0.178 \\
\hline Model 3 + waist circ. for BMI & $-0.066(-0.119,-0.014)$ & 0.014 & $-0.035(-0.087,0.016)$ & 0.181 \\
\hline Model $3+24 h$ for office BP & $-0.080(-0.136,-0.023)$ & 0.006 & $-0.052(-0.108,0.004)$ & 0.068 \\
\hline Model 3 + MRI quality & $-0.066(-0.117,-0.014)$ & 0.012 & $-0.036(-0.087,0.015)$ & 0.172 \\
\hline Model 3 + DHD score & $-0.069(-0.112,-0.016)$ & 0.011 & $-0.033(-0.086,0.020)$ & 0.219 \\
\hline Sedentary time (low to high) & $\operatorname{st} \beta(95 \% \mathrm{Cl})$ & & st $\beta(95 \% \mathrm{Cl})$ & \\
\hline Model 3 & $-0.029(-0.082,0.025)$ & 0.295 & $-0.008(-0.061,0.045)$ & 0.759 \\
\hline Model 3 + waist circ. for BMI & $-0.023(-0.077,0.031)$ & 0.402 & $-0.008(-0.061,0.045)$ & 0.766 \\
\hline Model $3+24 h$ for office BP & $-0.036(-0.094,0.023)$ & 0.233 & $-0.019(-0.076,0.039)$ & 0.531 \\
\hline Model 3 + MRI quality & $-0.025(-0.078,0.028)$ & 0.358 & $-0.009(-0.062,0.044)$ & 0.738 \\
\hline Model 3 + DHD score & $-0.020(-0.075,0.036)$ & 0.482 & $0.002(-0.052,0.057)$ & 0.930 \\
\hline \multicolumn{5}{|c|}{$\begin{array}{l}\text { Associations of physical activity measures with node degree of the basal ganglia and primary motor cortex. } \\
\text { Regression coefficients and } 95 \% \mathrm{Cl} \text { indicate the mean difference in node degree per SD lower physical activity } \\
\text { and higher sedentary time. Model } 3 \text { : wake time, age, sex, education level, MRI lag time, diabetes status, BMI, } \\
\text { systolic blood pressure, antihypertensive medication, total-to-HDL-cholesterol-ratio, lipid-modifying } \\
\text { medication, smoking status, alcohol use, and history of cardiovascular disease. } 24 \mathrm{~h} \mathrm{BP} \text { available in } \mathrm{n}=1408 \text {. MRI } \\
\text { quality available in } \mathrm{n}=1657 \text {. DHD score available in } \mathrm{n}=1581 \text {. }\end{array}$} \\
\hline
\end{tabular}

Supplementary Table 4.6: Relative change for HPA time and age in whole brain node degree.

\begin{tabular}{lcc}
\hline \multicolumn{3}{c}{ Node degree* $^{*}$} \\
\hline standardized $\boldsymbol{\beta}$ & p-value \\
\hline Age time & 0.081 & 0.001 \\
$\frac{s t \beta_{\text {age }}}{s t \beta_{H P A}} \cdot \frac{S D_{H P A}}{S D_{\text {age }}}$ & -0.177 & $<0.001$ \\
\hline
\end{tabular}

Adjusted for age, sex, education level, MRI lag time, and wake time. 


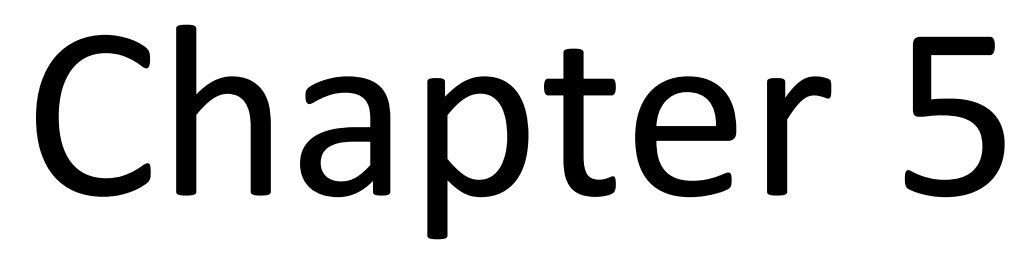

\section{Interplay of White Matter Hyperintensities, Cerebral Networks, and Cognitive Function in an Adult Population - Diffusion Tensor Imaging in The Maastricht Study}

L.W.M. Vergoossen, J.F.A. Jansen, T.T. van Sloten, C.D.A. Stehouwer, N.C. Schaper, A. Wesselius, P.C. Dagnelie, S. Köhler, M.P.J. van Boxtel, A.A. Kroon, J.J.A. de Jong, M.T. Schram, W.H. Backes

Radiology (2020), Dec 22; doi: 10.1148/radiol.2021202634

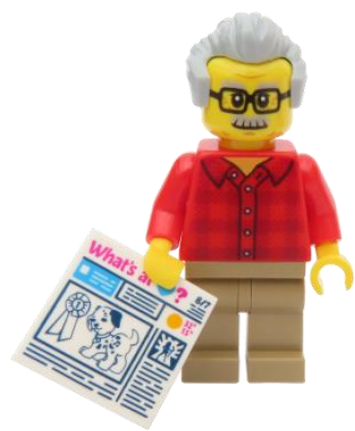




\section{Abstract}

\section{Background}

Lesions of cerebral small vessel disease in individuals with cardiometabolic risk factors, such as white matter hyperintensities (WMH), interfere with the trajectories of the white matter, and eventually contribute to cognitive decline. However, there is no consensus yet about the precise underlying topological mechanism.

\section{Purpose}

To examine whether WMH and cognitive function are associated, and whether any of such association is mediated or explained by structural connectivity measures in an adult population. Additionally, underlying local abnormalities in white matter are investigated, by assessing the tract-specific WMH volumes and their tract-specific association with cognitive function.

\section{Materials and methods}

In the prospective type-2 diabetes-enriched population-based Maastricht Study, structural and diffusion tensor MRI was performed (December 2013-February 2017). Total and tract-specific WMH volumes, network measures, cognition scores, and demographic, cardiovascular, and lifestyle characteristics were determined. Multivariable linear regression and mediation analyses were employed to investigate the association of WMH volume, tract-specific WMH volumes, and network measures with cognitive function. Associations were adjusted for age, sex, education, diabetes-status, and cardiovascular risk factors.

\section{Results}

A total of 5083 participants ( $59 \pm 9$ years, 2592 men, 1027 with diabetes) were evaluated. Larger WMH volumes were associated with stronger local (standardized beta [st $\beta], 0.065, p<0.001$ ), but not global, network efficiency and lower information processing speed (st $\beta,-0.073, p<0.001)$. Moreover, lower local efficiency (st $\beta,-0.084, p<0.001$ ) was associated with lower information processing speed. In particular, the relationship between WMHs and information processing speed was mediated (percentage mediated $7.2 \%$ [95\% Cl: $3.5,10.9], \mathrm{p}<0.05)$ by the local network efficiency. Finally, WMH load was larger in the white matter tracts important for information processing speed.

\section{Conclusion}

White matter hyperintensity volume, local network efficiency, and information processing speed scores are interrelated, and local network properties explain lower cognitive performance due to white matter network alterations. 


\section{Introduction}

Cerebral small vessel disease (cSVD) is a major cause of vascular cognitive impairment (1). The characteristic lesions, of which white matter hyperintensities (WMHs) are the most prevalent, interfere with the trajectories of the white matter, and may disrupt the connections between distributed gray matter regions. Well-known risk factors for the occurrence of these lesions are of cardiometabolic origin and include diabetes, hypertension, abdominal obesity, dyslipidemia, physical inactivity, and ageing ( 2 , $3)$. The changes in white matter connectivity may contribute to general cognitive decline, and decline in various specific cognitive domains, including information processing speed, executive function and attention, and memory $(3,4)$. Cognitive function generally relies on the integrity and spatiotemporally orchestrated interplay of large-scale structural white matter connections of the underlying brain network (5).

Previously it was shown in a population based study of elderly individuals that periventricular WMHs are related to worse cognitive function in contrast to more deeply located, subcortical WMHs (6). This finding is of interest because periventricular WMHs are located in areas with a high density of longassociation white matter tracts that connect various widely distributed cortical regions supporting multiple cognitive functions. Similarly, initially it was thought that only the extensive level of WMH load would impair cognitive function, while currently it is clear that cardiovascular risk factors are associated with CSVD and cognitive performance (7).

Previous studies provided some insight in the mechanisms underlying CSVD-related cognitive decline (8-10). However, the precise topological manner in which white matter connectivity is disrupted, how cSVD contributes, and consequently how strong cognitive function is affected remains unknown. Similarly, it is unclear to what extent variations in locations of CSVD lesions in a population affect cognitive function. To unravel these interrelations, more information about the underlying local and tract-specific characteristics of the white matter network is needed.

The Maastricht Study provides the opportunity to investigate the associations between CSVD MRI markers and cognitive function in a large population with extensive availability of cardiometabolic risk factors. Therefore, the aim of the present study was to investigate whether CSVD lesions and cognitive function are associated, and whether this association is mediated, or explained by structural connectivity measures (ie global and local network efficiency). To investigate underlying local changes in white matter, we assessed the tract-specific WMH volumes in the three types of white matter tracts (ie association, projection, and commissural tracts) and their tract-specific association with cognitive function.

\section{Materials and Methods}

\section{The Maastricht Study}

We used data from The Maastricht Study, an observational prospective population-based cohort study. The rationale and methodology have been described previously (7). In brief, the study focuses on the etiology, pathophysiology, complications, and comorbidities of type 2 diabetes and is characterized by an extensive phenotyping approach. Eligible for participation were all individuals aged between 40 and 75 years living in the southern part of the Netherlands. Participants were recruited through mass media 
campaigns, from the municipal registries, and regional Diabetes Patient Registry by mail. Recruitment was stratified according to known type 2 diabetes status, with an oversampling of individuals with type 2 diabetes, for reasons of efficiency. The present report includes cross-sectional data from the first 7689 participants, who completed the baseline survey between November 2010 and December 2017. The examinations of each participant were performed within a time window of three months. MRI measurements were implemented from December 2013 onwards until February 2017. 5547 participants were invited for MRI, 464 were excluded due to contra-indications (Supplementary Material 2), and 5083 participants had complete data without artifacts (Figure 5.1). The study was approved by the institutional medical ethical committee (NL31329.068.10) and the Dutch Ministry of Health, Welfare and Sports (Permit 131088-105234-PG). All participants gave written informed consent.

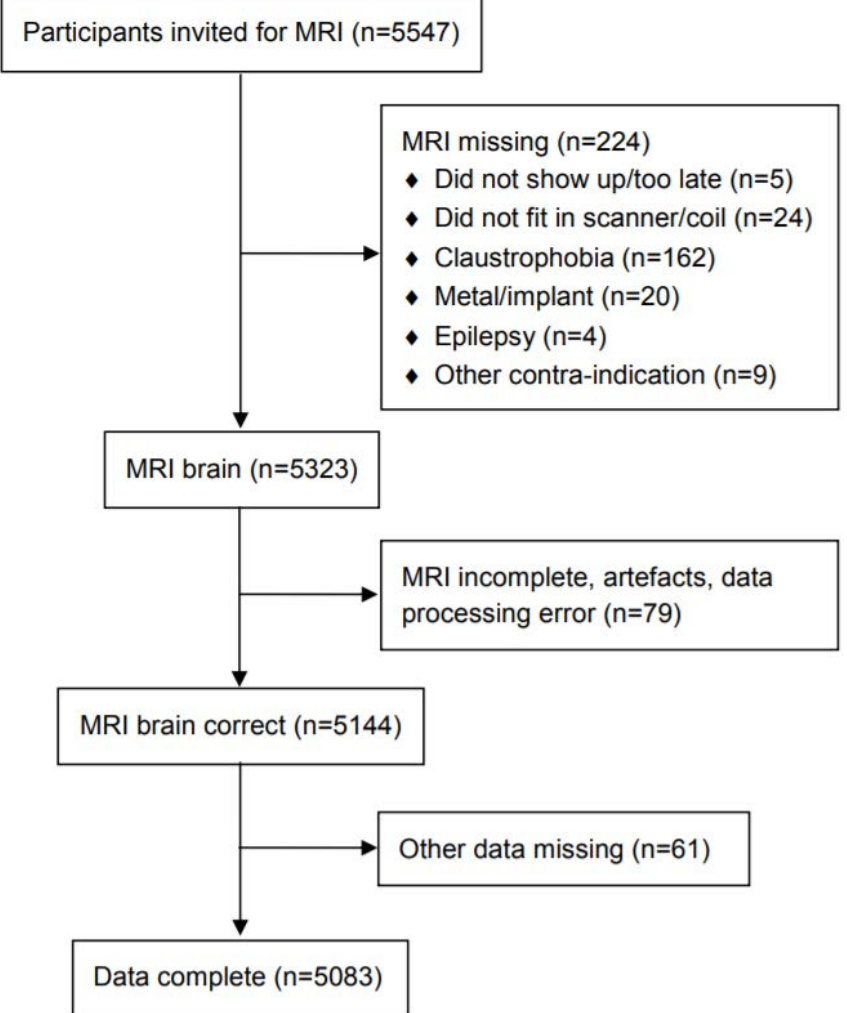

Figure 5.1: Flowchart of the study population.

\section{MRI Scans}

MRI was performed on a 3T scanner (MAGNETOM Prisma-fit Syngo MR D13D, Siemens Healthcare, Germany) using a 64-element head and neck coil. A three-dimensional T1-weighted magnetizationprepared rapid acquisition gradient echo sequence (repetition time, $2300 \mathrm{~ms}$; inversion time, $900 \mathrm{~ms}$; echo time, $2.98 \mathrm{~ms}$; 176 slices; $256 \times 240$ matrix; and $1.00 \mathrm{~mm}$ voxel size) was acquired for anatomic 
reference. Diffusion-weighted MRI comprised a diffusion sensitized echo-planar imaging sequence (repetition time, $6100 \mathrm{~ms}$; echo time, $57 \mathrm{~ms}$; 65 slices; $100 \times 100$ matrix; $2.00 \mathrm{~mm}$ voxel size; and 64 diffusion sensitizing gradient directions $[b=1200 \mathrm{~s} / \mathrm{mm} 2])$, with three $b=0$ images.

\section{Image Preprocessing}

Ninety-four regions were defined by a standard (AAL2) atlas software (11). After transformation (12), images were segmented into gray and white matter, WMH volume and intracranial volume were calculated, and CSVD lesions were identified (13) (Supplementary Material 1). Periventricular WMHs were automatically defined as WMHs $<3 \mathrm{~mm}$, and deep WMHs as WMHs $\geq 3 \mathrm{~mm}$ from the cerebrospinal fluid in the ventricles (14). We focused on WMH volume, as these are prominent in aging, and centrally and deeply located in the cerebrum (analyses for periventricular and deep WMHs separately are provided in Supplementary Table 5.1, 5.2, and 5.4)(15). Diffusion-weighted MRI analysis comprised tractography as described previously (12).

\section{White Matter Networks}

Graph measures served to describe the network topology (15-17) using specialized software (Brain Connectivity Toolbox, version 2017-15-01 (18)). Local efficiency was calculated as the inverse of the average shortest path connecting all neighbors of a region (excluding that region) and determines a network's resistance to failure at small scale. Global efficiency was determined by the inverse of the average shortest path length calculated over the entire brain and quantifies the exchange of information on the whole network scale (19). Also, whole brain node degree was calculated as the average number of connections per region. Subsequent steps were calculation of a standard network frame by proportional sparsity thresholding (80\%), and normalization of the network measures to random networks (12).

\section{White Matter Tract Segmentation}

We determined the spatial distribution of WMHs, and the WMH volumes of a number of well-known tracts with automated atlas-guided tract reconstruction (20) (Figure 5.2). Among the selected tracts are long association, projection, and commissural tracts (21). Volumes were merged for bilateral tracts. We transformed an atlas with 130 gray and white matter regions to diffusion-space (22), and selected for each tract a specific subset of streamlines (20). Individual WMH maps transformed to diffusion-space were used to determine the WMH volume traversed by the selected tracts (Flowchart with processing steps in Supplementary Figure 5.1). 


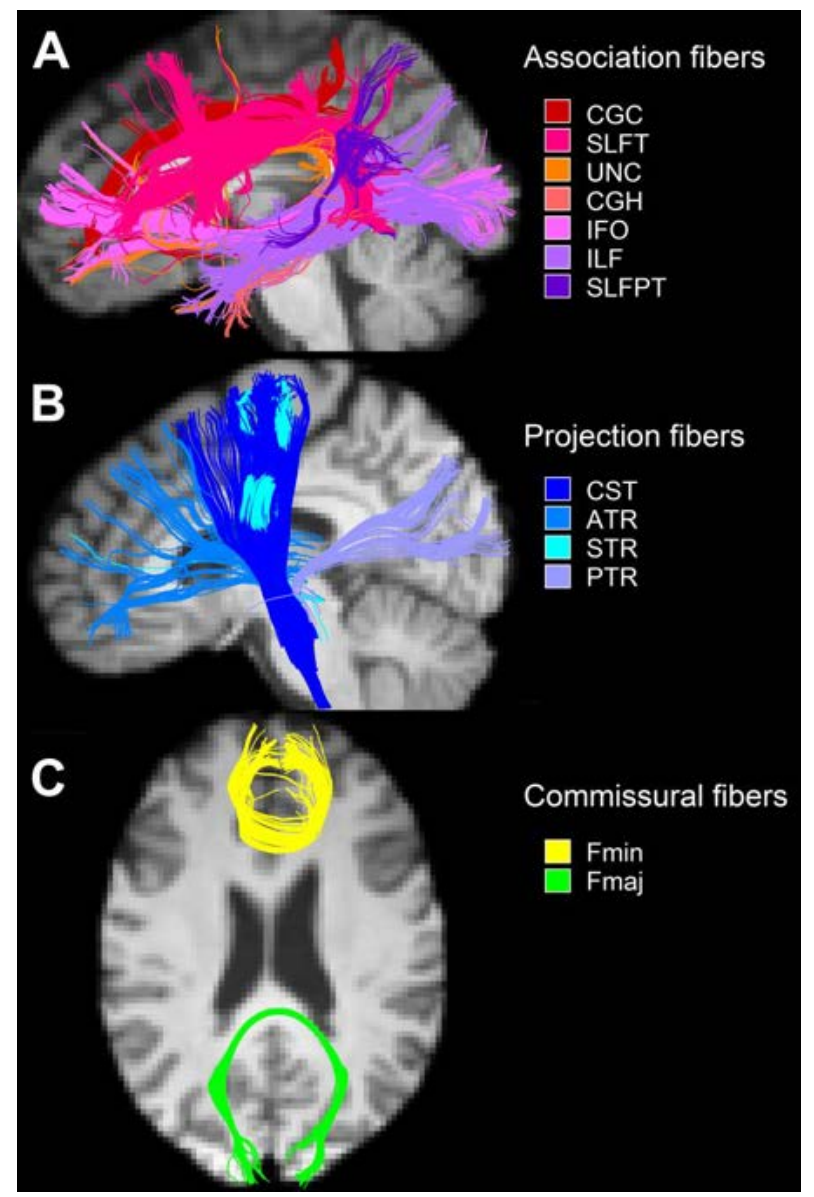

Figure 5.2: Three orthogonal views of the 13 preselected white matter tracts acquired with automated atlas-guided tract reconstruction. (A) Long association tracts shown for cingulum of cingulate gyrus (CGC), hippocampal part of cingulate gyrus (CGH), fronto-occipital fasciculus (IFO), inferior-longitudinal fasciculus (ILF), parietal part of the superior-longitudinal fasciculus (SLFPT), temporal part of the superiorlongitudinal fasciculus (SLFT), and the uncinate fasciculus (UNC). (B) Projection tracts shown for corticospinal tract (CST), anterior thalamic radiation (ATR), posterior thalamic radiation (PTR), and the superior thalamic radiation (STR). (C) Commissural tracts shown for the forceps major (Fmaj) and the forceps minor (Fmin).

\section{Cognitive Performance}

Cognitive performance was assessed using a concise neuropsychological test-battery (23). Information processing speed was primarily reported as it is captures complex cognitive functioning (24), affects various major tracts simultaneously (25), and is strongly impaired in CSVD (10). Detailed descriptions of the tests and other cognitive domain scores are provided in Supplementary Material 3. 


\section{Statistical analysis}

\section{Multivariable Linear Regression}

Multivariable linear regression was used to investigate the association of (tract-specific) WMH volume and structural connectivity with cognitive function. Analyses were adjusted for age, sex, education level, MRI patch update, and intracranial volume (the latter only in models with WMH volume, as network measures were already adjusted for intracranial volume) (Model 1). Subsequent analyses were adjusted for diabetes-status (Model 2), and body-mass index, total cholesterol-to-high-density lipoprotein-ratio, systolic blood pressure, lipid-modifying and antihypertensive medication, and prior cardiovascular disease (Model 3). Skewed variables (WMH volumes) were log10 transformed. P-values < .05 were considered statistically significant. Interaction terms with sex and diabetes-status were incorporated in the fully adjusted model (Model 3). All analyses were performed by use of commercial software (SPSS Statistics 23.0, IBM, Chicago, IL, USA).

\section{Mediation analysis}

Mediation analysis was used to test whether alterations in structural connectivity are on the potential causal pathway of the association between WMH volume and cognition, as it is biologically plausible that the white matter network is affected by WMHs (more details can be found in Supplementary Material 4). For this, we used bootstrapping (5000 samples) to calculate bias-corrected $95 \%$ confidence intervals (Cls) using the PROCESS statistical package for SPSS (26). Analyses were fully adjusted (Model 3).

\section{Results}

\section{General Characteristics of the Study Population}

Table 5.1 shows the general characteristics of the study population, which consisted of 5083 individuals (Flowchart, Figure 5.1), had a mean age of $59 \pm 9$ years, 2491 (49\%) women and 1027 (20\%) had type 2 diabetes (oversampled by design). From the 5547 participants invited for MRI, 224 were excluded due to missing data (5 did not show up/too late; 24 did not fit in scanner/coil; 162 with claustrophobia; 20 with metal implant; 4 with epilepsy; 9 with other contra-indications or known brain abnormalities). MRI brain assessment was performed for 5323 participants, but 79 of them did not full-fill the whole scan protocol, or the data contained artefacts or other data processing errors. From 5144 participants with correct MRI brain data available, 61 had other data missing, which led to 5083 participants with complete data. 
Table 5.1: Characteristics of the study population

\begin{tabular}{|c|c|}
\hline Characteristic & $n=5083$ \\
\hline \multicolumn{2}{|l|}{ Demographics } \\
\hline Age (years) & $59 \pm 9$ \\
\hline Sex, female (\%) & $2491[49]$ \\
\hline Education level (\%), Low/Middle/High & $32 / 28 / 40$ \\
\hline \multicolumn{2}{|l|}{ Cardiovascular risk factors } \\
\hline BMI $\left(\mathrm{kg} / \mathrm{m}^{2}\right)$ & $26.6 \pm 4.2$ \\
\hline Waist circumference $(\mathrm{cm})$ & $94.1 \pm 13.0$ \\
\hline Systolic blood pressure (mmHg) & $132.9 \pm 17.3$ \\
\hline Diastolic blood pressure (mmHg) & $75.5 \pm 9.7$ \\
\hline T2DM (n, [\%]) & $1027[20]$ \\
\hline $\mathrm{HbA} 1 \mathrm{c}(\mathrm{mmol} / \mathrm{mol})$ & $38.9 \pm 8.9$ \\
\hline Hypertension, yes (\%) & 50 \\
\hline Total cholesterol-to-HDL-ratio & $3.6 \pm 1.2$ \\
\hline History of CVD, yes (\%) & 13 \\
\hline \multicolumn{2}{|l|}{ Medication use } \\
\hline Antihypertensive medication, yes (\%) & 34 \\
\hline Lipid-modifying medication, yes (\%) & 28 \\
\hline \multicolumn{2}{|l|}{ Lifestyle factors } \\
\hline Alcohol (\%), None/Low/High & $17 / 59 / 24$ \\
\hline Smoking (\%), Never/Former/Current & $39 / 49 / 12$ \\
\hline Dutch Healthy Diet Index score & $84.2 \pm 15.0$ \\
\hline Total physical activity (hours/week) & $14.1 \pm 8.0$ \\
\hline Mild-to-vigorous physical activity (hours/week) & $5.6 \pm 4.4$ \\
\hline \multicolumn{2}{|l|}{ Cognitive score } \\
\hline MMSE total score [maximum score 30] & $29[29,30]$ \\
\hline Information processing speed & $0.11[-0.41,0.58]$ \\
\hline Executive function and attention & $0.09[-0.43,0.61]$ \\
\hline Memory function & $0.09[-0.60,0.75]$ \\
\hline \multicolumn{2}{|l|}{ Cerebral small vessel disease characteristics } \\
\hline Total WMH volume $(\mathrm{mL})$ & $0.22[0.07,0.70]$ \\
\hline Periventricular $\mathrm{WMH}$ volume $(\mathrm{mL})$ & $0.15[0.04,0.48]$ \\
\hline Deep WMH volume (mL) & $0.05[0.01,0.20]$ \\
\hline Fazekas 0/1/2/3 (\%) & $55.8 / 22.8 / 13.3 / 8.1$ \\
\hline Cerebral microbleeds present (\%) & 10.0 \\
\hline Cerebral lacunar infarcts present (\%) & 4.3 \\
\hline \multicolumn{2}{|l|}{ Structural connectivity graph measures } \\
\hline Whole brain node degree & $17.75 \pm 0.36$ \\
\hline Local efficiency & $1.49 \pm 0.04$ \\
\hline Global efficiency & $0.84 \pm 0.03$ \\
\hline \multicolumn{2}{|c|}{$\begin{array}{l}\text { Data are presented as means } \pm \text { standard deviation, median [interquartile range] or percentage. BMI indicates body } \\
\text { mass index; T2DM, type } 2 \text { diabetes; } \mathrm{HbA1c} \text {, hemoglobin } \mathrm{A} 1 \mathrm{c} ; \mathrm{HDL} \text {, high-density lipoprotein; CVD, cardiovascular } \\
\text { disease; MMSE, Mini-Mental State Examination; } \mathrm{WMH} \text {, white matter hyperintensity. Detailed protocols of the general } \\
\text { measurements are presented in Supplementary Material } 2 \text {. }\end{array}$} \\
\hline
\end{tabular}




\section{White Matter Hyperintensities}

Median WMH volume was $0.22 \mathrm{~mL}$ (interquartile range [IQR], $0.07-0.70 \mathrm{~mL}$ ); in $19.2 \%$ of the participants the total WMH volume was greater than or equal to $1 \mathrm{~mL}$, and $44.2 \%$ had a Fazekas score greater than or equal to 1 . Cerebral microbleeds and lacunar infarcts were less prevalent (in $10 \%$ and $4 \%$, respectively). In Figure 5.5B, the spatial distribution of WMHs is depicted. Volumes of periventricular WMHs, near the lateral ventricles, were approximately three times larger compared to deep WMHs, located distant from the lateral ventricles in the subcortical white matter (Table 5.1).

In the connectogram in Figure 5.3, the 100 connections between automated anatomical labeling atlas 2 regions with the largest difference in tract volume between subgroups with Fazekas scores 0 and greater than or equal to 1 are depicted. This figure indicates that in both hemispheres, especially the short connections between cortical regions located close to the corpus callosum, have smaller tract volumes in participants with WMHs. Connections between the left and right deep gray matters regions and cingulate cortex have larger tract volumes in participants with WMHs.

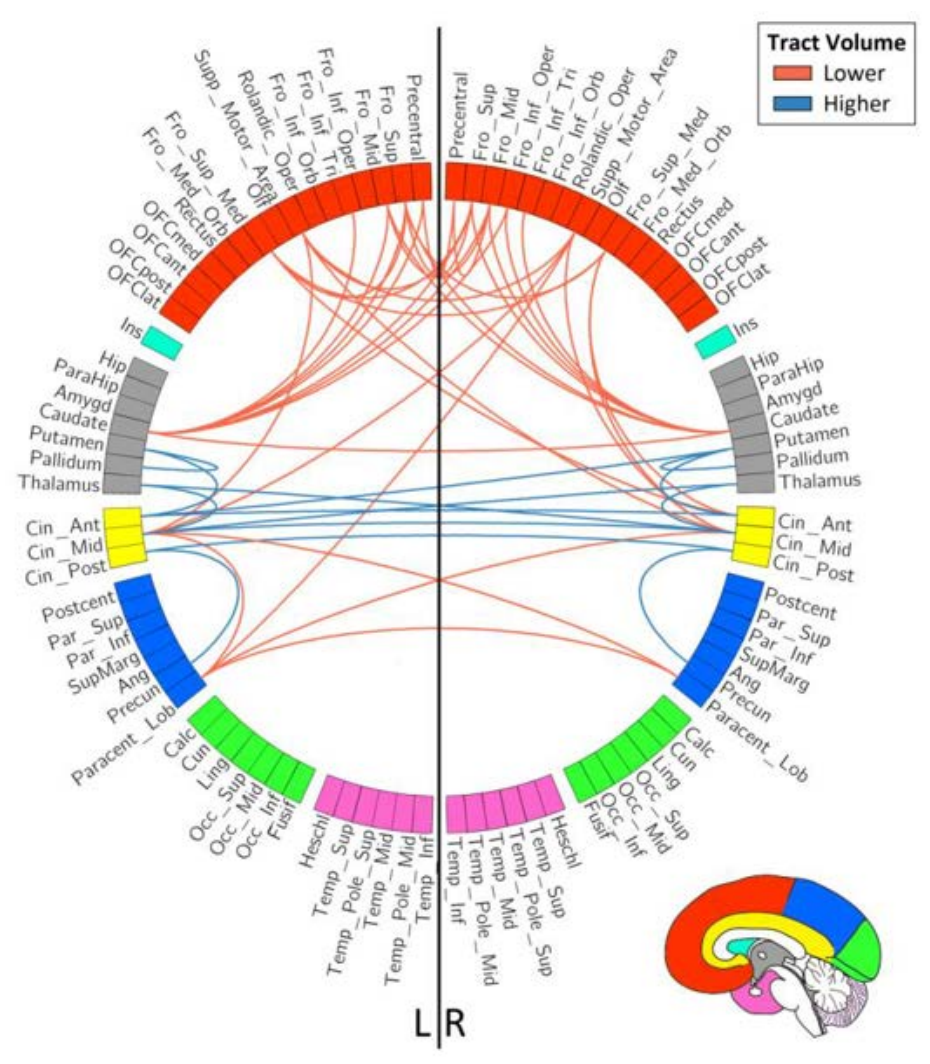

Figure 5.3: Connectogram depicting qualitatively the 100 white matter tracts between AAL-atlas regions with the largest (absolute) difference in tract volume between groups with Fazekas scores. Red lines indicate the tracts with lower tract volumes in the group with WMHs (Fazekas score $\geq 1$ versus 0), and blue lines the higher tract volumes. 


\section{Association Between WMH Volumes and Cognitive Function}

Larger WMH volumes were associated with lower information processing speed scores (standardized beta [st $\beta$ ], -0.073 [95\% $\mathrm{Cl}:-0.101,-0.046], \mathrm{p}<0.001$ ) after adjusting for demographical and cardiovascular risk factors (Model 3, Supplementary Table 5.1). The associations were present for periventricular as well as deep WMHs.

\section{Association Between WMH Volumes and Network Measures}

Larger WMH volumes were associated with higher local network efficiency $(0.065$ [95\% $\mathrm{Cl}: 0.035,0.096$, $\mathrm{p}<0.001])$, but not with whole brain node degree $(-0.027$ [95\% $\mathrm{Cl}:-0.058,0.003], \mathrm{p}=0.08)$ and global efficiency $(-0.011$ [95\% Cl: $-0.044,0.021], p=0.48)$. A comparable association was found for both periventricular and deep WMHs (Supplementary Table 5.2).

\section{Association Between Network Measures and Cognition}

Higher whole brain node degree (st $\beta, 0.113$ [95\% Cl: 0.089, 0.1438], $p<0.001$ ) and lower local efficiency (st $\beta,-0.084$ [95\% Cl: $-0.109,-0.059], p<0.001$ ) were associated with higher information processing speed scores. Global efficiency was not associated with information processing speed scores (st $\beta,-0.014$ [ $95 \%$ Cl: -0.038, 0.010], p=0.25, Supplementary Table 5.3).

\section{Mediation Analysis}

Local efficiency mediated for $7.2 \%$ ([95\% Cl: 3.5, 10.9], $p<0.05$; indirect effect: st $\beta,-0.005$ [95\% Cl: -0.009 , $-0.002], p<0.05$ ) the association between $\mathrm{WMH}$ volume and information processing speed (Figure 5.4, Supplementary Table 5.4).

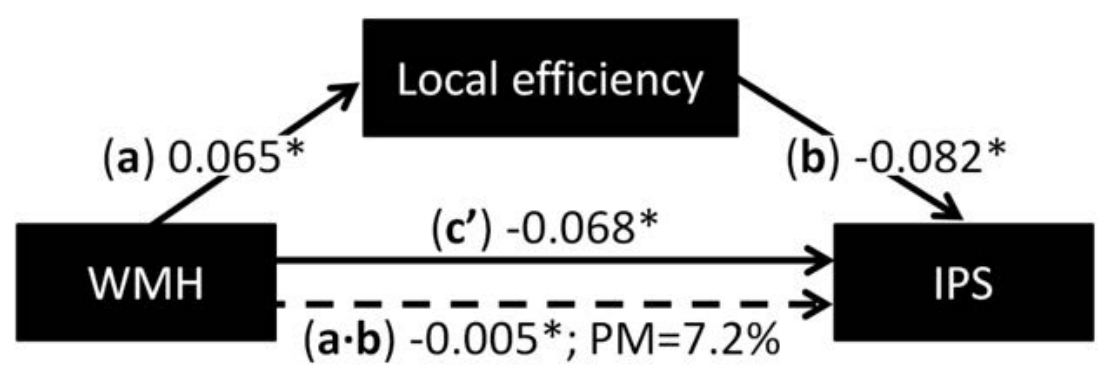

Figure 5.4: Associations between white matter hyperintensity (WMH) volume, local network efficiency, and information processing speed (IPS) score, and the mediation by local efficiency. Solid lines indicate direct effects $\left(c^{\prime}\right)$; dashed lines indicate indirect effects $(a \cdot b)$ and percentage mediated (percentage mediated $[P M]=$ indirect/total $=$ indirect/[indirect+total]). Associations are given as standardized regression coefficients (standardized $B$ ), and are adjusted for age, sex, education, intracranial volume, diabetes status, MRI patch update, BMI, total cholesterol-to-HDL-ratio, systolic blood pressure, lipidmodifying and antihypertensive medication, and prior cardiovascular disease.

${ }^{*}$ P-value $<.01$. 


\section{Characteristics in Type 2 Diabetes}

The population-based design, with oversampling of participants with type 2 diabetes, enabled an accurate comparison of individuals with and without diabetes. Participants with diabetes had approximately two times larger WMH volumes (without diabetes: median 0.19 [IQR, 0.06-0.58]; with diabetes: 0.38 [IQR, 0.13-1.28]) (27). Furthermore, participants with diabetes had slightly higher local efficiency (with diabetes: mean \pm standard deviation, $1.51 \pm 0.05$; without diabetes: $1.49 \pm 0.04, P<.01$ ) and slightly lower information processing speed scores (with diabetes: median [IQR], -0.20 [IQR, $-0.80-$ 0.29]; without diabetes: 0.18 [IQR, $-0.32-0.62], P<.01$ compared to participants without diabetes in the fully adjusted regression model (Model 3 ). We did not find interactions with diabetes-status or sex.

\section{Tract specific analysis}

For the majority of the tracts (9 out of 12) a larger WMH volume was significantly associated with slower information processing, and a comparable effect was found for the other cognitive domains (Supplementary Table 5.5, Supplementary Figure 5.1, and Supplementary Material 5).

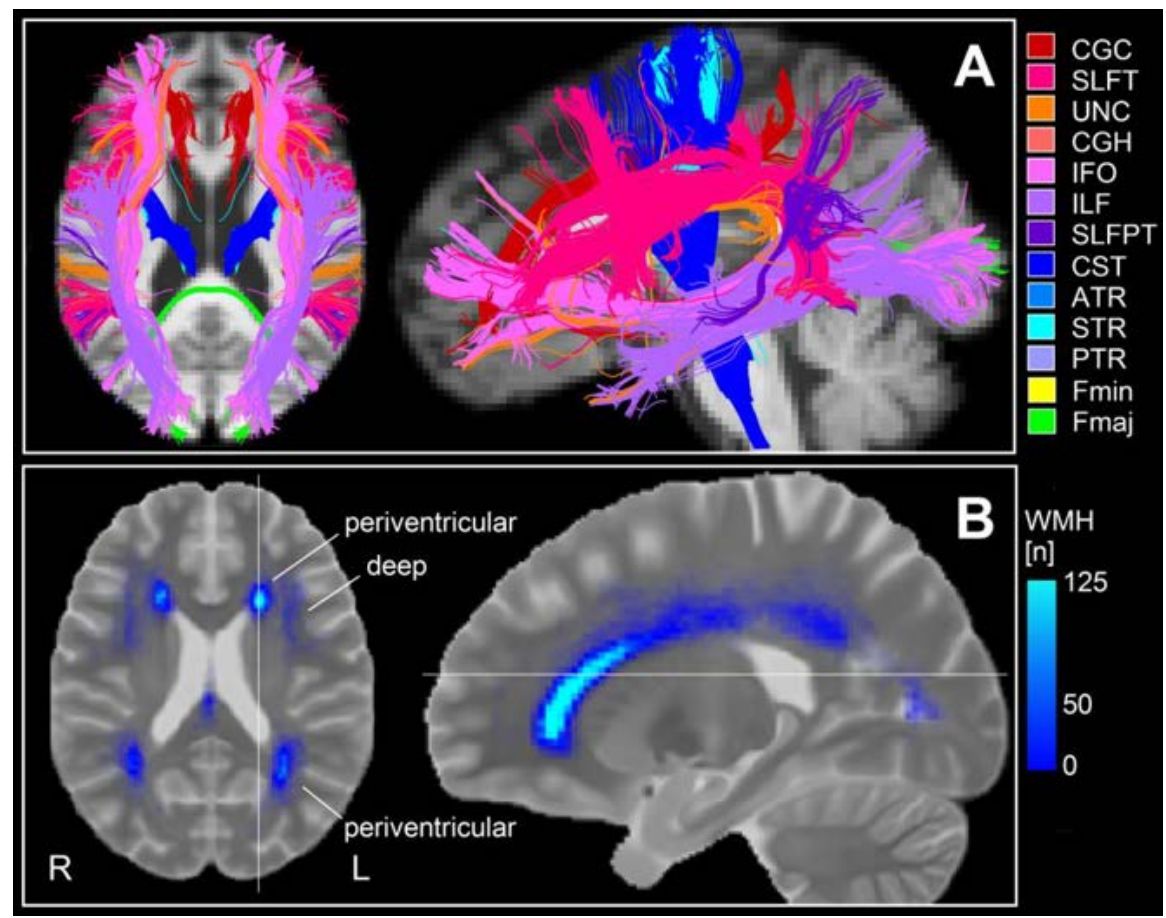

Figure 5.5: Tracts with significant associations $(P<.05)$ of tract-specific WMH volume, with information processing speed (A) scores, adjusted for age, sex, education, diabetes-status, and cardiovascular risk factors (Model 3). (B) White matter hyperintensity prevalence map of the study sample. Note the higher prevalence and overlap of the white matter lesions in the periventricular region, while the deep lesions are more spread. Colors indicate the number of participants that had WMHs in that voxel. 


\section{Long Association Tracts}

We found the largest WMH volumes in the tracts fronto-occipital fasciculus and temporal-part of superior-longitudinal fasciculus (respectively 40 and $18 \%$ of the total WMH in the selected tracts). From Figure 5.5 can be appreciated that, the fronto-occipital fasciculus and temporal-part of superiorlongitudinal fasciculus (Figure 5.5A) both cross the anterior and posterior horns, which are regions with a high WMH prevalence (Figure 5.5B). For almost all association tracts (cingulum of cingulate gyrus, parietal- and temporal-part of superior-longitudinal fasciculus, uncinate fasciculus $[P$-values $<.01]$, fronto-occipital fasciculus, and inferior-longitudinal fasciculus [ $P$-values $<.05]$ ) larger WMH volumes (Figure 5.5A) were, after adjustment for demographic and cardiovascular risk factors, still strongly associated with lower information processing speed.

\section{Projection Tracts}

We did not find large WMH volumes in the projection tracts. However, the WMH volume in the superior thalamic radiation covers approximately $7 \%$ of the total $\mathrm{WMH}$ volume over all selected tracts (Supplementary Table 5.5). This tract traverses regions with WMHs that are mainly located in the deep subcortical structures of the frontal and parietal lobe. Larger WMH volumes in the superior thalamic radiation and cortico-spinal tract, but not in the anterior thalamic radiation and posterior thalamic radiation, were associated with lower information processing speed $(P$-values $<.01)$.

\section{Commissural Tracts}

The forceps major and forceps minor have small absolute WMH volumes, which however cover a substantial part of their relatively small total tract volume ( 7 and $9 \%$, respectively). The forceps major crosses the regions with high WMH prevalence located near the posterior horns, and the forceps minor near the anterior horns. Associations between WMH volumes and information processing speed were only found for the forceps major $(P$-value $<.01)$. More details are provided in Supplementary Table 5.5.

\section{Discussion}

We set out to find interrelations between white matter hyperintensity (WMH) volumes, white matter connectivity, and domain specific cognitive function in a large adult population with cardiometabolic risk factors. Larger WMH volumes were associated with stronger local network efficiency and slower information processing. The relationship between $\mathrm{WMHs}$ and information processing speed was partly mediated by the local network efficiency. Additionally, larger WMH load in white matter tracts important for information processing were associated with cognitive slowing.

In the white matter, the local but not the global network efficiency, acted as a mediator between WMHs and cognitive slowing. WMHs are focally isolated lesions that disturb connections of specific tracts, while the global brain network topology is preserved. We found a higher local efficiency for more WMHs, which indicates that the local network organization is compensated by use of alternative white matter pathways that strengthen connections (higher tract volume in Figure 5.3) with the neighboring regions (12). 
Two previous studies found that both lower local and global efficiency were associated with lower processing and/or psychomotor speed and mediated the associations between MRI markers for CSVD and cognition $(8,9)$. However, these studies involved participants with more severe (eg, symptomatic) CSVD as compared to our study population. In contrast, the current study comprises milder or commencing CSVD pathology without obvious global network impairment but with local adaptations.

The majority of tracts with a substantial amount of WMHs, reveal negative effects on information processing speed for higher WMH load. In this study, we focused on the cognitive domain information processing speed as this is important for fluent execution of perceptual, cognitive, and psychomotor processes (28). Therefore, information processing speed is associated with the properties of connections between many distributed brain regions and does not appeal to highly distinctive tracts but more a variety of tracts $(21,29,30)$.

To put the degree of the cognitive decline into perspective, a $0.51 \mathrm{~mL}$ larger $\mathrm{WMH}$ volume was equivalent to 10 years of cognitive aging in the association between $\mathrm{WMH}$ volume and information processing speed, while $1.69 \mathrm{~mL}$ more WMHs was equivalent to 10 years of network aging in terms of local efficiency. This comparison suggests that the impact of WMHs on the local network topology is approximately three times stronger than would be expected for cognitive decline, which can be explained by compensatory network adaptations outside the lesions. Cerebral lacunar infarcts and microbleeds were less prominent in comparison to $\mathrm{WMHs}$, and also provided associations with both cognitive function and structural connectivity, as expected from literature $(8,31)$, though less evident as for WMHs. Participants with type-2 diabetes had larger WMH volumes, higher local efficiency, and lower information processing speed scores compared to participants without. The lower cognitive scores were equivalent to 3.3 years of cognitive aging. For the other cardiometabolic risk factors no clear effects were found (only marginal differences between model 2 and 3 ), likely because these risk factors already led to higher WMH volumes. In addition, previous studies reported associations of hypertension $(32,33)$, visceral obesity (34), abnormal body-mass index (33), and metabolic syndrome (2) with increased risk of having WMHs.

Strengths of this study were the large sample size, the population-based design, the extensive assessment of potential confounders, and the combined approach of whole-brain network and tractspecific analysis to confirm the robustness of results. Furthermore, we used an automated atlas-guided tract reconstruction method based on whole brain fiber tractography, instead of a diffusion-weighted MRI atlas co-registered to a structural image to determine tract volumes. There were also some limitations. First, the cross-sectional design of the study implies that no conclusions about temporality of alterations in $\mathrm{WMH}$, network properties and cognition can be made. Second, WMHs expressed at locations that are typical for ageing populations with cardiometabolic risk factors. Therefore, for the specific cognitive domains we are restricted to infer on the specific white tracts with the current distribution of WMHs and cannot infer on the susceptibility of other white matter regions, though the whole brain network analysis demonstrated widely distributed alterations. In line with this, standardized regression coefficients were small $(<0.1)$, likely because of the relatively healthy population. The pathology of CSVD is rather limited, and cognition scores were relatively high. Therefore, the associations that were found, indicate that the first signs of CSVD pathology already relate to alterations in the structural network organization and cognitive decrements.

In conclusion, we found that WMH volume, local efficiency, and information processing speed scores are interrelated. More specifically, the detrimental effect of larger WMH volume on cognitive function was mediated by local efficiency. Locally, we found that larger WMH volumes in white matter 
tracts that are important for information processing were associated with cognitive slowing, which reflects cognitive decrements due to white matter pathology in aging individuals with cardiometabolic risk factors.

\section{References}

1. Roman GC, Erkinjuntti T, Wallin A, Pantoni L, Chui HC. Subcortical ischaemic vascular dementia. The Lancet Neurology 2002;1(7):426-436.

2. Abraham HM, Wolfson L, Moscufo N, Guttmann CR, Kaplan RF, White WB. Cardiovascular risk factors and small vessel disease of the brain: Blood pressure, white matter lesions, and functional decline in older persons. Journal of cerebral blood flow and metabolism : official journal of the International Society of Cerebral Blood Flow and Metabolism 2016;36(1):132-142. doi: 10.1038/jcbfm.2015.121

3. van Dijk EJ, Prins ND, Vrooman HA, Hofman A, Koudstaal PJ, Breteler MM. Progression of cerebral small vessel disease in relation to risk factors and cognitive consequences: Rotterdam Scan study. Stroke 2008;39(10):27122719. doi: $10.1161 /$ strokeaha.107.513176

4. Dong C, Nabizadeh N, Caunca M, Cheung YK, Rundek T, Elkind MS, DeCarli C, Sacco RL, Stern Y, Wright CB. Cognitive correlates of white matter lesion load and brain atrophy: the Northern Manhattan Study. Neurology 2015;85(5):441-449. doi: 10.1212/wnl.0000000000001716

5. Petersen SE, Sporns O. Brain Networks and Cognitive Architectures. Neuron 2015;88(1):207-219. doi: 10.1016/j.neuron.2015.09.027

6. de Groot JC, de Leeuw FE, Oudkerk M, van Gijn J, Hofman A, Jolles J, Breteler MM. Cerebral white matter lesions and cognitive function: the Rotterdam Scan Study. Annals of neurology 2000;47(2):145-151. doi: 10.1002/15318249(200002)47:2<145::aid-ana3>3.3.co;2-g

7. Vergoossen LWM, Jansen JFA, Backes WH, Schram MT. Cardiometabolic determinants of early and advanced brain alterations: Insights from conventional and novel MRI techniques. Neuroscience \& Biobehavioral Reviews 2020. doi: https://doi.org/10.1016/j.neubiorev.2020.04.001

8. Tuladhar AM, van Dijk E, Zwiers MP, van Norden AGW, de Laat KF, Shumskaya E, Norris DG, de Leeuw F-E. Structural network connectivity and cognition in cerebral small vessel disease. Human brain mapping 2016;37(1):300-310. doi: 10.1002/hbm.23032

9. Lawrence AJ, Chung AW, Morris RG, Markus HS, Barrick TR. Structural network efficiency is associated with cognitive impairment in small-vessel disease. Neurology 2014;83(4):304-311. doi: 10.1212/WNL.0000000000000612

10. Wiseman SJ, Booth T, Ritchie SJ, Cox SR, Muñoz Maniega S, Valdés Hernández MDC, Dickie DA, Royle NA, Starr JM, Deary IJ, Wardlaw JM, Bastin ME. Cognitive abilities, brain white matter hyperintensity volume, and structural network connectivity in older age. Human brain mapping 2018;39(2):622-632. doi: 10.1002/hbm.23857

11. Tzourio-Mazoyer N, Landeau B, Papathanassiou D, Crivello F, Etard O, Delcroix N, Mazoyer B, Joliot M. Automated anatomical labeling of activations in SPM using a macroscopic anatomical parcellation of the MNI MRI single-subject brain. Neuroimage 2002;15(1):273-289. doi: 10.1006/nimg.2001.0978

12. Vergoossen LW, Schram MT, de Jong JJ, Stehouwer CD, Schaper NC, Henry RM, van der Kallen CJ, Dagnelie PC, van Boxtel MP, Eussen SJ, Backes WH, Jansen JF. White Matter Connectivity Abnormalities in Prediabetes and Type 2 Diabetes: The Maastricht Study. Diabetes care 2019:dc190762. doi: 10.2337/dc19-0762

13. de Boer R, Vrooman HA, van der Lijn F, Vernooij MW, Ikram MA, van der Lugt A, Breteler MM, Niessen WJ. White matter lesion extension to automatic brain tissue segmentation on MRI. Neurolmage 2009;45(4):1151-1161. doi: 10.1016/j.neuroimage.2009.01.011

14. Kim KW, MacFall JR, Payne ME. Classification of white matter lesions on magnetic resonance imaging in elderly persons. Biol Psychiatry 2008;64(4):273-280. doi: 10.1016/j.biopsych.2008.03.024 
15. Watts DJ, Strogatz SH. Collective dynamics of 'small-world' networks. Nature 1998;393(6684):440-442. doi: $10.1038 / 30918$

16. Stam CJ, Reijneveld JC. Graph theoretical analysis of complex networks in the brain. Nonlinear biomedical physics 2007;1(1):3. doi: 10.1186/1753-4631-1-3

17. Bullmore $E$, Sporns $O$. Complex brain networks: graph theoretical analysis of structural and functional systems. Nature reviews Neuroscience 2009;10(3):186-198. doi: 10.1038/nrn2575

18. Rubinov $M$, Sporns $O$. Complex network measures of brain connectivity: uses and interpretations. Neurolmage 2010;52(3):1059-1069. doi: 10.1016/j.neuroimage.2009.10.003

19. Latora V, Marchiori M. Efficient behavior of small-world networks. Physical review letters 2001;87(19):198701. doi: 10.1103/PhysRevLett.87.198701

20. Zhang Y, Zhang J, Oishi K, Faria AV, Jiang H, Li X, Akhter K, Rosa-Neto P, Pike GB, Evans A, Toga AW, Woods R, Mazziotta JC, Miller MI, van Zijl PC, Mori S. Atlas-guided tract reconstruction for automated and comprehensive examination of the white matter anatomy. Neurolmage 2010;52(4):1289-1301. doi: 10.1016/j.neuroimage.2010.05.049

21. Aralasmak A, Ulmer JL, Kocak M, Salvan CV, Hillis AE, Yousem DM. Association, commissural, and projection pathways and their functional deficit reported in literature. J Comput Assist Tomogr 2006;30(5):695-715. doi: 10.1097/01.rct.0000226397.43235.8b

22. Oishi K, Faria A, Jiang H, Li X, Akhter K, Zhang J, Hsu JT, Miller MI, van Zijl PC, Albert M, Lyketsos CG, Woods R, Toga AW, Pike GB, Rosa-Neto P, Evans A, Mazziotta J, Mori S. Atlas-based whole brain white matter analysis using large deformation diffeomorphic metric mapping: application to normal elderly and Alzheimer's disease participants. Neurolmage 2009;46(2):486-499.

23. Schram MT, Sep SJ, van der Kallen CJ, Dagnelie PC, Koster A, Schaper N, Henry RM, Stehouwer CD. The Maastricht Study: an extensive phenotyping study on determinants of type 2 diabetes, its complications and its comorbidities. Eur J Epidemiol 2014;29(6):439-451. doi: 10.1007/s10654-014-9889-0

24. Salthouse TA. The processing-speed theory of adult age differences in cognition. Psychol Rev 1996;103(3):403428. doi: 10.1037/0033-295x.103.3.403

25. Penke L, Muñoz Maniega S, Murray C, Gow AJ, Hernández MCV, Clayden JD, Starr JM, Wardlaw JM, Bastin ME, Deary IJ. A general factor of brain white matter integrity predicts information processing speed in healthy older people. The Journal of neuroscience : the official journal of the Society for Neuroscience 2010;30(22):7569-7574. doi: 10.1523/JNEUROSCI.1553-10.2010

26. Hayes AF. Introduction to mediation, moderation, and conditional process analysis: A regression-based approach. New York, NY, US: Guilford Press, 2013.

27. van Agtmaal MJM, Houben A, de Wit V, Henry RMA, Schaper NC, Dagnelie PC, van der Kallen CJ, Koster A, Sep SJ, Kroon AA, Jansen JFA, Hofman PA, Backes WH, Schram MT, Stehouwer CDA. Prediabetes Is Associated With Structural Brain Abnormalities: The Maastricht Study. Diabetes care 2018;41(12):2535-2543. doi: 10.2337/dc181132

28. Lezak MD, Howieson DB, Loring DW, Fischer JS. Neuropsychological assessment: Oxford University Press, USA, 2004.

29. Usui N, Haji T, Maruyama M, Katsuyama N, Uchida S, Hozawa A, Omori K, Tsuji I, Kawashima R, Taira M. Cortical areas related to performance of WAIS Digit Symbol Test: a functional imaging study. Neuroscience letters 2009;463(1):1-5. doi: 10.1016/j.neulet.2009.07.048

30. Kuznetsova KA, Maniega SM, Ritchie SJ, Cox SR, Storkey AJ, Starr JM, Wardlaw JM, Deary IJ, Bastin ME. Brain white matter structure and information processing speed in healthy older age. Brain Structure and Function 2016;221(6):3223-3235. doi: 10.1007/s00429-015-1097-5

31. Caunca MR, De Leon-Benedetti A, Latour L, Leigh R, Wright CB. Neuroimaging of Cerebral Small Vessel Disease and Age-Related Cognitive Changes. Frontiers in aging neuroscience 2019;11:145-145. doi: 10.3389/fnagi.2019.00145 
32. Wiseman RM, Saxby BK, Burton EJ, Barber R, Ford GA, O’Brien JT. Hippocampal atrophy, whole brain volume, and white matter lesions in older hypertensive subjects. Neurology 2004;63(10):1892-1897. doi: 10.1212/01.Wnl.0000144280.59178.78

33. King KS, Peshock RM, Rossetti HC, McColl RW, Ayers CR, Hulsey KM, Das SR. Effect of normal aging versus hypertension, abnormal body mass index, and diabetes mellitus on white matter hyperintensity volume. Stroke 2014;45(1):255-257. doi: 10.1161/STROKEAHA.113.003602

34. Kim KW, Seo H, Kwak MS, Kim D. Visceral obesity is associated with white matter hyperintensity and lacunar infarct. International journal of obesity (2005) 2017;41(5):683-688. doi: 10.1038/ijo.2017.13 


\section{Supplementary Material}

\section{Identification and scoring of cSVD lesions}

\subsection{Identification of white matter hyperinsities}

WMHs identified were summed to assess total WMH burden in $\mathrm{mL}$. Two types of WMHs were distinguished, periventricular WMHs (pWMHs) are located around the horns of the ventricles, and deep WMHs (dWMHs) are located in the subcortical white matter distinct from the periventricular area. pWMHs were automatically defined as WMHs $<3 \mathrm{~mm}$, and dWMHs as WMHs $\geq 3 \mathrm{~mm}$ from the cerebrospinal fluid (1).

\subsection{Scoring lacunar infarct and microbleeds}

Lacunar infarcts were defined as focal lesions of $\geq 3 \mathrm{~mm}$ and $<15 \mathrm{~mm}$ in size with a similar signal intensity as cerebrospinal fluid on all sequences and a hyperintense rim on T2 and FLAIR images (2).

Cerebral microbleeds were rated on three-dimensional T2* GRE imaging with SWI by use of the Microbleed Anatomical Rating Scale (3), and were defined as focal lesions of $\geq 2 \mathrm{~mm}$ and $\leq 10 \mathrm{~mm}$ in size with a hypointense signal on T2* GRE and SWI images (2). The number and location of lacunar infarcts and cerebral microbleeds were rated manually by three neuroradiologists. The intraclass correlation coefficient for the three raters based on 50 randomly selected scans was 0.84 [0.74; 0.91$]$ and 0.83 [0.72; $0.90]$ for the presence of lacunar infarcts and cerebral microbleeds, respectively.

\section{Detailed protocols of measurements performed within The Maastricht}

\section{Study}

Questionnaires. As described elsewhere (4), we used web-based questionnaires to obtain information regarding smoking status (never/former/current), alcohol consumption, educational level, physical activity, diet, prior cardiovascular disease (CVD) and cognitive impairment. Alcohol consumption was classified as none, low (1- 7 glasses/wk for women and 1-14 glasses/wk for men) and high (> 7 glasses/wk for women and $>14$ glasses/wk for men). Educational level was classified as low (no education, primary education, lower vocational education), intermediate (intermediate general secondary education, intermediate vocational education, higher general secondary education), or high (higher vocational education or university). Diet was assessed by a tailor-made food frequency questionnaire (FFQ) developed by use of the National FFQ Tool. Prior CVD was defined as a history of myocardial infarction; stroke; or vascular surgery (including angioplasty) on coronary, carotid, abdominal aortic, or peripheral arteries based on the Rose questionnaire. Cognitive impairment was measured using the Mini-Mental State Examination (MMSE). Medication use was assessed in a medication interview where generic name, dose, and frequency were registered. Subjective physical activity was assessed by means of a modified version of the Champs questionnaire.

Laboratory assessments. Plasma glucose is measured with a standard enzymatic hexokinase reference method, and serum total cholesterol, HDL cholesterol, and triglycerides are measured with standard 
(enzymatic and/or colorimetric) methods by an automatic analyzer (until 9 May 2012: Beckman Synchron LX20, Beckman Coulter Inc., Brea, USA; after 9 May 2012: Cobas 6000, Roche diagnostics, Mannheim, Germany). When appropriate LDL cholesterol is calculated according to the Friedewald formula(5). $\mathrm{HbA1C}$ is measured with ion-exchange high performance liquid chromatography (HPLC) (Variant tm II, Bio-Rad, Hercules, California, USA).

Glucose metabolism status. To determine glucose metabolism status, all participants, except those who used insulin, underwent a standardized $2-\mathrm{h} 75 \mathrm{~g}$ oral glucose tolerance test (OGTT) after an overnight fast. For safety reasons, participants with a fasting glucose level above $11.0 \mathrm{mmol} / \mathrm{L}$, as determined by a finger prick, did not undergo the OGTT. For these individuals, fasting glucose level and information about diabetes medication were used to determine glucose metabolism status. Glucose metabolism status was defined according to the WHO 2006 criteria into normal glucose metabolism (NGM), prediabetes, and type 2 diabetes mellitus (T2DM) (6). Participants were considered to have T2DM if they had a fasting blood glucose (FBG) $\geq 7.0 \mathrm{mmol} / \mathrm{l}$, or a $2 \mathrm{hr}$ post-load blood glucose $\geq 11.1 \mathrm{mmol} / \mathrm{l}$ or used oral glucoselowering medication or insulin, prediabetes if they had a FBG $\geq 6.1 \mathrm{mmol} / \mathrm{l}$ and/or a $2 \mathrm{hr}$ post-load blood glucose $\geq 7.8 \mathrm{mmol} / \mathrm{l}$, and NGM if they had a FBG $<6.1 \mathrm{mmol} / \mathrm{l}$, and a $2 \mathrm{hr}$ post-load blood glucose $<7.8$ $\mathrm{mmol} / \mathrm{l}$ and no use of diabetes medication. Participants with type 1 diabetes or other types of diabetes were excluded from the analysis.

Physical examination. Weight and height are measured without shoes and wearing light clothing using a scale and stadiometer to the nearest $0.5 \mathrm{~kg}$ or $0.1 \mathrm{~cm}$ (Seca, Hamburg, Germany). Waist circumference is measured with a flexible plastic tape measure (Seca, Hamburg, Germany) in a duplicate midway between the lower rib margin and the iliac crest at the end of expiration, to the nearest $0.5 \mathrm{~cm}$.

Blood pressure. Office blood pressure is determined three times on the right arm after a 10-minute rest period, using a non-invasive blood pressure monitor (Omron 705IT, Japan). When the difference between measurement two and three is more than $10 \mathrm{mmHg}$, a fourth measurement is performed. All available measurements are used to calculate the average blood pressure. Ambulatory 24-h blood pressure (WatchBP 03, Microlife, Switzerland, respectively) is measured at the non-dominant arm, using an ambulatory device that is programmed to take blood pressure readings every 15 minutes from $8.00-$ 23.00 and every 30 minutes from $23.00-8.00$.

MRI. Contra-indications for MRI assessments were the presence of a cardiac pacemaker or implantable cardioverter-defibrillator, neurostimulator, non-detachable insulin pump, metallic vascular clips or stents in the head, cochlear implant, metal-containing intra-uterine device, metal splinters or shrapnel, dentures with magnetic clip, an inside bracket, pregnancy, epilepsy, claustrophobia, or did not fit in scanner/coil. Data was excluded whether participants did not full-fill the whole scan protocol, or the data contained artefacts or other data processing errors. 


\section{Description of the individual cognitive tests used in the present study}

\subsection{Verbal Learning Test (7)}

Fifteen unrelated, monosyllabic, words were presented on a computer screen in five subsequent trials. After each trial, participants were instructed to recall as many words as possible in any order. Twenty minutes after the last trial, participants were asked again to reproduce the words. Outcomes recorded included the total number of words correctly recalled over the five trials (total immediate recall) and the number of correctly recalled words during delayed recall (delayed recall).

\subsection{Stroop Colour Word Test (8)}

In this test that consisted of three parts participants were firstly asked to read aloud colour names (i.e. red, blue, yellow, and green) that were printed in black ink (Part I). Secondly, they were instructed to name solid colour patches (Part II). Finally, participants had to name the ink color of colour names that were printed in an incongruent colour (e.g. participants were asked to say red when the word yellow was printed in red) (Part III). The time needed to complete Part III was adjusted for the average time needed to complete Part I and II.

\subsection{Concept Shifting Test (9)}

This test, a modification of the Trailing Making Test, consisted of four subtasks. During each subtask, participants were shown 16 small circles aligned along a larger imaginary circle. The small circles contained (a combination of) digits, letters, or were empty. Participants were instructed to cross-out as quickly as possible the digits in ascending order (Part A), the letters in alphabetic order (Part B), and the letters and digits in alternating order (Part C). Thereafter, participants were asked to cross-out empty circles in a clockwise fashion in two consecutive trials (Part 0 ). In this way, test results could be accounted for basic motor speed. The time needed to complete subtasks A and B was adjusted for the average time needed to complete Part 0 , the time needed to complete Part $C$ for the average time of Part A and B.

\subsection{Letter-Digit Substitution Test (10)}

Participants were requested to match digits to letters according to a given key. This key included the numbers 1 to 9 , each paired with a different letter. The outcome of interest was the number of correct substitutions within 90 seconds.

\subsection{Methods used to calculate domain scores}

Briefly, information processing speed was derived from the Stroop Color-Word Test, Part I and II (31), the Concept Shifting Test, Part A and B (32), and the Letter-Digit Substitution Test (33). Executive function and attention was assessed with the Stroop Color-Word Test Part III and the Concept Shifting Test Part C. The composite score for memory function was evaluated using the Verbal Learning Test (34) by calculating the average of standardized total immediate and delayed recall scores. Other domain scores 
were calculated analogously. If necessary, individual test scores were log-transformed to fulfil the normality assumption and/or inverted so that higher scores indicated better cognitive performance.

\section{Additional explanation of the concept underlying the mediation analysis:}

In a mediation model, the relationship of an independent variable (e.g., WMH volume) with an outcome (processing speed) is hypothesized to be indirect and due to the influence of a mediator variable (local efficiency). Thus, the mediation analysis modelled the relationship by assuming that WMH volume affects the local efficiency, which in turn affects processing speed. The total effect of WMH volume on processing speed was decomposed into the natural direct effect (NDE) and the natural indirect effect (NIE) and the percentage mediated (PM) was computed as the ratio of the total effect to NIE, PM = $\mathrm{NIE} /(\mathrm{NIE}+\mathrm{NDE})$. PM provides an estimate of the extent to which the total effect of WMH volume on processing speed is accounted for by the pathway through local efficiency. However, the PM is probably an underestimation of the influence of $\mathrm{WMH}$, because according to the literature, WMHs affect also the white matter adjacent to the lesion (Reginold et al., 2018; Wardlaw et al., 2017).

\section{Additional discussion about tract-specific findings:}

More specifically, previous studies showed that impairments in the association tracts cingulum of cingulate gyrus, fronto-occipital fasciculus, inferior-longitudinal fasciculus, parietal- and temporal-part of superior-longitudinal fasciculus, the projection tract cortico-spinal tract, and the commissural tract forceps major were associated with lower information processing speed, but deficits in the association tracts hippocampal part of cingulate gyrus and uncinate fasciculus, the three thalamic radiations, i.e., anterior thalamic radiation, superior thalamic radiation and posterior thalamic radiation, and the commissural tract forceps minor were not (11-13). Furthermore, previously associations of reduced white matter microstructure in terms of higher fractional anisotropy and lower mean diffusivity, with lower information processing speed scores were found, which were strongest in the association tracts fronto-occipital fasciculus, inferior-longitudinal fasciculus, parietal- and temporal-part of superiorlongitudinal fasciculus and uncinate fasciculus, in the projection tracts anterior thalamic radiation and posterior thalamic radiation, and in the commissural tracts forceps major and forceps minor (14-16). In the present study, we also found associations of higher WMH volumes in long association tracts between motor regions and the four lobes (cingulum of cingulate gyrus, fronto-occipital fasciculus, inferiorlongitudinal fasciculus, parietal- and temporal-part of superior-longitudinal fasciculus, and uncinate fasciculus) with lower information processing scores. Additional associations were observed in two projection tracts, i.e., superior thalamic radiation and cortico-spinal tract, and in the commissural tract forceps major, which connects the occipital lobes.

\subsection{Executive function and attention}

Larger WMH volumes (Supplementary Figure $1 \mathrm{~A}$ ) in a variety of long association tracts, i.e., cingulum of cingulate gyrus( $p$-value<0.01), fronto-occipital fasciculus, inferior-longitudinal fasciculus, parietal- and temporal-part of superior-longitudinal fasciculus, and uncinate fasciculus ( $p$-values $<0.05$ ); projection tracts, i.e., superior thalamic radiation and cortico-spinal tract ( $p$-values $<0.001)$, were associated with 
lower executive function and attention scores. No associations between WMH volumes and executive function and attention scores were found in the association tract cingulum of cingulate gyrus, the projection tracts anterior thalamic radiation and posterior thalamic radiation, and in both commissural tracts.

Executive function relies mainly on regions in the frontal and parietal lobes, cingulate gyrus and cerebellum $(11,17)$, and executive attention on the cingulate gyrus, prefrontal cortex, and basal ganglia $(11,18)$. The temporal part of the superior longitudinal fasciculus is a tract from angular gyrus to the temporal lobe, and is important for attention (19). In a previous cohort study, an association of lower executive attention scores with larger WMH volumes in the corticospinal tract and superior longitudinal fasciculus was found (13). Furthermore, another study found that WMHs in the frontal white matter adjacent to the frontal horns were much more pronounced in participants with worse performance in executive function, while participants with high cognitive performance in executive functions had less WMH in the frontal, periventricular white matter (12). This study found that all WMH locations with negative effects on cognition were bilateral with a symmetrical pattern. In the present study, associations were found between higher $\mathrm{WMH}$ volumes in a variety of long association tracts and lower executive function and attention scores. Furthermore, we found associations in the superior thalamic radiation and cortico-spinal tract, which are located adjacent to the frontal horns.

\subsection{Memory}

Higher tract-specific WMH volumes in all long association tracts, i.e., cingulum of cingulate gyrus, inferior-longitudinal fasciculus, parietal- and temporal-part of superior-longitudinal fasciculus, uncinate fasciculus ( $p$-values<0.001), hippocampal part of cingulate gyrus, and fronto-occipital fasciculus( $p$ values<0.05); in several projection tracts, i.e., anterior thalamic radiation, superior thalamic radiation, and cortico-spinal tract ( $p$-values<0.05); and in the commissural forceps major ( $p$-value $<0.01$ ) were associated with lower memory function scores (Supplementary Figure 1B). No associations were found in the projection tract posterior thalamic radiation and the commissural tract forceps minor.

Memory function (short-term/working) is mainly facilitated by connections between the prefrontal cortex, regions in the parietal lobe, cerebellum, and basal ganglia $(11,20)$. The temporal part of the superior longitudinal fasciculus is a tract important memory function (19). One population based study found an association of lower memory function with more WMHs in the bilateral parietal-temporal white matter junctions adjacent to the posterior horns of the lateral ventricles (12). However, another cohort study found no associations for memory (13), but this study used a white matter tractography atlas instead of tract tracking on diffusion-weighted MRI scans. In our study, we found associations of higher WMH volumes in several long association tracts connecting the frontal and occipital lobe (frontooccipital fasciculus), the frontal, temporal and parietal lobe (parietal-and temporal-part of superiorlongitudinal fasciculus) and the basal ganglia (uncinate fasciculus), with lower memory scores. We also found associations in all the projection and commissural tracts, except for the posterior thalamic radiation, and the commissural tract forceps major. Another population-based study found similar associations between larger WMH volumes in association and projection tracts and worse memory function, but this study also used a white matter tract atlas instead of tractography (21). 


\section{Supplemental References}

1. Kim KW, MacFall JR, Payne ME. Classification of white matter lesions on magnetic resonance imaging in elderly persons. Biol Psychiatry 2008;64(4):273-280. doi: 10.1016/j.biopsych.2008.03.024

2. Wardlaw JM, Smith EE, Biessels GJ, Cordonnier C, Fazekas F, Frayne R, Lindley RI, O'Brien JT, Barkhof F, Benavente OR, Black SE, Brayne C, Breteler M, Chabriat H, Decarli C, de Leeuw FE, Doubal F, Duering M, Fox NC, Greenberg S, Hachinski V, Kilimann I, Mok V, Oostenbrugge R, Pantoni L, Speck O, Stephan BC, Teipel S, Viswanathan A, Werring D, Chen C, Smith C, van Buchem M, Norrving B, Gorelick PB, Dichgans M. Neuroimaging standards for research into small vessel disease and its contribution to ageing and neurodegeneration. The Lancet Neurology 2013;12(8):822-838. doi: 10.1016/s1474-4422(13)70124-8

3. Gregoire SM, Chaudhary UJ, Brown MM, Yousry TA, Kallis C, Jäger HR, Werring DJ. The Microbleed Anatomical Rating Scale (MARS): reliability of a tool to map brain microbleeds. Neurology 2009;73(21):1759-1766. doi: 10.1212/WNL.0b013e3181c34a7d

4. Schram MT, Sep SJ, van der Kallen CJ, Dagnelie PC, Koster A, Schaper N, Henry RM, Stehouwer CD. The Maastricht Study: an extensive phenotyping study on determinants of type 2 diabetes, its complications and its comorbidities. Eur J Epidemiol 2014;29(6):439-451. doi: 10.1007/s10654-014-9889-0

5. Friedewald WT, Levy RI, Fredrickson DS. Estimation of the concentration of low-density lipoprotein cholesterol in plasma, without use of the preparative ultracentrifuge. Clin Chem 1972;18(6):499-502.

6. Organization WH. Definition and diagnosis of diabetes mellitus and intermediate hyperglycemia: report of a WHO/IDF consultation. Geneva, Switzerland2006.

7. Van der Elst W, van Boxtel MP, van Breukelen GJ, Jolles J. Rey's verbal learning test: normative data for 1855 healthy participants aged 24-81 years and the influence of age, sex, education, and mode of presentation. Journal of the International Neuropsychological Society : JINS 2005;11(3):290-302. doi: 10.1017/S1355617705050344

8. Van der Elst W, Van Boxtel MP, Van Breukelen GJ, Jolles J. The Stroop color-word test: influence of age, sex, and education; and normative data for a large sample across the adult age range. Assessment 2006;13(1):62-79. doi: 10.1177/1073191105283427

9. Van der Elst W, Van Boxtel MP, Van Breukelen GJ, Jolles J. The Concept Shifting Test: adult normative data. Psychol Assess 2006;18(4):424-432. doi: 10.1037/1040-3590.18.4.424

10. van der Elst W, van Boxtel MP, van Breukelen GJ, Jolles J. The Letter Digit Substitution Test: normative data for 1,858 healthy participants aged 24-81 from the Maastricht Aging Study (MAAS): influence of age, education, and sex. Journal of clinical and experimental neuropsychology 2006;28(6):998-1009. doi: 10.1080/13803390591004428

11. Aralasmak A, Ulmer JL, Kocak M, Salvan CV, Hillis AE, Yousem DM. Association, commissural, and projection pathways and their functional deficit reported in literature. J Comput Assist Tomogr 2006;30(5):695-715. doi: 10.1097/01.rct.0000226397.43235.8b

12. Lampe L, Kharabian-Masouleh S, Kynast J, Arelin K, Steele CJ, Löffler M, Witte AV, Schroeter ML, Villringer A, Bazin P-L. Lesion location matters: The relationships between white matter hyperintensities on cognition in the healthy elderly. Journal of Cerebral Blood Flow \& Metabolism 2017;39(1):36-43. doi: 10.1177/0271678X17740501

13. Jiang J, Paradise M, Liu T, Armstrong NJ, Zhu W, Kochan NA, Brodaty H, Sachdev PS, Wen W. The association of regional white matter lesions with cognition in a community-based cohort of older individuals. Neurolmage: Clinical 2018;19:14-21. doi: https://doi.org/10.1016/j.nicl.2018.03.035

14. Cremers LGM, de Groot M, Hofman A, Krestin GP, van der Lugt A, Niessen WJ, Vernooij MW, Ikram MA. Altered tract-specific white matter microstructure is related to poorer cognitive performance: The Rotterdam Study. Neurobiology of aging 2016;39:108-117. doi: https://doi.org/10.1016/j.neurobiolaging.2015.11.021

15. Kerchner GA, Racine CA, Hale S, Wilheim R, Laluz V, Miller BL, Kramer JH. Cognitive processing speed in older adults: relationship with white matter integrity. PloS one 2012;7(11):e50425. doi: 10.1371/journal.pone.0050425 
16. Duering M, Gesierich B, Seiler S, Pirpamer L, Gonik M, Hofer E, Jouvent E, Duchesnay E, Chabriat H, Ropele S, Schmidt R, Dichgans M. Strategic white matter tracts for processing speed deficits in age-related small vessel disease. Neurology 2014;82(22):1946-1950. doi: 10.1212/wnl.0000000000000475

17. Nowrangi MA, Lyketsos C, Rao V, Munro CA. Systematic review of neuroimaging correlates of executive functioning: converging evidence from different clinical populations. J Neuropsychiatry Clin Neurosci 2014;26(2):114-125. doi: 10.1176/appi.neuropsych.12070176

18. Raz A. Anatomy of attentional networks. The Anatomical Record Part B: The New Anatomist 2004;281B(1):21-36. doi: 10.1002/ar.b.20035

19. Seghier ML. The Angular Gyrus:Multiple Functions and Multiple Subdivisions. The Neuroscientist 2013;19(1):4361. doi: 10.1177/1073858412440596

20. Eriksson J, Vogel EK, Lansner A, Bergström F, Nyberg L. Neurocognitive Architecture of Working Memory. Neuron 2015;88(1):33-46. doi: 10.1016/j.neuron.2015.09.020

21. Rizvi B, Lao PJ, Colón J, Hale C, Igwe KC, Narkhede A, Budge M, Manly JJ, Schupf N, Brickman AM. Tract-defined regional white matter hyperintensities and memory. Neurolmage: Clinical 2020;25:102143. doi:

https://doi.org/10.1016/j.nicl.2019.102143

\section{Supplementary Figures}

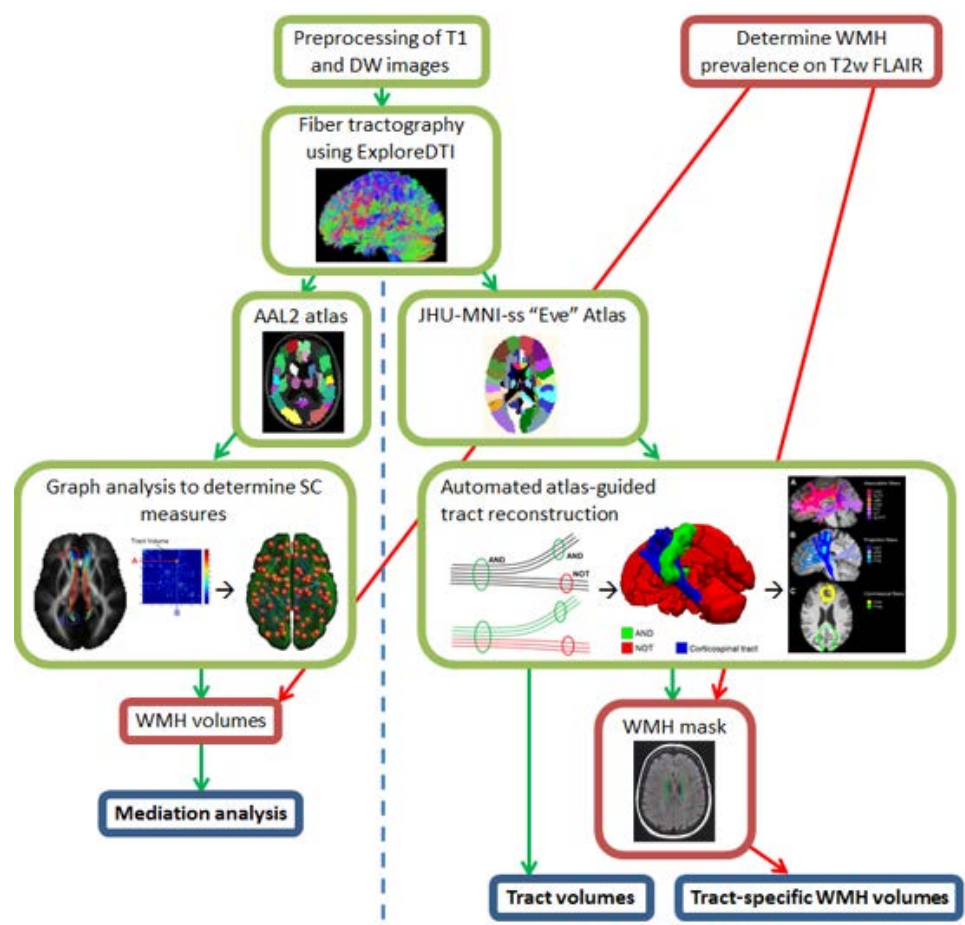

Supplementary Figure 5.1: Flowchart with most important image processing steps. Left side: calculation of graph measures and total WMH volumes for mediation analysis. Right side: automated atlas-guided tract reconstruction for calculated of tract volumes and tract-specific WMH volumes. 


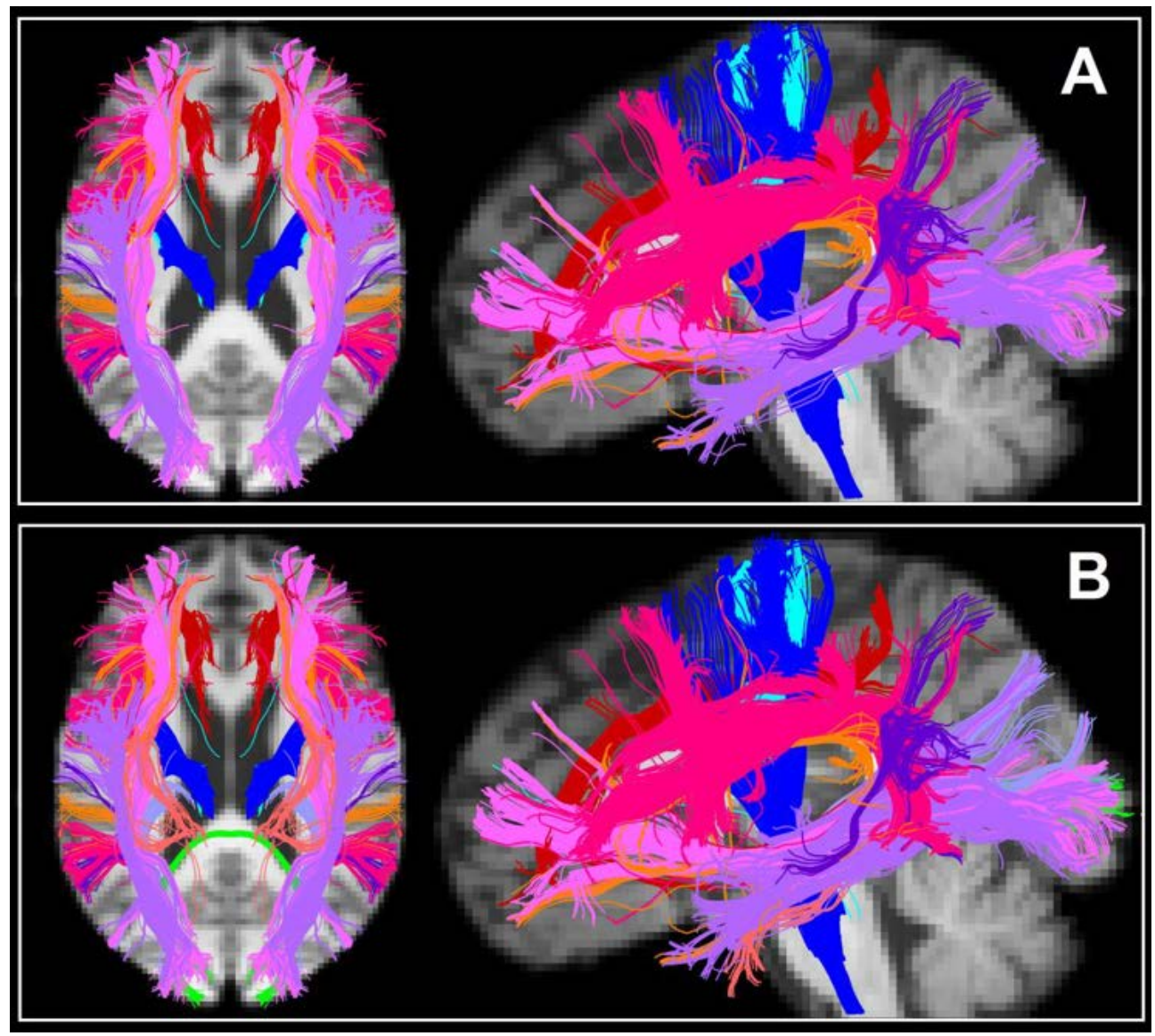

Supplementary Figure 5.2: Tracts with significant associations $(p<0.05)$ of tract-specific WMH volume, with executive function and attention (A) and memory (B) scores, adjusted for age, sex, education, diabetes-status, and cardiovascular risk factors (Model 3). 


\section{Supplementary Tables}

Supplementary Table 5.1: Associations of cSVD markers with cognition scores.

\begin{tabular}{|c|c|c|c|c|c|c|c|}
\hline & & \multicolumn{2}{|c|}{ Information processing speed } & \multicolumn{2}{|c|}{ Executive function $\&$ attention } & \multicolumn{2}{|l|}{ Memory } \\
\hline & & St $\beta[95 \% \mathrm{Cl}]$ & p-value & St $\beta[95 \% \mathrm{Cl}]$ & p-value & St $\beta[95 \% \mathrm{Cl}]$ & p-value \\
\hline \multirow{3}{*}{$\begin{array}{l}\text { Total WMH } \\
\text { Volume }\end{array}$} & Model 1 & $-0.080(-0.108,-0.053)$ & $<0.001$ & $-0.067(-0.096,-0.038)$ & $<0.001$ & $-0.083(-0.110,-0.055)$ & $<0.001$ \\
\hline & Model 2 & $-0.074(-0.102,-0.046)$ & $<0.001$ & $-0.064(-0.093,-0.034)$ & $<0.001$ & $-0.076(-0.104,-0.048)$ & $<0.001$ \\
\hline & Model 3 & $-0.073(-0.101,-0.046)$ & $<0.001$ & $-0.060(-0.089,-0.030)$ & $<0.001$ & $-0.073(-0.101,-0.045)$ & $<0.001$ \\
\hline \multirow{3}{*}{$\begin{array}{l}\text { Periventricular } \\
\text { WMH volume }\end{array}$} & Model 1 & $-0.068(-0.095,-0.040)$ & $<0.001$ & $-0.070(-0.099,-0.040)$ & $<0.001$ & $-0.079(-0.106,-0.051)$ & $<0.001$ \\
\hline & Model 2 & $-0.061(-0.089,-0.034)$ & $<0.001$ & $-0.066(-0.095,-0.037)$ & $<0.001$ & $-0.072(-0.099,-0.044)$ & $<0.001$ \\
\hline & Model 3 & $-0.060(-0.088,-0.033)$ & $<0.001$ & $-0.062(-0.092,-0.033)$ & $<0.001$ & $-0.069(-0.097,-0.041)$ & $<0.001$ \\
\hline \multirow{3}{*}{$\begin{array}{l}\text { Deep } \\
\text { WMH volume }\end{array}$} & Model 1 & $-0.082(-0.109,-0.056)$ & $<0.001$ & $-0.056(-0.084,-0.028)$ & $<0.001$ & $-0.071(-0.098,-0.044)$ & $<0.001$ \\
\hline & Model 2 & $-0.077(-0.104,-0.051)$ & $<0.001$ & $-0.053(-0.081,-0.025)$ & $<0.001$ & $-0.065(-0.092,-0.038)$ & $<0.001$ \\
\hline & Model 3 & $-0.077(-0.103,-0.050)$ & $<0.001$ & $-0.049(-0.078,-0.021)$ & 0.001 & $-0.063(-0.090,-0.036)$ & $<0.001$ \\
\hline \multirow{3}{*}{$\begin{array}{l}\text { Number of } \\
\text { CMBs }\end{array}$} & Model 1 & $-0.039(-0.071,-0.007)$ & 0.016 & $-0.027(-0.061,0.007)$ & 0.118 & $-0.044(-0.075,-0.012)$ & 0.007 \\
\hline & Model 2 & $-0.039(-0.071,-0.007)$ & 0.018 & $-0.027(-0.061,0.007)$ & 0.121 & $-0.043(-0.075,-0.012)$ & 0.007 \\
\hline & Model 3 & $-0.037(-0.069,-0.005)$ & 0.023 & $-0.026(-0.060,0.008)$ & 0.137 & $-0.042(-0.073,-0.011)$ & 0.009 \\
\hline \multirow{3}{*}{$\begin{array}{l}\text { Number of } \\
\text { CLIs }\end{array}$} & Model 1 & $-0.065(-0.089,-0.041)$ & $<0.001$ & $-0.009(-0.035,0.017)$ & 0.490 & $-0.023(-0.047,0.002)$ & 0.071 \\
\hline & Model 2 & $-0.062(-0.087,-0.038)$ & $<0.001$ & $-0.008(-0.034,0.018)$ & 0.558 & $-0.020(-0.045,0.005)$ & 0.111 \\
\hline & Model 3 & $-0.057(-0.081,-0.032)$ & $<0.001$ & $-0.005(-0.031,0.021)$ & 0.721 & $-0.017(-0.041,0.008)$ & 0.190 \\
\hline \multicolumn{8}{|c|}{$\begin{array}{l}\text { Model 1: Adjusted for age, sex, education level, intracranial volu } \\
\text { Model 2: Model } 1 \text { + additionally adjusted for diabetes-status; }\end{array}$} \\
\hline
\end{tabular}

Supplementary Table 5.2: Associations of CSVD markers with structural connectivity measures.

\begin{tabular}{|c|c|c|c|c|c|c|c|}
\hline & & \multicolumn{2}{|l|}{ Whole brain node degree } & \multicolumn{2}{|l|}{ Local efficiency } & \multicolumn{2}{|l|}{ Global efficiency } \\
\hline & & St $\beta[95 \% \mathrm{Cl}]$ & p-value & St $\beta[95 \% \mathrm{Cl}]$ & $\mathrm{p}$-value & St $\beta[95 \% \mathrm{Cl}]$ & p-value \\
\hline \multirow{3}{*}{$\begin{array}{l}\text { Total WMH } \\
\text { Volume }\end{array}$} & Model 1 & $-0.040(-0.070,-0.010)$ & 0.010 & $0.074(0.044,0.104)$ & $<0.001$ & $-0.010(-0.042,0.021)$ & 0.524 \\
\hline & Model 2 & $-0.030(-0.060,0.000)$ & 0.050 & $0.066(0.035,0.096)$ & $<0.001$ & $-0.011(-0.043,0.021)$ & 0.498 \\
\hline & Model 3 & $-0.027(-0.058,0.003)$ & 0.078 & $0.065(0.035,0.096)$ & $<0.001$ & $-0.011(-0.044,0.021)$ & 0.484 \\
\hline \multirow{3}{*}{$\begin{array}{l}\text { Periventricular } \\
\text { WMH volume }\end{array}$} & Model 1 & $-0.027(-0.057,0.003)$ & 0.080 & $0.068(0.037,0.098)$ & $<0.001$ & $-0.024(-0.055,0.008)$ & 0.145 \\
\hline & Model 2 & $-0.017(-0.047,0.013)$ & 0.265 & $0.059(0.029,0.089)$ & $<0.001$ & $-0.024(-0.056,0.007)$ & 0.132 \\
\hline & Model 3 & $-0.015(-0.045,0.015)$ & 0.337 & $0.060(0.029,0.090)$ & $<0.001$ & $-0.025(-0.057,0.007)$ & 0.129 \\
\hline \multirow{3}{*}{$\begin{array}{l}\text { Deep } \\
\text { WMH volume }\end{array}$} & Model 1 & $-0.060(-0.099,-0.031)$ & $<0.001$ & $0.082(0.053,0.111)$ & $<0.001$ & $0.004(-0.026,0.035)$ & 0.781 \\
\hline & Model 2 & $-0.053(-0.082,-0.024)$ & $<0.001$ & $0.075(0.046,0.105)$ & $<0.001$ & $0.004(-0.027,0.035)$ & 0.804 \\
\hline & Model 3 & $-0.050(-0.079,-0.020)$ & $<0.001$ & $0.073(0.045,0.104)$ & $<0.001$ & $0.004(-0.028,0.035)$ & 0.824 \\
\hline \multirow{3}{*}{$\begin{array}{l}\text { Number of } \\
\text { CMBs }\end{array}$} & Model 1 & $-0.016(-0.042,0.009)$ & 0.212 & $0.027(0.001,0.053)$ & 0.042 & $-0.021(-0.048,0.006)$ & 0.131 \\
\hline & Model 2 & $-0.017(-0.043,0.009)$ & 0.194 & $0.027(0.002,0.053)$ & 0.038 & $-0.021(-0.048,0.006)$ & 0.132 \\
\hline & Model 3 & $-0.015(-0.041,0.011)$ & 0.253 & $0.026(0.000,0.052)$ & 0.050 & $-0.021(-0.048,0.006)$ & 0.130 \\
\hline \multirow{3}{*}{$\begin{array}{l}\text { Number of } \\
\text { CLIs }\end{array}$} & Model 1 & $-0.052(-0.079,-0.026)$ & $<0.001$ & $0.071(0.044,0.098)$ & $<0.001$ & $0.009(-0.019,0.037)$ & 0.524 \\
\hline & Model 2 & $-0.049(-0.076,-0.023)$ & $<0.001$ & $0.068(0.041,0.095)$ & $<0.001$ & $0.009(-0.019,0.037)$ & 0.534 \\
\hline & Model 3 & $-0.044(-0.071,-0.017)$ & 0.001 & $0.065(0.038,0.092)$ & $<0.001$ & $0.010(-0.018,0.039)$ & 0.486 \\
\hline \multicolumn{8}{|c|}{$\begin{array}{l}\text { Model 1: Adjusted for age, sex, education level, intracranialvol } \\
\text { Model 2: Model } 1 \text { + additionally adjusted for diabetes-status; }\end{array}$} \\
\hline
\end{tabular}



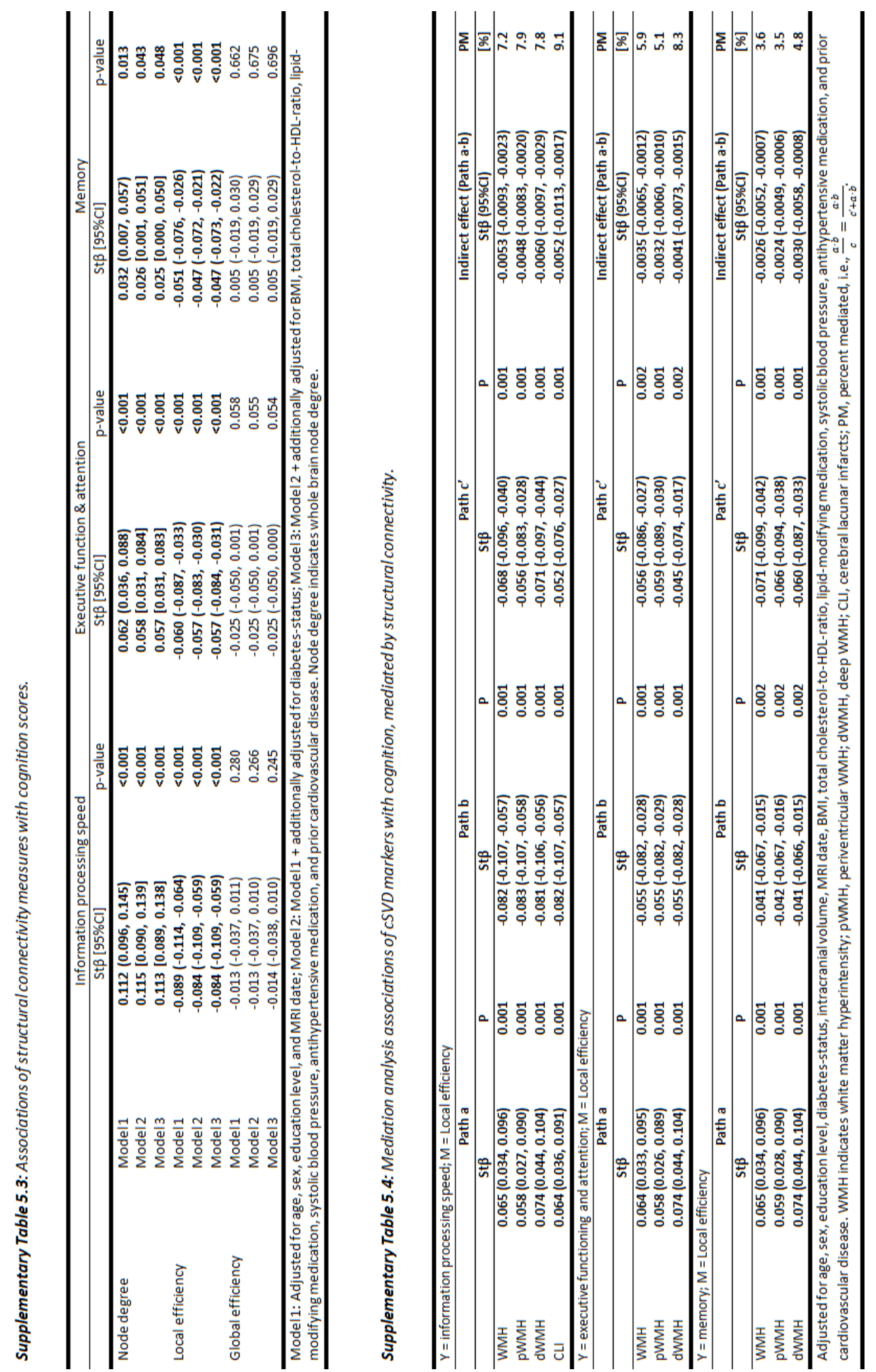
Supplementary Table 5.5: Total tract and tract-specific WMH volumes, and associations of tract specific WMH volume with domain-specific cognition.

\begin{tabular}{|c|c|c|c|c|c|}
\hline & $\begin{array}{l}\text { WMH } \\
\text { Volume }[\mu \mathrm{L}]\end{array}$ & $\begin{array}{l}\text { Tract } \\
\text { Volume [mL] }\end{array}$ & IPS & EF\&A & MEM \\
\hline & Median [IQR] & Median [IQR] & st $\beta$ wмH & st $\beta$ wмH & st $\beta$ wмн \\
\hline \multicolumn{6}{|l|}{ Association } \\
\hline CGC & $3[0,74]$ & $23.8[14.7,39.7]$ & $-0.084 * *$ & $-0.090 * *$ & $-0.064 * *$ \\
\hline $\mathrm{CGH}$ & $0[0,2]$ & $8.6[6.5,11.2]$ & -0.023 & -0.021 & $-0.034^{*}$ \\
\hline IFO & $278[41,1226]$ & $31.8[24.7,38.4]$ & $-0.027^{*}$ & $-0.038 *$ & $-0.028^{*}$ \\
\hline ILF & $52[3,320]$ & $28.6[23.1,34.7]$ & $-0.030 *$ & $-0.035^{*}$ & $-0.041 * *$ \\
\hline SLFPT & $1[0,39]$ & $18.5[14.5,23.0]$ & $-0.046 * *$ & $-0.029 *$ & $-0.050^{* *}$ \\
\hline SLFT & $123[5,1208]$ & $60.1[51.6,69.0]$ & $-0.049 * *$ & $-0.030 *$ & $-0.058^{* *}$ \\
\hline UNC & $18[1,145]$ & $17.1[11.9,23.0]$ & $-0.048 * *$ & $-0.036 *$ & $-0.060 * *$ \\
\hline \multicolumn{6}{|l|}{ Projection } \\
\hline ATR & $19[1,140]$ & $6.8[4.9,9.1]$ & -0.022 & 0.017 & $-0.033^{*}$ \\
\hline STR & $48[3,347]$ & $20.6[15.3,27.0]$ & $-0.054 * *$ & $-0.056 * *$ & $-0.048 *$ \\
\hline PTR & $36[2,255]$ & $10.4[7.3,13.8]$ & -0.032 & -0.023 & -0.030 \\
\hline CST & $0[0,27]$ & $18.0[14.1,21.8]$ & $-0.049 * *$ & $-0.042 * *$ & $-0.039 *$ \\
\hline \multicolumn{6}{|l|}{ Commissural } \\
\hline Forceps major & $51[1,499]$ & $6.7[3.7,10.7]$ & $-0.044 * *$ & -0.025 & $-0.044 * *$ \\
\hline Forceps minor & $62[3,315]$ & $8.0[6.2,9.7]$ & -0.008 & -0.026 & -0.021 \\
\hline
\end{tabular}

Adjusted for tract volume, age, sex, education level, MRI date, intracranial volume, diabetes-status, BMI, totalcholesterol-to-HDL-ratio, lipid-modifying medication systolic blood pressure, antihypertensive medication, and prior cardiovascular disease. ${ }^{*}$ indicates $\mathrm{p}<0.05 ;{ }^{*}$ indicates $\mathrm{p}<0.01 . \mathrm{WMH}=$ white matter hyperintensity, IPS $=$ information processing speed, EF\&A = executive function \& attention, $\mathrm{MEM}=$ memory, $\mathrm{CGC}=$ cingulum of cingulate gyrus, $\mathrm{CGH}=$ hippocampal part of cingulate gyrus, IFO = fronto-occipital fasciculus, ILF = inferior-longitudinal fasciculus, SLFPT = parietal part of the superior-longitudinal fasciculus, SLFT = temporal part of the superior-longitudinal fasciculus, UNC = uncinate fasciculus, CST = cortico-spinal tract, ATR = anterior thalamic radiation, PTR = posterior thalamic radiation, $\mathrm{STR}=$ superior thalamic radiation, Fmaj $=$ forceps major, Fmin $=$ forceps minor. 

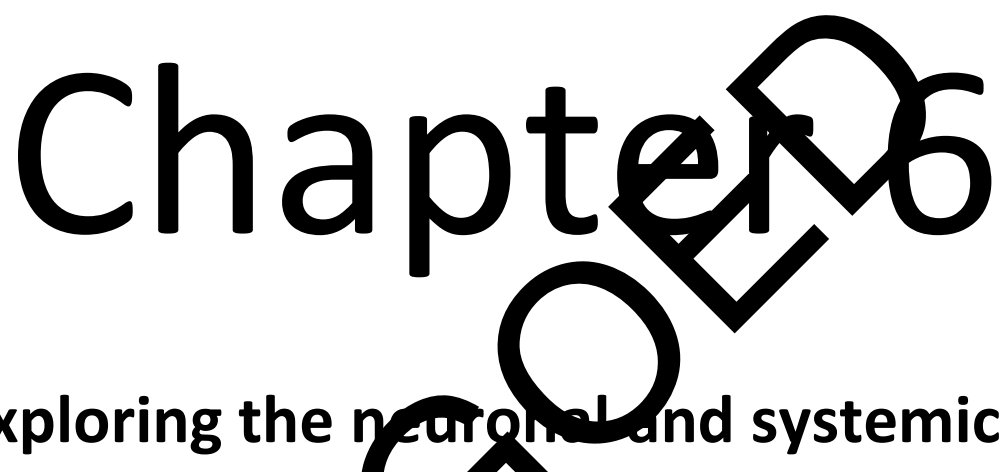
physiological contrib tion to spontaneous cerebral fluct at ons - Insights from The Maastricht Study

L.W.M. Vergog sen ILE.A Jansen, M.T. Schram, M.P.J. van Boxtel, J.P.H. Reulen, C.D.A s choy ver, A.J.H.M. Houben, M.M.J. Greevenbroek, D. Huybrechs, W.H. Backes

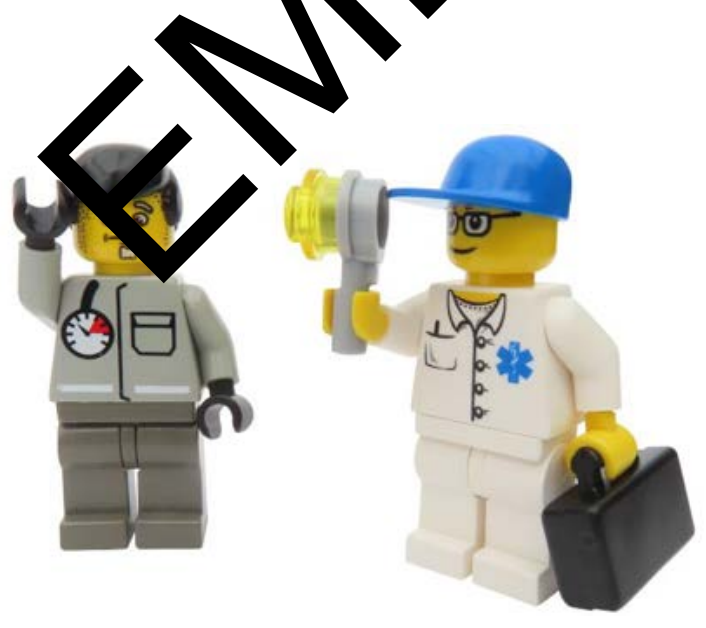




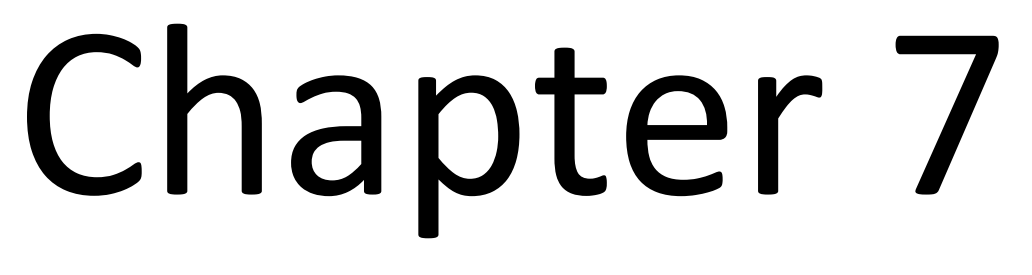

General Discussion

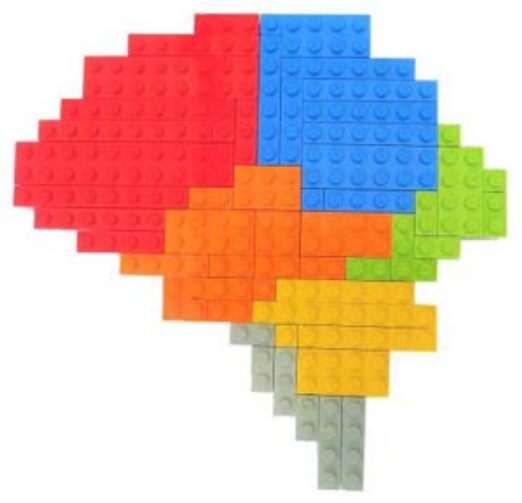




\section{Outline}

Multiple cardiometabolic risk factors are associated with chronic diseases, including type 2 diabetes and cardiovascular conditions. Accumulating evidence shows that these risk factors are associated with a higher risk of late-life cognitive detriments and eventually brain diseases such as dementia. Brain imaging in population-based cohort studies plays a key role to reveal underlying mechanism between life style, cardiovascular risk factors, and brain alterations, by use of the combined data provided by brain imaging and advanced phenotyping. The main objectives of this thesis were twofold. We investigated whether cardiometabolic risk factors are associated with novel neuronal imaging markers and evaluated the value of structural and functional brain network measures for that purpose.

This final chapter summarizes, combines, and discusses the main outcomes of this thesis in two parts:

- The influences of cardiometabolic risk factors on brain imaging markers in a population-based cohort study;

- A motivated selection of MR imaging measures and techniques.

\section{Influences of cardiometabolic risk factors on brain imaging}

\section{markers}

\section{Findings in population-based imaging studies}

In Chapter $\mathbf{2}$ of this thesis, we conducted a narrative review. In this review, we collected evidence from (mostly) cross-sectional MR imaging studies on the associations between cardiometabolic risk factors and brain atrophy, cerebral small vessel disease (CSVD), and white matter microstructure alterations. Less clear were the associations of an adverse lipid profile, as well as the association of relatively novel risk factors including physical inactivity and sedentary behavior, with MRI markers of the brain. In particular, the evidence from more advanced MRI measures, such as microstructural, functional, and perfusion MRI needs to be extended. Insight into more subtle brain alterations, which may represent early markers of brain disease, their change over time, and subsequent brain dysfunction and disease is needed to find new treatment targets.

In Figure 7.1, the gray symbols indicate findings from studies as described in the review in Chapter 2. Our results were generally in agreement with literature. However, with this thesis, we were able to add to almost all the cardiometabolic risk factor categories structural connectivity and functional MRI insights from a large cross-sectional study, as indicated with blue symbols in Figure 7.1. 


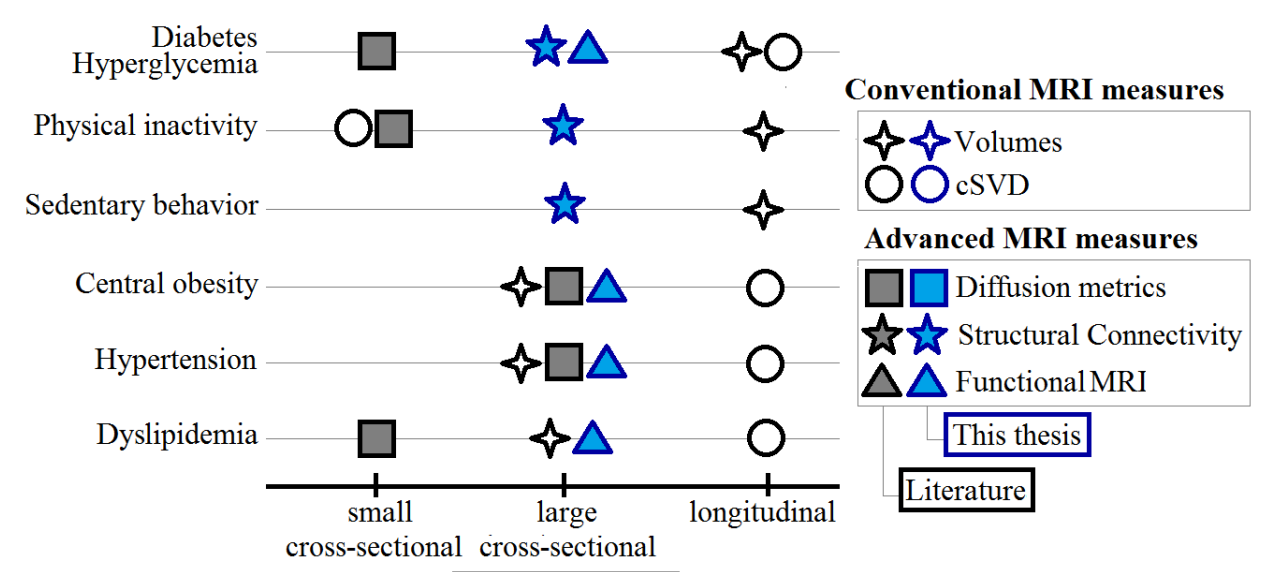

Level of evidence

Figure 7.1: Highest level of evidence in the available literature and in this thesis on the associations between cardiometabolic risk factors and conventional and advanced MRI measures. Gray symbols indicate findings from other studies, and blue symbols the additions from this thesis.

\section{Findings in The Maastricht Study}

In Chapter 3, we investigated whether hyperglycemia was associated with structural brain connectivity. We observed already in the prediabetes phase weaker white matter connections and altered organization of white matter networks. More specifically, we found that prediabetes, type 2 diabetes, and continuous measures of hyperglycemia were associated with a lower node degree, and thus globally fewer or weaker white matter connections. Furthermore, in prediabetes, the local efficiency and clustering coefficient were lower, which indicates that there was a weaker local connectivity. In addition, type 2 diabetes was associated with higher communicability, which was not yet observed in prediabetes, and which may reflect the use of alternative white matter connections to facilitate structural connectivity between brain regions. These outcomes support the concept that hyperglycemia, even in the prediabetes phase, may be harmful to the brain, and that type 2 diabetes affects the global and local organization of brain structures.

In Chapter 4, we investigated whether physical inactivity and sedentary behavior were associated with markers of brain connectivity. We found that objectively measured lower high intensity physical activity, but not low intensity physical activity and sedentary time, were associated with lower whole brain node degree and node degree in specific brain regions highly specialized in motor function. This suggests that high intensity physical activity can slow down structural deterioration in the brain.

In Chapter 5, we focused on the interrelations of white matter hyperintensities (WMH), white matter connectivity, and cognitive function. We found that WMH volume, white matter connectivity, and various cognitive functions display significant inter-relationships. In particular, larger WMH volumes were associated with lower local network efficiency and worse information processing. The relationship between WMHs and information processing speed was mediated by the local network efficiency. In tract specific analysis, we found that more WMHs in those white matter tracts that are important for information processing, were associated with cognitive slowing. 
In Chapter 6, we investigated whether we could recognize physiological measures in the blood oxygen level dependent (BOLD) signal. We found that both neuronal and systemic non-neuronal physiological measures are associated with frequency subbands of the measured dynamic fMRI signal. Most importantly, the subband analysis showed an association of cognitive performance as well as blood pressure variations with the signal of the subband with the frequency range 31.2-62.5 mHz, which is usually thought to reflect the signal of spontaneous neuronal fluctuations. Finally, the measured BOLD signal is altered in participants with cardiometabolic risk factors, consistent with what was expected from vascular impairment which is characteristic for cardiometabolic risk factors. These findings highlight the strong intertwining of neuronal and cardiometabolic activity, emphasize the importance of a proper selection of the resting-state frequency range, and also advice cautiousness in the interpretation fMRI signal changes as pure neuronal signals, especially when cardiometabolic risk factors are involved.

\section{Imaging measures and techniques}

In this thesis we used a number of MRI techniques, e.g., structural, diffusion-weighted, and resting-state functional MRI, and a variety of analysis techniques, e.g., graph theory, automated atlas-guided fiber tractography, and wavelet transformation, which provided various new insights. More specifically, the use of diffusion MRI scans to study structural connectivity measures enabled us to find more subtle brain alterations than gross brain volume changes. For example in Chapter 4, by using dMRI we were able to capture structural alterations, while there were no significant changes in white matter volumes found yet. Moreover, we used an automated atlas-guided tract reconstruction method based on whole brain fiber tractography, instead of a DTI atlas co-registered to a structural image to determine tract volumes. The automated atlas-guided tract reconstruction method has several advantages. Compared to manual $\mathrm{ROI}$ selection, it is automated, and thus better reproducible and less time consuming for the operator, and it enables the selection of tracts for which manual ROI placement is very difficult. Compared to a DTI atlas, it uses dMRI data, and thus actual streamlines instead of only structural scans.

However, the imaging protocol used in this study also has some limitations. In Chapter 5, we investigated local tract changes due to WMHs, but as is known, WMHs are situated at locations that are typical for ageing populations with cardiometabolic risk factors. Therefore, for specific cognitive domains (e.g., information processing speed or memory function), we are restricted to infer on the specific white matter tracts with the current distribution of WMHs in this population and cannot infer on the susceptibility of other white matter regions, though the whole brain network analysis demonstrated widely distributed alterations. To investigate this in more detail a scan protocol with a smaller voxel size could be used to refine the fiber tractography, and participants with more severe WMHs could be included to study the influence of more widespread WMHs.

In Chapter 3, 4, and 5, we employed structural connectivity analysis, which is easy to interpret, as it describes the white matter network. However, functional MRI (fMRI) techniques can provide more insight in the underlying mechanisms, for example in how the brain adapts to white matter damage. It is also possible to combine structural and functional connectivity analysis, but that was beyond the scope of the current thesis. In line with that, other graph measures could possibly provide more insight. The graph measure communicability (used in Chapter $\mathbf{3}$ ) could have been added to the analysis in Chapter $\mathbf{5}$, as this measure provides information about the compensatory mechanisms in case of white matter damage (e.g., WMHs). 
A relatively new interesting technique is dynamic functional connectivity (DFC), which is based on the observation that functional connectivity changes over time (non-stationarity (Jones, Vemuri et al. 2012)). Sliding window analysis is the most common used analysis technique in DFC. In this method, FC analysis is performed on several signal time series. However, this method is not very suitable for population-based research, as interpretation of the data from sliding window analysis is most accurate in case-control studies. Another method to conduct DFC analysis is time-frequency analysis. In Chapter $\mathbf{6}$ of this thesis, we employed a technique to perform time-frequency analysis: Wavelet Transformation.

\section{Clinical implications}

\section{Health perspectives}

Most advanced MRI outcome measures may be able to detect early changes prior to end-organ damage, which makes them potentially more useful as response markers for intervention studies than gross volumetric data or structural deviations. In this thesis, most associations of cardiometabolic risk factors with brain markers were comparable to accelerated brain aging. For instance, in participants with prediabetes and type 2 diabetes we found a lower node degree that was equivalent to 2 and 9 years of aging, respectively, as compared to participants with a normal glucose metabolism. In terms of cognitive impairment, a $0.51 \mathrm{~mL}$ larger WMH volume was equivalent to 10 years of cognitive aging, while $1.69 \mathrm{~mL}$ more WMHs was equivalent to 10 years of network aging in terms of structural connectivity. This comparison suggests that the impact of WMHs on the local network topology is approximately three times stronger than the impact on cognitive decline. Participants with diabetes had larger WMH volumes, higher local efficiency, and lower information processing speed scores compared to nondiabetic participants. The lower cognitive scores in participants with diabetes were equivalent to 3.3 years of cognitive aging.

Furthermore, for physical activity, we showed that objectively measured higher high intensity physical activity was associated with both higher global structural connectivity and in specific brain regions that are highly specialized in motor function. The difference in whole brain node degree with 5 minutes less high intensity physical activity per day was equivalent to one year of aging.

It is known from literature that physical activity increases blood flow to the brain, resulting in increased vascularization of the brain, improved supply of nutrients and removal of metabolic waste. More specifically, higher levels of physical activity or cardiorespiratory fitness have been associated with an increase in cerebral perfusion and cerebral oxygen supply to the prefrontal cortex (Dupuy, Gauthier et al. 2015), which is an area involved in motor function (Goldman-Rakic 1987).

\section{Prevention strategies}

In general, advanced MRI techniques, including microstructural, functional, and perfusion MRI, may provide more insight into underlying processes that lead from cardiometabolic risk factors to brain dysfunction and disease, compared to structural MRI. These insights may help to develop treatment strategies to delay or even prevent brain alterations and eventually brain disease. In addition, early biomarkers for brain disease may enable us to identify people at risk, to prevent further escalation to 
functional decrements and eventual disease. More specifically, we found that brain changes already occur in prediabetes, before the clinical diagnosis of type 2 diabetes. Therefore, treatment of prediabetes should be considered as a potential target of intervention for prevention of complications of type 2 diabetes, including structural brain changes. Furthermore, stimulating physical activity should still be considered as target of intervention in the general population, because more high intensity physical activity was associated with higher structural connectivity. This can be substantiated, because higher levels of physical activity stimulate processes of neurogenesis (formation of new neurons) and angiogenesis (formation of blood vessels) (Lei, Wu et al. 2019), and reduce inflammation (Trigiani and Hamel 2017). In addition, being physically active has been shown to reduce cardiovascular risk factors such as type 2 diabetes and hypertension through increasing neurotropic factors, reducing oxidative stress, and/or reducing beta-amyloid formation (Zimmerman, Sutton et al. 2014). Another study based on The Maastricht Study data revealed that replacement of 30 minutes of sedentary time per day to standing or stepping was associated with lower risk for type 2 diabetes, and more favorable waist circumference and BMI, and improved levels of cholesterol and blood glucose (Van Der Berg, Van Der Velde et al. 2017). These mechanisms may reduce the incidence of mild cognitive impairment and dementia (Gallaway, Miyake et al. 2017, Kennedy, Hardman et al. 2017).

\section{Methodological considerations}

\section{Population study of brain imaging markers and influences of cardiometabolic}

\section{risk factors}

Strengths of the analysis of cardiometabolic risk factors in this thesis were the large sample size and population-based design, and the extensive assessment of the cardiometabolic profile and potential confounders. Reduction of residual confounding is of key importance to correctly interpret the results, also because cardiometabolic risk factors are interrelated. Specific strengths were the use of $\mathrm{HbA1c}$ levels and a 2-hr OGTT to accurately characterize glucose metabolism, and the objective measurement of physical activity and sedentary behavior as opposed to self-reported questionnaire data, because questionnaires are prone to over- or underestimation.

Limitations were that we cannot infer any conclusion about the causality/temporality of the associations found yet due to the cross-sectional design of the study. Therefore, future longitudinal studies are needed to address if cardiometabolic risk factors really precede the development of the observed brain abnormalities, and interventional studies to study to what extent specific brain alterations can be reversed or prevented by improving lifestyle to lower cardiometabolic risk. The Maastricht Study is already planning a follow-up to investigate changes over time, but this is a very expensive and time-consuming process. Furthermore, participants of The Maastricht Study in general were highly educated, intensively treated with regard to cardiovascular risk factors, and mainly of Caucasian race, because they were recruited through mass media campaigns, from municipal registries, and the regional Diabetes Patient Registry via mailings. This might have led to selective non-response bias, as individuals who choose to participate may be different from individuals who do not wish to participate. Additionally, only participants that fulfilled the inclusion criteria for undergoing MRI were included, and these individuals had less often a history of prior cardiovascular disease, were younger, 
were less likely to have type 2 diabetes, were less often smokers, and less often had a low educational level, as compared to the study population which did not undergo MRI. This may have led to an underestimation of the observed associations, as our study population may have had a lower exposure to cardiovascular risk factors as compared to a general population.

\section{Imaging measures and techniques}

Strengths of MR imaging used in this thesis were the large amount of MRI scans available, the broad array of additional analyses, which all gave consistent results, and most findings remained statistically significant after adjustment for potential confounders.

Limitations were that the rs-fMRI scan protocol used in this study was designed for the large population-based Maastricht Study, and not for the very specific type of analysis described in Chapter 6 . Therefore, a commonly used repetition time of $\mathbf{2 0 0 0}$ ms was available. However, to filter out cardiac and respiratory influences, scans with a shorter repetition time (and thus higher sampling frequency) might provide more information, as we were not able to detect to actual cardiac and respiratory frequencies from the current dataset. Moreover, we did not acquire the cardiac/respiratory physiological measures simultaneously with the rs-fMRI, which might be a constraint of our analysis, but on the other hand, we have an extensive data set with longer measurements. Furthermore, biases introduced during MRI data acquisition and/or processing might affect the connectivity data used in most chapters of this thesis. In the study of de Jong et al. (de Jong, Jansen et al. 2019), the influence of signal-to-noise ratio (SNR), head motion, and spatial mismatch between MRI-based anatomy and a brain atlas were investigated.

According to this study, more head motion and low SNR were negatively associated with structural and functional connectivity, respectively, and image quality metrics had larger effects on brain connectivity estimates than demographic variables such as age or sex. To minimize confounding effect image quality, we adjusted for these image quality metrics.

\section{Future outlook}

\section{Future studies and follow-up}

Longitudinal studies are needed to address the usefulness of these novel biomarkers in relation to disease outcomes. Furthermore, it would be interesting to evaluate whether brain alterations could be delayed or even reversed in participants that improved their lifestyle. For this purpose, structural connectivity and tract-specific analysis should be repeated and compared between time points. Additionally, the suggestion of performing functional connectivity analysis on both baseline and followup data, in comparison with the SC data could be of great additive value, as brain function relies on the interplay of both structure and function. The future plans of The Maastricht Study are to start in fall 2020 with inviting all the participants for follow-up measurements and MRI assessments. 


\section{Other sequences and measures}

With respect to the scanning protocol, other novel MRI approaches, such as dynamic contrast enhanced (DCE) MRI, to investigate blood-brain-barrier leakage; magnetic resonance spectroscopy (MRS), to investigate the metabolic characteristics of brain alterations; or ultra-high field MRI (>3Tesla) might provide alternative ways to elucidate the early signs and complex pathophysiology of brain diseases. However, not all of these options (e.g., contrast, high field) are feasible in a population-based setting due to ethical issues as for instance potential side effects. Furthermore, it would be interesting whether we could improve the rs-fMRI scan protocol in order to distinguish systemic circulatory dysfunction in pathologies such as hypertension and diabetes from the intrinsic neurogenic and neurovascular coupling effects in the rs-fMRI signal.

\section{Conclusion}

This thesis summarizes and extends the existing evidence on associations between cardiometabolic risk factors and subtle brain changes as assessed by structural and advanced imaging modalities. More specifically, in participants with several cardiometabolic risk factors, we found structural and functional network alterations beyond visible brain lesions. Future studies should clarify to which extent the observed brain alterations are predictive for health regression and are suitable biomarkers for monitoring treatment and prevention strategies or are merely adaptive changes to compensate for initial brain impairments. 


\section{References}

1. Jones DT, Vemuri P, Murphy MC, Gunter JL, Senjem ML, Machulda MM, et al. Non-stationarity in the "resting brain's" modular architecture. PloS one. 2012;7(6):e39731-e.

2. Dupuy $\mathrm{O}$, Gauthier CJ, Fraser SA, Desjardins-Crèpeau L, Desjardins M, Mekary S, et al. Higher levels of cardiovascular fitness are associated with better executive function and prefrontal oxygenation in younger and older women. Frontiers in human neuroscience. 2015;9(66).

3. Goldman-Rakic PS. Motor control function of the prefrontal cortex. Ciba Found Symp. 1987;132:187-200.

4. Lei X, Wu Y, Xu M, Jones OD, Ma J, Xu X. Physical exercise: bulking up neurogenesis in human adults. Cell \& Bioscience. 2019;9(1):74.

5. Trigiani $\sqcup$, Hamel E. An endothelial link between the benefits of physical exercise in dementia. Journal of Cerebral Blood Flow \& Metabolism. 2017;37(8):2649-64.

6. Zimmerman B, Sutton B, Low K, Fletcher M, Tan CH, Schneider-Garces N, et al. Cardiorespiratory fitness mediates the effects of aging on cerebral blood flow. Frontiers in aging neuroscience. 2014;6(59).

7. Van Der Berg JD, Van Der Velde JHPM, De Waard EAC, Bosma H, Savelberg HHCM, Schaper NC, et al. Replacement Effects of Sedentary Time on Metabolic Outcomes: The Maastricht Study. Medicine \& Science in Sports \& Exercise. 2017;49(7).

8. Kennedy G, Hardman RJ, Macpherson H, Scholey AB, Pipingas A. How Does Exercise Reduce the Rate of AgeAssociated Cognitive Decline? A Review of Potential Mechanisms. Journal of Alzheimer's disease : JAD. 2017;55(1):1-18.

9. Gallaway PJ, Miyake H, Buchowski MS, Shimada M, Yoshitake Y, Kim AS, et al. Physical Activity: A Viable Way to Reduce the Risks of Mild Cognitive Impairment, Alzheimer's Disease, and Vascular Dementia in Older Adults. Brain Sci. 2017;7(2).

10. de Jong JJA, Jansen JFA, Vergoossen LWM, Schram MT, Stehouwer CDA, Wildberger JE, et al. The Effect of MR Image Quality on Structural and Functional Brain Connectivity: The Maastricht Study. bioRxiv. 2019:806075. 
Summary

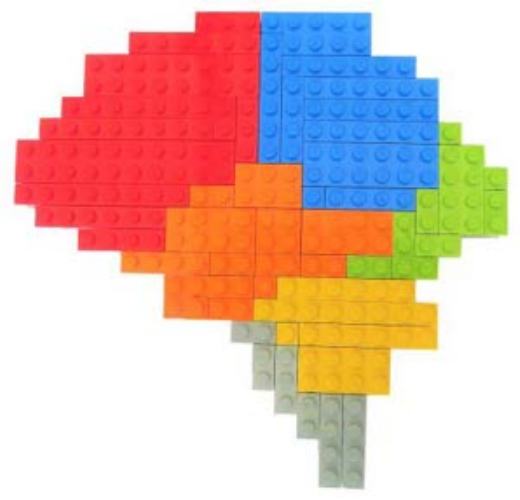


Cardiometabolic risk factors, such as hyperglycemia, physical inactivity, sedentary behavior, central obesity, hypertension, and dyslipidemia, increase the risk of chronic diseases, such as (pre)diabetes and dementia. In particular, these risk factors may affect the smallest brain vessels and are thought to lead to cerebral small vessel disease (CSVD) and neurodegeneration (brain atrophy), which represent early features in the pathophysiology of cognitive decline and dementia. Currently, it is not fully understood how these risk factors exactly contribute to cognitive decline. Therefore, this thesis aims to gain more insight into the brain alterations underlying cognitive decline and brain pathology.

Structural magnetic resonance imaging (MRI) techniques are able to detect macroscopically visible brain abnormalities, such as microvascular lesions and atrophy. More advanced MRI techniques also provide detailed insights into subtle brain changes, and thus early development of pathology. In this thesis, we focus on two advanced MRI techniques: diffusion-weighted MRI to analyze the structure and efficiency of the constellation of white matter fiber tracts, and functional MRI to study brain activity. We used population data from The Maastricht Study, which provided us a combination of advanced phenotyping and brain MRI data.

Chapter 1 provides a general introduction on the associations between cardiometabolic risk factors, the developing, or expressing alterations of the brain tissue, and the emerging health detriments and disorders. Thereafter, the added value of MRI and brain population imaging studies is discussed. Furthermore, an explanation of the advanced MRI and analysis methods used in this thesis, and an overview of European population imaging studies with brain imaging are provided.

In Chapter 2, a narrative review is conducted that summarizes the existing evidence on associations between cardiometabolic risk factors and subtle brain changes as assessed by structural and advanced MRI. Clear evidence was found that hyperglycemia, physical inactivity, central obesity, and hypertension are associated with both structural and functional brain alterations, while the role of dyslipidemia is far less clear. However, longitudinal evidence that assesses temporality of the associations with more advanced and thus more precise brain imaging methods is needed to improve insights into the complex etiology of brain diseases.

In Chapter 3, the association of prediabetes and type 2 diabetes, with white matter network characteristics, in terms of the number (node degree) and organization (graph measures) of the white matter connections was investigated. The findings in this chapter indicated that prediabetes and type 2 diabetes are associated with fewer white matter connections, and weaker organization of the corresponding networks. Additionally, type 2 diabetes was associated with higher communicability, which was not yet observed in prediabetes, which may reflect the use of alternative connections. These findings support the concept that hyperglycemia, even in the prediabetes phase, may be harmful to the connectivity of the brain, and that type 2 diabetes affects the global and local organization of brain structures.

In Chapter 4, we investigate the association of objectively measured low- and high-intensity physical activity and sedentary time with structural connectivity, both throughout the whole brain, and in brain regions involved in motor function, as a measure of white matter integrity. Objectively measured lower high-intensity, but not lower low-intensity physical activity and higher sedentary time, were associated with lower node degree of the whole cerebrum and in specific brain regions highly specialized in motor function. These observations suggest that more high-intensity physical activity may preserve structural brain connectivity, which needs to be demonstrated in future studies following stimulation of physical activity. 
In Chapter 5, we investigate the association between cSVD lesions, cerebral networks, cognitive function, and cardiometabolic risk factors. The association found between white matter hyperintensities and information processing speed was partly mediated by the local network efficiency. Locally, larger white matter hyperintensity volumes in white matter tracts that are important for information processing were associated with cognitive slowing. These observations provide insight in how white matter pathology in aging individuals with cardiometabolic risk factors are biologically related to cognitive decrements.

In Chapter 6, we decompose the dynamic resting-state fMRI brain signal into wavelet components and explore whether the various physiological measures, including cardiac activity, respiration, myogenic activity, neurogenic activity, and endothelial activity, are associated with the wavelet frequency subbands. Physiological measures were associated with the energy of certain frequency subbands of the fMRI signal spectrum. Cognitive performance and blood pressure variations, as measures of neurogenic and myogenic activity respectively, were associated with the energy of the frequency subband $3(31.2-62.5 \mathrm{mHz})$. Furthermore, cardiac and respiratory activity were associated with the energy of high frequency subband $1(125-250 \mathrm{mHz})$, and endothelial activity with the energy of low frequency subbands 6 and $7(<10 \mathrm{mHz})$. Finally, the measured BOLD signal, including the frequency component relevant for neurogenic activity, was associated with cardiometabolic risk factors. These findings highlight the influence of systemic physiologic fluctuations to the dynamic BOLD signal, the strong intertwining of neuronal, vascular, and cardiometabolic activity and emphasize the importance of a proper selection of the resting-state frequency range in studies on cognitive function applying brain fMRI.

Finally, Chapter $\mathbf{7}$ combines and discusses the key findings of this thesis. In addition, methodological considerations and directions for future research are addressed. 
Samenvatting

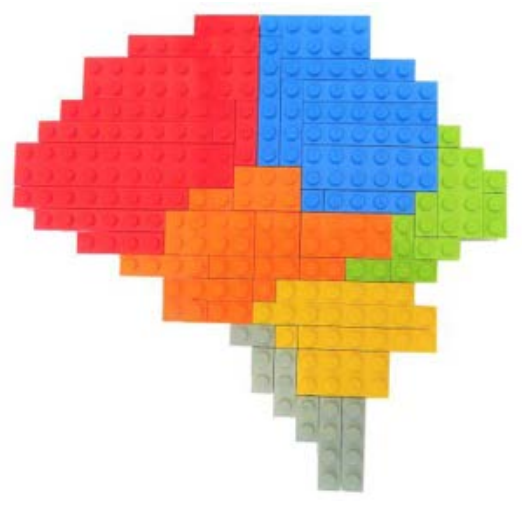


Cardiometabole risicofactoren, zoals hyperglykemie, lichamelijke inactiviteit, sedentair gedrag, overgewicht, hoge bloeddruk (hypertensie), en hoog cholesterol (dyslipidemie), vergroten het risico op chronische ziektes, zoals (pre)diabetes en dementie. Deze risicofactoren tasten vooral de kleine vaatjes in de hersenen aan en men vermoedt dat ze kunnen leiden tot "cerebral small vessel disease" (cSVD) en neurodegeneratie (hersenatrofie), wat vroege kenmerken zijn van het ontstaan van cognitieve achteruitgang en dementie. Momenteel is het nog niet volledig duidelijk hoe deze risicofactoren precies bijdragen aan cognitieve achteruitgang. Daarom is het doel van dit proefschrift meer inzicht krijgen in de hersenveranderingen die ten grondslag liggen aan cognitieve achteruitgang en hersenaandoeningen.

Structurele magnetic resonance imaging (MRI) technieken zijn in staat om macroscopisch zichtbare hersenafwijkingen, zoals microvasculaire laesies en atrofie te detecteren. Meer geavanceerde MRI technieken kunnen ook inzicht geven in subtielere hersenverandering, en dus vroege ontwikkeling van pathologie. In dit proefschrift focussen we op twee geavanceerde MRI technieken: diffusie-gewogen MRI om de structuur en efficiëntie van witte stof verbindingen te analyseren, en functionele MRI om hersenactiviteit te onderzoeken. We hebben hiervoor populatie data van De Maastricht Studie gebruikt, wat ons een combinatie van geavanceerde fenotypering en hersen MRI scans overleverde.

Hoofdstuk 1 geeft een algemene inleiding over de associaties tussen cardiometabole risicofactoren, de ontwikkelende of al tot uiting gekomen veranderingen van het hersenweefsel, en het ontstaan van gezondheidsschade. Daarna wordt de toegevoegde waarde van MRI en populatie studies met beeldvorming van het brein bediscussieerd. Bovendien worden de geavanceerde MRI en analyse methoden die gebruikt worden in dit proefschrift uitgelegd, en wordt er een overzicht gegeven van Europese populatie studies met hersenscans.

In Hoofdstuk 2, wordt de beschikbare literatuur over associaties tussen cardiometabole risicofactoren en subtiele hersenveranderingen, onderzocht met structurele en geavanceerde MRI samengevat. Er werd gevonden dat hyperglykemie, lichamelijke inactiviteit, centrale obesitas, en hypertensie geassocieerd zijn met zowel structurele als functionele hersenveranderingen, terwijl de invloed van dyslipidemie veel minder duidelijk is. Er zijn echter longitudinale studies nodig die de temporaliteit van de associaties met meer geavanceerde en dus nauwkeurigere beeldvormingsmethoden voor de hersenen beoordelen, om inzichten in de complexe etiologie van hersenziekten te verbeteren.

In Hoofdstuk 3 worden de associaties van prediabetes en type 2 diabetes met structurele netwerk eigenschappen, in termen van het aantal (node degree) en de organisatie (graafmaten) van de witte stof verbindingen onderzocht. De bevindingen in dit hoofdstuk gaven aan dat prediabetes en type 2 diabetes geassocieerd zijn met minder witte stof verbindingen, en een slechtere organisatie van de bijbehorende netwerken. Daarnaast was type 2 diabetes geassocieerd met een hogere "communicability", wat het gebruik van alternatieve verbindingen reflecteert, en dit werd nog niet waargenomen in het voorstadium prediabetes. Deze bevindingen ondersteunen de opvatting dat hyperglykemie, zelfs in de prediabetes fase, schadelijk kan zijn voor de verbindingen in de hersenen, en dat type 2 diabetes de globale en lokale organisatie van hersenstructuren beïnvloedt.

In Hoofdstuk 4 onderzoeken we de associatie tussen objectief gemeten laag- en hoogintensieve lichamelijke activiteit en zittijd en structurele connectiviteit, zowel voor het hele brein als in hersengebieden die belangrijk zijn voor motor functie. Objectief gemeten lagere hoog-intensieve, maar niet laag-intensieve lichamelijke activiteit en zittijd, waren geassocieerd met lagere node degree voor het hele cerebrum en in specifieke hersengebieden die gespecialiseerd zijn in motor functie. Deze bevindingen suggereren dat meer hoog-intensieve lichamelijke activiteit structurele hersen connectiviteit 
kan behouden. Dit moet worden bevestigd door toekomstige studies na het stimuleren van meer lichamelijke activiteit.

In Hoofdstuk 5, onderzoeken we de associatie tussen cSVD laesies, cerebrale netwerken, cognitieve functie, en cardiometabole risicofactoren. De associatie die gevonden werd tussen witte stof laesies en informatie verwerkingssnelheid werd deels gemedieerd door de lokale netwerk efficiëntie. Lokaal, waren grotere witte stof laesie volumes in verbindingen belangrijk voor informatie verwerkingssnelheid geassocieerd met cognitieve vertraging. Deze bevindingen geven inzicht in hoe witte stof pathologie in oudere personen met cardiometabole risicofactoren biologisch gerelateerd is aan cognitieve achteruitgang.

In Hoofdstuk 6, ontbinden we het dynamische resting-state fMRI signaal in wavelet componenten en onderzoeken we of verschillende fysiologische maten, zoals hartactiviteit, ademhaling, myogene activiteit, neurogene activiteit, en endotheel activiteit, geassocieerd zijn met wavelet frequentie subbanden. Fysiologische maten waren geassocieerd met de energie van bepaalde frequentie subbanden van het fMRI signaal spectrum. Cognitieve functie en bloeddruk variaties, als maten van respectievelijk neurogene en myogene activiteit, waren geassocieerd met de energie van frequentie subband 3 (31.2-62.5 mHz). Bovendien waren hartactiviteit en ademhaling geassocieerd met de energie van hoge frequentie subband $1(125-250 \mathrm{mHz})$, en endotheel activiteit met de energie van lage frequentie subbanden 6 en $7(<10 \mathrm{mHz})$. Tenslotte was het gemeten BOLD signaal, inclusief de frequentie component relevant voor neurogene activiteit, geassocieerd met cardiometabolic risicofactoren. Deze bevindingen benadrukken de invloed van systemische fysiologische schommelingen op het dynamische BOLD signaal, de sterke verstrengeling van neuronale, vasculaire, en cardiometabole activiteit, en accentueren het belang van een goede selectie van de resting-state frequentie range in studies naar cognitieve functie met fMRI.

Tenslotte worden in Hoofdstuk $\mathbf{7}$ de belangrijkste bevindingen van dit proefschrift gecombineerd en bediscussieerd. Daarnaast worden methodologische overwegingen en ideeën voor toekomstig onderzoek gesproken. 


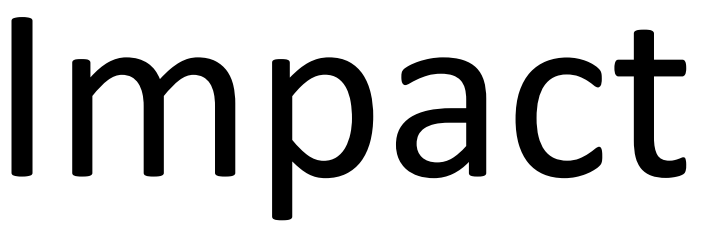

Paragraph

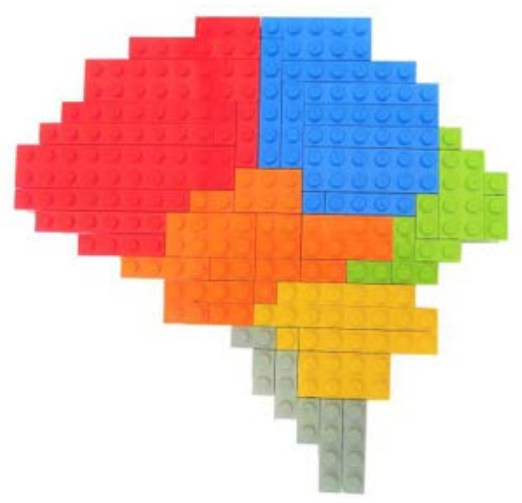




\section{Main findings}

In this thesis, we investigated whether life style related risk factors are associated with novel neuronal imaging markers and evaluated the value of structural and functional brain network measures for that purpose. The life style related risk factors, also called cardiometabolic risk factors, studied in this thesis are (pre)diabetes, physical inactivity, high sedentary time, high blood pressure, obesity, and high cholesterol. We summarized and extended the existing evidence on associations between cardiometabolic risk factors and subtle brain changes as assessed by structural and advanced MRI. More specifically, we found that high blood sugar was associated with structural brain alterations, even in the prediabetes phase. Physical inactivity was also associated with structural brain alteration, especially in brain regions highly specialized in motor function. Furthermore, we found an interrelation of brain damage in the form of white matter hyperintensities (WMH), structural brain alterations, and cognitive function. In particular, WMHs in structural brain connections important for information processing speed were associated with cognitive slowing. Finally, we observed that neuronal and non-neuronal physiological signals could be recognized in the functional MRI signal, and that this signal is altered in people with cardiometabolic risk factors. To show the relevance of our findings, we can express brain changes in years of aging. The impact on the amount of connections between regions in prediabetes and type 2 diabetes was equivalent to 2 and 9 years of aging, respectively, as compared to participants with a normal glucose metabolism, and for cognition scores of participants with diabetes this was equivalent to 3.3 years of cognitive aging. Physical inactivity also led to brain changes, participants with on average 5 minutes less high intensity physical activity per day had a lower node degree equivalent to one year of aging. As cardiometabolic risk factors are also associated with small lesions in the brain, we also made such a comparison in participants with $\mathrm{WMH}$ presence. A larger $\mathrm{WMH}$ volume of $0.51 \mathrm{~mL}$ was equivalent to 10 years of cognitive aging, while a larger $\mathrm{WMH}$ volume of $1.69 \mathrm{~mL}$ was equivalent to 10 years of network aging.

\section{Relevance}

Due to the aging population, there is an increase in age-associated conditions such as cognition problems and Alzheimer's disease. However, there is currently no medication available for treatment of cognitive decline. Accumulating evidence shows that cardiometabolic risk factors are associated with a higher risk of late-life cognitive detriments and eventually brain diseases such as dementia. Additionally, cardiometabolic risk factors are associated with chronic diseases, including type 2 diabetes, heart disease, and renal failure. In The Netherlands, more than 1.2 million people have type 2 diabetes, which is 1 in 14, and this group increases with 1000 every week. Even more people, over 1.6 million, suffer from cardiovascular conditions. As cardiometabolic risk factors are often behavioural and therefore modifiable, these are an interesting target for prevention of brain diseases. Therefore, it is important to reveal underlying mechanism between life style, cardiovascular risk factors, and brain alterations. Brain imaging in population studies is ideal for this due to the use of the combined data provided by brain imaging and the availability of multiple other characteristics of the participants.

The results from the advanced MRI techniques presented in this thesis, provide more insight into underlying processes that lead from cardiometabolic risk factors to brain dysfunction and disease, 
compared to structural MRI. Since we were able to detect early brain changes, these insights may help to develop treatment strategies to delay or even prevent brain alterations and eventually brain disease. Simply stimulating a healthier lifestyle, by for example more physical activity or a diet, might already contribute to prevention of future brain alterations. In addition, early signs for brain disease may enable us to identify people at risk, to prevent further escalation to functional problems and eventual disease. Additionally, these findings acquired from advance brain MRI also emphasize the importance of further development of MRI scan protocols and analysis techniques.

\section{Target group}

The findings from this thesis are important for the general aging population, but probably also for more specific target groups. This thesis extended the insight into the association of cardiometabolic risk factors and brain alterations, and the results underline the importance of promoting a healthier lifestyle and its importance in the battle to prevent brain disorders. More specifically, the finding that modifiable cardiometabolic risk factors are associated with brain alterations might be interesting for healthcare policy makers, for instance, to promote physical activity in order to prevent for brain alterations. The new insights on the early MR imaging markers is interesting for neuroscientists, in order to early detect brain abnormalities before onset of cognitive problems, but also for the MRI vendors, to improve their software, and finally, the pharmaceutical industry might be interested, as these new insights emphasize the importance of treatment of cardiometabolic risk factors. All studies in this thesis were conducted in the large population-based Maastricht Study. The Maastricht Study is characterized by an extensive phenotyping approach. This made it possible to obtain findings that are likely also applicable to the general population, in particular to middle-aged people with cardiometabolic risk factors.

\section{Activities}

The findings from this study could be used by policy makers to inform, to comprehend and to convince people that improving lifestyle is not only good for their general health, but also specifically for their brain. The Maastricht Study is also committed to informing the participants by its website and the local media. For instance, the findings from Chapter 3 of this thesis were published in a local newspaper (de Limburger), and national media (Elsevier and Libelle). Furthermore, there is an annual Maastricht Study symposium, which is an interactive meeting for the participants of the study to inform them about the current state of the study and the most recent findings. 


\section{Future directions}

Future longitudinal studies should clarify the usefulness of novel biomarkers in relation to disease outcome and to which extent the observed brain alterations are predictive for health regression. Furthermore, the suitability of biomarkers for monitoring treatment and prevention strategies, and whether brain changes are merely adaptive and able to compensate for initial brain impairments, needs to be addressed. The Maastricht Study will start in fall 2020 with inviting all the participants of The Maastricht Study for follow-up measurements and MRI assessments. Finally, intervention studies will be essential to evaluate whether brain alterations could be delayed or even reversed in people that improved their lifestyle. 
Dankwoord 


\section{Dankwoord}

Dit proefschrift was nooit tot stand gekomen zonder de hulp van velen. Ik wil dan ook graag iedereen bedanken die op wat voor manier dan ook heeft geholpen.

Een speciaal woord van dank aan mijn promotieteam. Walter Backes, Jaap Jansen, en Miranda Schram: bedankt dat jullie mij deze kans hebben gegeven en dat ik zo veel van jullie heb kunnen leren. Walter, heel erg bedankt voor alle leerzame overleggen en het op alle mogelijke momenten voor mij klaar staan met nuttige feedback. Jaap, dank voor de snelle en nuttige feedback, die me vooral erg geholpen heeft om dingen efficiënt aan te pakken. Miranda, bedankt voor alle hulp op het gebied van epidemiologie en schrijven. Ik vond het erg fijn en leerzaam om samen stukken kritisch te bekijken en te herschrijven. Daarnaast was ook de steun op persoonlijk vlak erg fijn.

Vervolgens wil ik graag de leden van de beoordelingscommissie bedanken, Prof. dr. P.A.M. Hofman, Prof. dr. F.R.J. Verhey, Prof. dr. G.J. Biessels, en Prof. dr. S.A.R.B. Rombouts, voor de tijd die zij hebben genomen om mijn proefschrift te beoordelen.

Graag wil ook alle coauteurs bedanken voor hun waardevolle inbreng. Pieter Dagnelie, Joost de Jong, Simone Eussen, Marleen Greevenbroek, Ronald Henry, Boy Houben, Daan Huybrechs, Seb Köhler, Annemarie Koster, Bram Kroon, Jos Reulen, Hans Savelberg, Nicolaas Schaper, Coen Stehouwer, Martin van Boxtel, Carla van der Kallen, Thomas van Sloten, en Anke Wesselius: bedankt voor jullie bijdrage aan de wetenschappelijke publicaties.

Daarnaast wil ik alle deelnemers en medewerkers van de De Maastricht Studie bedanken, zonder jullie medewerking was dit proefschrift er niet geweest.

De enorme hoeveelheid data van De Maastricht Studie verwerken was ook een enorm project. Joost, Jos, en Jan, bedankt voor de hulp hierbij! Tenslotte wil ik graag Daan Huybrechs bedanken voor de leerzame lessen over wavelets.

De fijne tijd met collega's op kantoor heeft ook zeker geholpen bij het tot stand komen van dit proefschrift. Anouk, Cécile, Elles, Gerald, Harmen, Inge, Jennifer, Joost, Leonie, Lisanne, Marieke, May, Merel, Paulien, Roald, en Whitney, bedankt voor de gezelligheid op kantoor, tijdens activiteiten en op congressen!

Ook wil ik de andere promovendi bij De Maastricht Studie ook bedanken voor de fijne tijd: Anouk, April, Cindy, Frank, Niki, Rianneke, Sytze, Tan Lai, en Yuri, bedankt voor de gezellige tijd met meten en de leuke activiteiten zoals het weekendje in de Ardennen!

Tenslotte wil ik alle vrienden en familie heel bedanken voor de gezelligheid, mooie vakanties, en interesse. Pap, mam, Roel, opa, oma, en Bas jullie zijn het allerbelangrijkste geweest voor mij. Pap, mam, opa en oma, jullie geloven er al in 29 jaar in dat ik het onmogelijk mogelijk kan maken. Bedankt voor de onvoorwaardelijke steun. Zonder jullie had ik dit nooit kunnen bereiken! Lieve oma, helaas kun je er niet meer bij zijn, maar je hebt voor altijd een speciaal plekje in mijn hart. 
Curriculum

Vitae

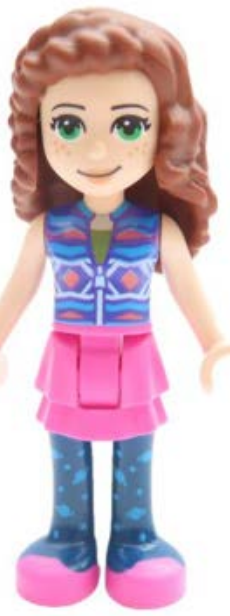


CV 


\section{Curriculum Vitae}

Laura Wilfrieda Maria was born on January $7^{\text {th }} 1992$ in Geleen, The Netherlands. In 2010 she graduated secondary school at Trevianum in Sittard. Subsequently, she started her academic education at the Eindhoven University of Technology, where she obtained her Bachelor of Science degree (BSc) in Biomedical Engineering in August 2014, along with the certificate Technical Management, and her Master of Science degree (MSc) in Biomedical Engineering in June 2016. During the Master program, she did an internship entitled "DoseWise - Real-time patient dose monitoring in fluoroscopy guided interventions" at Philips Healthcare in collaboration with the Maastricht University Medical Center under supervision of dr. Cécile Jeukens and dr. Sjirk Boon. Furthermore, she conducted her graduation project, entitled "A quantitative description of the myocardial fiber architecture of the ex- en in-vivo heart using Diffusion Weighted MRI" at the University Medical Center Utrecht under supervision of dr. ir. Martijn Froeling and Prof. dr. Klaas Nicolay. In August 2016, she started her PhD project at the department of Radiology of the Maastricht University Medical Center and The Maastricht Study. The research, as presented in the present thesis, was performed under supervision of promotor Prof. dr. ir. Walter $\mathrm{H}$. Backes and copromotores dr. Jacobus F.A. Jansen and dr. Miranda T. Schram. During her PhD, Laura received accolades for her work including invited presentations, awards and stipends. Currently, Laura works as Software Test Engineer at the MRI Research and Development department of Philips Healthcare.

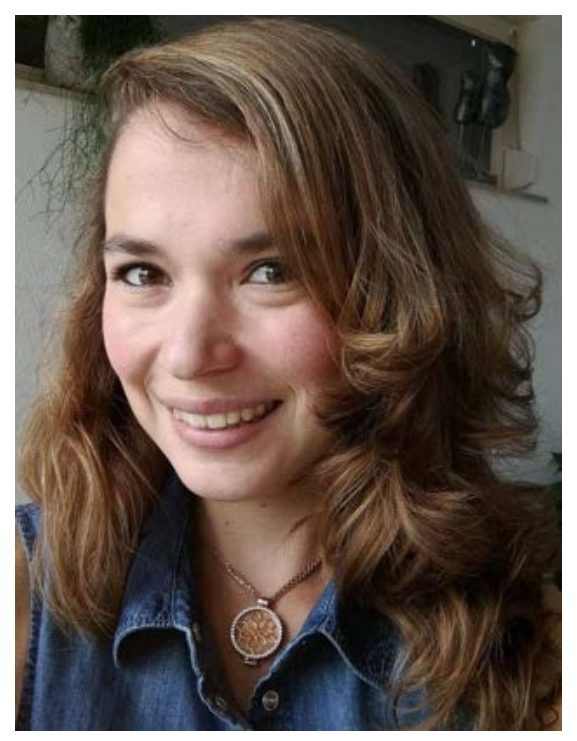


Publications

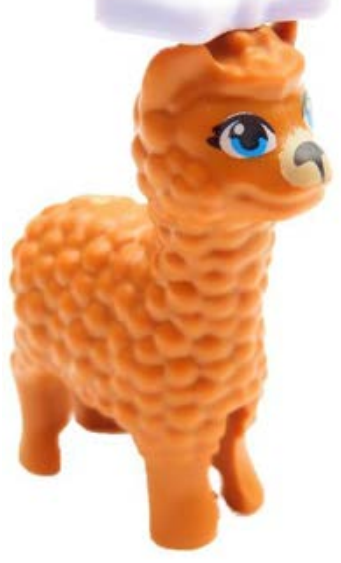




\section{Journal Contributions}

\section{This thesis}

Vergoossen L.W.M., Jansen J.F.A., van Sloten T.T., Stehouwer C.D.A., Schaper N.C., Wesselius A., Dagnelie P.C., Köhler S., van Boxtel M.P.J., Kroon A.A., de Jong J.J.A., Schram M.T., Backes W.H. Interplay of white matter hyperintensities, white matter network, and cognitive function - The Maastricht Study. Radiology (2020), Dec 22. doi: 10.1148/radiol.2021202634. IF 7.931

Vergoossen L.W.M., Jansen J.F.A., de Jong J.J.A., Stehouwer C.D.A., Schaper N.C., Savelberg H.H.C.M., Koster A., Backes W.H., Schram M.T Association of physical activity and sedentary time with structural brain networks - The Maastricht Study. Geroscience (2020); Oct 9. doi: 10.1007/s11357-020-00276-z. IF 4.360

Vergoossen L.W.M., Jansen J.F.A., Backes W.H., Schram M.T. Cardiometabolic determinants of early and advanced brain alterations: Insights from conventional and novel MRI techniques.

Neuroscience and Biobehavioral Reviews (2020); 115: 308-320. doi: 10.1016/j.neubiorev.2020.04.001. IF 8.002

Vergoossen L.W.M., Schram M.T., de Jong J.J., Stehouwer C.D.A., Schaper N.C., Henry R.M., van der Kallen C.J., Dagnelie P.C., van Boxtel M.P., Eussen S.J., Backes W.H., Jansen J.F.A. White Matter Connectivity Abnormalities in Prediabetes and Type 2 Diabetes: The Maastricht Study. Diabetes Care (2020); Jan; 43(1):201-208. doi: 10.2337/dc19-0762. IF 16.019

\section{Other}

de Jong J.J.A., Jansen J.F.A., Vergoossen L.W.M., Schram M.T., Stehouwer C.D.A., Wildberger J.E., Linden D.E.J., Backes W.H. The Effect of MR Image Quality on Structural and Functional Brain Connectivity: The Maastricht Study. Biorxiv Neuroscience (2019); Oct 19. doi: 10.1101/806075

Sailer A.M., Paulis L.E., Vergoossen L.W.M., Wlidberger J.E., Jeukens C.R.L.P.N. Optimizing Staff Dose in Fluoroscopy Guided Interventions by Comparing Clinical Data with Phantom Experiments. Journal of Vascular and Interventional Radiology (2019), 30(5), 701-708.e1. IF 2.828

Sailer A.M., Vergoossen L.W.M., Paulis L.E., van Zwam W.H., Das M., Wildberger J.E., Jeukens C.R.L.P.N. Personalized Feedback on Staff Dose in Fluoroscopy-Guided Interventions: A New Era in Radiation Dose Monitoring. Cardiovasc Intervent Radiol (2017) 40: 1756. IF 1.928

Sailer A.M., Paulis L.E., Vergoossen L.W.M., Kovac A.O., Wijnhoven G., Schurink G.W.H., Mees B., Das M., Wildberg J.E., de Haan M.W., Jeukens C.R.L.P.N. Real-Time Patient and Staff Radiation Dose Monitoring in IR Practice. Cardiovasc Intervent Radiol (2017) 40:421-429. IF 1.928 


\section{Oral presentations and awards - this thesis}

Exploring the neurovascular nature of spontaneous cerebral blood oxygen level dependent (BOLD) fluctuations in 1730 individuals- The Maastricht Study. Oral Presentation Ann Meeting ISMRM 2020. Travel Award received.

Why white matter matters - Interplay of white matter hyperintensities, white matter tracts, and processing speed - The Maastricht Study. Oral Presentation Ann Meeting ISMRM 2020. Travel Award and Summa Cum Laude Merit Award received.

Are physical activity and sedentary time associated with measures of structural brain connectivity? - The Maastricht Study. Oral Presentation Ann Meeting ESMRMB 2019, Rotterdam. Travel Award received.

Are physical activity and sedentary time associated with measures of structural brain connectivity? - The Maastricht Study. Oral Presentation Ann Meeting Benelux Chapter ISMRM 2019, Leiden.

Prediabetes and type 2 diabetes are associated with white matter connectivity - The Maastricht Study. Oral Presentation Ann Dutch Diabetes Research Meeting 2018, Oosterbeek.

Are prediabetes and type 2 diabetes associated with white matter connectivity alterations? - The Maastricht Study. Oral Presentation Joint Ann Meeting ISMRM-ESMRMB 2018, Paris. Travel Award and Summa Cum Laude Merit Award received.

Are prediabetes and type 2 diabetes associated with white matter connectivity alterations? - The Maastricht Study. Oral Presentation Ann Meeting Benelux Chapter ISMRM 2018, Antwerp.

\section{Oral presentations and awards - other}

Procedural DAP can be used for Relative Dose Estimation for Staff Dose in Fluoroscopy-Guided Interventions. Oral Presentation Ann Meeting ECR 2017, Vienna. Travel Award received.

Personalized Dose Feedback to Medical Staff involved in Fluoroscopy-Guided Interventions - a New Era in Radiation Dose Monitoring. Oral Presentation Ann Meeting ECR 2017, Vienna. Travel Award received.

Realtime Patient and Staff Dose Monitoring in Fluoroscopy Guided Interventions. ePoster Ann Meeting AAPM 2016, Washington DC. 
